\title{
TESIS DE DOCTORADO
}

Facultad de Arquitectura y Urbanismo

Universidad Nacional de La Plata

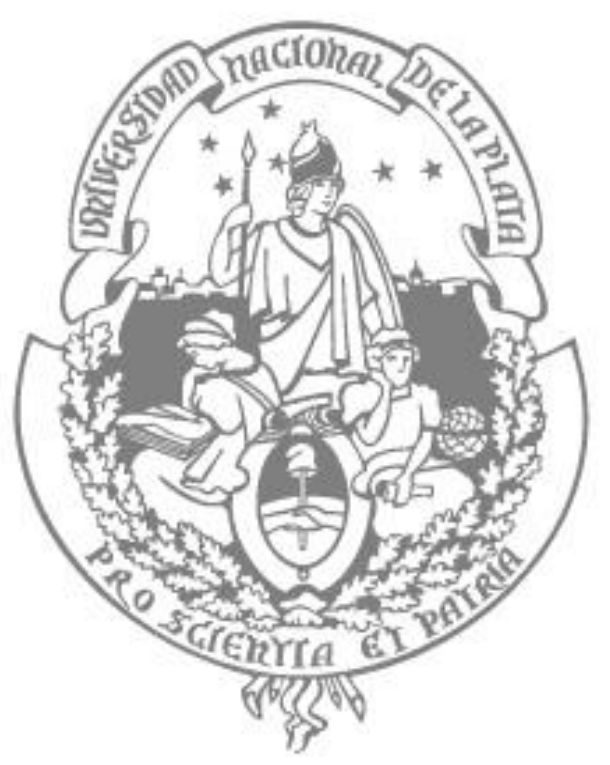

Título de la Tesis:

"Condiciones Ambientales en los Espacios de Internación de Cuidados Intensivos Cardiológicos"

Doctoranda: Arq. Astrid María DEBUCHY 
Mi agradecimiento;

A mi Director de Tesis, Arq. Analia GOMEZ y a mi Codirector de Tesis Dr. Jorge Daniel CZAJKOWSKI.

Al Centro de Investigación en Planeamiento del Recursos Físico en Salud, de la Facultad de Arquitectura, Diseño y Urbanismo de la Universidad de Buenos Aries CIRFS FADU UBA y sU Directora Prof. Consulto Arq. Astrid M. C. BØGEDAM de DEBUCHY.

A todos los que colaboraron interdisciplinarmente con esta Investigación, resalto la contribución del Dr. Carlos RUBIANES y deI Dr. Javier GUETTA.

A mi familia, siempre presente, por su apoyo incondicional e invaluable. 


\section{Director:}

Nombre: Arq. Analia GOMEZ

Profesor Titular Ordinario de la Facultad de Arquitectura y Urbanismo de la Universidad Nacional de la Plata, Provincia de Buenos Aires, Argentina Investigador Adjunto CONICET

\section{Co Director:}

Nombre: Dr. Jorge Daniel CZAJKOWSKI

Profesor Titular Ordinario de la Facultad de Arquitectura y Urbanismo de la Universidad Nacional de la Plata, Provincia de Buenos Aires, Argentina Investigador Adjunto CONICET

\section{Lugar donde radicara el Trabajo de Investigación:}

Centro de Investigación en Planeamiento del Recurso Físico En Salud - CIRFS Facultad de Arquitectura, Diseño y Urbanismo, Universidad de Buenos Aires Pagina Internet CIRFS: www.cirfs.com.ar TE CIRFS: +054 11 4789-6233 

Facultad de Arquitectura y Urbanismo

Universidad Nacional de la Plata

\section{INDICE:}

Introducción y Sintesis del trabajo de Investigación..

Capitulo 1. Las condicionantes ambientales que determinan la obtención de espacios saludables

1.1. Presentación del tema de Investigación.....................................09

1.2. Formulación del problema.....................................................11

Capítulo 2. Marco Conceptual Teórico y Estado del Arte del Proyecto de Investigación

2.1. Presentación del marco conceptual o "marco teórico". 14

2.2. Estado del arte del tema a desarrollar

2.2.1. Estado del Arte sobre la Caracterización del Recurso Físico para los

Cuidados Intensivos.

2.2.1.1. A nivel Nacional

2.2.1.2. A Nivel Internacional

2.2.2. Estado del Arte sobre el Diseño de Espacios Saludables

Capítulo 3. Hipótesis, Objetivos y Metodología

3.1. Formulación de la hipótesis de investigación.

3.2. Formulación de objetivos para esta investigación.........................25

3.3. Metodología de Investigación..................................................26

Capítulo 4. Análisis y Desarrollo de la Investigación

Capítulo 4. 1. Estudio de la Unidad de Cuidados Intensivos y Cuidados Intensivos Cardiológicos

4.1.1. Breve Reseña Histórica. .29

4.1.2. Diferentes Tipos de Unidades de Cuidados Intensivos

4.1.3. Normas de Organización y Funcionamiento y Matrices de Atención de Internación Cuidados Intensivos Cardiológicos .............................30 4.1.3.1. Normas para la Organización y Funcionamiento de Cuidados Intensivos Cardiológicos

4.1.3.2. Anteproyecto del Manual de Estándares Internación Cuidados Intensivos Adultos y Pediátricos

4.1.3.3. Matrices de Atención de Internación Cuidados Intensivos y Cuidados Intensivos Cardíológicos

4.1.3.4. Compendio de Normativas para Cuidados Intensivos y Cuidados Intensivos Cardiológicos de la Fundación Favaloro

4.1.4. Caracterización de la Política Operacional para Cuidados Intensivos Cardiológicos.

4.1.5. Caracterización de la Operación de los Cuidados Intensivos Cardiológicos

4.1.6. Caracterización Arquitectónica de los Cuidados Intensivos

Cardiológicos

4.1.7. Caracterización de la Organización Espacial - Funcional de los

Cuidados Intensivos Cardiológicos. 
Facultad de Arquitectura y Urbanismo

Universidad Nacional de la Plata

\section{Capítulo 4.2. Estudio de las Condicionantes Ambientales}

\subsubsection{Primera Etapa Modelo Referencial MR...................................45}

\subsubsection{Segunda Etapa Modelo Observado Preliminar MOP y Modelo \\ Observado Final MOF..................................................................48 \\ 4.2.2.1. Presentación de la Encuesta "Evaluación del Recurso Fisico en Atención de Intemación en busca de los "Satisfactores del Recurso Fisco" \\ 4.2.2.1.1. Estructura de la Encuesta \\ 4.2.2.2. Modelo Observado Preliminar MOP \\ 4.2.2.3. Modelo Observado Final MOF \\ 4.2.2.4. Especialistas Médicos de Cuidados Intensivos Generales y \\ Cardiológicos \\ 4.2.2.5. Estudio de los Datos de la Encuesta \\ 4.2.2.6. Rangos de las respuestas de los Pacientes}

4.2.3. Tercera Etapa Modelo Normalizado MN

4.2.3.1. Variables del ambiente que estimule los sentidos

4.2.3.2. Variables de optimización de los aspectos funcionales

4.2.3.3. Variables de Bienestar

Capítulo 5. Elaboración de la Propuesta y Contrastación de la Tesis

5.1. Cuarta Etapa Modelo Propuesto MP

5.1.1. Variables del ambiente que estimule los sentidos.........................80

5.1.2. Variables de optimización de los aspectos funcionales....................86

5.1.3. Variables de Bienestar..........................................................90

5.1.4. Estudio Comparativos de Condicionantes Arquitectónicos...............94

5.2. Propuesta de Tipologías "Espacio - Tarea" para la Habitación de Cuidados Intensivos Cardiológicos................................................98

5.3. Contrastación de la Hipótesis. Propuesta Arquitectónica para la Habitación de Cuidados Cardiológicos. 107

Conclusiones.....................................................................112

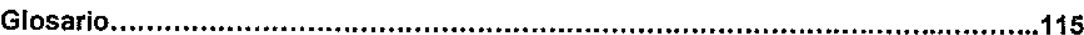

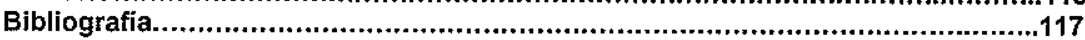

Presentaciones en Reuniones Científicas ................................................121

Apéndice 1

Encuestas en Unidades de Cuidados Intensivos y Cuidados Intensivos Cardiológicos. Sub Sector Público y Privado (2009-2011)

Apéndice 2

Consolidado de Encuestas en Unidades de Cuidados Intensivos y Cuidados Intensivos Cardiológicos. Sub Sector Público y Privado (2009-2011)

Anexo 1

Normas del Programa Nacional de Garantía de la Calidad de la Atención Medica del Ministerio Nacional de Salud, RM318/2001 y RM 375/2002.

Anexo 2

"Matriz de Atención de Internación Cuidados Intensivos Cardiológicos." Proyecto UBACYT A056 2004-2007. CIRFS FADU UBA.

"Las Normativas para Cuidados Intensivos y Cuidados Intensivos Cardiológicos de la Fundación Favaloro" 14/12/2010.

Anexo 3

"Las Condicionantes Ambientales y de Humanización de los Espacios en el Desarrollo del Recurso Fisico en Salud" Proyecto UBACyT A810 2006-2009. CIRFS FADU UBA. 


\section{Prologo}

Recuerdo que la primer vez que me puse en contacto con la temática de los "espacios saludables" fue con motivo de un viaje que realicé junto con mi madre para participar el "Seminario Anual del Grupo de Salud Pública de la Unión Internacional de Arquitectos" UIA PHG en Estocolmo Suecia, a continuación del Seminario se realizó la que fue la segunda Conferencia Internacional de la" Academia de Diseño y Salud, "Integrating Design and Care in Hospital Planning for the New Millennium" organizada por el Dr. Arq. Alan Dilani en el año 2000.

Catorce años han pasado, entre esa primera introducción y esta presentación de Tesis de Doctorado. 

"La idea de que el espacio está compuesto por múltiples elementos que conforman entre si una composición, que puede pasar desapercibida pero que de todos modos se encuentra alli, esperando ser interpretada".

Astrid Maria Debuchy

\section{Introducción y Síntesis del Trabajo de Investigación}

La Unidad de Cuidados Intensivos Cardiológicos es definida por el Programa Nacional de Garantía de la Calidad Medica PNGC, Ministerio de Salud de la Nación MSN RM 375/2002, como "el área asistencial del Hospital dotada de medios técnicos $y$ de los recursos humanos (médicos y enfermería), necesarios para la atención y vigilancia continuada de los pacientes con cardiopatías agudas graves $y$ potencialmente recuperables", es también una de las área donde se localizan los pacientes de máxima vulnerabilidad de un Establecimiento de Salud.

Sin embargo, los pacientes se ven sujetos a grandes tensiones, problemas que van de lo psicológico a problemas que surgen del diseño arquitectónico, estas realidades medico arquitectónicas que se observan en la práctica social de la Atención de Internación, se hacen particularmente más críticas cuando se trata de la internación en una Unidad de Cuidados Intensivos Cardiológicos.

La búsqueda de una humanización ${ }^{1}$ de los espacios junto con el diseño de espacios saludables llamados en inglés "healing environment o supportive environment", intenta dar respuestas a esta problemática con una visión más completa del paciente, donde se reconoce los nuevos enfoques en la atención de salud los cuales proponen que sean tomadas en cuenta las necesidades sociales y psicológicas de los pacientes, en el diseño arquitectónico. No obstante, son muchas las miradas y diversos los abordajes de los investigadores, sin que haya un trabajo unificador de estas teorías.

Los problemas antes señalados y una propuesta contraria a una arquitectura tecnomédica para la salud donde solo se observa la parte operativa de los procesos, plantean la necesidad de un trabajo de investigación integrador, que vincule los trabajos de diferentes investigadores relacionados con el estudio de los "espacios saludables", que identifique, delimite y califique aquellos posibles condicionantes arquitectónicos ausentes como determinantes en la Programación del Recurso Físico en Salud.

Concurrente con esta perspectiva, es esencial reconocer el impacto de la Modalidad de Atención de Internación de Cuidados Intensivos Cardiológicos en la Capacidad Instalada General del Sector Salud, con la demanda de nuevas Unidades de

\footnotetext{
${ }^{1}$ Real Academia Española humanizar. 1. tr. Hacer humano, familiar y afable a alguien o algo. 2. prnl. Ablandarse, desenojarse, hacerse benigno.
} 
Cuidados Intensivos, con la consecuente necesidad del reestudio de las mismas, para que sean adaptadas a los nuevos requerimientos.

El Marco Conceptual seleccionado para esta Investigación es el del Centro de Investigación del Planeamiento del Recurso Físico en Salud CIRFS FADU UBA, lugar donde se radica este trabajo de investigación, el cual ha sido generado a través de un proceso evolutivo y a su vez aplicado en diversos escenarios tanto nacionales como internacionales, se partirá de dicho Marco Conceptual al que paralelamente se incorporan nuevos componentes dado la especificidad de la temática abordada.

Se reconoce primeramente el Estado del Arte y las Normas, Guías y Estándares disponibles a nivel nacional e internacional, en relación a la caracterización funcional de las Servicios de Cuidados Intensivos, con énfasis en los Cuidados Intensivos Cardiológicos, para luego reconocer el Estado del Arte sobre el Estudio de Espacios Saludables, donde se presentaran referencias a trabajos desarrollados por distintos investigadores y profesionales, relacionados a este tema.

La documentación previamente elaborada nos permite presentar la Hipótesis de Investigación: se formula: "Que existe un conjunto de condicionantes ambientales, que favorecen la obtención de espacios saludables, que actúan desde lo proyectual arquitectónico y que podrán ser incorporadas en una habitación de Cuidados Intensivos Cardiológicos, en el marco del Planeamiento del Recurso Físico en Salud".

Concurrente con esta hipótesis se plantea como Objetivo Principal de esta investigación: la caracterización de las variables ambientales en la determinación de las nuevas condicionantes del diseño, para el desarrollo de una nueva propuesta de resolución proyectual arquitectónica para la habitación del paciente de Cuidados Intensivos Cardiológicos, en el marco del Planeamiento del Recurso Físico en Salud.

Se plantean los siguientes Objetivos Particulares, la definición de la tecnología de operación Atención de Internación de Cuidados Intensivos Cardiológicos; en política, operación y procesos; la caracterización de la organización espacial funcional de los espacios de atención del paciente, la satisfacción del paciente internado a través de la categorización e impacto de las variables ambientales como condicionantes de diseño arquitectónico y la definición de nuevas soluciones proyectuales, a partir del estudio de Tipologías, Espacio - Tareas como antecedente y base de la propuesta arquitectónica para la habitación de Cuidados Intensivos Cardiológicos.

Se reconoce en este proyecto la Metodología de Interacción de Modelos, esta Metodología de Investigación requiere el diseño de modelos que interaccionan en los planos, referencial, de observación, normalizado, de propuesta y de implementación, según etapas que dependen de la finalidad perseguida, para la delimitación de un modelo observado, de un modelo normalizado, de un modelo 
propuesto y/o de un modelo de implementación. Esta metodología interactuando con otras complementarias, construirá el eje instrumental del desarrollo de la presente investigación.

El trabajo de investigación se desarrolla en dos vertientes, que sin embargo serán abordadas de forma simultánea.

Por un lado se realizará un estudio de la Unidad de Cuidados Intensivos Cardiológicos a través de la caracterización de la tecnología ${ }^{2}$ de operación de dicho Servicio, para luego reconocer la organización espacial funcional de la habitación del paciente. De esta manera se recorre el Servicio a través de los procesos que allí se desarrollan, para luego focalizarse en el área correspondiente a la atención del paciente. La habitación de Cuidados Intensivos es un espacio sumamente crítico, los elementos que lo componen funcionan con mucha precisión y es necesario un estudio profundo de cuáles son los requerimientos, para comprender su funcionamiento, el Planeamiento del Recurso Físico en Salud, surge como pieza clave y a la vez como herramienta de estudio.

Por otro lado se busca acotar las condicionantes ambientales que favorecen y determinan la obtención de espacios saludables, a través del aporte de investigadores en esta materia, junto con el Trabajo de Investigación a través de Encuestas a pacientes internados en Instituciones Públicas y Privadas, que se complementa con Entrevistas a Expertos Médicos especialistas en Cuidados Intensivos y Cuidados Intensivos Cardiológicos.

El Estudio de la Unidad de Cuidados Intensivos se introducirá con una breve reseña histórica y los diferentes tipos de Cuidados Intensivos, donde se reconocen los Cuidados Intensivos Cardiológicos.

La Normativa referente a la Calidad de esas Unidades se encuentra en las Normas de Organización y Funcionamientos de Unidades de Cuidados Intensivos, Unidades de Cuidado Intensivo. RM 318/2000 y en las Normas de Organización y Funcionamientos de Unidades de Cuidados Intensivos Cardiológicos. Unidades de Cuidado Intensivo Cardiológicos. RM 375/2002 ambas del Programa Nacional de Garantía de la Calidad de la Atención Medica PNGC, Ministerio de Salud de la Nación MNS (esta información se encuentra en el Anexo 1).

Como complemento a esta documentación se presenta la información sobre "Establecimientos con Internación Cuidados Intensivos Adultos y Pediátricos" del "Anteproyecto del Manual de Estándares del Instituto Técnico para la Acreditación de Establecimientos de Salud (ITAES) 2010, "Las Atención de Internación Cuidados Intensivos", del Proyecto de Investigación "Nuevas Conceptualizaciones y

\footnotetext{
2 Entendiendo el concepto de "tecnología" como la incorporación conjunta de los "componentes físicos" y los "componentes lógicos"; con una concepción análoga al área de informática, "el hardware" y "el software" respectivamente. Guias para el Desarrollo del Recurso Físico en Salud, CIRFS FADU UBA - OMSOPS 2010.
} 
Enfoques en Programación: Programación Funcional y Fisica del Recurso Físico en Salud", Proyecto UBACyT A056 2004-2007" "y "El Compendio de Normativas para Cuidados Intensivos y Cuidados Intensivos Cardiológicos de la Fundación Favaloro".

Concluida la etapa recolección y elaboración de la información Normativa, se inicia la Caracterización de la Atención de Internación ${ }^{4}$; Cuidados Intensivos Cardiológicos, primeramente mediante el reconocimiento de la Política Operacional que sienta las bases para la caracterización de la Operación, donde se referirá a la calificación y cuantificación de las Funciones, Actividades y Tareas, así como del Recurso Humano participante en cada una de ellas, que definirán las Líneas de Proceso, la cual será presentada a través de un ejemplo en la Unidad de Cuidados Intensivos Cardiológicos del Centro de Estudios Médicos e Investigaciones Clínicas "Norberto Quirno" CEMIC Saavedra (2011).

En el desarrollo de la caracterización tanto Arquitectónica del Servicio y como de la Organización Espacial - Funcional de Cuidados Intensivos Cardiológicos, se definirán los principios y pautas en relación al medio social y al medio físico, así como de la conformación del sistema espacial, para la identificación diferenciada de unidades funcionales UF y áreas complementarias AC.. Completando esta información, se adjuntaran ejemplos Arquitectónicos de Unidades de Cuidados Intensivos y Cuidados Intensivos Cardiológicos, del Sub Sector Público y del Sub Sector Privado, donde también se estudiará la habitación de dichos Establecimientos.

Para el Estudio de las Condicionantes Ambientales, se utilizará la Metodología de Interacción de Modelos, ya señalada. En una primera Etapa se conformará un Modelo Referencial MR de Condicionantes Ambientales, el cual se constituirá con los siguientes aportes: el reconocimiento y análisis de las situaciones y tendencias vinculadas a esta temática, junto con el estudio del estado del arte sobre el diseño de espacios saludables tanto a nivel nacional como internacional.

A partir de los análisis realizados, se reconocen cuatro conjuntos de variables ambientales, para la conformación de los espacios saludables. El primer conjunto de variables se denomina "ambiente que estimule los sentidos" (variables: colores, iluminación, sonidos, olores y texturas), el segundo conjunto de variables se denomina "optimización de los aspectos funcionales", (variables: accesibilidad, orientación, proporciones y distribución del equipamiento), el tercer conjunto de variables se denomina "bienestar", (variables, incorporación de la naturaleza, arte, música y confort), el cuarto y último conjunto de variables se denomina "cumplimiento de normas y seguridad", (cumplimiento de normas y leyes vigentes junto con la observación de las guías de garantía de la calidad, nacionales e internacionales).

\footnotetext{
${ }^{3}$ La Matriz de Cuidados Intensivos Cardiológicos del Proyecto de Investigación UBACyT A056 2004-2007, se adjunta como Anexo 2 a esta documentación.

4 De las Fichas Técnicas sobre el Recurso Físico en Salud. CIRFS 1990 actualizada en las Guias de Programación Funcional G5 CIRFS FADU UBA - OMS OPS Actualizadas 2010.
} 
La evaluación de estas variables como posibles condicionantes del diseño arquitectónico hace necesaria la utilización de una herramienta metodológica para su estudio, se plantea la necesidad de crear una Encuesta que incluya los conjuntos de variables antes mencionados. He denominado a esta Encuesta "Evaluación del Recurso Físico en Atención de Internación en busca de los "Satisfactores del Recurso Fisco", ya que con su contenido intenta investigar sobre los conjuntos de variables y determinar a través de la visión del paciente sobre su posible interés como condicionante del diseño arquitectónico. La palabra Satisfactores surge de la búsqueda de satisfacción por parte del paciente y es la denominación con la que he designado el universo donde interactúan las variables. Se presenta como parte de esta documentación el análisis y estructura de la Encuesta.

En una segunda Etapa de estudio de las Condicionantes Ambientales, se desarrollan los Modelos Observados, el universo de variables del Modelo Referencial es aplicado y evaluado en varios "escenarios" del área metropolitana, en Establecimientos del Subsector Público y Privado.

Se comienza con la presentación del Modelo Observado Preliminar MOP para el Servicio de Atención de Internación Cuidados Generales (2006-2009) donde se entrevistaron sesenta (60) pacientes internados en este Servicio.

El Trabajo de Investigación "Las Condicionantes Ambientales y de Humanización de los Espacios en el Desarrollo de los Recursos Físicos en Salud", Proyecto UBACyT A 810 (2006-2009), Dirigido por esta Doctoranda, fue el marco en que se realizó la primera prueba de la Encuesta "Evaluación del Recurso Físico en Atención de Internación en busca de los Satisfactores del Recurso Fisco". El trabajo de Investigación contó con la participación interdisciplinaria de Investigadores ${ }^{6}$, del Centro de Investigación en Planeamiento del Recurso Físico en Salud, de la Facultad de Arquitectura Diseño y Urbanismo, de la Universidad de Buenos Aires CIRFS FADU UBA.

Habiendo delimitado el Modelo Observado Preliminar MOP se desarrolla el estudio del Modelo Observado Final MOF para Unidades de Cuidados Intensivos y Cuidados Intensivos Cardiológicos (2009-2011), con el mismo cuestionario de la Encuesta (2006-2009) se entrevistan veintiséis (26) pacientes internados en estas Unidades.

Para la conformación del Modelo Observado Final $^{7}$ se entrevistaron a tres grupos de pacientes. Grupo 1. La Unidad de Cuidados Intensivos del Hospital General de Agudos Carlos G. Durand (del Subsector Público). Diez (10) pacientes. Grupo 2. La Unidad de Cuidados Intensivos Cardiológicos del Centro de Estudios Médicos e Investigaciones Clínicas "Norberto Quirno" UCO CEMIC Saavedra

\footnotetext{
${ }^{5}$ Segmentos del Proyecto de Investigación UBACyT A 810 2006-2009, se adjunta en Anexo 3.

6 Director Arq. Astrid María Debuchy, Investigadores: Prof. Consulto Arq. Astrid Bögedam de Debuchy, Lic. Francisco Turull, Dra. Nélida Nervi, Arq. Catalina Scavino, Arq. Marcelo Lamorgese e Ing. Martin Borghi CIRFS FADU UBA:

7 Apéndice 1 Encuestas Unidades de Cuidados Intensivos y Cuidados Intensivos Cardiológicos. Sub Sector Público y Privado (2009-2011). Apéndice 2 Consolidado de Encuestas Unidades de Cuidados Intensivos y Cuidados Intensivos Cardiológicos. Sub Sector Público y Privado (2009-2011).
} 
(del Subsector Privado). Diez (10) pacientes. Grupo 3. La Unidad de Cuidados Intensivos de Swiss Medical Group, la Unidad de Cuidados Intensivos Los Arcos, La Unidad de Cuidados Intensivos Cardiológicos Suizo Argentina, la Unidad de Cuidados Intensivos Sanatorio San Camilo y la Unidad de Cuidados Intensivos del Hospital Bryn Mawr, Pensilvania EE UU. (del Subsector Público y Privado). Seis (6) pacientes.

Luego se observará si los datos obtenidos en los pacientes entrevistados del Servicio Internación de Cuidados Generales, son concurrentes a los datos obtenidos en los pacientes entrevistados en Unidades de Cuidados Intensivos y Cuidados Intensivos Cardiológicos, se busca determinar si se corroboran los datos alcanzados por las Encuestas anteriores o surgen nuevos datos.

Paralelamente a la recolección y elaboración de la información suministrada por las Encuestas, se realizaron Entrevistas y corroboración de datos con Profesionales Médicos, Doctores en Medicina Especializados en la Cuidados Intensivos y Cuidados Intensivos Cardiológicos. Se realizaron Entrevistas con el Dr. Javier Guetta, Consultor de la de la Unidad de Cuidados Intensivos Cardiológicos CEMIC Saavedra y el Dr. Carlos Rubianes uno de los primeros Médicos Intensivistas de la Argentina y Consultor de la Unidad Polivalente de Cuidados Intensivos y Cuidados Cardiológicos del Instituto Argentino de Diagnóstico y Tratamiento IADT.

En una tercera Etapa se elabora el Modelo Normalizado $\mathbf{M N}$, se parte de las variables recreadas en el Modelo Referencial MR con los aportes de los datos del Modelo Observado Final MOF. Es necesario aclarar que en este trabajo de Investigación se refiere al Modelo Normalizado MN Inicial, debido a la ausencia de normativas para algunas de las variables.

En una cuarta Etapa se realizara el Modelo Propuesto MP donde se presentará la calificación de variables ambientales y su comportamiento como Condicionantes del diseño Arquitectónico, con el mismo ordenamiento del Modelo Normalizado MN, se presenta una propuesta para cada una de las variables ambientales junto con una estructura de calificación, donde se considera un valor de alto-fundamental, medio-de interés y bajo- de menor interés, acorde su efecto como condicionante del diseño Arquitectónico, dicho resultado surge de la valorización de Normas del PNGC MNS RM 318/2001 y RM 375/2002, el estudio de los resultados de la Entrevistas a Pacientes, basada en los tres tipos de $\operatorname{Rangos}^{8}$ y el aporte de Médicos Especializados en Cuidados Intensivos.

A continuación, en el marco de la valorización de las variables ambientales como condicionante del diseño arquitectónico del Modelo Propuesto MP se realiza un

\footnotetext{
${ }^{8}$ Rango 1, en este grupo el Paciente se mostró indiferente o respondió no haber puesto atención a estos aspectos a los que hace alusión el Entrevistador, dentro de este rango de respuesta se incluyen Pacientes que dicen no recordar o no contestar. Rango 2, en este grupo el Paciente, mostró cierto interés con la variable y comunicó una preferencia especifica. Rango 3 en este grupo el Paciente mostro mayor interés y se expresó más allá de lo solicitado por el Encuestador, en este rango se consideran también las respuestas que aluden a emociones, sensaciones, y estados de ánimo que pudieron afectar de un modo o de otro al paciente.
} 
estudio comparativo con los resultados de las Encuestas ya señaladas. A través de este estudio comparativo de los resultados de los dos escenarios se fundamenta la valorización realizada en el Modelo Propuesto MP, con el cual se inicia el proceso de contrastación de la propuesta.

Con la documentación y datos obtenidos de la Caracterización de la Tecnología de Operación, donde se desarrolló una matriz con Funciones, Actividades, Tareas y Recurso Humano, sumandos a los aportes del Modelo Propuesto MP de las Condiciones Ambientales, se desarrolla una propuesta de seis Tipologías "Espacio - Tarea" para la habitación de Cuidados Intensivos Cardiológicos.

Los Condicionantes de Diseño Arquitectónico serán primeramente incorporados en el diseño de las Tipologías seleccionadas y luego en la Propuesta Proyectual de la Habitación para Cuidados Intensivos Cardiológicos.

Las Tipologías seleccionadas son: T1 Examen Médico Inicial, T2 Control de Signos Vitales y/u Observación, T3 Higiene y/o Confort del Paciente (incluye cambios de ropa y cama), T4 Movilización - Traslado a otro Servicio, T5 Toma de Muestras para Laboratorio y T6 Visitas Familiares y Amigos. A cada una de las Tipologías le corresponde un cuadro de análisis de requerimientos para la Tarea en estudio.

La Etapa de Contrastación de la Hipótesis a través de la argumentación proyectual presenta La Propuesta de la Solución Proyectual para la Habitación de Internación de Cuidados Intensivos Cardiológicos, la cual se define a partir de los Condicionantes de Diseño Arquitectónico propuestos y del estudio de las Tipologías señaladas. Se completa con una descripción espacial arquitectónica, el estudio del recurso humano participante, los conjuntos equipamiento, con sus Detalles y Códigos y el requerimiento de Instalaciones junto con el Cumplimiento con la Normas del PNGC MNS RM 318/2001 y RM 375/2002.

Por último, se presentan las Conclusiones del trabajo de investigación a través del señalamiento de los resultados alcanzados, la valorización de la propuesta, su contribución y antecedente al Planeamiento del Recurso Físicos en Salud y sus posibles líneas futuras de investigación. 



\section{Capítulo 1.}

Las condicionantes ambientales que determinan la obtención de espacios saludables 



\section{Capítulo 1}

\section{Las condicionantes ambientales que determinan la obtención de espacios saludables}

\subsection{Presentación del tema de Investigación.}

"La salud es un estado de completo bienestar físico, mental y social, y no solamente la ausencia de afecciones o enfermedades".

La Organización Mundial de la Salud ${ }^{9}$

La cita procede del Preámbulo de la Constitución de la Organización Mundial de la Salud, que fue adoptada por la Conferencia Sanitaria Internacional, celebrada en Nueva York el 22 de julio de 1946 por los representantes de sesenta y un Estados (Official Records of the World Health Organization, $N^{\circ} 2$, p. 100), y entró en vigor el 7 de abril de 1948. La definición no ha sido modificada desde esa fecha.

La presente Tesis propone el desarrollo de una investigación proyectual, orientada a la búsqueda de "condicionantes ambientales" que partiendo del ámbito arquitectónico, permitirán establecer determinantes de diseño que concurran a la obtención de "espacios saludables", que favorezcan la atención de salud del paciente internado en el área de Atención Cuidados Intensivos Cardiológicos, en el marco de la teoría de Planeamiento del Recurso Físico en Salud.

La teoría del Planeamiento del Recurso Físico en Salud señala que en un Establecimiento de Salud se reconoce la participación de Servicios Nucleares, que comprenden: la Atención Ambulatoria Programada, la Atención Ambulatoria de Urgencia, la Atención de Internación y la Educación e Investigación y Servicios de Apoyo, que comprenden: los Servicios de Diagnóstico y Tratamiento, los Complementarios, los de Abastecimiento y Procesamiento y los de Conducción y Administración.

En los Servicios de Atención de Internación, se reconocen los Cuidados Intensivos: Generales, Cardiológicos y Neonatológicos, los Cuidados Intermedios y el Auto-Cuidado.

Se ha seleccionado como ámbito de estudio la habitación donde el paciente se encuentra internado en la Unidad de Cuidados Intensivos Cardiológicos.

\footnotetext{
${ }^{9}$ La OMS fundada en el año 1948 es la autoridad directiva y coordinadora de la acción sanitaria en el sistema de las Naciones Unidas. Es la responsable de desempeñar una función de liderazgo en los asuntos sanitarios mundiales, configurar la agenda de las investigaciones en salud, establecer normas, articular opciones de política basadas en la evidencia, prestar apoyo técnico a los países y vigilar las tendencias sanitarias mundiales.
} 
El área de Cuidados Intensivos es donde se localizan los pacientes de máxima vulnerabilidad y donde mayores deberán ser los esfuerzos para que el proceso de atención se realice dentro de un ambiente que brinde no sólo confort, sino que también acompañe y sea soporte del proceso de recuperación de la salud.

La detección de los condicionantes ambientales que determinan la obtención de espacios saludables, nos permitirá un acercamiento a la visualización de las necesidades del paciente y por lo tanto contribuirá la satisfacción del mismo como usuario - beneficiario del sistema de salud.

La razón de ser de la temática seleccionada, se funda en el reconocimiento de:

La satisfacción de los usuarios beneficiarios señalada por la Organización Mundial de la Salud, OMS, como la base para el mejor desempeño de los sistemas de salud.

-

El creciente valor de la acreditación de servicios de salud, que consiste en la verificación de un conjunto de estándares elaborados por consultores y expertos, provenientes de diferentes sociedades científicas, desarrolladas desde el año 1994 por el Instituto Técnico para la Acreditación de los Establecimientos de Salud, ITAES Argentina.

- El Programa Nacional de Garantía de Calidad de la Atención Medica Argentina, que se desarrolla desde el año 1996 en el Ministerio Nacional de Salud, en el cual se agrupan un conjunto de acciones destinadas a asegurar la calidad de las prestaciones de los Servicios de Salud, mediante el dictado de normas de organización y funcionamiento y guías de procedimientos, diagnóstico, tratamiento y evaluación de los mismos.

- Las "Políticas de salud" del Ministerio de Salud Argentina, año 2000, que reconocen que "El enfoque de calidad deberá primar en todo el proceso de planeamiento del recurso físico en salud, en el que se pondrá particular énfasis en la humanización de los espacios, preservando la identidad de las personas y las condiciones de privacidad, habitabilidad, confort y seguridad".

- El desarrollo y la promoción de actividades académico-científicas, destinadas al mejoramiento de la calidad de la atención de la salud, realizadas desde el año 2001 por la Sociedad Argentina para la Calidad en Atención de la Salud SACAS Argentina, miembro institucional de la International Society for Quality in Health Care (ISQua).

- La humanización y el medioambiente, señalada en las "Guías para el Desarrollo del Recurso Físico en Salud" CIRFS FADU UBA / OMS OPS, 1990, como en diferentes proyectos investigación o cooperación técnica del Centro de Investigación en Planeamiento del Recurso Físico en Salud, CIRFS. 
- Los espacios saludables. Los nuevos enfoques en la atención de salud, que orientan a enfatizar las necesidades psicológicas y sociales de los pacientes en el diseño de los recursos físicos en salud, con la aparición del concepto del "diseño centrado en el paciente", el "diseño basado en evidencia" y el "diseño salutogénico".

\subsection{Formulación del problema}

Los pacientes internados se ven sujetos a grandes tensiones, el miedo, la enfermedad, la pérdida del control, el estrés (Ulrich Roger. 2006) ${ }^{10}$, la falta de intimidad y privacidad, son solo ejemplos de los trastornos a los que se ven sometidos.

A estos problemas les podemos agregar desde lo arquitectónico, los efectos de la falta de iluminación natural (Ulrich Roger 1984) ${ }^{11}$, (Beauchemin, K. M., \& Hays, P., 1996) ${ }^{12}$, la inadecuada iluminación artificial, los colores monótonos o sobresaturados, el nivel de ruido (Ulrich Roger y Quan 2004) ${ }^{13}$, los espacios reducidos y la mala distribución del equipamiento, que no solo producen molestias en los pacientes y familiares, sino también a los encargados de brindar atención a estos.

La búsqueda de una humanización de los espacios junto con el diseño de espacios saludables en particular, intenta dar respuestas a esta problemática con una visión más completa del paciente, contraponiéndose con una visión tecno-medica de la salud, enfocada solo en lo operativo que no contempla aquellos aspectos vinculados a las necesidades del paciente y del recurso humano.

No obstante, son muchas las miradas y diversos los abordajes de los investigadores arquitectos, diseñadores de interiores, sociólogos y doctores en medicina, entre otras disciplinas, la que observa desde sus propias áreas de estudio esta temática altamente interdisciplinaria, sin que haya un trabajo unificador de estas teorías.

Estas realidades medico arquitectónicas se observan en los Servicios de Atención de Internación General, sin embargo se hacen particularmente más críticas cuando se trata de una Unidad de Cuidados Intensivos Cardiológicos.

\footnotetext{
${ }^{10}$ Ulrich, Roger. S., Zimring, C., Quan, X., \& Joseph, A. The environment's impact on Stress. In S. Marberry (Eds.), Improving healthcare with better building design (37-61). Chicago: Health Administration Press. 2006.

${ }_{11}$ Ulrich, Roger S. View through a window may influence recovery from surgery. Science, 224(4647), 420-421. 1984.

${ }^{12}$ Beauchemin K.M., Hays P: Sunny hospital rooms expedite recovery from severe and refractory depressions. Journal of Affective Disorders 40:49-51, 1996.

${ }_{13}$ Ulrich Roger S, Xiaobo Quan, The Role of the Physical Environment in the Hospital of the 21st Century. College of Architecture, Georgia Institute of Technology. 2004.
} 


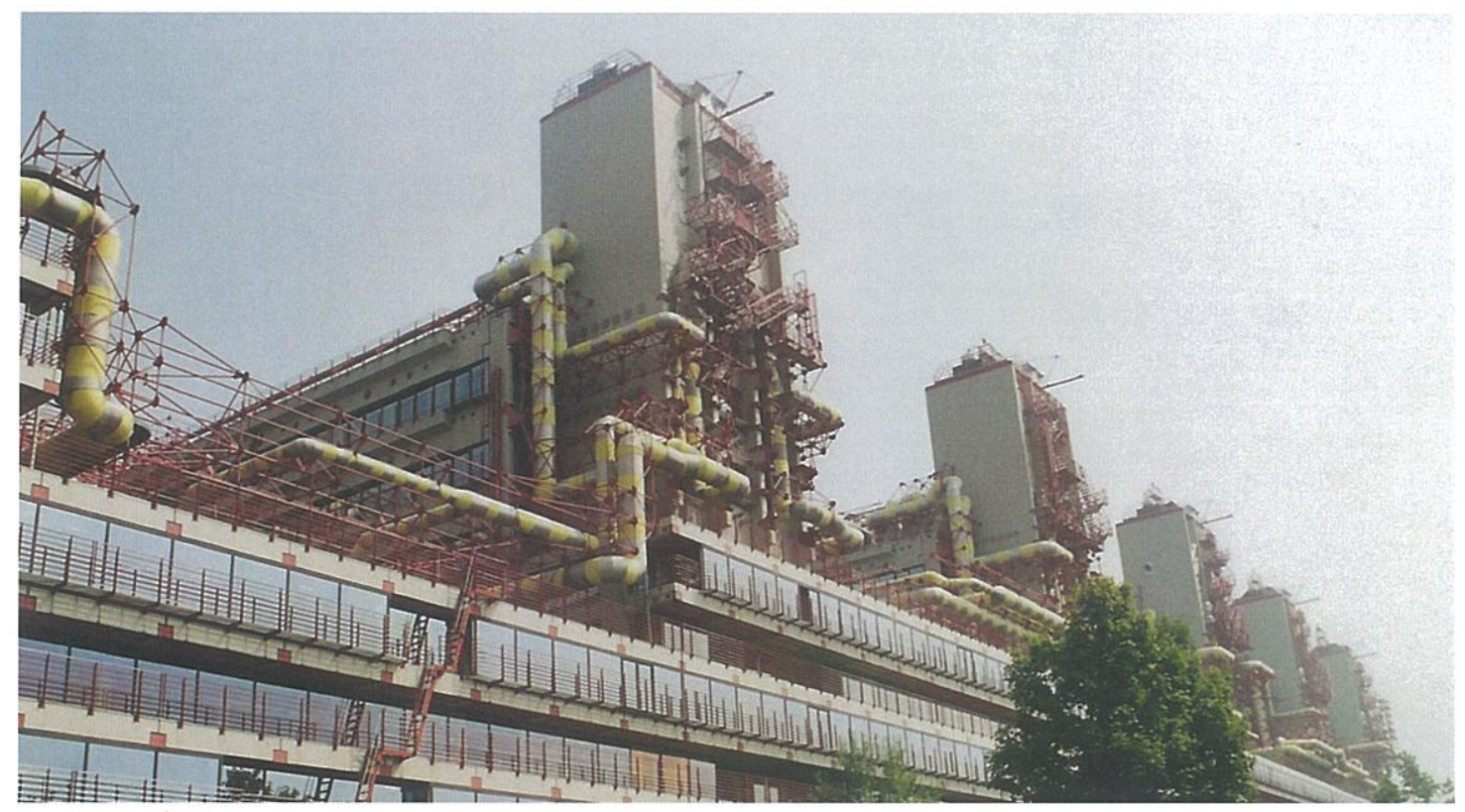

"La Maquinaria de la Salud"

Tecno - Hospital cerca de Dusseldorf Alemania, Vista Exterior (2005 Foto AMD ${ }^{14}$ ).

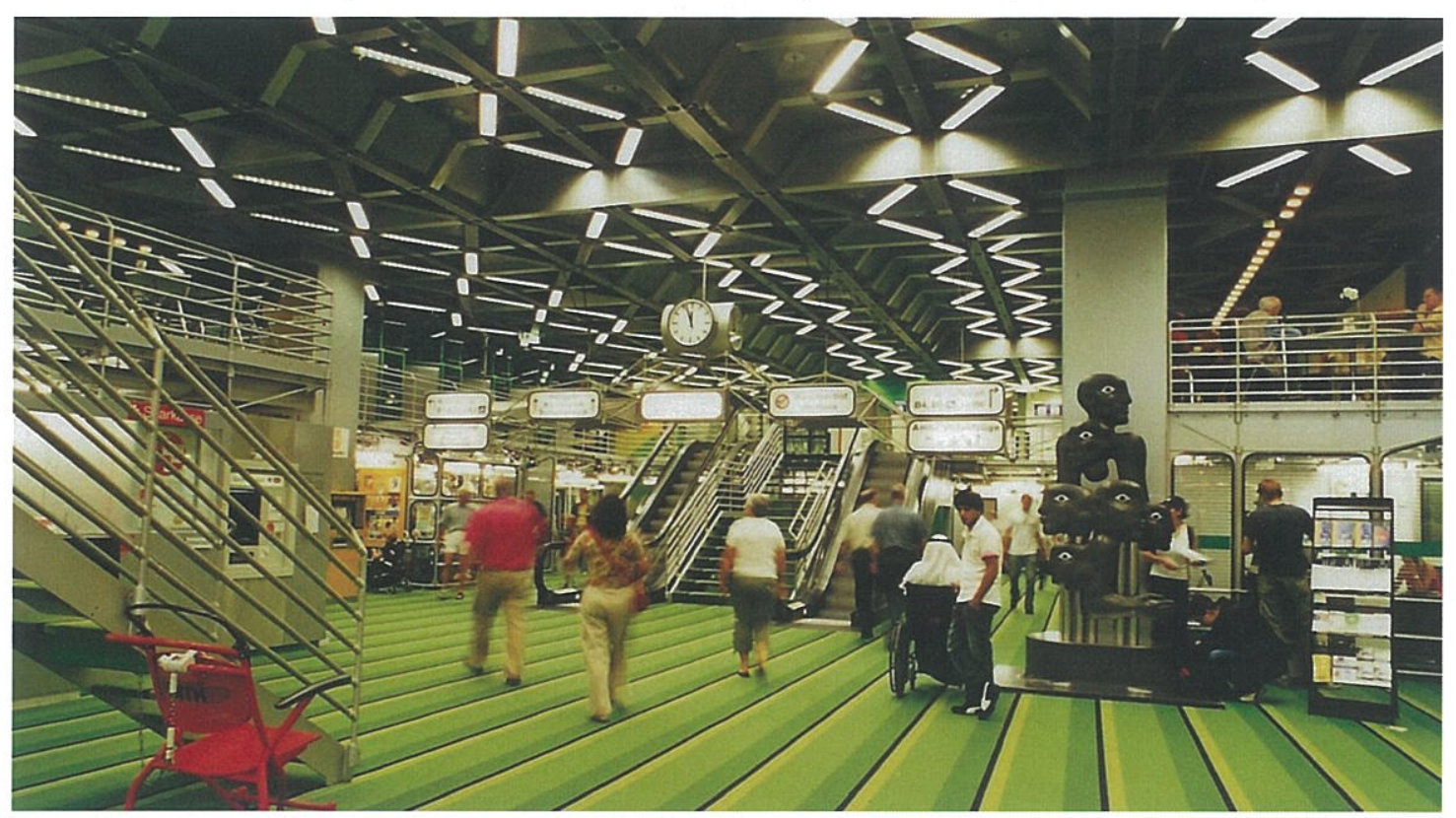

La Maquinaria de la Salud

Tecno - Hospital cerca de Dusseldorf Alemania, Hall de Acceso (2005 Foto AMD).

${ }^{14}$ AMD son las iniciales de mi nombre. 
Los problemas antes señalados plantean la necesidad de un trabajo de investigación integrador, que intente vincular los trabajos de diferentes investigadores relacionados con el estudio de los "espacios saludables", que identifique, delimite y califique aquellos posibles condicionantes arquitectónicos ausentes como determinantes en la Programación del Recurso Físico en Salud.

La modalidad de Atención de Internación Cuidados Intensivos y específicamente Cardiológicos ha adquirido un gran desarrollo en el marco de la Capacidad Instalada general del Sector Salud, lo cual exige soluciones para su caracterización espacial y ambiental, que reestudien los Procesos en Operación y la Organización espacial funcional de los mismos, adaptados a los nuevos requerimientos. Concurrente con este desarrollo es que se destaca, la importancia de un trabajo de investigación proyectual sobre la caracterización de estos Servicios, especialmente enfocada en las habitaciones de estas Unidades. 

Capítulo 2.

Marco Conceptual Teórico y Estado del Arte del Proyecto de Investigación 



\section{Capítulo 2}

\section{Marco Conceptual Teórico y Estado del Arte del Proyecto de Investigación}

\subsection{Presentación del marco conceptual o "marco teórico"}

Siendo el Centro de Investigación del Planeamiento del Recurso Físico en Salud CIRFS FADU UBA, el lugar donde se radica este trabajo de investigación y contando este con un Marco Conceptual ${ }^{15}$, el cual ha sido generado a través de un proceso evolutivo y a su vez aplicado en diversos escenarios tanto nacionales como internacionales, se partirá de dicho Marco Conceptual al que paralelamente se incorporan dado la especificidad de la temática las Condicionantes Ambientales, que se desarrollan en el Modelo Referencial MR, definidos en el Capítulo 4.2. Estudio de las Condicionantes Ambientales.

Se presenta el Marco Conceptual del Centro de Investigación del Planeamiento del Recurso Físico en Salud CIRFS:

- La definición del Recurso Físico en Salud:

Como un medio "espacio-instrumento" para acceder a la salud, condicionado por el medio ambiente social y físico, a partir de la interacción de los recursos humanos, financieros y legales.

- El Proceso de Planeamiento del Recurso Físico en Salud:

Como una metodología en la que se reconocen cinco etapas: formulación, programación, proyecto, ejecución y operación del Recurso Físico en Salud. Con un continuum de planificación, implementación y control-evaluación.

- La interacción de las condiciones del Medio Social y del Medio Físico:

Se reconocen dos áreas: Medio Social y Medio Físico, origen de los factores de riesgo y de la determinación de la situación de salud del individuo-familia y del ambiente urbano. Dentro del Medio Social pueden reconocerse los factores demográficos (vulnerabilidad biológica), sociales (vulnerabilidad social) y económicos (vulnerabilidad económica), y en el Medio Físico, los factores procedentes del medio natural y del medio construido (vulnerabilidad ambiental).

- La delimitación espacial de las Áreas Homogéneas de Condiciones de Vida: Que permite identificar las situaciones de riesgo de diferentes grupos de población, que requieren acciones particularizadas de desarrollo social-salud acordes al grupo espacial-problema.

- La Identificación de Acciones de Salud sobre el Hombre y sobre el Medio Físico:

Entre las Acciones de Salud sobre el Hombre se identifican las de Promoción de la Salud, de Prevención de la Enfermedad, de Atención de Patología y de

${ }^{15}$ Última revisión Marco Conceptual CIRFS FADU UBA Buenos Aires 2010 
Rehabilitación, contemplando en forma sistemática aspectos vinculados a la salud física, mental y social y considerando al hombre en su dinámica de vida.

Entre las acciones sobre el Medio Físico, natural y construido, se reconoce las acciones de Promoción, de Prevención, de Adecuación, Renovación y Mantenimiento, contemplando aspectos vinculados al uso, cobertura y calidad del servicio y calidad ambiental.

- El concepto de Tecnología de Operación:

El "cómo" organizar el desarrollo de la aplicación de las técnicas genera un conocimiento en sí que se reconoce como Tecnología de Operación, que hace referencia a la modalidad de ejecución de las acciones y a las reglas de juego de los distintos participantes, usuarios y prestadores. El término "tecnología", que invariablemente connota la idea de componentes físicos: "hardware", comprende también los que se puede determinar, por analogía tomada de la informática, como componentes lógicos: "software".

- La identificación de las Tecnologías de Operación sobre el Hombre y sobre el Medio Físico:

En las Tecnologias de Operación para el desarrollo de Acciones de Salud sobre el Hombre se identifica: la Comunicación -social, colectiva e individual-, el Control efectuado según norma- la Atención Ambulatoria programada y de urgencia y la Atención de Internación, a nivel institucional y domiciliario.

Mientras que en las Tecnologías de Operación como respuesta a las Acciones de Salud sobre el Medio Físico, se reconoce: la Comunicación -social, colectiva e individual-, el Control -efectuado según norma- y la Conservación.

- EI interaccionar sistémico de Tecnologías Nucleares y de Apoyo:

Con una concepción sistémica, se reconoce una trama donde a partir de las Tecnologías Nucleares se insertan las Tecnologías de Apoyo

- En las tecnologías de operación sobre el Hombre se reconoce como Tecnologías Nucleares las modalidades de Comunicación, Control, Atención Ambulatoria y Atención de Internación, adjetivadas por la Educación y la Investigación. En tanto como Tecnologías de Apoyo se reconoce cuatro conjuntos: las Tecnologías de Diagnóstico y Tratamiento, las Tecnologías Complementarias, las Tecnologias de Abastecimiento y Procesamiento y las Tecnologías de Conducción y Administración.

- La interacción de la Tecnología de Operación y la Tecnología de Recursos: La formulación de los Recursos en Salud se inicia a partir de los Recursos Humanos, los que se caracterizan en utilización, conformación por especialidad, desempeño y aptitudes, lo que a su vez definirá la caracterización de los Recursos Físicos, en su utilización y tipología espacial, concurriendo ambos a determinar la estructura de los Recursos Financieros, en sus gastos de operación y de inversión, el todo enmarcado por los Recursos Jurídicos. 
- La identificación de los Recursos Físicos en Salud:

Se parte del reconocimiento del Equipamiento Social como potencial Recurso Físico en Salud para la realización de Acciones sobre el Hombre y sobre el Medio.

- La conformación de Redes de Tecnologías de Operación con la participación del Equipamiento Social:

Las Redes de Tecnologías de Operación espacialmente materializadas, vinculan los recursos sectoriales y extra-sectoriales de la sociedad, a fin de concurrir a la resolución de la Atención de Salud. Con un nivel de análisis de macro sistema se definen los Roles de los Nodos integrantes de la Red.

- La caracterización de las Tecnologías de Operación:

En un cambio de escala macro sistema-microsistema, se califican y cuantifican las Tecnologías de Operación según Funciones, Actividades y Tareas.

- La definición del Cómo, Quién y Dónde:

A cada Tecnología de Operación definida en Funciones, Actividades y Tareas: "Cómo", le corresponde un Recurso Humano para su resolución: "Quién", quienes delimitan Espacios Actividad: "Dónde".

- La definición de las Líneas de Proceso, respuesta a la Tecnología seleccionada:

Definidos el Cómo, Quién y Dónde, se puede reconocer su participación e inserción en definidas Líneas de Proceso que establecen la secuencia de Actividades, los roles del Recurso Humano, y la secuencia de los Espacios Actividad.

- La definición de Tipología:

Se considera el concepto de Tipología como principio de clasificación de los medios estructurales básicos. Se la concibe a nivel de abstracción conceptual, no limitada a una referencia concreta de modelo u objeto terminado.

El análisis de cada Tecnología de Operación según Funciones Actividades y Tareas, permite clasificar los Espacios Actividad con un criterio tipológico, reconociéndose las diferentes Tipologías de Espacio-Actividad: Oficina, Reunión, Examen, Tratamiento, Procesamiento, Depósito, Sanitario, Habitación, Gimnasio, Vestuario, etc.

- La definición de Tipologías de Recurso Físico:

Las Tipologías Espacio-Actividad, por la interacción del equipamiento, del espacio y de las instalaciones, generan un número variable de Tipologías de Recurso Físico, las cuales se caracterizan por la incorporación del "instrumento-equipamiento" necesario para el desarrollo de la actividad; por la conformación dimensional y la calificación de las condiciones ambientales del espacio-arquitectura, y por la explicitación de las necesidades de las "instalaciones", como respuesta a las necesidades del equipamiento y a las condiciones ambientales del espacio. 
- Las leyes de conformación de los Sistemas y de los Conjuntos: Espacio, Equipamiento e Instalaciones:

Con una concepción sistémica y de conjuntos se puede reconocer en un sentido la interacción sistémica Espacio-Equipamiento-Instalaciones, y en el otro sentido, la conformación de conjuntos a partir de cada uno de estos sistemas, lo que permite efectuar un proceso de "catalogación" que posibilitará la obtención de un universo restringido de variables alternativas a ser seleccionadas.

- La interacción espacial de las Tipologias de Recurso Físico:

En cada nodo: Unidad de Salud se pueden identificar las Tipologías de Recurso Físico necesarias para el desarrollo de las Tecnologías de Operación, respuesta al $\mathrm{Rol}$ asignado en la Red. Se incorporan las unidades tipológicas: examen, oficina, sala de reunión, gimnasio, etc.; o sea las dimensiones y condiciones ambientales del espacio, los conjuntos de equipamiento y la presencia y calidad de las instalaciones. Concebida de esta forma, no existen tipologias representativas de establecimientos o unidades de salud, sino Unidades Tipológicas, que por agrupación e interacción, constituyen el Recurso Físico en Salud.

\subsection{Estado del arte del tema a desarrollar}

\subsubsection{Estado del Arte sobre la Caracterización del Recurso Físico para los Cuidados Intensivos:}

El objetivo de esta etapa es reconocer la información sobre el estado del arte y las normas, guías y estándares disponibles a nivel nacional e internacional, en relación a la caracterización funcional de las Servicios de Cuidados Intensivos, con énfasis en los Cuidados Intensivos Cardiológicos.

\subsubsection{A nivel Nacional}

A Nivel Nacional se reconocen las siguiente Guías y Normas:

- Las "Guías para el Desarrollo del Recurso Físico en Salud" CIRFS FADU UBA ${ }^{16}$, Publicadas por Organización Panamericana de la Salud, y la Organización Mundial de la Salud, OPS/OMS Washington -1990 , estas guías constituyen un instrumento de soporte y ayuda, que propone, explicita y ejemplifica las actividades a desarrollar en las etapas y sub-etapas del proceso de planificación de los recursos en salud.

Habiéndose cumplido veinte años de la publicación se abordó el proceso de actualización, comenzando por cinco (5) de las Guías de mayor demanda, dicho proceso se llevó a cabo en el año 2010, el proyecto fue financiado por la Organización Panamericana de la Salud, y la Organización Mundial de la Salud, OPS/OMS.

\footnotetext{
${ }^{16}$ Las Guías cuentan con la participación de otros tres centros latinoamericanos; el Centro de Ingeniería Biomédica de la Universidad Estatal de Campinas (UNICAMP), San Pablo - Brasil, el Fondo Nacional Hospitalario (FNH) del Ministerio de Salud, Bogotá - Colombia, y el Centro de Desarrollo y Aplicaciones Tecnológicas (CEDAT) del Ministerio de Salud, Ciudad de México - Estados Unidos de México
} 
- Las "Fichas Técnicas sobre el Recurso Físico en Salud. Espacio, Equipamiento e Instalaciones según Tecnologías"17, CIRFS FADU UBA.

Es importante aclarar que los Cuidados Intensivos, no se encuentra desarrollados en las "Fichas Técnicas" 1990 del CIRFS FADU UBA ya que estas abarcan solo el primer plano de resolución tecnológica, de todos modos resultan un valioso antecedente metodológico para este trabajo de investigación. Cabe destacar que recientemente se ha iniciado un nuevo proceso de actualización Proyecto: Caracterización del Recurso Físico en Salud para el desarrollo de las Tecnologías de Atención Ambulatoria Programada y Atención de Internación, de la Secretaria de Investigación SI FADU UBA 2011.

- Las "Guias de la Sociedad Argentina para la Calidad en la Atención de la Salud SACAS".

- Normas de Organización y Funcionamiento de Unidades de Terapia Intensiva. Dirección de Calidad de los Servicios de Salud, Programa Nacional de Garantía de la Calidad Medica PNGC, Ministerio de Salud de la Nación MSN - Resolución N 318/2001.

- Normas de Organización y Funcionamiento de Unidades de Cuidados Intensivos Cardiológicos. Unidades Cardiológicas. Dirección de Calidad de los Servicios de Salud, Programa Nacional de Garantía de la Calidad Medica PNGC, Ministerio de Salud de la Nación MSN - Resolución No $375 / 2002$.

- La Normativa AEA90364 (Asociación Electrotécnica Argentina). Reglas Particulares para la ejecución de las Instalaciones Eléctricas en Inmuebles. Parte 7. Sección 710. Locales para Usos Médicos y Salas Externas a los Mismos.

\subsubsection{A Nivel Internacional}

A nivel Internacional se reconocen las siguientes Guías y Normas:

- "Hospitales en el año 2050", publicación de GUPHA Red Global de Universidades con Programas de Arquitectura en Salud, programa coordinado por la Universidad de Tokio, Japón y la Universidad de Texas A \& M Estados Unidos.

- El "Índice de Seguridad Hospitalaria" 2008 y la "Guía para la Evaluación de Establecimientos de Salud de Mediana y Baja Complejidad" 2010, ambos concurrentes a la política de hospitales seguros frente a desastres de la OPS/OMS.

- "Guidelines for Design and Construction of Health Care Facilities", The Facility Guidelines Institute FGI. Included ANSI/ASHRAE/ASHE. Standard 170-2008, of Ventilation of Health Care Facilities, with the assistance from the U.S. Department of Health and Human Services. Publicado ASHE. ISBN 9780-87258-859-2. Edition 2010, contiene una sección dedicada a las Unidades de Cuidados Intensivos en los Estados Unidos.

- Las "Guías para el Desarrollo de Green Buildings" de la Fundación Kaiser de los Estados Unidos.

- "Citation Awards Program for well designed CCUs" (Unidades de Cuidados Intensivos) copiladas y publicadas por The Society of Critical Care Medicine (SCCM), patrocinado por la Society of Critical Care Medicine, la American Association of Critical Care Nurses (AACN), y la American Institute of Architects, Academy on Architecture for Health (AIA/AAH), representa alguno de los últimos conceptos en diseño de Unidades de Cuidado Intensivo en los Estados Unidos.

17 Las Fichas Técnicas conforman un volumen de aproximadamente 1500 páginas estructurado en tres capítulos: Capítulo 1: Tecnologias de Operación - Tipologías de Recurso Físico. Capítulo 2: Sistema de Equipamiento. Capítulo 3: Sistema de Instalaciones. Publicación OPS/OMS - Fundación Kellogg CIRFS/FADU/UBA - FIRS. 1990. En proceso de actualización 2010. 
- Las "Guías para Diseño de Unidades de Cuidado Intensivo" de la Society of Critical Care Medicine y la American Association of Critical Care Nurses de los Estados Unidos.

- "The Technical Guidance" publicadas por The National Health Service NHS Estates: en formato de CD-ROM, 98-02 en el Reino Unido.

- Las "Guías para Construcción de Hospitales Generales" del Ministerio de Salud de Holanda.

- Las Normas ISO 9001 - Quality Management Standard

- La Normativa NFPA 99. (Nacional FIRE Protection Association). Health Care Facilities. Edición 2005.

- La Normativa NFPA 70. NEC (Nacional Electrical Code). Artículo 517. Health Care Facilities. Edición 2008.

- IEEE Whitebook. IEEE Recommended Practice for Electric Systems in Health Care Facilities. Std $602^{\mathrm{TM}}-2007$.

- Design Manual for Hospitals and Clinics; HVAC (Heating, Ventilating, and Air Conditioning). Capitulo 12. Room Design. Edición 2003.

\subsubsection{Estado del Arte sobre el Diseño de Espacios Saludables}

La humanización de los espacios junto con el diseño de espacios saludables en particular, es una fuerte tendencia que ha captado la atención de investigadores de varias disciplinas relacionadas con el diseño para la salud.

Como se había mencionado en el 1.2. Formulación del problema, son muchas las miradas y diversos los abordajes de los investigadores, sociólogos, arquitectos, diseñadores de interiores y doctores en medicina, entre otras disciplinas, la que observa desde sus propias áreas de estudio los Espacios Saludables.

A continuación se presentaran referencias a trabajos desarrollados por distintos investigadores y profesionales, relacionados la temática de los Espacios Saludables:

\section{Dr. Roger Ulrich}

Roger Ulrich Psicólogo Ambientalista y Director del "Center for Health Systems and Design" y Profesor del Colegio de Arquitectura y del Colegio de Medicina de la Universidad de Texas A\&M, conduce en su Centro investigaciones científicas interdisciplinarias sobre la influencia de los recursos físicos en salud en los resultados médicos de los pacientes.

Roger Ulrich, ha desarrollado una teoria sobre The Supportive Health Care Design (Ulrich 2006), que se ha transformado en un elemento de gran influencia en el diseño de arquitectura para la salud.

Roger Ulrich ha abordado junto con otros investigadores, el estudio de los espacios saludables o espacios soporte, como el los llama, a través de diferentes trabajos de investigación, View through a window may influence recovery from surgery.(Ulrich Roger 1984), observa la relación entre la recuperación del paciente de cirugía y el acceso a vistas a través de una ventana, Effects of interior design on wellness (Ulrich Roger 1991), estudia los efectos del diseño en el bienestar, Stress 
Facultad de Arquitectura y Urbanismo, Universidad Nacional de la Plata

recovery during exposure to natural and urban environments. (Ulrich Roger 1991), estudia los efectos del estrés en la recuperación de los pacientes, Effects of exposure to nature and abstract pictures on patients recovering from heart surgery. (Ulrich Roger 1991), estudia el impacto de cuadros con imagines de naturaleza e imagines abstractas, Healing arts: Nutrition for the soul (Ulrich Roger 2003), observa el arte como un elemento que nutre el alma, Exploring the patient environment (Ulrich Roger 2003), Effects of environmental simulations and television on blood donor stress. (Ulrich Roger 2003), estudia la relación de la televisión y el estrés, The Role of the Physical Environment in the Hospital of the 21st Century: A Once-in-a-Lifetime Opportunity, (Ulrich Roger 2004) hace un estudio y exposición de sus últimas investigaciones y The environment's impact on Stress (Ulrich Roger 2006) desarrolla un estudio que relaciona el estrés y el medio ambiente.

Dr. Arq. Alan Dilani

Alan Dilani, Presidente de la "Academia Internacional de Diseño \& Salud" de Estocolmo, destaca en su discurso en el $4^{\circ}$ Congreso Internacional de la Academia de Diseño y Salud en Frankfut, Alemania (2005): "la calidad del ambiente que nos rodea tiene un importante papel que desempeñar en el mantenimiento de nuestra salud". "La Arquitectura y el medio ambiente son reflejos de conceptos humanos. Por esta razón la Arquitectura en los Hospitales debe expresar el humanismo y no solo la tecnología o la producción edilicia."

Un ejemplo representativo de lo antes mencionado se encuentra en la Comunidad "Järna Antropologic Center", Järna cerca de la Ciudad de Estocolmo, Suecia, diseñada por el arquitecto danés Erik Asmussen (1913-1998).

Alan Dilani uno de los precursores en el estudio de los "Espacios Saludables" y el "The Supportive Health Care Design", apoya su trabajo de investigación en la teoria del llamado "Diseño Salutogénico" ${ }^{18}$, desarrollado por Aaron Antonovsky, antropólogo investigador del Departamento de Sociología de la Salud de la Facultad de Ciencias de la Salud de la Universidad de Ben-Gurion de Negev, en Beer Sheva, Israel, 1979.

\section{Prof. Clare Cooper Marcus}

Clare Cooper Marcus en su libro Healing Gardens: the Therapeutic Benefits and Design Recomendetions, (1999) nos presenta su trabajo de investigación sobre los "Jardines Saludables" haciendo hincapié en el efecto de bienestar terapéutico que estos proporcionan, considera concurrentemente con los estudios del Dr. Roger Ulrich (2006) que estos son esenciales a la hora de mitigar uno de los mayores males de la internación, el estrés.

Clare Cooper Marcus, es Profesora Emérita del Departamento de Arquitectura y Diseño Paisajístico de la Universidad de California, Berkeley, autora de cuatro libros y numerosos artículos sobre "Espacios Saludables". Ha publicado un artículo junto con Roger Ulrich, sobre el efecto de los jardines

\footnotetext{
${ }^{18}$ El Diseño Salutogénico.

Aaron Antonovsky incorpora el concepto del "Diseño Salutogénico" en su libro How People manage stress and stay well (1987) en este libro realiza una mirada crítica a los desafíos que enfrenta el campo de la promoción de la salud, señalando la persistencia de la orientación de la enfermedad y los límites de los enfoques factor de riesgo para la conceptualización y la realización de investigaciones sobre la salud. La orientación salutogénico se presenta como un paradigma más viable para la ìnvestigación y la práctica de promoción de la salud. El "Sentido de Coherencia" S.C. se ofrece como el marco de una teoria útil para la adopción de un enfoque salutogénico a la investigación sanitaria. Los tres componentes del SC son comprensibilidad, capacidad de gestión y el significado.
} 
Facultad de Arquitectura y Urbanismo, Universidad Nacional de la Plata

en los resultados médicos, Effects of gardens on health outcomes: Theory and research. In C. Cooper Marcus \& M. Barnes (Eds.), Healing Gardens (pp. 27-86). New York: Wiley.

Arq. José Luis Caivano

En la Facultad de Arquitectura, Diseño y Urbanismo de la Universidad de Buenos Aires el Programa "Color, Luz y Semiótica Visual" que dirige el Arq. José Luis Caivano, realiza trabajos sobre el color y la luz considerados como "signos visuales". Si bien no existe a la fecha un trabajo de investigación que vincule la elección de un color determinado con la obtención de un espacio saludable, o la relación entre color y estados de ánimo, se resalta su contribución a la investigación del color.

José Luis Caivano, en su trabajo de Investigación lleva publicado un libro sobre el color. Sistemas de orden del color (Buenos Aires: Secretaría de Investigaciones FADU-UBA, Serie Difusión № 12) Caivano, J. (1995).y varios artículos entre ellos un sobre la "Textura" "Towards an order system for visual texture", Caivano, J. (1994).

Entre los proyectos en que se halla trabajando el Programa "Color, Luz y Semiótica Visual", se encuentra el de "Nuevos aportes a los estudios interdisciplinarios sobre color en relación a la arquitectura y los diseños: el color en prácticas del habitar" Proyecto UBACyT A009, 2008-2010.

\section{Prof. Paul Robertson}

Si el tema es la música, el Prof. Paul Robertson Músico líder por más de treinta años de la prestigiosa Medici String Quartet e Investigador del Music Research Institute, Gran Bretaña, se encuentra estudiando sobre la relación de la música como elemento de control del dolor.

Paul Robertson también colabora en una investigación sobre el uso de la música en la demencia, el mal de Parkinsons y los dolores crónicos. A lo largo de estos años sus trabajos lo han vinculado con la Neurociencia y la Neuropsiquiatría, donde junto con el Dr. Peter Fenwick ha desarrollado un nuevo concepto de como la música y el cerebro en su funcionamiento se correlacionan y sintetizan.

Parte de su trabajo de Investigación fue presentado en el $2^{\circ}$ Congreso Internacional de la Academia de Diseño y Salud de Estocolmo, Suecia (2000) y estan publicados en el libro Design and Health, the Therapeutic Benefits of Desing, (Alan Dilani 2001).

\section{J. Philip Lathrop, de Booz, Allen \& Hamilton}

En el año 1991 / 1992, el Heathcare Forum Journal, publicaba un artículo de "The Patient - Focused Hospital" J. Philip Lathrop, de Booz, Allen \& Hamilton, USA, donde señalaba "la fragmentación actual de los servicios, contribuye primariamente a un servicio deficiente y de alto costo." Por otro lado, agregaba, el Establecimiento debe brindar un mejor servicio, evitar los intermediarios, esperas inútiles, llenado de planillas interminables, reestudiar el sistema de manera tal, que se evidencien sus problemas, para ofrecer una atención de una forma innovadora y eficiente, donde es fundamental la activa participación del recurso humano. 
En la teoria del "Paciente como centro de atención" 19 se da un paso de acercamiento: a las necesidades de éste colocándolo en el centro de nuestra atención y se logra la valorización del al recurso humano participante ya que se estudia el apropiado desagregado de las tareas que realiza y se lo provee con el apoyo de adiestramiento, educación y entrenamiento.

\section{Arq. Donald C. Axon}

El Arq. Donald C. Axon, teniendo como foro el Seminario del Grupo de Salud Pública UIA desarrollado Thesaloniki/Grecia (1998) que tuyo como temática "Hospital planning in an era of economy and ecology health care facilities for a changing population health promoting hospitals - A challenge for Architects", desarrolla el siguiente concepto, "Hoy, dentro del proceso de planeamiento del recurso físico en salud es necesario incorporar el "espacio saludable" - healing environment - como uno de los principales factores en el pronto y eficiente proceso de recuperación de la salud". Las variables que colaboran con la creación de espacios saludables, deben ser "tejidas" desde los comienzos de la programación, observando ciertos hechos fundamentales: La información recolectada debe ser mejorada a partir de la participación de personas con un profundo conocimiento de los procesos y que estén a su vez directamente involucrados en los eventos: médicos, enfermeras, personal, arquitectos, ambientalistas, trabajadores sociales pacientes y sus familias".

Donald C. Axon, Representante por EE UU del Grupo de Salud Pública de la Unión Internacional de Arquitectos en el $18^{\circ}$ Seminario Internacional UIA PHG desarrollado Thesaloniki/Grecia (1998).

\section{Prof. Peter Senior}

El arte también se incluye como variable en la determinación de "espacios saludables", "Es claro que el arte incorporado al diseño para salud, es un movimiento internacional que en este momento se encuentra creciendo como significado de humanización de las actividades del cuidado de la salud..." nos dice el Prof. Peter Senior, Director de "Arts for Health", en Manchester Metropolitan University MMU, en el Reino Unido.

El Programa "Arts for Health" ha desarrollado recientemente un método de evaluación sobre la calidad del medio ambiente (Peter Scher 1999) que proporciona una importante información para diseñadores, artistas y administradores de la salud. Con más de treinta años de experiencia en la relación entre el Arte y la Salud, Peter Senior y su equipo han reunido documentación científica que se reconoce como base de datos confidencial tanto para investigación como para estudios académicos.

Dra. Arq. Ruzica Bozovic - Stamenovic

\footnotetext{
${ }^{19}$ El Paciente como centro de la Atención - El hospital Focalizado en el Paciente El Diseño Centrado en el Paciente. consiste en localizar la mayor parte de los servicios cercanos al paciente para brindar mayor confort y evitar superposición de tareas, este diseño tiende a la búsqueda de la humanización del servicio.
} 
Concurrente con la temática de la estimulación sensorial, desarrollada por el Prof. Peter Senior, la Dra. Arq. Ruzica Bozovic - Stamenovic, Profesora del Department of Architecture, la Universidad Nacional de Singapur, se encuentra trabajando en las, "Guidelines for sensory stimulation design in healthcare". Publicadas en el libro: Programming, Guidelines and Masterplanning for Hospitals, ed. UIA International Union of Architects Workprogramme Public Health, 7-17. Dusseldorf: UIA Work Programme Public Health, (Bozovic-Stamenovic, R, 2004).

Ruzica Bozovic - Stamenovic, también Profesor Titular de la Facultad de Arquitectura de la Universidad de Belgrado, estudia en estas Guias de Estimulación Sensorial para la Atención de Salud, la relación entre el eustres (estrés positivo).y la estimulación sensorial del diseño.

Dn. Jain Malkin

La reconocida diseñadora norteamericana de interiores Jain Malkin observa, que si bien hace unos años atrás el diseño de ambientes saludables era generalista, en este momento debemos dar un paso más y estudiar las necesidades particulares de cada tipo de paciente para lograr espacios saludables. Jain Malkin en su nuevo libro A Visual Reference for Evidence-Based Design ${ }^{20}$, Publicado por Center for Health Design; (2008), nos habla del "Diseño Basado en Evidencia" (Hamilton 2003), señalando la importancia de la investigación científica y el seguimiento riguroso de una metodologías para la búsqueda y recolección de datos.

Jain Malkin es la Presidenta de la firma Interior Architecture for Healthcare y autora de varios libros sobre "espacios saludables".

\section{Dr. Arq. David Allison}

Con el mismo encuadre científico de Jain Malkin de Diseño Basado en Evidencia, la Dra. Dina Battisto, y el Dr. Arq. David Allison, están trabajando en un Prototipo replicable para la Habitación de Internación, en un artículo de American Institute of Architects: "A Patient Room Prototype: Bridging Design and Research", señalan:

"Los problemas de diseño en las habitaciones de internación pueden agravar los factores de estrés (y posiblemente aumentar los errores del personal médico). Estos problemas se han relacionado con muchos factores, incluyendo la iluminación inadecuada, la falta de luz natural, el ruido, habitaciones dobles en lugar de habitaciones individuales, la falta de habitaciones estándar, los materiales y el diseño (Chaudhury y Valente, 2005; Chaudhury et al, 2006; Reiling de 2007, Ulrich et al, 2004)".

David Allison es Profesor y Director del Graduate Studies in Architecture + Health en la Universidad de Clemson EE UU, Consultor y Miembro de la Academia de Arquitectura para la Salud.

\footnotetext{
${ }^{20}$ El Diseño Basado en Evidencia

Existen cuatro niveles de diseño "basado en evidencia", a medida que se profundiza el nivel se va haciendo más rigurosa la investigación. http://archived.healthdesign.org/malkin/Malkin_CH1.pdf 
Capítulo 3. Hipótesis, Objetivos y Metodología 



\section{Capítulo 3.}

Hipótesis, Objetivos y Metodología

\subsection{Formulación de la hipótesis de investigación}

La documentación presentada en los Capítulos 11.2. Formulación del problema y 2. Estado del Arte del Proyecto de Investigación permite formular:

Que existe un conjunto de condicionantes ambientales, que favorecen la obtención de espacios saludables, que actúan desde lo proyectual arquitectónico y que podrán ser incorporadas en una habitación de Cuidados Intensivos Cardiológicos, en el marco del Planeamiento del Recurso Físico en Salud.

a) Que existe un conjunto de condicionantes ambientales concurrentes con la obtención de espacios saludables

b) Que dichas condicionantes ambientales actúan desde lo proyectual arquitectónico por lo tanto podrán ser delimitadas, caracterizadas y estudiadas

c) Que por actuar desde lo proyectual arquitectónico, podrán ser incorporadas en un ámbito como lo es la habitación del Cuidados Intensivos Cardiológicos, tomando como marco el Planeamiento del Recursos Físico en Salud.

A través de las condicionantes ambientales se plantea una relación - vínculo entre el paciente y el ámbito de la habitación de internación, de forma tal que el espacio es concebido como "soporte" en el proceso de recuperación de la salud.

El espacio está compuesto por múltiples elementos que conforman entre si una composición, que puede pasar desapercibida pero que de todos modos se encuentra allí, esperando ser interpretada. 


\subsection{Formulación de Objetivos para esta Investigación}

\section{Objetivo principal}

Se reconoce como objetivo principal de esta investigación; la caracterización de las variables ambientales en la determinación de las nuevas condicionantes del diseño, para el desarrollo de una nueva propuesta de resolución proyectual arquitectónica para la habitación del paciente de Cuidados Intensivos Cardiológicos, en el marco del Planeamiento del Recurso Físico en Salud.

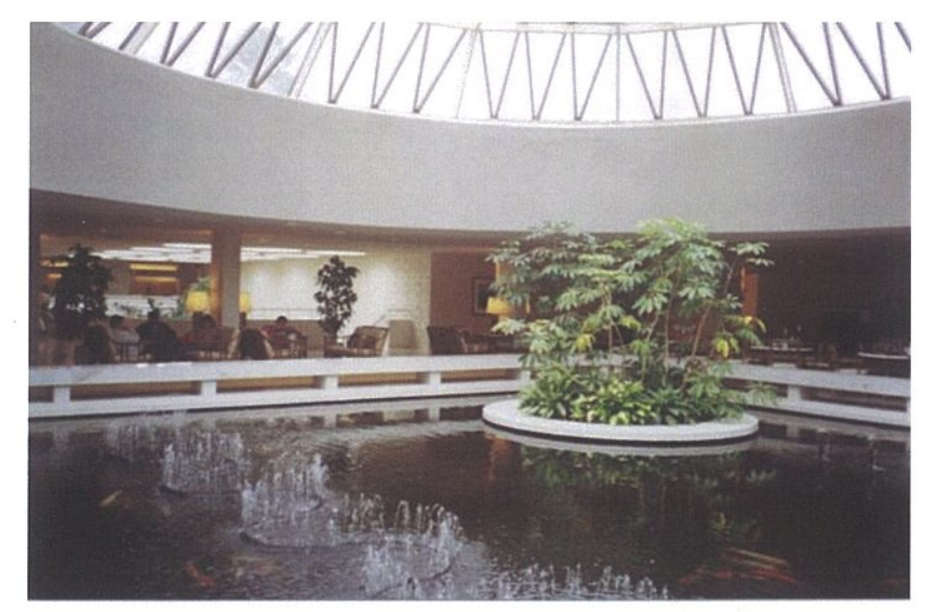

Areas interiores del Establecimiento con incorporación de fuentes y plantas Kaiser Permanente Hospital San Francisco, EE UU (2003 Foto AMD ${ }^{21}$ )

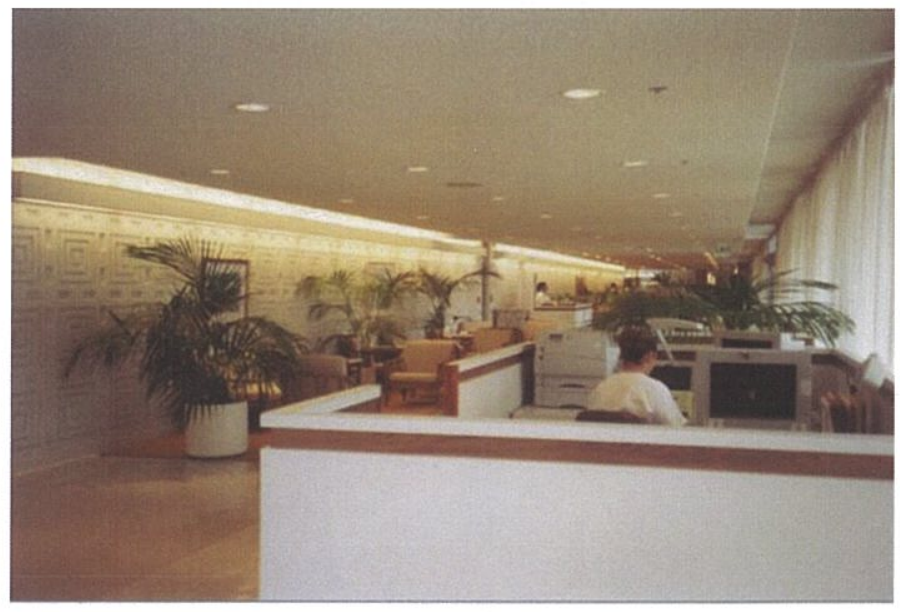

\footnotetext{
${ }^{21}$ AMD son las iniciales de mi nombre.
} 


\section{Son objetivos particulares}

- El estudio de los procesos, mediante la definición de la tecnología de operación de Internación de Cuidados Intensivos Cardiológicos, a partir de la caracterización de; la política operacional, la operación mediante el desarrollo de funciones, actividades, tareas, recurso humano y recurso físico participantes y procesos - líneas de proceso.

- La caracterización de la organización espacial funcional de los espacios de atención del paciente. A partir de la interacción entre la Arquitectura, el Equipamiento y las Instalaciones.

- La satisfacción del paciente internado a través de la categorización e impacto de las variables ambientales como condicionantes de diseño arquitectónico.

- La definición de nuevas soluciones proyectuales, a partir del estudio de Tipologías, Espacio - Tareas como antecedente y base de la propuesta arquitectónica para la habitación de Cuidados Intensivos Cardiológicos

\subsection{Metodología de Investigación}

Se reconoce que en el desarrollo de una metodología de investigación se requiere el diseño de modelos que interaccionan en los planos, referencial, de observación, normalizado, de propuesta y de implementación, según etapas que dependen de la finalidad perseguida.

Hay una primera etapa sustantiva en el desarrollo de la investigación en la que se conforma el modelo referencial, este se constituye con dos aportes: el reconocimiento y análisis de las situaciones y las tendencias vinculadas con la atención y los recursos en salud.

Una segunda etapa se emplea para leer la realidad y confrontarla con el modelo referencial. Esa lectura permite elaborar un modelo que, por tener su génesis en la realidad concreta, se denomina modelo observado. Los instrumentos metodológicos para observar esa realidad siguen los lineamientos trazados por el modelo referencial, pero permiten incorporar, en forma sistemática y completa, aspectos que la realidad entrega. Este modelo expresa la situación existente, sus particularidades, sus valores y sus falencias, el cual es el sujeto de análisis y reformulación.

De esta manera se va construyendo, sucesivamente y por retroalimentación, el modelo normalizado, sistema de relaciones que trata de captar los elementos esenciales de una situación idealmente concebida, e incorpora determinantes y condicionantes que se elaboran en un grado relativamente alto de abstracción. 
Dicho modelo normalizado, siguiendo los lineamientos y el encuadre del modelo referencial, incorpora aquellos contenidos que recrea la realidad del modelo observado.

Si la finalidad es aplicar la metodología para analizar y dar respuesta a una situación particular, se desarrolla otra etapa de comparación de modelo normalizado con el modelo observado, que deriva en el modelo propuesto, modelo diferencial que determina la meta objetivo alcanzable con la realidad observada; que antecede al modelo de implementación, el cual incorpora los instrumentos de evaluación correspondientes.

En sintesis se reconoce una imagen sistemática proyectual que, a partir de un modelo referencial de planeamiento del Recurso Físico en Salud, se ajusta y prueba en una realidad concreta: modelo observado y por aplicación o diferencia genera un modelo propuesto, que en su operación y evaluación define el modelo de implementación, línea directriz que recrea la evolución y dinámica de los conocimientos del modelo normalizado del cual un estadio es la "Norma".

Esta metodología interactuando con otras complementarias como lo son utilización de metodologías cualitativas de investigación, que enriquecen la descripción de la información a través de Encuestas a Pacientes y Entrevistas con Médicos Especialistas en Cuidados Intensivos Cardiológicos, construirá el eje instrumental del desarrollo de la presente investigación. 
Capítulo 4.

Análisis y Desarrollo de la Investigación 



\section{Capítulo 4.}

\section{Análisis y Desarrollo de la Investigación} "Comunicar es poner en común - es tender puentes por lo menos entre dos sujetos, asi
emerjan de un mismo individuo"

Katia Mandoki, Estética y Comunicación de acción, pasión y seducción (2006)

Este trabajo de Investigación Proyectual, se desarrolla en dos vertientes, que sin embargo serán abordadas de forma simultánea.

Por un lado se realizara un estudio de la Unidad de Cuidados Intensivos a través de la caracterización del recurso físico, la definición de las tecnologías ${ }^{22}$ de operación de Atención de Internación de Cuidados Intensivo y su posterior organización espacial funcional en los espacios correspondientes a la habitación del paciente de Cuidados Intensivos.

Por otro lado se busca definir las condicionantes ambientales que favorecen y determinan la obtención de espacios saludables. El sustento teórico de este estudio estará dado por los aportes de investigadores que se han pronunciado al respecto en el Capítulo 2.2.2. Estado del Arte sobre el Diseño de Espacios Saludables, junto con el Trabajo de Investigación a través de Encuestas a pacientes internados en Instituciones Públicas y Privadas, que se complementará con Entrevistas a Expertos Médicos Especialistas en Cuidados Intensivos y Cuidados Intensivos Cardiológicos.

El estudio de la caracterización de las tecnologías de operación y la organización espacial funcional para los espacios de Cuidados Intensivos, nos permitirá alcanzar el objetivo principal de este trabajo de investigación que es la determinación de las condicionantes ambientales para el desarrollo de una nueva propuesta de resolución proyectual arquitectónica para la habitación del paciente de Cuidados Intensivos Cardiológicos, en el marco del Planeamiento del Recurso Físico en Salud.

\footnotetext{
${ }^{22}$ Entendiendo el concepto de "tecnología" como la incorporación conjunta de los "componentes físicos" y los "componentes lógicos"; con una concepción análoga al área de informática, "el hardware" y "el software" respectivamente. Guias para el Desarrollo del Recurso Físico en Salud, CIRFS FADU UBA. OMS/OPS 2010.
} 

Capítulo 4. 1.

Estudio de la Unidad de Cuidados Intensivos y Cuidados Intensivos Cardiológicos 



\section{1. Estudio de la Unidad de Cuidados Intensivos}

\subsubsection{Breve Reseña Histórica}

La primera Unidad de Cuidados Intensivos fue diseñada en el año 1854 como una unidad de seguimiento de pacientes graves por la Enfermera Florence Nightingale. A comienzos de la guerra de Crimea en la que Inglaterra, Francia y Turquía declararon la guerra a Rusia, las malas condiciones de los pacientes hicieron elevar las tasas de mortalidad de los soldados hospitalizados. La incorporación a la atención intensiva bajó la mortalidad. Florence Nightingale sentó las bases para el posterior descubrimiento de la importancia de las condiciones sanitarias en los hospitales, un componente critico de Cuidados Intensivos.

El Dr. Walter Edward Dandy, de origen norteamericano, creó la primera Unidad de Cuidados Intensivos en el mundo de tres camas en Boston en 1926.

El Anestesiólogo Peter Safar fue el primer Doctor Intensivista de los Estados Unidos, nacido en Austria, estableció el concepto de "Apoyo Avanzado de Vida," que consistía en mantener a los pacientes sedados y ventilados en un entorno de cuidados intensivos. Safar es considerado como el primer practicante de la medicina de Cuidados Intensivos.

El Anestesiólogo Bjørn Aage Ibsen, de origen danés, del Massachusetts General Hospital en la Ciudad de Boston, creó la primera unidad de Cuidados Intensivos en Copenague en 1953.

La primera aplicación de la Modalidad de Cuidados Intensivos Cardiológicos en los Estados Unidos la realizo el Dr. William Mosenthal, cirujano del Centro Médico Dartmouth-Hitchcock. En la década de 1960, reconoció la importancia de las arritmias cardíacas como una fuente de morbilidad y mortalidad en el infarto de miocardio (ataques al corazón). Esto llevó al uso rutinario de la monitorización cardiaca en la $\mathrm{UClC}$, especialmente después de los ataques al corazón.

En la Argentina la primera Unidad de Cuidado Intensivo se creó en el año 1956. El Dr. Carlos Rubianes, cuya Entrevista es parte de este trabajo de investigación, fue uno de los primeros Médicos Intensivistas de la Argentina y precursor en la creación de la Unidad de Cuidados Críticos Polivalente en el Instituto Argentino de Diagnóstico y Tratamiento IADT.

En el año 1972 se funda La Sociedad Argentina de Terapia Intensiva (SATI). 


\subsubsection{Diferentes Tipos de Unidades de Cuidados Intensivos}

Dependiendo del volumen de pacientes ingresados puede haber varias Unidades de Cuidados Intensivos especializadas en diferentes áreas de la Medicina, como son:

\section{Cuidados Intensivos Cardiológicos o Unidad Coronaria}

Unidad Postoperatoria de Cirugía Cardiaca

Trasplante de Órganos

Cuidados Intensivos Psiquiátricos

Cuidados Postoperatorios, en su mayoria Unidades de Cuidados Intensivos Polivalentes.

Si la población pediátrica lo justifica, se desarrollan:

Unidades de Cuidados Intensivos Pediátricos

Unidades Neonatales (cuyos pacientes se mueven en un rango estrecho de edad (desde el nacimiento hasta el día 28 de edad) conocido como período neonatal).

\subsubsection{Normas de Organización y Funcionamiento y Matrices de Cuidados Intensivos Cardiológicos}

\subsubsection{Normas para la Organización y Funcionamiento de Cuidados Intensivos Cardiológicos}

La Dirección de Calidad de los Servicios de Salud, Programa Nacional de Garantía de la Calidad Medica PNGC, Ministerio de Salud de la Nación MSN, establece en la Resolución 375/2002, sobre las Normas de Organización y Funcionamientos de Unidades de Cuidados Intensivos Cardiológicos. Unidades de Cuidado Intensivo Cardiológicos.

En el marco de dichas Normas encontramos la siguiente definición de Unidad Cuidados Cardiológicos UCIC:

"La Unidad Coronaria (UC) es el área asistencial del Hospital dotada de medios técnicos y de los recursos humanos (médicos y enfermería), necesarios para la atención y vigilancia continuada de los pacientes con cardiopatías agudas graves y potencialmente recuperables". 
La práctica ha demostrado que la evolución asistencial de la UC se ha ido extendiendo desde la asistencia, prácticamente exclusiva, del infarto agudo de miocardio (IAM) a distintas situaciones de agudización y empeoramiento de muy diversas cardiopatías. Por esta razón, hoy en día se puede hablar con mayor propiedad de Unidad de Cuidados Intensivos Cardiológicos (UCIC).

La UCIC debe tener estrecha relación con los Servicios de Cardiología, Hemodinámica y Cirugía Cardiaca si los hubiera en la Institución, puede estar integrada a los Servicios de Terapia Intensiva y debe en caso de estar separada tener muy estrecha relación con los mismo y con el Servicio de Urgencia.

\section{Anexo 1}

Comprende el texto completo de:

Normas de Organización y Funcionamientos de Unidades de Cuidados Intensivos. Programa Nacional de Garantia de la Calidad de la Atención Medica PNGC, Ministerio de Salud de la Nación MSN Resolución 318/2001.

Normas de Organización y Funcionamientos de Unidades de Cuidados Intensivos Cardiológicos. Programa Nacional de Garantía de la Calidad de la Atención Medica PNGC, Ministerio de Salud de la Nación MSN Resolución 375/2002. 


\subsubsection{Anteproyecto del Manual de Estándares Internación Cuidados Intensivos Adultos y Pediátricos}

\begin{tabular}{|c|c|c|}
\hline TEXTODELESTANDAR & ACLARACION DEL TEXTO & $\begin{array}{l}\text { INFORMAGIÓN } \\
\text { DISPONIBLE }\end{array}$ \\
\hline $\begin{array}{l}\text { a) Cuenta con una Unidad destinada a } \\
\text { pacientes en estado critico (con actual o } \\
\text { inminente riesgo de vida) con posibilidades de } \\
\text { recuperación total o parcial, que requieran } \\
\text { servicios integrales de atención médica, } \\
\text { además de equipos e instrumental, que } \\
\text { aseguren el adecuado control de tratamiento. El } \\
\text { nivel minimo de equipamiento disponible } \\
\text { corresponde al nivel } 2 \text { de la Sociedad Argentina } \\
\text { de Terapia Intensiva (SATI). } \\
\text { Para los casos que superen la capacidad } \\
\text { resolutiva del servicio, deberá disponer de los } \\
\text { medios o mecanismos suficientes para } \\
\text { trasladarlos a instituciones de mayor } \\
\text { complejidad } \\
\text { (nivel } 1 \text { de la SATI). }\end{array}$ & $\begin{array}{l}\text { a) Los equipos e instalaciones requeridos en el nivel } \\
2 \text { de SATI deben ser: } \\
\text { - monitoreo y registro electrocardiográfico continuo; } \\
\text { o } 1 \text { monitor por cada cama, } \\
\text { o más } 2 \text { electrocardiógrafos en la Unidad; } \\
\text { - asistencia del paro cardio-respiratorio (carro de } \\
\text { paro, laringoscopio, tubos endotraqueales, } \\
\text { AMBÜ, medicamentos y descartables); } \\
\text { - marcapasos cardiaco transitorio; } \\
\text { - posibilidad de efectuar diälisis renal aguda; } \\
\text { - asistencia respiratoria mecánica: } \\
\text { o } 1 \text { respirador volumétrico cada } 4 \text { camas, } \\
\text { o no menos de } 2 \text { en la Unidad; } \\
\text { - oxigeno, aire comprimido y aspiración centrales; } \\
\text { - tomacorrientes, no menos de } 7 \text { por cama; } \\
\text { - bombas de infusión, no menos de } 1 \text { por cama; } \\
\text { - disponibilidad para efectuar control del estado } \\
\text { ácido-base e ionograma durante las } 24 \text { horas. } \\
\text { Todos los artefactos instalados para gases centrales } \\
\text { deben ser de calidad aprobada, estar conectados y } \\
\text { ventilados reglamentariamente y contar con } \\
\text { elementos de control y seguridad. } \\
\end{array}$ & $\begin{array}{l}\text { a) Observar en forma directa la } \\
\text { disponibilidad del equipamiento, } \\
\text { dispositivos e insumos mencionados, asi } \\
\text { como los criterios de calidad de las } \\
\text { instalaciones de gases centrales. } \\
\text { Verificar los medios y normas de } \\
\text { derivación a servicios de mayor capacidad } \\
\text { resolutiva. }\end{array}$ \\
\hline $\begin{array}{l}\text { b) Cuenta con personal exclusivo, tanto } \\
\text { médicos como de Enfermeria, capacitado en la } \\
\text { especialidad y disponible en forma permanente } \\
\text { durante las } 24 \text { horas. }\end{array}$ & $\begin{array}{l}\text { b1) Condiciones del responsable del servicio: } \\
\text { - médico, con título de especialista en Terapia } \\
\text { Intensiva o Cuidados Críticos (otorgado por una } \\
\text { instítución oficialmente reconocida en la } \\
\text { jurisdicción); } \\
\text { - preferentemente con Recerificación de } \\
\text { Especialidad emitida por entidad reconocida; } \\
\text { - antecedentes de al menos } 5 \text { (cinco) años en } \\
\text { servicios de Medicina Critica o residencia } \\
\text { completa en la especialidad. } \\
\text { b2) Condiciones de los médicos de guardia: deben } \\
\text { tener entrenamiento demostrable en Medicina } \\
\text { Crítica. } \\
\text { b3) Condiciones del responsable de Enfermeria: } \\
\text { debe tener titulo habilitante de enfermero/ licenciado } \\
\text { en Enfermeria, con un minimo de } 3 \text { (tres) años de } \\
\text { trabajo en áreas criticas, debidamente certificados. } \\
\text { b4) Condiciones de los enfermeros de guardia activa } \\
\text { permanente y exclusiva: tendrán conocimientos del } \\
\text { funcionamiento de la Unidad; poseerán título de } \\
\text { enfermero/ licenciado en una proporción minima de } \\
60 \% \text { y hasta } 40 \% \text { de auxiliares, según los niveles } \\
\text { establecidos para el ejercicio de la Enfermeria. } \\
\text { b5) Dotación de Enfermeria: será como minimo de } \\
\text { un enfermero cada } 2 \text { camas. }\end{array}$ & $\begin{array}{l}\text { Verificar: } \\
\text { bi) Titulos y certificaciones del } \\
\text { responsable médico; } \\
\\
\text { b2) Listado de profesionales médicos con } \\
\text { titulos y certificaciones; } \\
\text { b3) Titulos y certificaciones del } \\
\text { responsable de Enfermeria; }\end{array}$ \\
\hline $\begin{array}{l}\text { c) Dispone en el ámbito del establecimiento de } \\
\text { guardia activa de Laboratorio, Radiologia y } \\
\text { Hemoterapia. }\end{array}$ & $\begin{array}{l}\text { c) Las guardias activas de Laboratorio, Radiología y } \\
\text { Hemoterapia estarán cubiertas al menos por } \\
\text { técnicos en esas disciplinas. }\end{array}$ & $\begin{array}{l}\text { c) Observar e programa de guardias de } \\
\text { esos servicios, identificando ellilos } \\
\text { responsable/s de cada dia. }\end{array}$ \\
\hline
\end{tabular}




\begin{tabular}{|c|c|c|}
\hline TEXTO DEL ESTANDAR & ACLARACION DELTEXTO & $\begin{array}{l}\text { INFORMACION } \\
\text { DISPONIBLE }\end{array}$ \\
\hline $\begin{array}{l}\text { d) Cuenta con normas activas sobre } \\
\text { procedimientos médicos y de Enfermeria } \\
\text { propios de la Unidad. Estos procedimientos se } \\
\text { registran en la HC. }\end{array}$ & $\begin{array}{l}\text { d) Las normas médicas serán al menos las referidas } \\
\text { a la atención del paro cardio-respiratorio y } \\
\text { procedimientos invasivos. Las normas de Enfermeria } \\
\text { estarán referidas como minimo a procedimientos y } \\
\text { técnicas, incluyendo los procedimientos invasivos y } \\
\text { normas de bioseguridad } \\
\text { Deberán registrarse en la HC: } \\
\text { - procedimientos, valoración y observaciones de } \\
\text { Enfermeria, signos vitales, balance hidro-salino y } \\
\text { todo procedimiento realizado; } \\
\text { - monitoreo hemodinámico y respiratorio; } \\
\text { - evolución del paciente en cada turno; } \\
\text { - resultados de los análisis de laboratorio; } \\
\text { - informes de los estudios de diagnóstico por } \\
\text { imágenes. }\end{array}$ & $\begin{array}{l}\text { d) Verificar la existencia de nomas } \\
\text { escritas activas. Analizar una muestra de } \\
\text { HC. }\end{array}$ \\
\hline $\begin{array}{l}\text { e) Lleva sistemáticamente registros sobre el } \\
\text { estado del paciente al ingreso y egreso, asi } \\
\text { como lugar de derivación. Registra estadisticas } \\
\text { básicas de rendimiento. }\end{array}$ & $\begin{array}{l}\text { e) Debe registrar sistemáticamente los siguientes } \\
\text { datos: } \\
\text { - diagnóstico y fechas de ingreso y egreso; } \\
\text { - score de gravedad al ingreso (APACHE* o } \\
\text { similar); } \\
\text { - lugar de derivación del paciente al egresar de la } \\
\text { Unidad; } \\
\text { - promedio de estadia de los pacientes en la } \\
\text { Unidad; } \\
\text { - porcentaje ocupacional. }\end{array}$ & $\begin{array}{l}\text { e) Observar registros del sistema } \\
\text { estadistico. }\end{array}$ \\
\hline $\begin{array}{l}\text { f) La unidad dispone de las facilidades de } \\
\text { estructura que se consignan a continuación: }\end{array}$ & f) La Unidad debe contar con: & \\
\hline$\left.f_{1}\right)$ Office de Enfermeria limpio. & $\begin{array}{l}\text { f) El office de Enfermeria debe estar ubicado en } \\
\text { lugar aproximadamente equidistante de las camas } \\
\text { de internación y debe contar con: } \\
\text { - medios de comunicación con el resto del } \\
\text { nosocomio y el exterior; } \\
\text { - mesadas de trabajo; } \\
\text { - pileta con provisión de agua fria y caliente; } \\
\text { - espacio para HC de pacientes internados, si se } \\
\text { confeccionan en papel, o terminal de com- } \\
\text { putación en sistemas informatizados; } \\
\text { - central repetidora del monitoreo de pacientes } \\
\text { internados; } \\
\text { - mesada o escritorio para tareas administrativas, } \\
\text { con taburetes o sillas; } \\
\text { - botiquin periférico para medicamentos y } \\
\text { materiales descartables. }\end{array}$ & f) Observación directa \\
\hline $\begin{array}{l}\text { f) Almacenamiento de ropa y materiales } \\
\text { limpios. } \\
\text { f3) Office de mucamas (limpieza). }\end{array}$ & $\begin{array}{l}\text { f2) Area de depósito de materiales y ropa limpia. } \\
f_{3} \text { ) El office de mucamas debe contar con: } \\
\text { - medios de comunicación con el resto del } \\
\text { nosocomio; } \\
\text { - mesadas de trabajo; } \\
\text { - pileta con provisión de agua fria y caliente; } \\
\text { - depósito de corta estadia de materiales de } \\
\text { limpieza. }\end{array}$ & $\begin{array}{l}\text { f) Observación directa. } \\
\text { f) Observación directa. }\end{array}$ \\
\hline
\end{tabular}




\begin{tabular}{l} 
TEXTO DEEL ESTANDAR \\
\hline f) Depósito de materiales sucios y deshechos. \\
f5) Área de lavado y preparación de materiales \\
a esterilizar, en caso que esta labor no esté \\
centralizada. \\
f́l Posibilidad de circulación diferenciada de \\
materiales sucios, deshechos y alimentos.
\end{tabular}

$f_{7}$ Habitación de médico de guardia dentro o contigua a la unidad.

ACLARACION DEL TEXTO,
f4) El depósito debe estar ubicado lo más cercano
posible a su salida de la Unidad, de modo que no se
cruce con elementos limpios en su interior.
f5) Esta área debe ubicarse cerca de la estación de
enfermeria.
enfermeria.

$f_{6}$ ) Circuitos que impidan el contacto de materiales sucios y desechos con los elementos limpios.

INFORMACION
DISPONIBLE
f4) Observación directa.

\section{f5) Observación directa}

f7) El área de descanso del/de los médicos de guardia debe permitir el más rápido acceso del/de los profesionalles a la Unidad. En caso de no estar ubicada dentro de ella, debe disponer de una puerta de comunicación directa.

f9) Baño para personal y chatero.

f9) El baño para el personal debe estar de acuerdo a la cantidad de personas que lo usen y contar al menos con:

- lavabo;

- ducha;

- inodoro;

- provisión de agua fría y caliente;

- elementos comunes de higiene;

- dispensador de alcohol para manos.

$f_{10}$ ) Visualización directa de los pacientes desde:

$\left.f_{10}\right)$ Los sistemas de alarma y/o recepción a distancia de parámetros vitales no superan la observación del personal entrenado. Con este fin las paredes de la

- la central de Enfermeria; central de Enfermeria y de las unidades cubiculadas, deben ser de vidrio o material transparente que no

- la cama de otro paciente.

$f_{11}$ ) Facilidades para la higiene de manos del personal que està en contacto con los pacientes y familiares, en cantidad y calidad suficientes. obstaculice la vista, desde el techo hasta la altura de la cama del paciente.

$\left.f_{11}\right)$ La Unidad debe disponer de sistemas dispensadores de alcohol al $70 \%$, líquido o gel, en el ingreso y salida de familiares, en todas las estaciones de Enfermeria y mucamas, y en los sanitarios ubicados dentro del área. Los dispensadores deben contener alcohol al menos en $1 / 3$ (un tercio) de su capacidad en el momento de la evaluación en terreno.

$f_{12}$ ) Espacio suficiente para la ubicación de las camas de internación.

$\left.f_{12}\right)$ Cada uno de los cubículos del senvicio debe ser lo suficientemente grande como para que en él se ubique:

- una cama de tipo UTI;

- una mesa de luz;

- pies porta-sueros;

- los equipos de monitoreo descriptos;

- acceso amplio en el contorno de la cama.

f,3) El diseño debe permitir la libre movilidad de las camas de la unidad.

$\left.f_{13}\right)$ Los accesos a la unidad, sus pasillos interiores y los de los cubiculos de internación deben permitir el libre paso de las camas de la unidad.

fi4) Tipo de cama adecuado para la Unidad.

$f_{14}$ ) Cama rodante, con freno al menos en 2 ruedas; cabecera y pies rebatibles; lecho en 4 planos, con posiciones de Trendelemburg y anti-Trendelemburg; barandas laterales de seguridad.

$f_{15}$ ) Sistema de protección eléctrica que asegure $f_{15}$ ) Integrada por conexión a tierra con jabalina y la prevención de accidentes. disyuntores 0 similares.

fto) Observación directa.

fa) Observación directa y de planos de la unidad.

f7) Observación directa y de planos de la unidad.

f) Observación directa.

$\left.f_{11}\right)$ Observación directa.

$f_{12}$ ) Observación directa.

fi3) Observación directa.

f14) Observación directa.

$f_{t 5}$ Registro de puesta a tierra, firmado por Ing. Electricista matriculado en el ENRE. 


\begin{tabular}{|l|l|l|}
\hline $\begin{array}{l}\text { g) Desarrolla programas anuales de educación } \\
\text { Continua para el personal y se registra la } \\
\text { concurrencia. }\end{array}$ & $\begin{array}{l}\text { g) Los programas podrán ser internos o externos al } \\
\text { establecimiento. }\end{array}$ & $\begin{array}{l}\text { g) Verificar programas y registro de } \\
\text { asistencia. }\end{array}$ \\
\hline
\end{tabular}

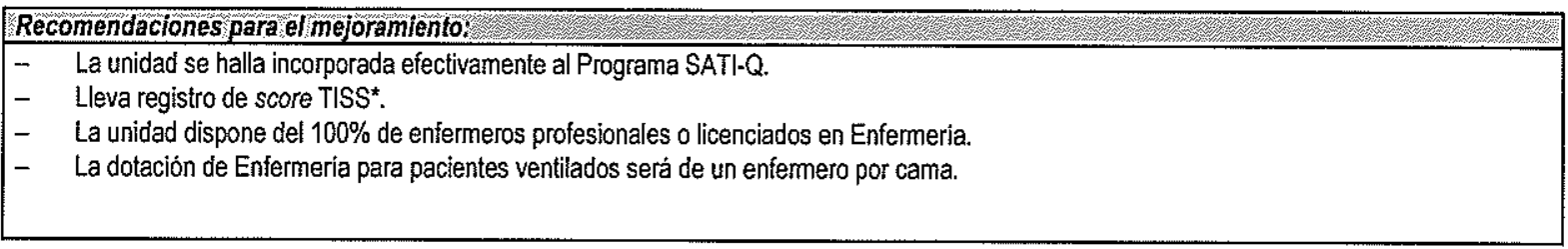

*APACHE: Acute Phisiologic And Cronic Health Evaluation

El estudio presentado forma parte del Anteproyecto del Manual de Estándares del Instituto Técnico para la Acreditación de Establecimientos de Salud (ITAES). Mimeo, Buenos Aires, 2010. Si bien estos Estándares aún no se encuentran vigentes es interesante tenerlos como Guía para la Calidad de estos Servicios ya que contaron con el asesoramiento de la Sociedad Argentina de Terapia Intensiva (SATI).

Se agradece la colaboración del Dr. Hugo Arce, Secretario General para Latinoamérica de la Sociedad de Calidad de la Atención Medica SolCaSa, Director General del Instituto Técnico para la Acreditación de los Establecimientos de Salud (ITAES) y Director del Departamento de Salud Pública del Instituto Universitario en Ciencias de la Salud IUCS de la Fundación Barceló, por esta información.

\subsubsection{Matrices de Atención de Internación Cuidados Intensivos}

Las Matrices de Atención de Internación Cuidados Intensivos Cardiológicos, fueron realizadas como parte del Proyecto UBACyT A056 2004-2007, Título del Proyecto: "Nuevas Conceptualizaciones y Enfoques en Programación: Programación Funcional y Física del Recurso Físico en Salud", las mismas fueron Dirigidas por el Prof. Consulto Arq. Astrid Bögedam de Debuchy y Codirigidas por la Arq. Ana María Sandoval y contaron con la colaboración de los siguientes integrantes: Arq. Bernardo Debuchy; Arq. Astrid Maria Debuchy (esta doctoranda); Dr. Néstor Perrone; Lic. Francisco Turull Torres; Arq. Gisela Urroz. Sede del Trabajo de Investigación: CIRFS/SICyT/FADU/UBA.

En estas Matrices se observan las Normas de Organización y Funcionamiento en Unidades de Cuidados Intensivos Cardiológicos. Resolución 375/2002, con las diferentes Denominaciones de Bajo Riesgo, Mediano Riesgo y Alto Riesgo

En la Matriz se observa Denominación, Definición, Dimensiones Mínimas (Superficie, Dimensiones y Puerta), Criterios de Cuantificación, Equipamiento Mínimo, Instalaciones Mínimas, Condiciones Ambientales y Observaciones. 


\section{Anexo 2}

Comprende el texto completo de:

Las Matrices de Atención de Internación Cuidados Intensivos Cardiológicos, del Proyecto: "Nuevas Conceptualizaciones y Enfoques en Programación: Programación Funcional y Física del Recurso Físico en Salud" UBACYT A056 2004-2007. CIRFS FADU UBA.

\subsubsection{Compendio de Normativas para Cuidados Intensivos y Cuidados Intensivos Cardiológicos de la Fundación Favaloro}

El Compendio de Normativas para Cuidados Intensivos y Cuidados Intensivos Cardiológicos de la Fundación Favaloro contiene especificaciones de Instalaciones y Equipamiento y comprende un estudio comparativo entre las siguientes Normas:

\begin{tabular}{|c|c|c|c|c|c|c|}
\hline $\begin{array}{l}\text { PNGC Res. } \\
\mathbf{3 7 5} \cdot \mathbf{0 2}\end{array}$ & $\begin{array}{l}\text { AEA } \\
90364\end{array}$ & AIA 2006 & NFPA 99 & $\begin{array}{l}\text { NFPA } 70 \\
\text { NEC } 2008\end{array}$ & $\begin{array}{l}\text { IEEE Whitebook } \\
2007\end{array}$ & HVAC \\
\hline
\end{tabular}

\section{Referencias:}

- PNGC (Programa Nacional de Garantía de Calidad de la Atención Medica). RM 375/2002. Presentadas en el Capitulo 4.1.3.

- Normativa AEA90364 (Asociación Electrotécnica Argentina). Reglas Particulares para la ejecución de las Instalaciones Eléctricas en Inmuebles. Parte 7. Sección 710. Locales para Usos Médicos y Salas Externas a los Mismos.

- Normativa AlA (American Institute of Arquitects). Guidelines for the Design and Construction of Health Care Facilities. Edición 2006.

- Normativa NFPA 99. (Nacional FIRE Protection Association). Health Care Facilities. Edición 2005.

- Normativa NFPA 70. NEC (Nacional Electrical Code). Artículo 517. Health Care Facilities. Edición 2008.

- IEEE Whitebook. IEEE Recommended Practice for Electric Systems in Health Care Facilities. Std $602^{\mathrm{TM}}$ $-2007$.

- HVAC (Heating, Ventilating, and Air Conditioning) Design Manual for Hospitals and Clinics. Capítulo 12. Room Design. Edición 2003. hitp://uww. camfilfarr.info/library files/1-2009bs.pdf

\section{Anexo 2}

Comprende el texto completo de:

Las Normativas para Cuidados Intensivos y Cuidados Intensivos Cardiológicos de la Fundación Favaloro. Autores: Ingeniero Eduardo de Forteza, Bioingeniera Sabina Salles. Fundación FAVALORO Fecha: 14/12/2010. 


\subsubsection{Caracterización de la política operacional para Cuidados Intensivos Cardiológicos}

La Política Operacional de un servicio de salud establece los macro procesos organizacionales y actúa como variable dependiente del rol asignado para la Unidad de Salud en las Redes de Servicios de Salud. Esta define los principios y/o modalidades de organización propuestos; explicita y establece cómo se plantea la organización de cada Servicio, la definición del perfil del recurso humano participante y las relaciones con otros Servicios.

A continuación nos referiremos a la Política Operacional de la Unidad de Cuidados Intensivos Cardiológicos del Centro de Estudios Médicos e Investigaciones Clínicas "Norberto Quirno" UCO CEMIC Saavedra, elaborada con el Dr. Javier Guetta, Jefe Médico de dicha Unidad (2011).

\section{Politicas Operacionales Especificas, Cuidados Intensivos Cardiológicos CEMIC Saavedra}

\section{Organización:}

La unidad de cuidados intensivos Cardiológicos de adultos estará destinada a pacientes con serios desequilibrios de sus sistemas orgánicos, que corren riesgo de muerte y necesitan monitoreo continuo de sus funciones vitales, eventuales procedimientos especiales para la preservación de la vida y cuidados continuos de enfermería.

- Contará con camas especiales y deberá asegurar la visualización permanente de los pacientes, cuidado de las normas de asepsia y adecuada definición de los circuitos de materiales limpios y usados.

- Se contara con equipamiento para la asistencia en la reanimación cardiorrespiratoria.

- Se incluirá monitoreo hemodinámico invasivo con registro de presiones centrales y medición de volumen minuto, nomitoreo de presión intracraneana y bomba de infusión continua.

Tendrá acceso a estudios Intensivos de laboratorio e imágenes las 24 hs del día.

\section{Administración:}

- $\quad$ - $\quad$ Seberá contar con normas escritas de procedimiento y diagnóstico y tratamiento.

- $\quad$ Aplicará un sistema de clasificación de pacientes de uso corriente en las unidades del país.

- Para la documentación clínica del paciente se cuenta con historia clínica única, en la cual se incluyen todos los registros de prestaciones médicas, de enfermería, nutrición y protocolos de estudios de diagnóstico y tratamiento.

Contará con los siguientes registros:

1. Diagnóstico de ingreso y alta

2. Fecha de ingreso, de alta y tiempo aproximado de internación.

3. Indice ocupacional

4. Scores TIMI, Scores TIMI, Killip \& Kimbal entre otros. 


\section{Personal Médico:}

Todos los médicos deberán ser médicos cardiólogos.

- Deberá contar con un médico responsable de la unidad que tenga formación especifica en terapia intensiva, en lo posible no menor de 5 años. Los médicos que lo asistan deberán recibir tratamiento específico y serán de concurrencia diaria. Contará con médicos de guardia propios.

- La unidad es atendida por un equipo compuesto por un médico de planta, un médico de guardia y médicos residentes, bajo la supervisión de jefe de la unidad.

- Intervienen además médicos de inter consulta, kinesiólogos, infectólogos, neumonólogos y otras especialidades según el caso.

\section{Personal de Enfermeria:}

- Los cuidados de enfermería se organizan por método de asignación de pacientes, mediante la aplicación del plan de cuidados de enfermería por enfermeras profesionales, licenciadas y auxiliares bajo la supervisión de una enfermera jefe en cinco turnos de trabajo (mañana, tarde, noche, $y$ fines de semana $y$ dias francos)

- Se establecen 9 (nueve) horas de atención de enfermeria por paciente dia (correspondiente a una enfermera cada tres pacientes).

\section{Formación:}

- Se desarrollan funciones de educación en forma práctica (casos clínicos) y teóricas (clases, ateneos) para el equipo de salud con inclusión de residencias médicas acreditadas y régimen de becarios con tutorias.

\section{Pacientes internados:}

- La UCO es una unidad de internación para pacientes con posibilidad de recuperación parcial o total que requieran para su supervivencia de atención médica y de enfermeria en forma constante. Esto incluye pacientes en estado crítico, con riesgo potencial de muerte y/o la necesidad de efectuar procedimientos especiales de diagnóstico y/o terapéuticos que preserven la vida.

- El Servicio presta tratamientos personalizados a pacientes adultos con problemas cardiovasculares con régimen de internación programada (pos-operatorio) o de urgencia (del establecimiento y derivados de otros hospitales).

- La atención de pacientes infecto - contagioso o inmunodeprimido - comprometidos se realiza en camas aisladas para asegurar el aislamiento de contacto (lavado de manos y cambio de camisolin).

- No se administran internaciones para estudios o prestaciones para estudios o prestaciones que puedan ser realizadas ambulatoriamente.

\section{Régimen de visitas:}

- Los pacientes pueden ser visitados por un integrante del grupo de pertenencia en los horarios establecidos por el Servicio

Horario del mediodia: Horario de la tarde:
$12 \mathrm{hs}$ a $13 \mathrm{hs}$

$19 h s$ a $20 h s$ 


\subsubsection{Caracterización de la Tecnología de Cuidados Intensivos Cardiológicos}

El objetivo de realizar esta actividad es dar respuesta a los principios y modalidades establecidos en la política operacional del Servicio antes señalada, mediante la caracterización de la operación a través de la calificación y cuantificación de las Funciones, Actividades y Tareas, asi como del Recurso Humano participante en cada una de ellas y la definición de Líneas de Proceso. ${ }^{23}$ Mediante la secuencia e interrelación operacional de las distintas tareas.

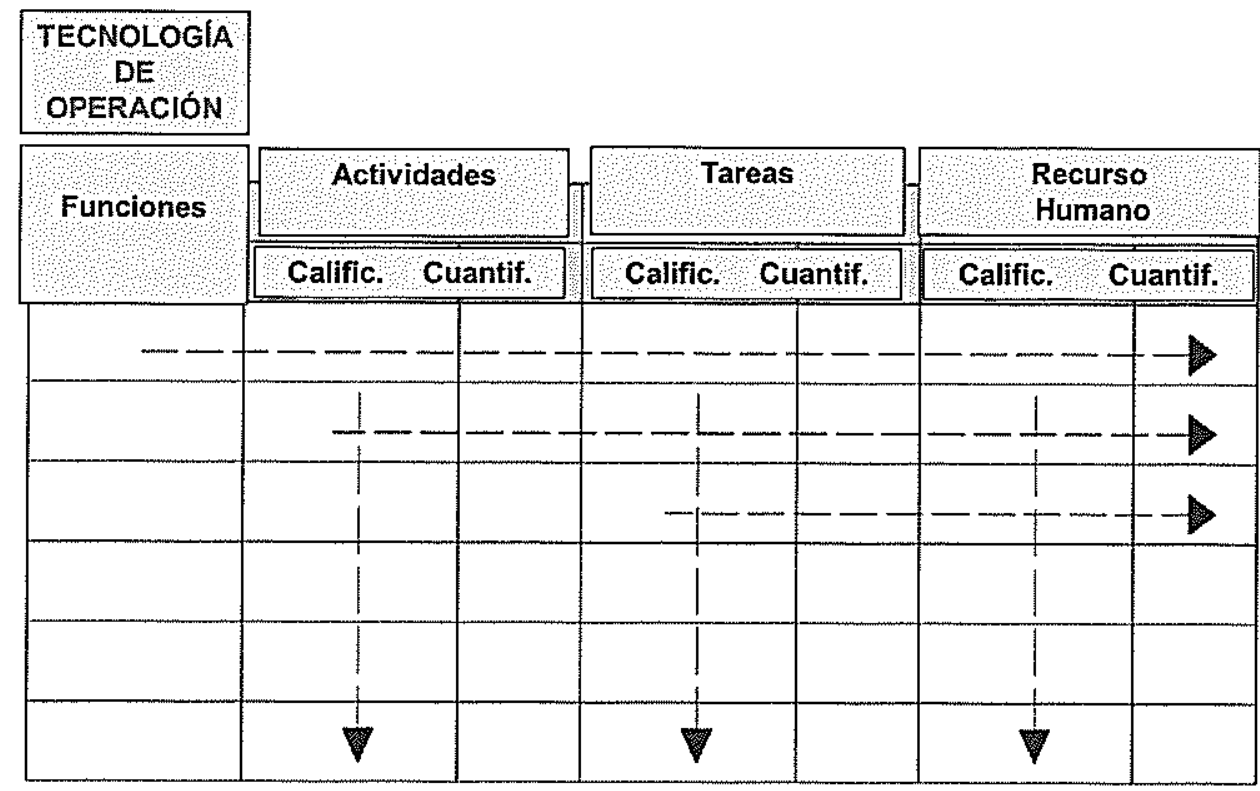

La programación funcional deja trazado los caminos para la etapa posterior la programación arquitectónica. A continuación se analizan las funciones, actividades, tareas y recurso humano de la Unidad de Cuidados Intensivos Cardiológicos.

${ }^{23}$ De las Fichas Técnicas sobre el Recurso Físico en Salud, 1990. Actualizada en las Guías de Programación Funcional Guía G 5 CIRFS FADU UBA - OMS OPS 2010. 
TECNOLOGÍA DE OPERACIÓN - CUIDADOS INTENSIVOS CARDIOLÓGICOS DESARROLLO EN FUNCIONES ACTIVIDADES - TAREAS Y RECURSO HUMANO

\begin{tabular}{|c|c|c|c|}
\hline FUNCIÓN & ACTIVIDAD & TAREAS & RECURSO HUMANO \\
\hline \multirow{6}{*}{$\begin{array}{l}\text { CUIDADOS } \\
\text { INTENSIVOS } \\
\text { CARDIOLÓGICOS }\end{array}$} & RECEPCIÓN DEL PACIENTE & $\begin{array}{l}\text { RECEPCIÓN - } \\
\text { DOCUMENTACIÓN DEL } \\
\text { PACIENTE } \\
\text { FIRMA DEL CONSENTIMIENTO } \\
\text { INFORMADO DE INTERNACIÓN }\end{array}$ & $\begin{array}{l}\text { SECRETARIA } \\
\text { PACIENTE } \\
\text { ACOMPAÑANTE (FAMILIARO } \\
\text { AMIGO). }\end{array}$ \\
\hline & $\begin{array}{l}\text { PREPARACIÓN DEL } \\
\text { PACIENTE PARA UNA } \\
\text { ATENCIÓN PERSONALIZADA }\end{array}$ & $\begin{array}{l}\text { INTERNACIÓN - PREPARACIÓN } \\
\text { DEL PACIENTE (RECONOCIMIENTO } \\
\text { DEL PERFIL DEL PACIENTE Y SU } \\
\text { GRUPO DE PERTENENCIA. } \\
\text { RECONOCIMIENTO POR EL } \\
\text { PACIENTE DE LA INSTITUCIÓN EN LA } \\
\text { QUE SE INSERTA). }\end{array}$ & $\begin{array}{l}\text { ENFERMERA O AUXILIAR DE } \\
\text { ENFERMERIA } \\
\text { PACIENTE } \\
\text { ACOMPAÑANTE } \\
\end{array}$ \\
\hline & \multirow[t]{2}{*}{ CUIDADOS MÉDICOS } & $\begin{array}{l}\text { ENTREVISTA MEDICA } \\
\text { NOTIFICACIÓN AL MÉDICO DE } \\
\text { CABECERA SOBRE LA } \\
\text { INTERNACIÓN }\end{array}$ & $\begin{array}{l}\text { MEDICO CARDIÓLOGOY } \\
\text { MEDICO CARDIÓLOGO } \\
\text { RESIDENTE } \\
\text { (MEDICO DE CABECERA, } \\
\text { POCO FRECUENTE) }\end{array}$ \\
\hline & & $\begin{array}{l}\text { Tipologia T1 } \\
\text { EXAMEN MEDICO INICIAL * }\end{array}$ & $\begin{array}{l}\text { MEDICO CARDIÓLOGOY } \\
\text { MEDICO CARDIÓLOGO } \\
\text { RESIDENTE } \\
\text { (MEDICO DE CABECERA, } \\
\text { POCO FRECUENTE) } \\
\text { ENFERMERA } \\
\text { PACIENTE } \\
\end{array}$ \\
\hline & \multirow[t]{2}{*}{ CUIDADOS MÉDICOS } & $\begin{array}{l}\text { ACTUALIZACIÓN DE HISTORIA } \\
\text { CLINICA } \\
\text { PLAN DE ACTIVIDADES } \\
\text { INDICACIONES MEDICAS } \\
\text { INDICACIONES DE ESTUDIOS } \\
\text { COMPLEMENTARIOS } \\
\end{array}$ & $\begin{array}{l}\text { MEDICO CARDIÓLOGOY } \\
\text { MEDICO CARDIÓLOGO } \\
\text { RESIDENTE } \\
\text { (MEDICO DE CABECERA, } \\
\text { POCO FRECUENTE) } \\
\text { PACIENTE }\end{array}$ \\
\hline & & $\begin{array}{l}\text { CONTROL PERIÓDICO POR } \\
\text { EVOLUCIÓN }\end{array}$ & $\begin{array}{l}\text { MEDICO CARDIÓLOGOY } \\
\text { MEDICO CARDIOLOGO } \\
\text { RESIDENTE } \\
\text { MEDICO DE CABECERA } \\
\text { ENFERMERA } \\
\text { PACIENTE }\end{array}$ \\
\hline
\end{tabular}




\begin{tabular}{|c|c|c|c|}
\hline FUNCIÓN & ACTIVIDAD & TAREAS & RECURSO HUMANO \\
\hline \multirow{13}{*}{$\begin{array}{l}\text { CUIDADOS } \\
\text { INTENSIVOS } \\
\text { CARDIOLÓGICOS }\end{array}$} & CUIDADOS MÉDICOS & $\begin{array}{l}\text { INFORME DEL MEDICO } \\
\text { CARDIOLOGO YIO DE } \\
\text { CABECERA A LOS FAMILIARES }\end{array}$ & $\begin{array}{l}\text { MEDICO CARDIÓLOGO } \\
\text { MÉDICO DE CABECERA } \\
\text { FAMILIARES }\end{array}$ \\
\hline & \multirow[t]{3}{*}{ CUIDADOS DE ENFERMERIA } & $\begin{array}{l}\text { Tipología T2 } \\
\text { CONTROL DE SIGNOS VITALES } \\
\text { Y/U OBSERVACIÓN }\end{array}$ & $\begin{array}{l}\text { ENFERMERA O AUXILIAR DE } \\
\text { ENFERMERIA } \\
\text { PACIENTE }\end{array}$ \\
\hline & & $\begin{array}{l}\text { Tipología T3 } \\
\text { HIGIENE Y / O CONFORT DEL } \\
\text { PACIENTE (INCLUYE CAMBIOS } \\
\text { DE ROPA Y CAMA). * }\end{array}$ & $\begin{array}{l}\text { ENFERMERA O AUXILIAR DE } \\
\text { ENFERMERÍA } \\
\text { PACIENTE }\end{array}$ \\
\hline & & $\begin{array}{l}\text { Típología T4 } \\
\text { MOVILIZACIÓN O TRASLADO A } \\
\text { OTRO SERVICIO* }\end{array}$ & $\begin{array}{l}\text { ENFERMERA O AUXILIAR DE } \\
\text { ENFERMERIA } \\
\text { PACIENTE }\end{array}$ \\
\hline & \multirow[t]{4}{*}{ CUIDADOS DE ENFERMERIA } & PREVENCIÓN DEL RIESGO & $\begin{array}{l}\text { ENFERMERA O AUXILIAR DE } \\
\text { ENFERMERIA } \\
\text { PACIENTE }\end{array}$ \\
\hline & & $\begin{array}{l}\text { REGISTROS DE CUIDADOS Y } \\
\text { TRATAMIENTOS }\end{array}$ & $\begin{array}{l}\text { ENFERMERA O AUXILIAR DE } \\
\text { ENFERMERIA }\end{array}$ \\
\hline & & $\begin{array}{l}\text { PROCESAMIENTO PERIFÉRICO } \\
\text { DE ELEMENTOS LIMPIOS }\end{array}$ & $\begin{array}{l}\text { ENFERMERA O AUXILIAR DE } \\
\text { ENFERMERIA } \\
\text { O AYUDANTE DE SERVICIO }\end{array}$ \\
\hline & & $\begin{array}{l}\text { PROCESAMIENTO PERIFÉRICO } \\
\text { DE ELEMENTOS USADOS }\end{array}$ & $\begin{array}{l}\text { AUXILIAR DE ENFERMERÍA } \\
\text { O AYUDANTE DE SERVICIO }\end{array}$ \\
\hline & \multirow[t]{3}{*}{$\begin{array}{l}\text { EXÁMENES DE } \\
\text { DIAGNOSTICO }\end{array}$} & $\begin{array}{l}\text { Tipologia T5 } \\
\text { TOMA DE MUESTRAS PARA } \\
\text { LABORATORIO* }^{*}\end{array}$ & $\begin{array}{l}\text { ENFERMERA O TÉCNICO } \\
\text { LABORATORIO } \\
\text { PACIENTE }\end{array}$ \\
\hline & & $\begin{array}{l}\text { TOMA DE EXÁMENES } \\
\text { RADIOGRÁFICOS EN CAMA } \\
\text { (EXCEPCIONALES) }\end{array}$ & $\begin{array}{l}\text { TÉCNICO RADIÓLOGO } \\
\text { PACIENTE }\end{array}$ \\
\hline & & $\begin{array}{l}\text { TOMA } \\
\text { ELECTROCARDIOGRAMAS }\end{array}$ & $\begin{array}{l}\text { TÉCNICO O MEDICO } \\
\text { CARDIOLOGO } \\
\text { PACIENTE }\end{array}$ \\
\hline & \multirow[t]{2}{*}{$\begin{array}{l}\text { TRATAMIENTO EN } \\
\text { INTERNACION }\end{array}$} & NEBULIZACIONES & $\begin{array}{l}\text { ENFERMERA } \\
\text { PACIENTE }\end{array}$ \\
\hline & & $\begin{array}{l}\text { ADMINISTRACIÓN DE } \\
\text { MEDICAMENTOS }\end{array}$ & $\begin{array}{l}\text { ENFERMERA O AUXILIAR DE } \\
\text { ENFERMERIA } \\
\text { PACIENTE }\end{array}$ \\
\hline
\end{tabular}




\begin{tabular}{|c|c|c|c|}
\hline FUNCIÓN & ACTIVIDAD & TAREAS & RECURSO HUMANO \\
\hline \multirow{12}{*}{$\begin{array}{l}\text { CUIDADOS } \\
\text { INTENSIVOS } \\
\text { CARDIOLÓGICOS }\end{array}$} & \multirow[t]{3}{*}{$\begin{array}{l}\text { TRATAMIENTO EN } \\
\text { INTERNACIÓN }\end{array}$} & CURACIONES & $\begin{array}{l}\text { MEDICO CARDIOLOGO } \\
\text { ENFERMERA } \\
\text { PACIENTE }\end{array}$ \\
\hline & & COLOCACIÓN DE SONDAS & $\begin{array}{l}\text { ENFERMERA } \\
\text { PACIENTE }\end{array}$ \\
\hline & & TRATAMIENTOS FISICOS & $\begin{array}{l}\text { TERAPISTA FÍSICO O } \\
\text { KINESIÓLOGO } \\
\text { PACIENTE } \\
\end{array}$ \\
\hline & APOYO FAMILIAR & $\begin{array}{l}\text { Tipologia T6 } \\
\text { VISITAS FAMILIARES Y } \\
\text { AMIGOS }^{*}\end{array}$ & $\begin{array}{l}\text { PACIENTE } \\
\text { FAMILIARES O AMIGOS }\end{array}$ \\
\hline & APOYO PSICOLÓGICO & $\begin{array}{l}\text { APOYO PSICOLÓGICO AL } \\
\text { PACIENTE Y GRUPO DE } \\
\text { PERTENENCIA }\end{array}$ & $\begin{array}{l}\text { MEDICO PSIQUIATRA O } \\
\text { PSICÓLOGO } \\
\text { PACIENTE } \\
\text { FAMILIARES O AMIGOS }\end{array}$ \\
\hline & \multirow{2}{*}{$\begin{array}{l}\text { ALIMENTACIÓNY } \\
\text { DIETOTERAPIA }\end{array}$} & $\begin{array}{l}\text { ENTREVISTA NUTRICIONISTAY } \\
\text { CONFECCIÓN RÉGIMEN }\end{array}$ & $\begin{array}{l}\text { NUTRICIONISTA } \\
\text { PACIENTE }\end{array}$ \\
\hline & & ALIMENTACIÓN PACIENTE & $\begin{array}{l}\text { AUXILIAR DE ALIMENTACIÓN } \\
\text { PACIENTE } \\
\text { AUXILIAR DE ENFERMERIAA } \\
\text { O ACOMPAÑANTE }\end{array}$ \\
\hline & ASISTENCIA SOCIAL & $\begin{array}{l}\text { ASISTENCIA SOCIAL AL } \\
\text { PACIENTE INTERNADO- } \\
\text { EVALUACIÓN DE SATISFACCIÓN } \\
\text { DE ATENCIÓN }\end{array}$ & $\begin{array}{l}\text { ASISTENTE SOCIAL } \\
\text { PACIENTE }\end{array}$ \\
\hline & ASISTENCIA ESPIRITUAL & $\begin{array}{l}\text { ASISTENCIA ESPIRITUAL AL } \\
\text { PACIENTE Y GRUPO DE } \\
\text { PERTENENCIA }\end{array}$ & $\begin{array}{l}\text { RELIGIOSOSO } \\
\text { SACERDOTES U OTROS } \\
\text { PACIENTE } \\
\text { ACOMPAÑANTE }\end{array}$ \\
\hline & \multirow[t]{3}{*}{$\begin{array}{l}\text { EGRESO ALTA (O } \\
\text { DEFUNCIÓN) O PASE }\end{array}$} & $\begin{array}{l}\text { REVISIÓN DEL ESTADO DEL } \\
\text { PACIENTE E INDICACIÓN DE } \\
\text { ALTA O PASE }\end{array}$ & $\begin{array}{l}\text { MEDICO CARDIÓLOGO } \\
\text { PACIENTE }\end{array}$ \\
\hline & & $\begin{array}{l}\text { CONSTATACIÓN DE LA } \\
\text { DEFUNCIÓN }\end{array}$ & MEDICO CARDIÓLOGO \\
\hline & & $\begin{array}{l}\text { REGISTRO Y CONTROL } \\
\text { ADMINISTRATIVO DEL_ ALTA, } \\
\text { PASE O DEFUNCIÓN }\end{array}$ & SECRETARIA \\
\hline
\end{tabular}




\begin{tabular}{|c|c|c|c|}
\hline FUNCIÓN & ACTIVIDAD & TAREAS & RECURSO HUMANO \\
\hline \multirow{3}{*}{$\begin{array}{l}\text { CUIDADOS } \\
\text { INTENSIVOS } \\
\text { CARDIOLÓGICOS }\end{array}$} & \multirow[t]{3}{*}{$\begin{array}{l}\text { EGRESO ALTA (O } \\
\text { DEFUNCIÓN) O PASE }\end{array}$} & $\begin{array}{l}\text { PREPARACIÓN DEL PACIENTE } \\
\text { PARA EL ALTA O PASE }\end{array}$ & $\begin{array}{l}\text { ENFERMERA } \\
\text { PACIENTE }\end{array}$ \\
\hline & & PREPARACIÓN DEL CADÁVER & ENFERMERA \\
\hline & & CONFECCIÓN EPICRISIS & MEDICO CARDIÓLOGO \\
\hline
\end{tabular}

*Recuadradas aparecen las Tipologías que luego serán estudiadas en el Capítulo 5.2. Propuesta de Tipologías Espacio-Tarea para Cuidados Intensivos Cardiológicos

Se agradece la colaboración del Dr. Javier Guetta Jefe de la Unidad de Cuidados Intensivos Cardiológicos CEMIC Saavedra en la realización de la Tabla de Funciones, Actividades y Tareas de la UCIC del CEMIC Saavedra (2011).

\subsubsection{Caracterización Arquitectónica de Cuidados Intensivos Cardiológicos}

Para realizar esta Caracterización Arquitectónica, se definirán los principios y pautas en relación al medio social y al medio físico, así como de la conformación del sistema espacial (del subsistema espacial funcional, del subsistema circulaciones, del subsistema instalaciones y del subsistema estructura).

Se definirán las condicionantes del medio ambiente, las condiciones de seguridad frente a los desastres, las condiciones de accesibilidad para personas con movilidad y comunicación reducida, para una vez estas definidas realizar la Caracterización de la Organización Espacial - Funcional de Cuidados Intensivos Cardiológicos.

\subsubsection{Caracterización de la Organización Espacial - Funcional de Cuidados Intensivos Cardiológicos}

La Caracterización Espacial - Funcional demanda la identificación diferenciada de unidades funcionales UF -donde se desarrolla la actividad principal del Servicio, y áreas complementarias $A C$-donde se realizan las actividades que apoyan y complementan la actividad principal.

En este trabajo de investigación se centrará en la unidad funcional UF correspondiente a la Atención de Internación Cuidados Intensivos Cardiológicos.

El siguiente cuadro presenta la clasificación de las distintos tipos de unidades funcionales UF correspondientes a las diferentes Servicios. 


\begin{tabular}{|c|c|}
\hline SERVICIOS & UF UNIDADES FUNCIONALES \\
\hline \multicolumn{2}{|l|}{ SERVICIOS NUCLEARES } \\
\hline $\begin{array}{l}\text { ATENCIÓN AMBULATORIA } \\
\text { PROGRAMADA } \\
\text { - Medicina, Cirugía, Tocoginecología y } \\
\text { Pediatría } \\
\text { - Salud Mental } \\
\text { - Salud Bucal }\end{array}$ & $\begin{array}{l}\text { Consultorios } \\
\text { Salas de prácticas - prestaciones } \\
\text { Consultorios individuales y grupales } \\
\text { Consultorios según } \mathrm{N}^{\circ} \text { sillones }\end{array}$ \\
\hline ATENCIÓN AMBULATORIA DE URGENCIA & $\begin{array}{l}\text { Consultorios } \\
\text { Salas de procedimientos - tratamientos }\end{array}$ \\
\hline ATENCIÓN DE INTERNACIÓN & Habitaciones según $\mathrm{N}^{\circ}$ camas \\
\hline EDUCACIÓN & $\begin{array}{l}\text { Aulas } \\
\text { Salas de reuniones }\end{array}$ \\
\hline INVESTIGACIÓN & $\begin{array}{l}\text { Oficinas } \\
\text { Salas de reuniones } \\
\text { Laboratorios }\end{array}$ \\
\hline
\end{tabular}

A continuación se presentan los Ejemplos Arquitectónicos de Unidades de Cuidados Intensivos y Cuidados Intensivos Cardiológicos, donde se realizará la "Encuesta de Evaluación del Recurso Fisco en Atención de Internación"

\section{Los planos se presentan en el siguiente orden:}

- Cuidados Intensivos y Cuidados Cardiológicos del Hospital General de Agudos Carlos G. Durand (2011).

- Estudio de la Habitación Individual de UCIC de Hospital Durand, al que se le ha incorporado el Recurso Humano y Equipamiento.

- Cuidados Intensivos y Cuidados Cardiológicos Centro de Educación Médica e Investigaciones Clínicas "Norberto Quirno" CEMIC Saavedra (2011).

- Estudio de la Habitación Individual de UCIC de CEMIC Saavedra, al que se le ha incorporado el Recurso Humano y Equipamiento.

- La Unidad Polivalentes de Cuidados Intensivos y Cuidados Cardiológicos del Instituto Argentino de Diagnóstico y Tratamiento IADT (2011).

Si bien los pacientes de la Unidad Polivalente de Cuidados Intensivos y Cardiológicos del IADT no pudieron ser entrevistado debido a las políticas de privacidad de dicha institución, se considera interesante la inclusión de la planta general debido a que en dicha Unidad trabaja el Dr. Carlos Rubianes, eminencia y precursor en el tema de Cuidados Intensivos en la Argentina (al cual se le realizó una extensa entrevista que se encuentra desarrollada en la Página 58). 


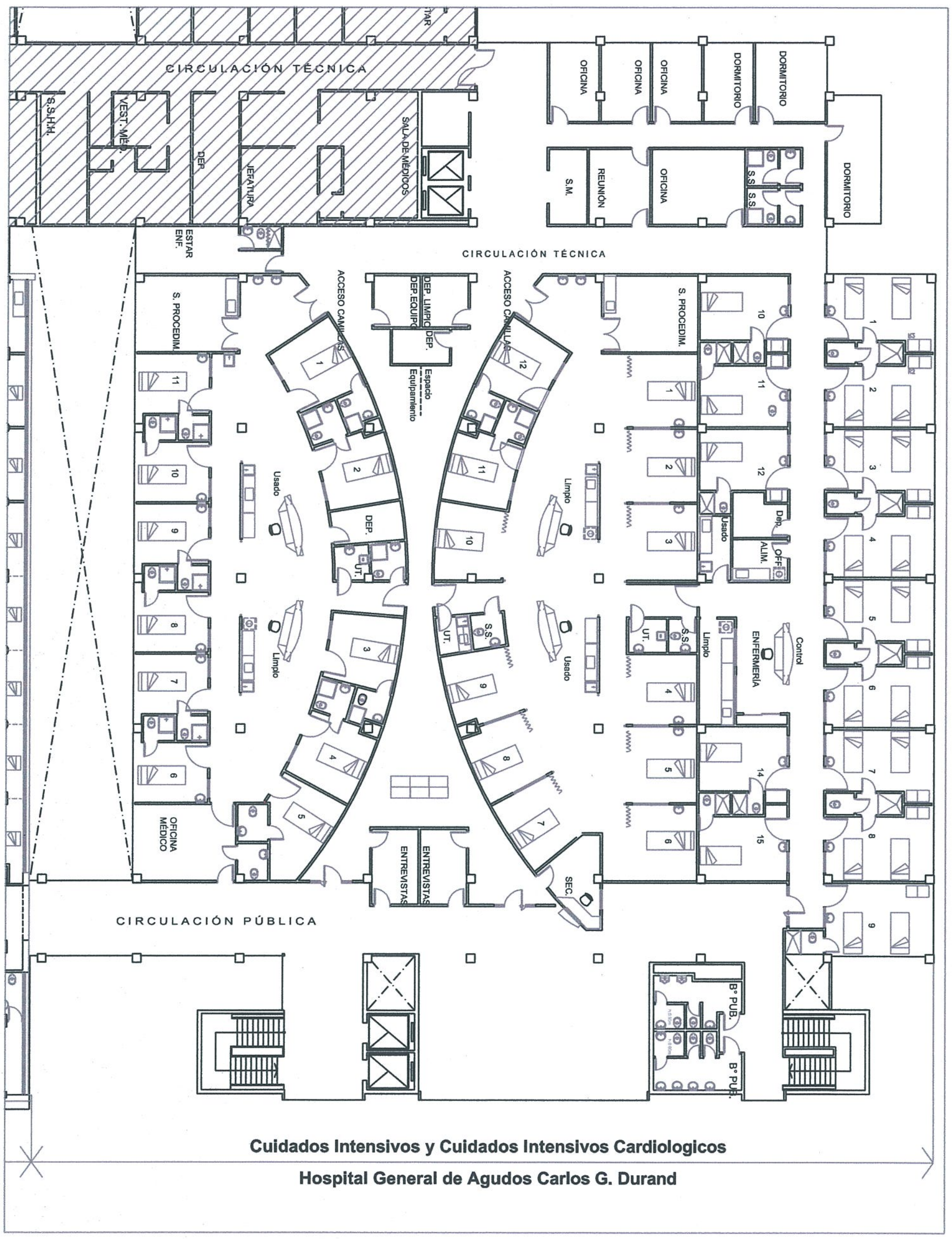






\begin{tabular}{|c|c|c|c|}
\hline \multicolumn{4}{|c|}{ HABITACION INDIVIDUAL } \\
\hline RECURSO HUMANO & EQUIPAMIENTO & COD. & DENOMINACION \\
\hline \multirow{5}{*}{$\begin{array}{l}\text { A-PACIENTE } \\
\text { C-MEDICO CARDIOLOGO }\end{array}$} & MUEBLES & $\begin{array}{l}\text { 01-M01 } \\
\text { 01-M02 }\end{array}$ & $\begin{array}{l}\text { CAMA } \\
\text { CAMILLA }\end{array}$ \\
\hline & ARTEFACTOS Y ACCESORIOS & & BAÑO COMPLETO \\
\hline & $\begin{array}{l}\text { APARATOS, EQUIPOS EINS- } \\
\text { TRUMENTOS }\end{array}$ & $\begin{array}{l}\text { 03-E01 } \\
\text { 03-E02 }\end{array}$ & $\begin{array}{l}\text { MONITOR MULTIPARAMETRICO } \\
\text { RESPIRADOR }\end{array}$ \\
\hline & UTENSILIOS & $\begin{array}{l}\text { 04-U01 } \\
04-\mathrm{U} 03\end{array}$ & $\begin{array}{l}\text { SOPORTE PARA SUERO } \\
\text { CESTO METALICO TAPA A PEDAL }\end{array}$ \\
\hline & ELEMENTOS DE TRANSPORTE & 05-T03 & CARRO PORTA EQUIPO \\
\hline
\end{tabular}

Cuidados Intensivos y Cuidados Intensivos Cardiológicos Hospital General de Agudos Carlos G. Durand 


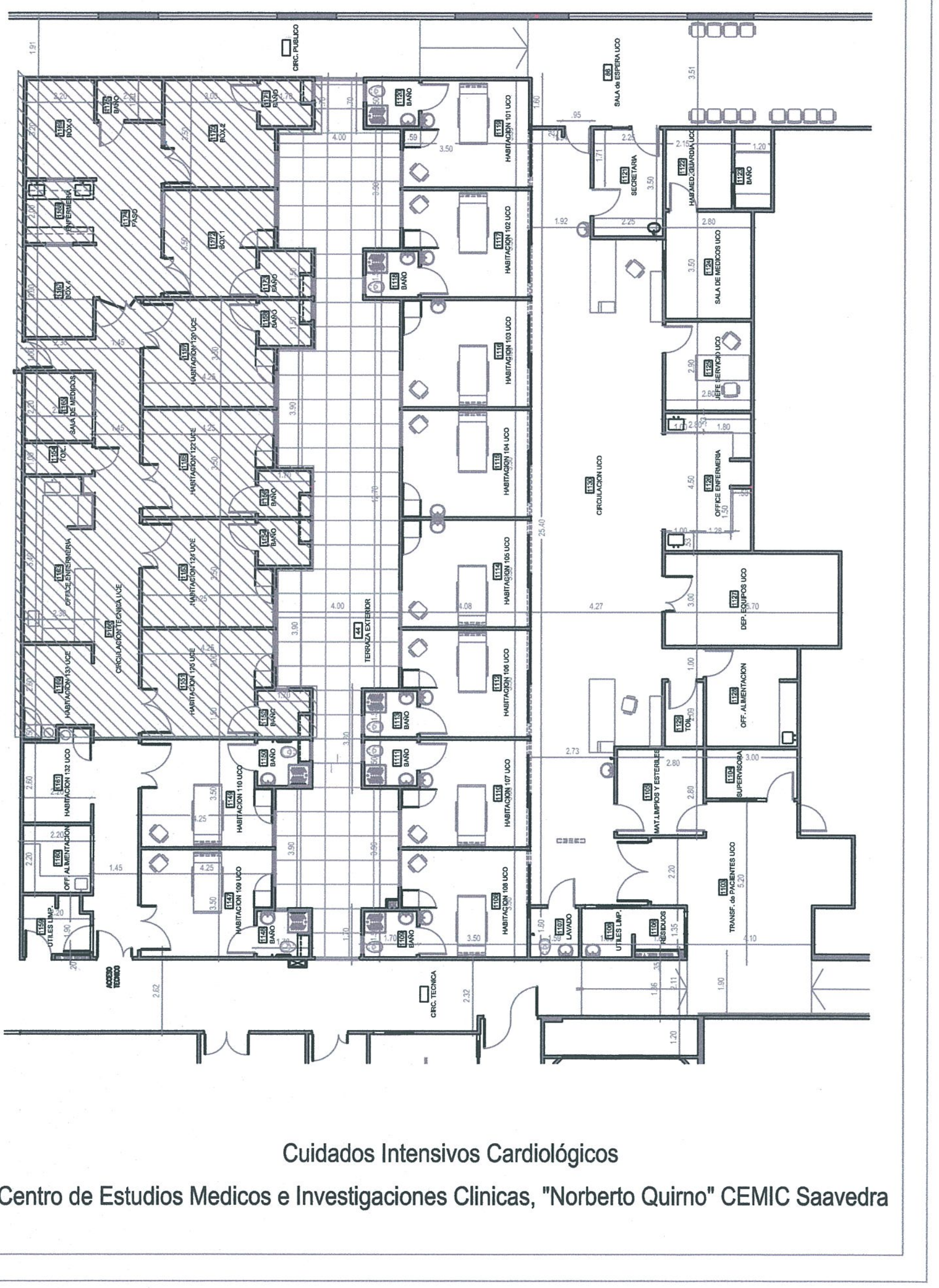




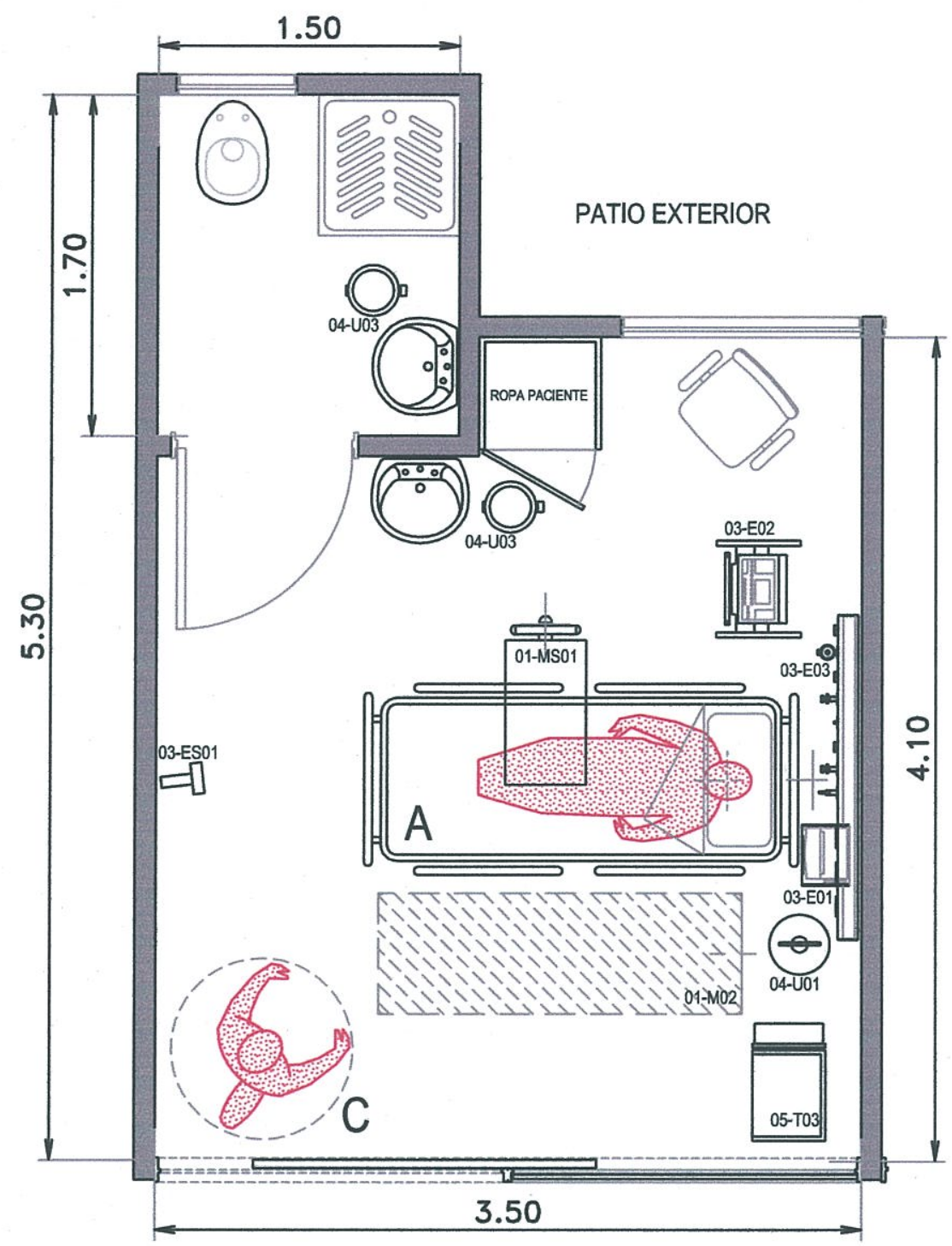

\begin{tabular}{|c|c|c|c|}
\hline \multicolumn{4}{|l|}{ HABITACION INDIVIDUAL } \\
\hline RECURSO HUMANO & EQUIPAMIENTO & COD. & DENOMINACION \\
\hline \multirow{5}{*}{$\begin{array}{l}\text { A-PACIENTE } \\
\text { C-MEDICO CARDIOLOGO }\end{array}$} & MUEBLES & $\begin{array}{l}\text { 01-M01 } \\
\text { 01-M02 } \\
\text { 01-MS01 }\end{array}$ & \begin{tabular}{|l} 
CAMA \\
CAMILLA \\
MESADA APOYO PARA PACIENTE
\end{tabular} \\
\hline & ARTEFACTOS Y ACCESORIOS & 02-A01 & $\begin{array}{l}\text { BANNO COMPLETO } \\
\text { LAVATORIO }\end{array}$ \\
\hline & $\begin{array}{l}\text { APARATOS, EQUIPOS EINS- } \\
\text { TRUMENTOS }\end{array}$ & $\begin{array}{l}\text { 03-E01 } \\
\text { 03-E02 } \\
\text { 03-ES01 }\end{array}$ & $\begin{array}{l}\text { MONITOR MULTIPARAMETRICO } \\
\text { RESPIRADOR } \\
\text { CAMARA A CIRCUITO CERRADO DE MONITOREO }\end{array}$ \\
\hline & UTENSILIOS & $\begin{array}{l}\text { 04-U01 } \\
\text { 04-U03 } \\
\end{array}$ & $\begin{array}{l}\text { SOPORTE PARA SUERO } \\
\text { CESTO METALICO TAPA A PEDAL. }\end{array}$ \\
\hline & ELEMENTOS DE TRANSPORTE & 05-T03 & CARRO PORTA EQUIPO \\
\hline
\end{tabular}

Cuidados Intensivos Cardiológicos CEMIC Saavedra 


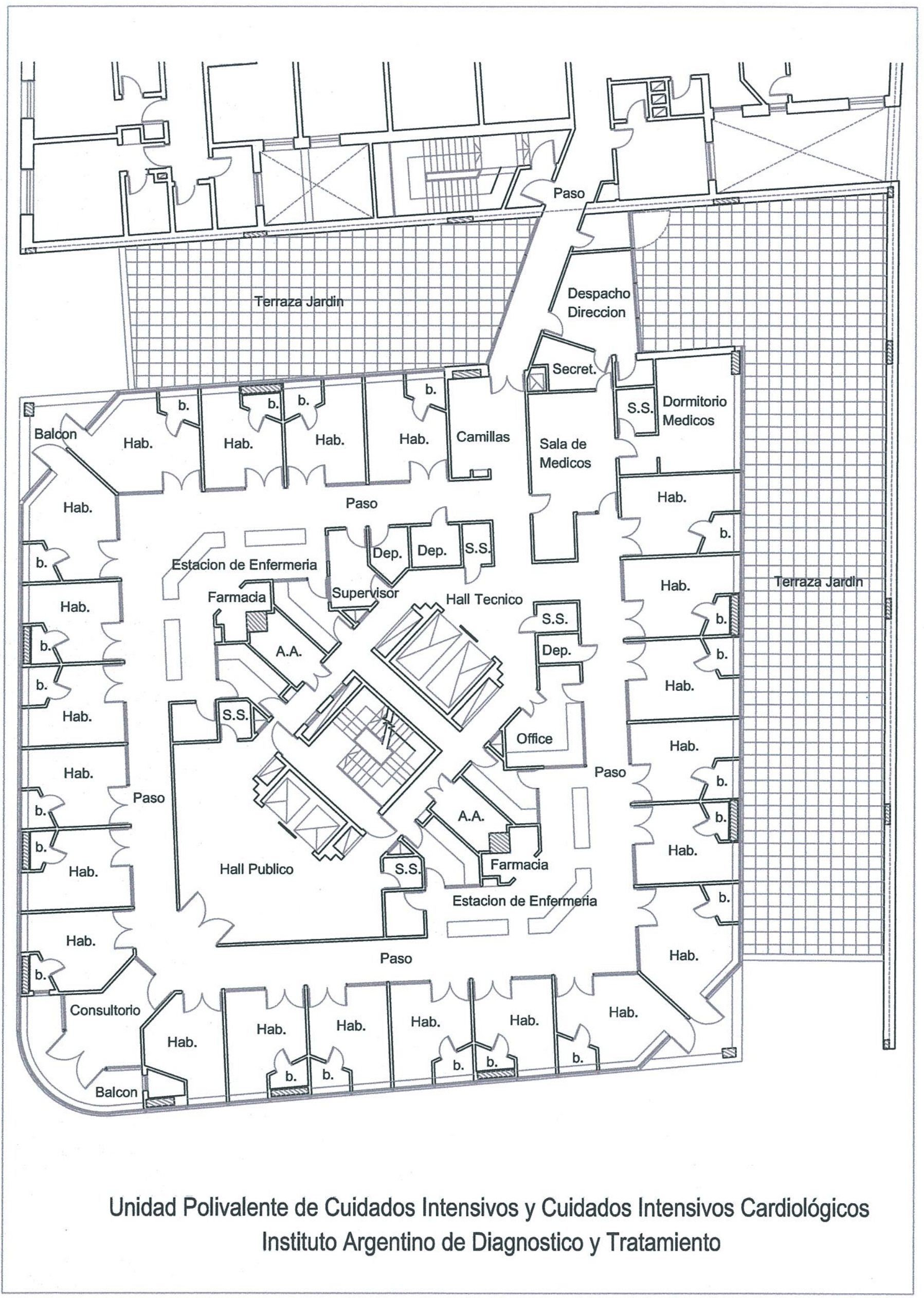



Capítulo 4.2.

Estudio de las Condicionantes Ambientales 



\subsection{Estudio de las Condicionantes Ambientales}

"La enunciación es pues una manera de atrapar en vigilia o somnolencia las sensaciones y percepciones que revolotean por diversos niveles de conciencia al prenderlas con un alfiler lingüístico, acústico o visual y volverlas apenas más persistentes que el flujo continuo de lo sensorial."

Katia Mandoki, Estética y Comunicación de acción, pasión y seducción (2006)

Para el estudio de las Condicionantes Ambientales se hará uso de la Metodología de Interacción de Modelos presentada en el Capítulo 3 Metodología. Como se había señalado en ese Capítulo, esta se desarrolla mediante el diseño de modelos que interaccionan en los planos, referencial, de observación, normalizado, de propuesta y de implementación, según etapas que dependen de la finalidad perseguida.

A continuación desarrollaremos los siguientes Modelos de Condicionantes Ambientales:

Primera Etapa

Segunda Etapa

Tercera Etapa

Cuarta Etapa
Modelo Referencial MR

Modelo Observado Preliminar MOP

Modelo Observado Final MOF

Modelo Normalizado MN

Modelo Propuesto MP

\subsubsection{Primera Etapa Modelo Referencial MR}

En una primera Etapa se conformará un Modelo Referencial MR de Condicionantes Ambientales, el cual se constituirá con los siguientes aportes: el reconocimiento y análisis de las situaciones y tendencias vinculadas a esta temática, junto con el estudio del estado del arte sobre el diseño de espacios saludables tanto a nivel nacional como internacional.

En el estudio de los "espacios saludables" es interdisciplinario y multifacético, en él se reconoce la importancia de los nuevos enfoques en la atención de salud los cuales proponen que sean tomadas en cuenta las necesidades sociales y psicológicas de los pacientes, en el diseño arquitectónico, teniendo al paciente como foco de la atención.

Pero ¿qué es un espacio saludable?, ensayaré la siguiente definición; 
"Un espacio saludable para la atención de la salud, es una determinada configuración cultural - ambiental, que brinda a pacientes, familiares y recurso humano respaldo desde lo ambiental, para sobrellevar las presiones impuestas por el estrés, que surge como consecuencia del proceso de la enfermedad y la hospitalización"

A partir de los análisis realizados, se reconocen cuatro conjuntos de variables ambientales, para la conformación de los espacios saludables, que determinarán la calidad del recuso físico.

Estos cuatro conjuntos son:

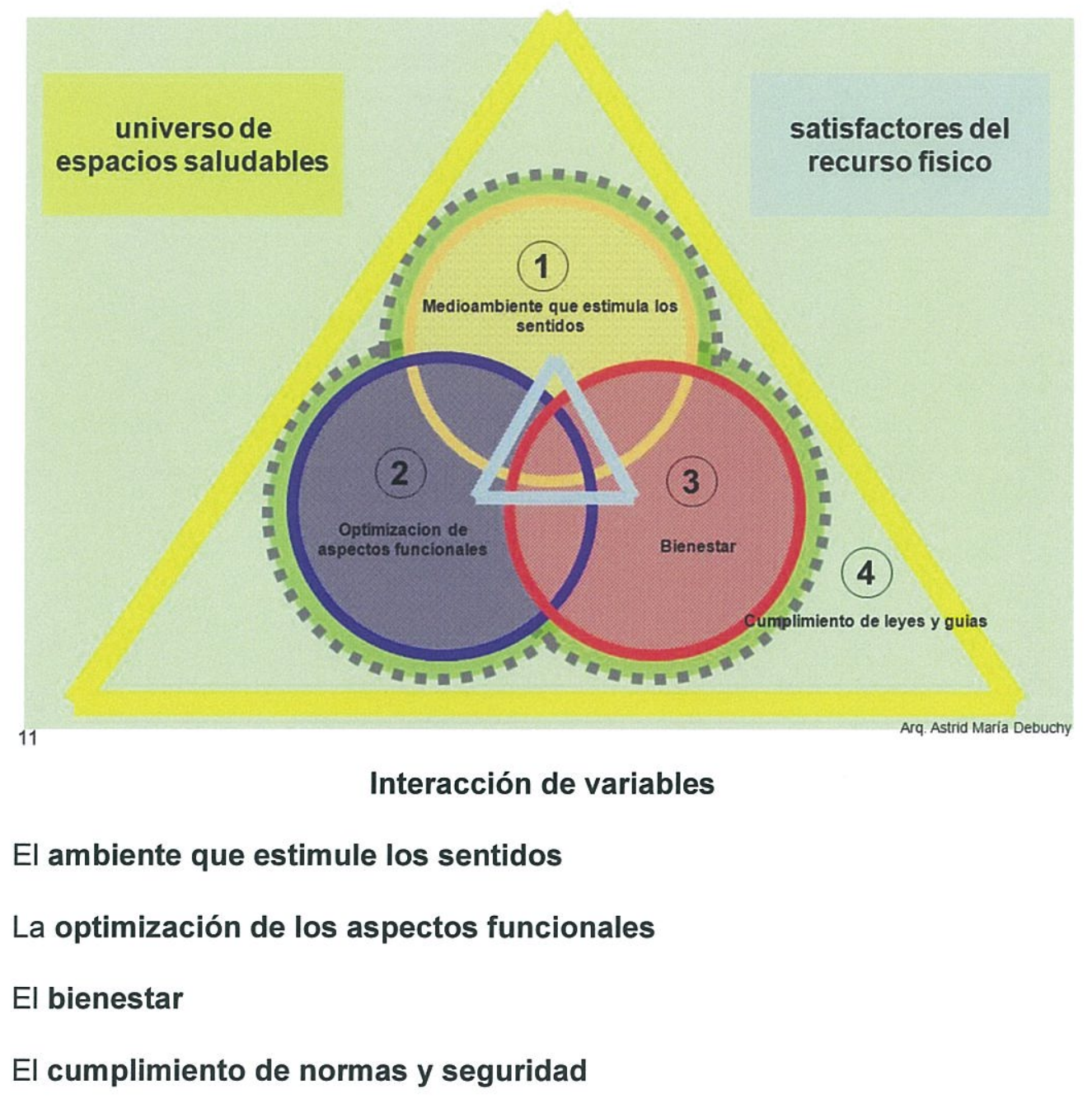


La interacción de estos conjuntos: "ambiente que estimule los sentido", "optimización de los aspectos funcionales", "bienestar" y "cumplimiento de normas y seguridad", determinaran el conjunto de "satisfactores ${ }^{24}$ del recurso físico".

A continuación estudiaremos como se encuentran compuestos los conjuntos de variables antes mencionados:

El primer conjunto "ambiente que estimule los sentidos" se encuentra conformado por las variables: colores, iluminación, sonidos, olores y texturas. En este conjunto se estudia la percepción y experiencia sensorial del paciente internado.

El segundo conjunto "optimización de los aspectos funcionales" se encuentra conformado por las variables: accesibilidad, orientación, proporciones y distribución del equipamiento. En este conjunto se estudia la organización del espacio y el modo en que se desarrollan las actividades de los servicios de atención de salud a través de la mirada del paciente.

El tercer conjunto "bienestar" se encuentra conformado por las variables, incorporación de la naturaleza, incorporación del arte, incorporación de la música y confort. En este conjunto se estudia cómo afectan al paciente los diferentes estímulos que partiendo del exterior podrían ser solidarios con el proceso de recuperación de los pacientes.

El cuarto y último conjunto "cumplimiento de normas y seguridad", se encuentra conformado por el cumplimiento de normas y leyes vigentes junto con la observación de las guías de garantía de la calidad, tanto nacionales como internacionales.

¿Cuál es el objetivo de la búsqueda, para cada conjunto de variables?

En el primer conjunto ambiente que estimule los sentidos, se observa cuáles son las preferencias individuales y valores placenteros, considerando si hay factores que sean comunes entre los pacientes.La búsqueda está focalizada en la percepción del paciente a través de sus sentidos

En el segundo conjunto optimización de los aspectos funcionales, se observa como es la percepción del espacio por parte del paciente. La búsqueda está focalizada en aquellos valores que mejoran y optimizan el uso de del espacio.

\footnotetext{
${ }^{24}$ Los "satisfactores", "Son los que definen la modalidad dominante que una cultura o una sociedad imprimen a las necesidades. Los satisfactores no son los bienes económicos disponibles sino que están referidos a todo aquello que, por representar formas de ser, tener, hacer y estar, contribuye a la realización de necesidades humanas": "Desarrollo a Escala Humana. Una opción para el futuro", de Development Dialogue Cepaur.
} 
En el tercer conjunto bienestar, se observa como es la percepción del medio ambiente del paciente, incluyendo aquellos elementos que pueden ser externos a la habitación. La búsqueda está focalizada en aquellos estímulos que, partiendo del exterior, logren transmitir efectos positivos en el paciente durante su internación.

En el cuarto conjunto cumplimiento de normas y seguridad, se observa el cumplimento de normas edilicias vigentes, de seguridad (prevención de vandalismo, prevención de accidentes), previsión y control contra incendio, prevención de contaminación y normas de garantía de la calidad.

Apartado

\section{Estética-Percepción}

"La palabra griega "estética" deriva del griego "aisthetes", de "aisthanesthai", percepción. Nótese que este término nada tiene que ver con el arte ni con lo bello sino con la "estesis", proceso que caracteriza a los organismos vivos, en la medida en que los abre al mundo y los dispone a lo sensorial".

Katia Mandoki, Estética y Comunicación de acción, pasión y seducción (2006)

\section{Sensación - Percepción}

"La diferente acepción que se ha dado a los términos "sensación" y "percepción" obedece principalmente al vocabulario propio de cada disciplina cientifica. Así, en el campo de la Fisiologia el concepto de sensación se aplica de preferencia al estudio de la sensibilidad - umbrales máximos, mínimos y diferenciales -, a la formulación de leyes psicofisicas y a todos aquellos fenómenos psíquicos que, de acuerdo con este enfoque, tienen su raiz en la Anatomía y Fisiología de los órganos receptores periféricos. En cambio, los problemas relativos a la percepción se sitúan en el dominio de la Psicología, juntamente con otros procesos que, se presupone, están determinados por procesos nerviosos centrales como el aprendizaje, la motivación y la memoria."

Miguelina Guirao, Los Sentidos base de la Percepción. (1980)

\subsubsection{Segunda Etapa Modelo Observado Preliminar MOP y Modelo Observado Final MOF}

En una segunda Etapa se desarrollan los diferentes Modelos Observados: Preliminar MOP y Final MOF

La evaluación de estas variables como posibles condicionantes del diseño arquitectónico hace necesaria la utilización de una herramienta metodológica para su estudio, se plantea la necesidad de crear una Encuesta que incluya los conjuntos de variables antes mencionados. 
El universo de variables del Modelo Referencial es aplicado y evaluado en varios "escenarios" del área metropolitana, en Establecimientos del Subsector Público y Privado, a través de esta Encuesta, focalizada en el área de Internación de dichos Establecimientos. Este proceso permite, por retroalimentación, ajustar el Modelo con aquellos contenidos que recrea la realidad.

\subsubsection{Presentación de la Encuesta "Evaluación del Recurso Físico en Atención de Internación en busca de los "Satisfactores del Recurso Fisco"}

He denominado a esta Encuesta "Evaluación del Recurso Físico en Atención de Internación en busca de los "Satisfactores del Recurso Fisco", ya que con su contenido intenta investigar sobre los conjuntos de variables desarrolladas en el Modelo Referencial para determinar a través de la visión del paciente sobre su posible interés como condicionante del diseño arquitectónico.

La Encuesta tiene como objetivo identificar sensaciones positivas o negativas en los pacientes internados. La palabra Satisfactores surge de la búsqueda de satisfacción por parte del paciente y es la denominación con la que he designado el universo donde interactúan las variables.

Secuencia de actividades de la Encuesta:

1. En una primera instancia, se definieron las variables de calificación de los pacientes entrevistados.

Se identificó el Establecimiento, Genero del paciente (en partes iguales mujeres y hombres), Edad (entre 35 y 80 años), Motivo de la internación, Duración de la internación y Condición del alojamiento (privado, compartido o sala general).

2. En una segunda instancia se definió el contexto del tema de Estudios.

Se observó que las preguntas fueran integrales, para detectar si lo ambiental aparecía espontáneamente tematizado y con qué grado de importancia en relación a otros aspectos de la vivencia de la internación en general.

La entrevista se realizó a modo de conversación, de libre recorrido temático. Sobre la base de la descripción dada por el paciente, el Encuestador recogió detalles acerca de las sensaciones y preferencias del paciente durante el proceso de su Internación.

\subsection{Estructura de la Encuesta}

La Encuesta estuvo compuesta por una serie de preguntas correspondientes a cada conjunto y a sus respectivas variables.

Para el Primer Conjunto de Variables: Ambiente que Estimula de los Sentidos, se realizaron veintidós (22) preguntas. 
Para el Segundo Conjunto de Variables: Optimización de los Aspectos Funcionales, se realizaron veinte (20) preguntas.

Para el Tercer Conjunto de Variables: Bienestar, se realizaron veinte (22) preguntas.

En total se realizaron sesenta y cuatro (64) preguntas en total a sesenta (60) pacientes internados.

\section{El Cuarto Conjunto de Variables no se encuentra en la Encuesta debido a que su cumplimiento corresponde al Establecimiento de Salud.}

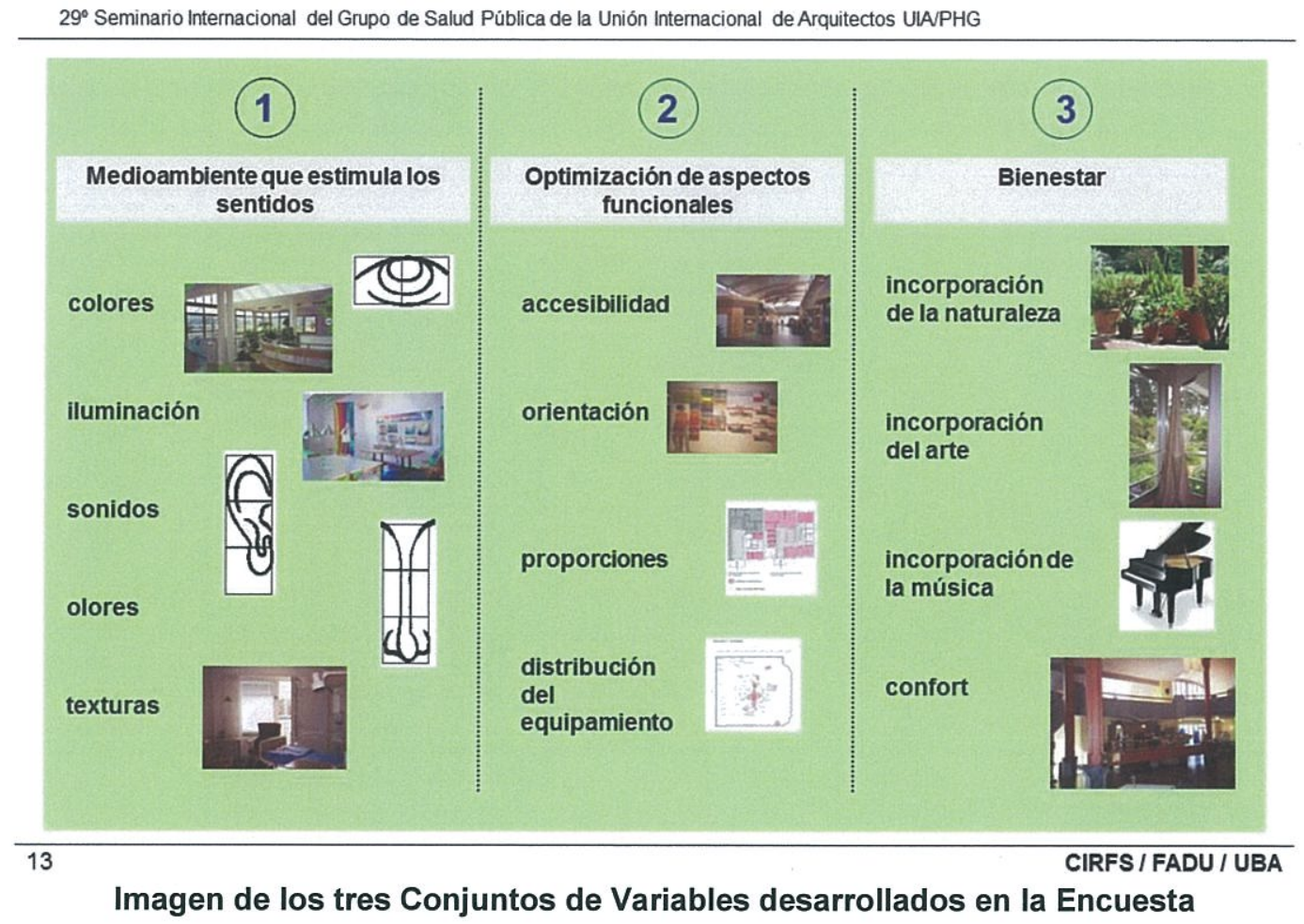

\section{A continuación la Encuesta:}

\section{ENTREVISTA A PACIENTE INTERNADO}

"Evaluación del Recurso Físico en Atención de Internación en busca de los Satisfactores del Recurso Fisco"

Paciente: XXXXXXX

Hospital:

Genero del Paciente

Edad del Paciente (entre 35 y 80 años)

Causa de Internación

Estadía de Internación

Tipo de Internación (privada, semi-privada o guardia) 


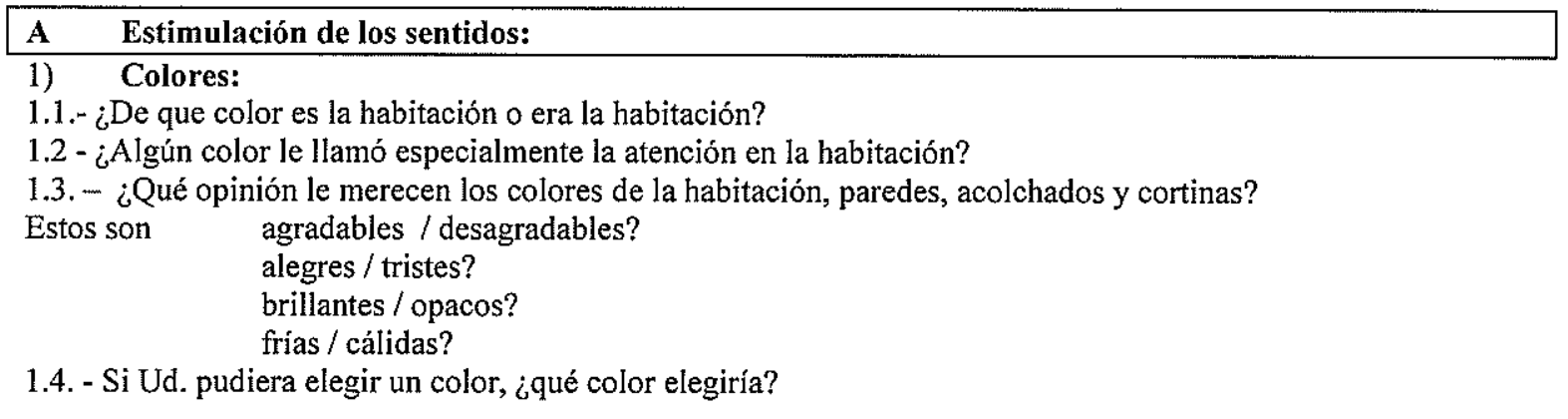

\section{2) Iluminación:}

\section{Luz Natural}

2.1. - ¿Hay luz natural en la habitación?

22. ¿Por las ventanas, entrar la luz del sol? Es: ¿Qué sensación le produce?

Luz artificial

2.3 - La luz artificial general de la habitación.

Es: suficiente demasiada insuficiente

¿Qué sensación le produce?

2.4 - La luz próxima a su cama, específica para el paciente.

Es: suficiente demasiada insuficiente

¿Es buena para leer o realizar otras actividades?

2.5 - Desde el lugar donde está en la cama, puede controlar las diferentes luces de la habitación?

\section{3) Sonidos:}

3.1. - Esta habitación con respecto a los sonidos

Es: muy ruidosa poco ruidosa no es ruidosa

3.2. - Si es ruidosa, puede especificar que produce los ruidos.

Son ruidos: del exterior, de la calle del interior, Público - Personal (Médicos o Enfermeras, etc.).

3.3. - ¿En que momento del día siente más ruidos, identifica de donde son?

3.4. - Si fuera demasiado silenciosa, piensa que, ¿esto le daría sensación de aislamiento?

\section{4) Olores:}

4.1. - Si percibió al entrar diferentes olores, aromas o perfumes.

¿Pudo identificar algún olor? medicamentos desinfectantes otros olores.

4.2. - Estos olores eran: agradables desagradables no había olores

4.3. - Si Ud. pudiera elegir un aroma para esta habitación que le gustara, qué aroma elegiría?

5) Texturas.

5.1. - ¿Qué opinión le merecen los pisos de esta habitación? Estos son: duros / blandos

cálido / frío

agradables / desagradables

$\mathrm{NR}^{25}$

5.2. - Si tuviera que elegir un material para el piso. ¿Qué material elegiría?

5.3. - ¿Qué opinión le merecen las sabanas y acolchados de esta habitación? Estos son: ásperas / lisas agradables / desagradables

NR

\footnotetext{
${ }^{25}$ NR No responde.
} 


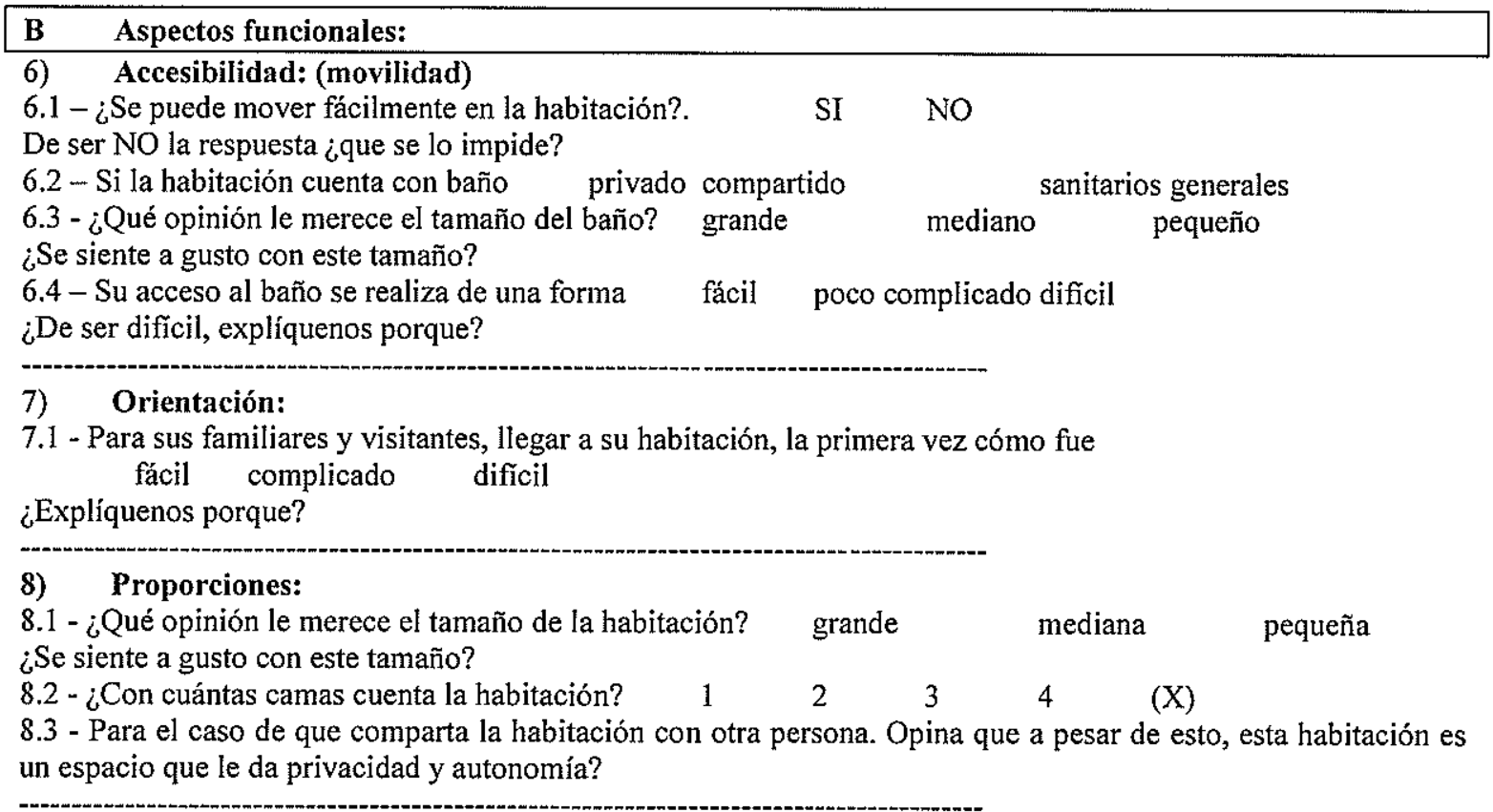

9) Disposición del Equipamiento:

9.1. - Los muebles de esta habitación son tipo hospitalario. ¿Tiene alguna opinión al respecto?

9.2. - Como considera que están puestos los muebles en esta habitación.

De forma correcta incorrecta o le es indiferente

9.3. - En cuanto al espacio, del Personal Médico (Médicos y Enfermeras, etc), los ve moverse cómodos en la habitación o ¿considera que le falta espacio?

9.4. - ¿Le agrada la ubicación de su cama dentro de la habitación?

Preferiría alguna ubicación en especial?

cerca de la ventana - cerca de la puerta - en el centro de la habitación

9.5. - ¿Hay en la habitación algún lugar específico para familiares y visitantes, donde puedan sentarse, dialogar cómodamente con Ud.?

¿Cómo es este espacio? cómodo (suficiente) incómodo (insuficiente) no existe este espacio ¿Qué opinión le merece, contar en de la habitación con ese espacio para familiares y visitantes?

\section{Bienestar:}

10) Incorporación de la naturaleza:

10.1. - ¿Tiene la habitación una ventana al exterior con vista a jardines, patio, plaza, etc?

¿Qué sensación le produce?

10.2. - ¿Qué opinión le merecen la plantas y el contacto con la naturaleza? ¿Tiene alguna opinión al respecto?

10.3. - Cerca de la habitación, ¿existe algún jardín, patio o plaza, etc. Donde puedan ir sus familiares o visitantes?

\section{1) Incorporación del arte:}

11.1. - Si hay algún cuadro en la habitación.

Si es así ¿Podría describirlo? Es: geométrica (abstracta) paisajes plantas (figurativas) personas (retratos)

¿Qué sensación le produce?

11.2. - Que tipo de representaciones le gustan más:

geométricas (abstractas) paisajes plantas (figurativas) personas (retratos) 
12) Incorporación de la música:

12.1. - ¿Tiene esta habitación música funcional?

12.2. - ¿Qué opinión le merece la música funcional?

12.3. - ¿Considera que la música pueda afectar su estado de ánimo?

12.4. - ¿Qué tipo de música le gustaría escuchar?

\section{3) Confort:}

13.1. - En su conjunto, Ud. considera que esta habitación es confortable

13.2. - ¿Su cama es cómoda?

¿Puede controlar Ud. sus posiciones?

13.3. - Tiene esta habitación:

TV

Equipo de Frío / Calor TE

$\begin{array}{lll}\text { SI } & \text { NO } & \text { Puede controlarlo } \\ \text { Si } & \text { NO } & \text { Puede controlarlo } \\ \text { SI } & \text { NO } & \end{array}$

¿Se sintió por lo antes expresado que Ud. se encontraba comunicado con el exterior, o por lo contrario se siente asilado?

13.4. - ¿Hay una Cafetería en el Establecimiento, o expendedor de bebidas o comestibles cerca en la habitación, para familiares y visitantes?

Buenos Aires 2006- 2011

\subsubsection{Modelo Observado Preliminar MOP} Modelo Observado Preliminar MOP para el Servicio de Atención de Internación
Cuidados Generales (2006-2009)

Primeramente se desarrolla un Modelo Observado Preliminar MOP, a partir de la aplicación de la Encuesta "Evaluación del Recurso Físico en Atención de Internación en busca de los "Satisfactores del Recurso Fisco" en el Servicio de Atención de Internación Cuidados Generales.

El Trabajo de Investigación "Las Condicionantes Ambientales y de Humanización de los Espacios en el Desarrollo de los Recursos Físicos en Salud", Proyecto UBACyT A-810, Dirigido por esta Doctoranda, fue el marco en que se realizó la primera prueba de la Encuesta (información sobre el Trabajo de Investigación en Anexo 3).

El trabajo de Investigación contó con la participación interdisciplinaria de Investigadores ${ }^{26}$, del Centro de Investigación en Planeamiento del Recurso Físico en Salud, de la Facultad de Arquitectura Diseño y Urbanismo, de la Universidad de Buenos Aires CIRFS FADU UBA.

Se desarrollaron dos conjuntos de Encuestas, en correspondencia con los dos periodos del Proyecto de Investigación 2006/2007 y 2008/2009. En el Periodo 2006/2007 se desarrolló la Primera Encuesta, se seleccionó en esa oportunidad el Hospital General de Agudos Juan A. Fernández de la Ciudad

${ }^{26}$ Investigadores: Prof. Consulto Arq. Astrid Bögedam de Debuchy, Lic. Francisco Turull, Dra. Nélida Nervi, Arq. Catalina Scavino, Arq. Marcelo Lamorgese e Ing. Martin Borghi CIRFS FADU UBA: 
Autónoma de Buenos Aires del Subsector Público y el Centro de Estudios Médicos e Investigaciones Clínicas "Norberto Quirno", CEMIC Las Heras y CEMIC Saavedra del Subsector Privado.

Los resultados obtenidos en del primer periodo del Proyecto de Investigación 2006/2007, indicaron la necesidad de un reajuste instrumental de la Encuesta, a la vez que señalaron la necesidad de una ampliación del universo a ser tomado en cuenta en cuanto a la selección de las muestras. Este proceso de estudios y evaluación dio como resultado una Segunda Encuesta, es así como en el Periodo 2008/2009, se seleccionó el Hospital General de Agudos Carlos G. Durand del Subsector Público para el desarrollo de la misma.

Se entrevistaron un total de sesenta (60) pacientes a los que se les realizaron las sesenta y cuatro (64) preguntas del cuestionario de la Encuesta.

Se entrevistaron en el primer periodo 2006/2007, a cuarenta pacientes, veinte del Subsector Público y veinte del Subsector Privado, se entrevistaron poblaciones similares de hombres y mujeres. En el caso de segundo periodo 2008/2009 se entrevistaron a veinte pacientes nuevamente como en el caso anterior las poblaciones fueron similares de hombres y mujeres.

\section{Anexo 3}

Comprende:

Segmentos del Trabajo del Investigación "Las Condicionantes Ambientales y de Humanización de los Espacios en el Desarrollo del Recurso Físico en Salud" UBACyT A810, 2006-2009.

De donde se extraerá de la Encuesta "Evaluación del Recurso Físico en Atención de Internación en busca de los "Satisfactores del Recurso Fisco", el Modelo Observado Preliminar MOP y los Resultados de la misma. 


\subsubsection{Modelo Observado Final MOF}

Modelo Observado Final MOF para Unidades de Cuidados Intensivos y Cuidados Intensivos Cardiológicos (2009-2011)

Habiendo desarrollado los Modelo Observado Preliminar MOP se desarrollará el estudio del Modelo Observado Final MOF.

Con el mismo Cuestionario de la Encuesta "Evaluación del Recurso Físico en Atención de Internación en busca de los Satisfactores del Recurso Fisco" (2006-2009), se entrevistan pacientes de Unidades de Cuidados Intensivos y Cuidados Intensivos Cardiológicos (la totalidad de las Encuestas se encuentran en el Apéndice 1).

Se observará si los datos obtenidos en los pacientes entrevistados Cuidados Intermedio son concurrentes a los datos obtenidos en los pacientes entrevistados en Unidades de Cuidados Intensivos y Cuidados Intensivos Cardiológicos, se busca determinar si se corrobora la información o si surgen nuevos datos.

Se entrevistaron a tres grupos de pacientes, primeramente se entrevistaran diez (10) pacientes de la Unidad de Terapia Intensiva del Hospital General de Agudos Carlos G. Durand (del Subsector Público), luego se entrevistaron diez (10) pacientes de la Unidad de Cuidados Intensivos Cardiológicos del Centro de Estudios Médicos e Investigaciones Clínicas "Norberto Quirno" UCO ${ }^{27}$ CEMIC Saavedra (del Subsector Privado), paralelamente se entrevistaron seis (6) pacientes de diferentes Instituciones públicas y privadas de: la Unidad de Terapia Intensiva de Swiss Medical Group, la Unidad de Terapia Intensiva Los Arcos, la Unidad Coronaria Suizo Argentina, la Unidad de Terapia Intensiva Sanatorio San Camilo y la Unidad de Terapia Intensiva del Hospital Bryn Mawr, Pensilvania EE UU.

Se entrevistaron en total a veintiséis (26) pacientes a los que se les realizaron las sesenta y cuatro (64) preguntas del cuestionario de la Encuesta.

Debido a que es difícil entrevistar a pacientes que se encuentren internados en Cuidados Intensivos, algunas de las entrevistas a estos pacientes fueron realizadas con posterioridad de la Internación.

A continuación y a modo de Ejemplo se presenta parte de una Encuesta referida al conjunto de variables; "Estimulación de los Sentidos", realizada a un paciente internado en Cuidados Intensivos del Hospital General de Agudos Carlos G. Durand. La intención de esta presentación es mostrar cómo han sido completadas las preguntas de la Encuesta ${ }^{28}$, las respuestas del paciente están en color azul.

${ }^{27}$ UCO Unidad Coronaria

${ }^{28}$ Las Encuestas completas se encuentran en el Apéndice 1. 


\section{ENTREVISTA A PACIENTE INTERNADO EN CUIDADOS INTENSIVOS UTI HOSPITAL DURAND "Evaluación del Recurso Físico en Atención de Internación en busca de los Satisfactores del Recurso Fisco"}

Paciente 10 A. P.

Hospital:

Genero del Paciente

Edad del Paciente (entre 35 y 80 años)

Causa de Internación

Estadía de Internación
UTI Hospital Durand

Masculino

60

Aneurisma de Aorta Abdominal 12 días en UTI

\section{Estimulación de los sentidos:}

1) Colores:

1.1.- ¿Recuerda de que color era la habitación?

Blanco y gris con los pasillos amarillos, creo

1.2 - ¿Algún color le llamó especialmente la atención en la habitación?

La verdad que no aquí no resalta nada todo es uniforme.

1.3. - ¿Qué opinión le merecen los colores de la habitación, paredes, acolchados y cortinas?

Estos son agradables / desagradables?

$$
\begin{aligned}
& \text { Alegres / tristes? } \\
& \text { brillantes/opacos? } \\
& \text { frías / cálidas? }
\end{aligned}
$$

1.4. - Si Ud. pudiera elegir un color, ¿qué color elegiría?

Blanco pero con algún cuadro o algo que corte

\section{2) Iluminación:}

Luz Natural

2.1. - ¿Hay luz natural en la habitación?

2.2. ¿Por las ventanas, entrar la luz del sol? Es:

No hay y uno no sabe cuanto lleva aquí encerrado

¿Qué sensación le produce?

Horrible de soledad y de encierro

\section{Luz artificial}

2.3 - La luz artificial general de la habitación.

Es: suficiente demasiada insuficiente

¿Qué sensación le produce? Incomodidad

2.4 - La luz próxima a su cama, específica para el paciente.

Es: suficiente demasiada insuficiente

¿Es buena para leer o realizar otras actividades? Si para leer

2.5 - Desde el lugar donde está en la cama, puede controlar las diferentes luces de la habitación?

3) Sonidos:

3.1. - Esta habitación con respecto a los sonidos
Es: muy ruidosa
poco ruidosa

3.2. - Si es ruidosa, puede especificar que produce los ruidos.

Son ruidos: del exterior, de la calle del interior, Público - Personal (Médicos o Enfermeras, etc.).

Son ruidos del Hospital, ni siquiera se escucha la calle

3.3. - ¿En qué momento del día siente más ruidos, identifica de donde son?

El personal de limpieza por la mañana y al mediodía y la tardecita los carros de la comida

3.4. - Si fuera demasiado silenciosa, piensa que, ¿esto le daría sensación de aislamiento?

\section{4) Olores:}

4.1. - Si percibió al entrar diferentes olores, aromas o perfumes.

¿Pudo identificar algún olor?

4.2. - Estos olores eran:

medicamentos desinfectantes

agradables desagradables

otros olores.

4.3. - Si Ud. pudiera elegir un aroma para esta habitación que le gustara, qué aroma elegiría?

El que tiene o alguno mas hogareño como a flores 
5) Texturas.

5.1. - ¿Que opinión le merecen los pisos de esta habitación? Estos son: $\underline{\text { duros / blandos }}$

cálido / frío

agradables / desagradables $\underline{\mathrm{NR}^{29}}$

5.2. - Si tuviera que elegir un material para el piso. ¿Qué material elegiría?

Mosaico o cerámico

5.3. - ¿Que opinión le merecen las sabanas y acolchados de esta habitación? Estos son: ásperas / lisas agradables / desagradables NR

Fin del Conjunto de variables de Estimulación de los sentidos

\section{Apéndice 1}

Encuestas a Pacientes de Unidades de Cuidados Intensivos y Cuidados Intensivos Cardiológicos (2009-2011)

Las Encuestas se encuentran organizadas con el siguiente orden:

Grupo 1. La Unidad de Cuidados Intensivos del Hospital General de Agudos Carlos G. Durand (del Subsector Público). Diez (10) pacientes.

Grupo 2. La Unidad de Cuidados Intensivos Cardiológicos del Centro de Estudios Médicos e Investigaciones Clínicas "Norberto Quirno" UCO CEMIC Saavedra (del Subsector Privado). Diez (10) pacientes.

Grupo 3. La Unidad de Cuidados Intensivos de Swiss Medical Group, la Unidad de Cuidados Intensivos Los Arcos, La Unidad de Cuidados Intensivos Cardiológicos Suizo Argentina, la Unidad de Cuidados Intensivos Sanatorio San Camilo y la Unidad de Cuidados Intensivos del Hospital Bryn Mawr, Pensilvania EE UU. (del Subsector Público y Privado). Seis (6) pacientes.

\footnotetext{
${ }^{29}$ NR No responde.
} 


\subsubsection{Especialistas Médicos de Cuidados Intensivos Generales y Cardiológicos}

Paralelamente al estudio de la Encuesta, se realizaron Entrevistas y corroboración de datos con Profesionales Médicos, Doctores en Medicina Especializados en la Cuidados Intensivos y Cuidados Intensivos Cardiológicos.

Se realizaron entrevistas con Dr. Javier Guetta Jefe de Unidad de Cuidados Intensivos Cardiológicos CEMIC Saavedra y con el Dr. Carlos Rubianes, Consultor de la Unidad Polivalente de Cuidados Intensivos y Cuidados Cardiológicos del Instituto Argentino de Diagnóstico y Tratamiento IADT.

El Dr. Guetta colaboró en el Capítulo 4.1.4. con la realización de la Política Operacional Especifica de Cuidados Intensivos Cardiológicos, también colaboró en el Capítulo 4.1.5.2., con la realización del Cuadro de las Tecnología de Operación de Atención de Internación Unidad Cardiológica con su desarrollo en Funciones, Actividades, Tareas y Definición del Recurso Humano, de la Unidad Cuidados Intensivos Cardiológicos del CEMIC Saavedra

\section{Instituto Argentino de Diagnóstico y Tratamiento IADT Entrevista con el Dr. Carlos Rubianes \\ "Hay elementos fundamentales a tener en cuenta en el diseño de las habitaciones de Unidad de Cuidados Intensivos $\mathrm{UCl}$ uno de estos elementos es la luz natural, todas las habitaciones tienen que tener luz natural, es esencial para el paciente tener noción del día y de la noche para no contribuir a su desorientación" señala el Dr. Carlos Rubianes Consultor de la Unidad Polivalente de Cuidados Intensivos y Cuidados Cardiológicos del Instituto Argentino de Diagnóstico y Tratamiento IADT y uno de los precursores en la creación de estos servicios la Argentina.}

Acerca de cuáles son elementos que considera fundamentales en el diseño de estas Unidades, el Dr Rubianes responde: "Otro elemento fundamental es que en todas las habitaciones haya un reloj frente al paciente, mejor dicho frente a la cama del paciente, para que este tenga noción también de la hora".

"Un caso particular es el de los pacientes añosos estos se desorientan, creen que están en su casa se levantan de la cama, con la consecuente posibilidad de accidentes, es por esto que es necesario un control por monitoreo permanente sobre el paciente, esto se realiza a través del circuito cerrado de televisión, que permite ver todas las camas con rotación cada diez segundos, este circuito cerrado de funciona de manera constante en la oficina del Medico Consultor y en el despacho donde se encuentran reunidos los médicos internos con los médicos de cabecera."

"Nosotros tenemos muchos pacientes que no pueden pasar rápidamente al piso, los pacientes pasan mucho tiempo aislados internados en la UCl y si bien tienen el horario de visitas en los cuales tienen contacto con familiares y amigos, pasan mucho tiempo solos, es por esto que nosotros consideramos la incorporación de otro elemento que es muy importante para la distracción del paciente un televisión."

El Dr. Rubianes agrega: "Por supuesto que hay pacientes que se encuentran en coma o con respirador que no van a poder utilizar estos equipos, pero hay que tomar en consideración aquellos pacientes que se encuentran lucidos", el Dr. Rubienes señala la pantalla en su oficina que constantemente monitorea los pacientes y agrega "podemos observar en el circuito cerrado de 
Facultad de Arquitectura y Urbanismo, Universidad Nacional de la Plata

televisión la cantidad de pacientes que se encuentran lucidos haciendo uso de este equipamiento. Estos detalles son fundamentales para la tranquilidad y para disminuir la ansiedad de los pacientes."

En cuanto al funcionamiento de la Unidad de Cuidados Críticos del IADT, el Dr Rubianes nos informa que "cuenta con dos centrales de enfermería, una tiene a su cargo doce camas y la otra diez camas, en la central de enfermería el circuito cerrado de televisión se encuentra fijo en cada uno de los pacientes, este monitorio es constante y permite ver que es lo que pasa con cada uno de ellos."

"En este momento la ocupación es total, están ocupadas las veintidós camas, sin embargo tenemos una de ellas siempre bloqueada para reparaciones y arreglos, esta reparación se realiza de forma rotatoria, todas las habitaciones son renovadas a cero en el año".

En cuanto a la pregunta de cómo es la modalidad de atención Polivalente que opera en este servicio el Dr. Rubianes nos informa, "como ya había comentado he sido precursor en la creación de este senvicio en la Argentina y consideré que la forma más práctica de realizar esto era que todas las habitaciones pudieran senvir para Unidad Coronaria, Terapia Intensiva y Terapia Intermedia, todas las camas son iguales". Entonces ¿cuál es la diferencia?, el Dr Rubianes responde: "Fundamentalmente reside en que haya un médico cardiólogo y otro intensivista de guardia, entonces de esa forma con esos dos médicos se cubre la atención de Unidad de Terapia Intensiva y Unidad Coronaria, es un tema más de RRHH ya que el equipamiento es prácticamente igual, también pasa que muchas veces un enfermo de terapia se puede rápidamente transformar en un enfermo Cardiológicos".

Respecto al RRHH en particular, el Dr. Rubianes señala que "cuenta con dos coordinadores, uno de Unidad Coronaria y otro de Terapia Intensiva, hay un Consultor que soy yo (Dr. Carlos Rubianes), hay tres médicos de guardia, hay una Enfermera Jefe por turno y un Supenisor, que es el que maneja todo, es el Jefe de las Enfermeras y además hay una enfermera cada tres camas."

El Dr. Rubianes nos comenta que "se fueron agregando cosas y elementos en la unidad a lo largo del tiempo, los primeros servicios no contaban con circuito cerrado de televisión, este elemento fue fundamental para nosotros ya que nos permitió tener una visión permanente del paciente, esto al comienzo no existía, ahora todo es cada vez más sofisticado, este circuito nos permite grabar a los pacientes, nosotros por un tema de seguridad grabamos la entrada y la sala de espera del servicio".

En cuanto a otros elementos de las habitaciones, esta son de colores claros cálidos, tienen además de todo los señalado, black-out para controlar el paso de la iluminación de las ventanas, estas a su vez dan un patio que se encuentra decorado con distintos tipos de plantas con macetas cerámicas. Las habitaciones no cuentan con cuadros, se considera por seguridad e higiene es preferible no agregar más de lo que sea estrictamente necesario, de todos modos agrega el Dr Rubianes, "la televisión además de ser un entretenimiento para el paciente, reemplaza muchos de los elementos ya mencionados en la encuesta de "Satisfactores del Recurso Físico" como lo son el arte y la música".

AMD 5 de mayo 2011 Buenos Aires

\subsubsection{Estudio de los Datos de la Encuesta}

Para realizar el estudio de los datos que arrojaron las Encuestas se elaboran las Tablas con el resumen de los datos a través de un Consolidado por grupo de Establecimiento. (Apéndice 2).

El Consolidado de los Datos por cada Establecimiento, seguirá el mismo ordenamiento de la Encuesta, se presentaran los conjuntos de variables y luego 
para cada una de las preguntas del cuestionario se ordenaran numéricamente los pacientes con sus respuestas.

A modo de Ejemplo se presenta la Encuestas referida solamente al conjunto de variables; "Estimulación de los Sentidos", la Encuesta que fue realizada a pacientes internados en Cuidados Intensivos Hospital Durand.

\section{CONSOLIDADO ENTREVISTAS \\ Unidades de Cuidados Intensivos Hospital Durand}

Encuesta: “Evaluación del Recurso Físico en Atención de Internación en busca de los Satisfactores del Recurso Fisco"

Estimulación de los sentidos:

1. Colores:

1.1. - ¿Recuerda de que color era la habitación?

Respuesta de Paciente:

\begin{tabular}{|l|l|}
\hline 1. & Todo era bianco brillante \\
\hline 2. & NO \\
\hline 3. & Blanco y gris \\
\hline 4. & Si. blanca y gris y el pasillo amarillo patito \\
\hline 5. & Blanco \\
\hline 6. & Blanco o gris \\
\hline 7. & Blanco \\
\hline 8. & Blanco \\
\hline 9. & Blanco y Gris \\
\hline 10. & Blanco y gris con los pasillos amarillos. creo \\
\hline
\end{tabular}

1.2. - ¿Algún color le llamó especialmente la atención en la habitación?

Respuesta de Paciente:

\begin{tabular}{|l|l|}
\hline 1. & Todo era del mismo color, me parece \\
\hline 2. & $\begin{array}{l}\text { En realidad todo es muy brillante y hay mucha luz artificial, creo que hay alguna pared color amarillo patito, pero } \\
\text { me parece que no está dentro de la habitación aunque si dentro de la terapia y los marcos de las puertas color gris, } \\
\text { imagínese todo muy "artificial" como una nave espacial. (Es importante destacar que el paciente es una persona } \\
\text { muy instruida y con grandes inquietudes, por lo cuál primero se interiorizó muy bien de qué se trataba la encuesta } \\
\text { y se alegró mucho de saber que había profesionales trabajando para humanizar los hospitales como el lo definió) }\end{array}$ \\
\hline 3. & No, la verdad es que todo es muy uniforme \\
\hline 4. & No, es todo muy brillante por la luz artificial, no hay luz natural y eso es feo \\
\hline 5. & No me fije \\
\hline 6. & No, es todo uniforme \\
\hline 7. & $\begin{array}{l}\text { La verdad que no, pero tenga en cuenta que uno anda muy distraido ahí adentro. Uno se concentra en hacer todo } \\
\text { bien para salir rápido, el resto no importa porque, el lugar es muy encerrado, muy solitario }\end{array}$ \\
\hline 8. & No, me da igual acá todo es muy triste \\
\hline 9. & $\begin{array}{l}\text { No, me da igual acá todo es triste como mi enfermedad, soy diabética desde que nací y nací en este Hospital. Vivo } \\
\text { enfrente como para recordar que nací enferma. }\end{array}$ \\
\hline 10. & La verdad que no aqui no resalta nada todo es uniforme \\
\hline
\end{tabular}

1.3. - ¿Qué opinión le merecen los colores de la habitación, paredes, acolchados y cortinas?

Estos son agradables / desagradables?

alegres / tristes?

brillantes / opacos?

frías / cálidas? 
Respuesta de Paciente:

\begin{tabular}{|l|c|c|c|c|}
\hline $\begin{array}{c}\text { Estos } \\
\text { son: }\end{array}$ & $\begin{array}{c}\text { agradables / } \\
\text { desagradables? }\end{array}$ & alegres / tristes? & brillantes / opacos? & frías / cálidas? \\
\hline 1. & desagradables & tristes & brillantes & fríos \\
\hline 2. & agradables & tristes & brillantes & fríos \\
\hline 3. & agradables & tristes & opacos & fríos \\
\hline 4. & agradables & tristes & opacos & fríos \\
\hline 5. & agradables & tristes & opacos & fríos \\
\hline 6. & agradables & tristes & opacos & fríos \\
\hline 7. & agradables & tristes & opacos & fríos \\
\hline 8. & agradables & tristes & opacos & fríos \\
\hline 9. & agradables & tristes & opacos & \\
\hline 10. & agradables & tristes & & \\
\hline
\end{tabular}

1.4. - Si Ud. pudiera elegir un color, ¿qué color elegiría? Respuesta de Paciente:

\begin{tabular}{|l|l|}
\hline 1. & Algo un poco menos blanco, mas alegre \\
\hline 2. & $\begin{array}{l}\text { Tonos pastel, algo que cuando uno retoma el estado de conciencia haga pensar en algo menos "Técnico". Esta } \\
\text { terapia es nueva, todo está reluciente pero es muy despersonalizado, no hay calidez, ni siquiera para el personal de } \\
\text { salud. Yo no recuerdo el color de mi habitación porque estuve confuso durante } 48 \text { hs. Pero lo único que viene a mi } \\
\text { memoria en éste momento, es blanco mucho blanco. }\end{array}$ \\
\hline 3. & $\begin{array}{l}\text { Algo un poco mas alegre, es muy triste estar en terapia, un poco de color ayudaría a sentirse mejor. A mi me } \\
\text { gustaría el rosa pero muy suave }\end{array}$ \\
\hline 4. & Colores mas relacionados con el verde, la naturaleza, algo mas vivo \\
\hline 5. & Un color sol mi hïita que es lo que hace falta acá \\
\hline 6. & Un empapelado con tonos pastel, sería lindo \\
\hline 7. & $\begin{array}{l}\text { Un colorcito suave pero más luminoso como rosa o celeste o amarillito vio los colores que usan para las } \\
\text { habitaciones de los bebés???, bueno esa sería la gama y no estos colores tan solemes }\end{array}$ \\
\hline 8. & Cualquiera menos blanco o gris \\
\hline 9. & Colores pastel \\
\hline 10. & Blanco pero con algún cuadro o algo que corte \\
\hline
\end{tabular}

Fin de la variable Color del conjunto de variables de "Estimulación de Ios sentidos". Hospital Durand

Apéndice 2
Los Consolidado de las Encuestas a Pacientes de Unidades de Cuidados Intensivos y
Cuidados Intensivos Cardiológicos (2009-2011).
Los Consolidados de las Encuestas se encuentran organizados con el siguiente orden:
Consolidado Grupo 1. La Unidad de Cuidados Intensivos del Hospital General de Agudos Carlos G.
Durand (del Subsector Público). Diez (10) pacientes.
Consolidado Grupo 2. La Unidad de Cuidados Intensivos Cardiológicos del Centro de Estudios
Médicos e Investigaciones Clínicas "Norberto Quirno" UCO CEMIC Saavedra (del Subsector Privado).
Diez (10) pacientes.
Consolidado Grupo 3. La Unidad de Cuidados Intensivos de Swiss Medical Group, la Unidad de
Cuidados Intensivos Los Arcos, La Unidad de Cuidados Intensivos Cardiológicos Suizo Argentina, la
Unidad de Cuidados Intensivos Sanatorio San Camilo y la Unidad de Cuidados Intensivos del Hospital
Bryn Mawr, Pensilvania EE UU. (del Subsector Público y Privado). Seis (6) pacientes.




\subsubsection{Rangos de las respuestas de los Pacientes}

Un análisis del Consolidado de las Entrevistas nos permite observar ciertos rasgos ${ }^{30}$ en las respuestas de los Pacientes a las variables presentadas, que nos permiten identificar tres Rangos o grupos de respuestas, estos indicaran el grado del interés que los Pacientes atribuyen a dichas variables. Un estudio posterior nos permitirá ver la frecuencia con que estos Rangos se repiten que se observará a través de un Histograma ${ }^{31}$ de Frecuencias.

Rango 1, en este grupo el Paciente se mostró indiferente o respondió no haber puesto atención a estos aspectos a los que hace alusión el Entrevistador, dentro de este rango de respuesta se incluyen Pacientes que dicen no recordar o no contestar.

Rango 2, en este grupo el Paciente mostró cierto interés con la variable y comunicó una preferencia especifica.

Rango 3 en este grupo el Paciente mostro mayor interés y se expresó más allá de lo solicitado por el Encuestador, en este rango se consideran también las respuestas que aluden a emociones, sensaciones y estados de ánimo que pudieron afectar de un modo o de otro al paciente.

\begin{tabular}{|c|c|c|c|c|c|c|c|}
\hline \multicolumn{3}{|l|}{ RANGO 1} & \multirow[t]{2}{*}{$\begin{array}{c}\text { GRUPO } \\
1 \\
\end{array}$} & \multirow[t]{2}{*}{$\begin{array}{c}\text { GRUPO } \\
\mathbf{2} \\
\end{array}$} & \multirow[t]{2}{*}{$\begin{array}{c}\text { GRUPO } \\
3 \\
\end{array}$} & \multicolumn{2}{|c|}{$\begin{array}{l}\text { Total } \\
\text { Pacientes }\end{array}$} \\
\hline $\begin{array}{c}\text { ESTIMULO DE LOS } \\
\text { SENTIDOS }\end{array}$ & & & & & & & $\%$ \\
\hline & A.1. & Colores & 0 & 0 & 0 & 0 & $0 \%$ \\
\hline & A.2. & lluminación natural & 2 & 0 & 0 & 2 & $8 \%$ \\
\hline & A.2. & Iluminación artificial & 1 & 0 & 1 & 2 & $8 \%$ \\
\hline & A.3. & Sonidos & 1 & 0 & 0 & 1 & $4 \%$ \\
\hline & A.4. & Olores & 0 & 1 & 0 & 1 & $4 \%$ \\
\hline & A.5. & Texturas & 0 & 2 & 0 & 2 & $8 \%$ \\
\hline \multicolumn{8}{|l|}{$\begin{array}{l}\text { OPTIMIZACION DE } \\
\text { ASPECTOS } \\
\text { FUNCIONALES }\end{array}$} \\
\hline & B.1. & Accesibilidad & 3 & 3 & 3 & 9 & $35 \%$ \\
\hline & B.2. & Orientación & 0 & 3 & 3 & 6 & $23 \%$ \\
\hline & B.3. & Proporciones & 2 & 0 & 0 & 2 & $8 \%$ \\
\hline & B.4. & Disposición del Equipamiento & 0 & 3 & 1 & 4 & $15 \%$ \\
\hline \multicolumn{8}{|l|}{ BIENESTAR } \\
\hline & C.1. & Incorporación de la naturaleza & 0 & 3 & 0 & 3 & $12 \%$ \\
\hline & c.2. & Incorporación del arte & 3 & 8 & 3 & 14 & $54 \%$ \\
\hline & C.3. & Incorporación de la música & 0 & 1 & 0 & 1 & $4 \%$ \\
\hline & C.4. & Confort & 0 & 1 & 0 & 1 & $4 \%$ \\
\hline
\end{tabular}

30 Samaja Juan, Libro de la Semiótica de la Ciencia (Textos en proceso de Elaboración) 2004.

31 Representación gráfica de una variable en forma de barras, donde la superficie de cada barra es proporcional a la frecuencia de los valores representados. 
En la primera columna se encuentran los Pacientes del Consolidado Grupo $1 \frac{32}{1}$ la segunda columna el Consolidado Grupo $2^{\frac{33}{3}}$ y en la tercera columna el Consolidado Grupo $3^{\frac{34}{}}$. Luego el total de Pacientes por variable y su correspondiente porcentaje.

\begin{tabular}{|c|c|c|c|c|c|c|c|}
\hline \multicolumn{3}{|l|}{ RANGO 2} & \multirow[t]{2}{*}{$\begin{array}{c}\text { GRUPO } \\
1 \\
\end{array}$} & \multirow[t]{2}{*}{$\begin{array}{c}\text { GRUPO } \\
2 \\
\end{array}$} & \multirow[t]{2}{*}{$\begin{array}{c}\text { GRUPO } \\
3 \\
\end{array}$} & \multicolumn{2}{|c|}{$\begin{array}{l}\text { Total } \\
\text { Pacientes }\end{array}$} \\
\hline $\begin{array}{l}\text { ESTIMULO DE LOS } \\
\text { SENTIDOS }\end{array}$ & & & & & & & $\%$ \\
\hline & A.1. & Colores & 7 & 10 & 6 & 23 & $88 \%$ \\
\hline & A.2. & Iluminación natural & 0 & 0 & 0 & 0 & $0 \%$ \\
\hline & A.2. & lluminación artificial & 2 & 1 & 5 & 8 & $31 \%$ \\
\hline & A.3. & Sonidos & 7 & 1 & 4 & 12 & $46 \%$ \\
\hline & A.4. & Olores & 10 & 9 & 5 & 24 & $92 \%$ \\
\hline & A.5. & Texturas & 10 & 8 & 6 & 24 & $92 \%$ \\
\hline \multicolumn{8}{|l|}{$\begin{array}{c}\text { OPTIMIZACION DE } \\
\text { ASPECTOS } \\
\text { FUNCIONALES }\end{array}$} \\
\hline & B.1. & Accesibilidad & 7 & 7 & 2 & 16 & $62 \%$ \\
\hline & B.2. & Orientación & 10 & 6 & 2 & 18 & $69 \%$ \\
\hline & B.3. & Proporciones & 7 & 9 & 5 & 21 & $81 \%$ \\
\hline & B.4. & Disposición del Equipamiento & 10 & 7 & 4 & 21 & $81 \%$ \\
\hline \multicolumn{8}{|l|}{ BIENESTAR } \\
\hline & C.1. & Incorporación de la naturaleza & 0 & 0 & 0 & 0 & $0 \%$ \\
\hline & C.2. & Incorporación del arte & 1 & 1 & 0 & 2 & $8 \%$ \\
\hline & C.3. & Incorporación de la música & 9 & 7 & 5 & 21 & $81 \%$ \\
\hline & C.4. & Confort & 1 & 1 & 0 & 2 & $8 \%$ \\
\hline
\end{tabular}

\begin{tabular}{|c|c|l|c|c|c|c|c|}
\hline \multicolumn{2}{|c|}{ RANGO 3 } & & \multicolumn{3}{c|}{$\begin{array}{c}\text { GRUPO } \\
1\end{array}$} & \multicolumn{2}{c|}{ Total } \\
GRUPO & GRUPO & Pacientes \\
\hline $\begin{array}{c}\text { ESTIMULO DE LOS } \\
\text { SENTIDOS }\end{array}$ & & & & & \\
\hline & A.1. & Colores & 3 & 0 & 0 & 3 & $12 \%$ \\
\hline & A.2. & lluminación natural & 8 & 10 & 6 & 24 & $92 \%$ \\
\hline & A.2. & lluminación artificial & 7 & 9 & 0 & 16 & $62 \%$ \\
\hline & A.3. & Sonidos & 2 & 9 & 2 & 13 & $50 \%$ \\
\hline & A.4. & Olores & 0 & 0 & 1 & 1 & $4 \%$ \\
\hline & A.5. & Texturas & 0 & 0 & 0 & 0 & $0 \%$ \\
\hline
\end{tabular}

32 La Unidad de Cuidados Intensivos del Hospital General de Agudos Carlos G. Durand (del Subsector Público). Diez (10) pacientes.

33 La Unidad de Cuidados Intensivos Cardiológicos del Centro de Estudios Médicos e Investigaciones Clinicas "Norberto Quirno" UCO CEMIC Saavedra (del Subsector Privado). Diez (10) pacientes.

$34 \mathrm{La}$ Unidad de Cuidados Intensivos de Swiss Medical Group, la Unidad de Cuidados Intensivos Los Arcos, La Unidad de Cuidados Intensivos Cardiológicos Suizo Argentina, la Unidad de Cuidados Intensivos Sanatorio San Camilo y la Unidad de Cuidados Intensivos del Hospital Bryn Mawr, Pensilvania EE UU. (del Subsector Público y Privado). Seis (6) pacientes. 


\begin{tabular}{|c|c|c|c|c|c|c|c|}
\hline $\begin{array}{l}\text { OPTIMIZACION DE } \\
\text { ASPECTOS } \\
\text { FUNCIONALES }\end{array}$ & & & & & & & \\
\hline & B.1. & Accesibilidad & 0 & 0 & 1 & 1 & $4 \%$ \\
\hline & B.2. & Orientación & 0 & 1 & 1 & 2 & $8 \%$ \\
\hline & B.3. & Proporciones & 1 & 1 & 1 & 3 & $12 \%$ \\
\hline & B.4. & Disposición del Equipamiento & 0 & 0 & 1 & 1 & $4 \%$ \\
\hline \multicolumn{8}{|l|}{ BIENESTAR } \\
\hline & C.1. & $\begin{array}{l}\text { Incorporación de la } \\
\text { naturaleza }\end{array}$ & 10 & 7 & 6 & 23 & $88 \%$ \\
\hline & C.2. & Incorporación del arte & 6 & 1 & 3 & 10 & $38 \%$ \\
\hline & C.3. & Incorporación de la música & 1 & 2 & 1 & 4 & $15 \%$ \\
\hline & C.4. & Confort & 9 & 8 & 6 & 23 & $88 \%$ \\
\hline
\end{tabular}

Tabla resumen de las tres anteriores con las cantidades de Pacientes por Rango

\begin{tabular}{|c|c|c|c|c|c|}
\hline & & & $\begin{array}{c}\text { RANGO } \\
1 \\
\end{array}$ & $\begin{array}{c}\text { RANGO } \\
2 \\
\end{array}$ & $\begin{array}{c}\text { RANGO } \\
3 \\
\end{array}$ \\
\hline \multicolumn{6}{|l|}{$\begin{array}{l}\text { ESTIMULO DE LOS } \\
\text { SENTIDOS }\end{array}$} \\
\hline & A.1. & Colores & 0 & 23 & 3 \\
\hline & A.2. & Iluminación natural & 2 & 0 & 24 \\
\hline & A. 2 . & lluminación artificial & 2 & 8 & 16 \\
\hline & A.3. & Sonidos & 1 & 12 & 13 \\
\hline & A.4. & Olores & 1 & 24 & 1 \\
\hline & A.5. & Texturas & 2 & 24 & 0 \\
\hline \multicolumn{6}{|l|}{$\begin{array}{c}\text { OPTIMIZACION DE } \\
\text { ASPECTOS } \\
\text { FUNCIONALES }\end{array}$} \\
\hline & B.1. & Accesibilidad & 9 & 16 & 1 \\
\hline & B.2. & Orientación & 6 & 18 & 2 \\
\hline & B.3. & Proporciones & 2 & 21 & 3 \\
\hline & B.4. & $\begin{array}{l}\text { Disposición del } \\
\text { Equipamiento }\end{array}$ & 4 & 21 & 1 \\
\hline \multicolumn{6}{|l|}{ BIENESTAR } \\
\hline & C.1. & $\begin{array}{l}\text { Incorporación de la } \\
\text { naturaleza }\end{array}$ & 3 & 0 & 23 \\
\hline & C.2. & Incorporación del arte & 14 & 2 & 10 \\
\hline & C.3. & Incorporación de la música & 1 & 21 & 4 \\
\hline & C.4. & Confort & 1 & 2 & 23 \\
\hline
\end{tabular}

Se resaltan en la tabla los resultados de las respuestas con más cantidad de Pacientes por Rango. 


\section{A continuación se realiza un nueva Tabla resumen con los porcentajes de Pacientes por Rango.}

\begin{tabular}{|c|c|c|c|c|c|}
\hline & & & $\begin{array}{c}\text { RANGO } \\
1\end{array}$ & $\begin{array}{c}\text { RANGO } \\
\mathbf{2} \\
\end{array}$ & $\begin{array}{l}\text { RANGO } \\
3 \\
\end{array}$ \\
\hline \multicolumn{6}{|l|}{$\begin{array}{l}\text { ESTIMULO DE LOS } \\
\text { SENTIDOS }\end{array}$} \\
\hline & A.1. & Colores & $0 \%$ & $88 \%$ & $12 \%$ \\
\hline & A.2. & lluminación natural & $8 \%$ & $0 \%$ & $92 \%$ \\
\hline & A.2. & lluminación artificial & $8 \%$ & $31 \%$ & $62 \%$ \\
\hline & A.3. & Sonidos & $4 \%$ & $46 \%$ & $50 \%$ \\
\hline & A.4. & Olores & $4 \%$ & $92 \%$ & $4 \%$ \\
\hline & A.5. & Texturas & $8 \%$ & $92 \%$ & $0 \%$ \\
\hline \multicolumn{6}{|l|}{$\begin{array}{c}\text { OPTIMIZACION DE } \\
\text { ASPECTOS } \\
\text { FUNCIONALES }\end{array}$} \\
\hline & B.1. & Accesibilidad & $35 \%$ & $62 \%$ & $4 \%$ \\
\hline & B.2. & Orientación & $23 \%$ & $69 \%$ & $8 \%$ \\
\hline & B.3. & Proporciones & $8 \%$ & $81 \%$ & $12 \%$ \\
\hline & B.4. & $\begin{array}{l}\text { Disposición del } \\
\text { Equipamiento }\end{array}$ & $15 \%$ & $81 \%$ & $4 \%$ \\
\hline \multicolumn{6}{|l|}{ BIENESTAR } \\
\hline & C.1. & $\begin{array}{l}\text { Incorporación de la } \\
\text { naturaleza }\end{array}$ & $12 \%$ & $0 \%$ & $88 \%$ \\
\hline & C.2. & Incorporación del arte & $54 \%$ & $8 \%$ & $38 \%$ \\
\hline & C.3. & $\begin{array}{l}\text { Incorporación de la } \\
\text { música }\end{array}$ & $4 \%$ & $81 \%$ & $15 \%$ \\
\hline & C.4. & Confort & $4 \%$ & $8 \%$ & $88 \%$ \\
\hline
\end{tabular}

Se resalta en las tablas los porcentajes más altos por variable, donde se observa el gran impacto del conjunto de variables del Rango 2 y Rango 3.

A continuación se presenta por separado los Histogramas de Frecuencia de las respuestas de los pacientes a las variables, de acuerdo a cada Rango y luego uno con las variables en su conjunto.

La información recolectada nos permitirá un primer acercamiento a la valorización de las variables como condicionantes del diseño Arquitectónico. 

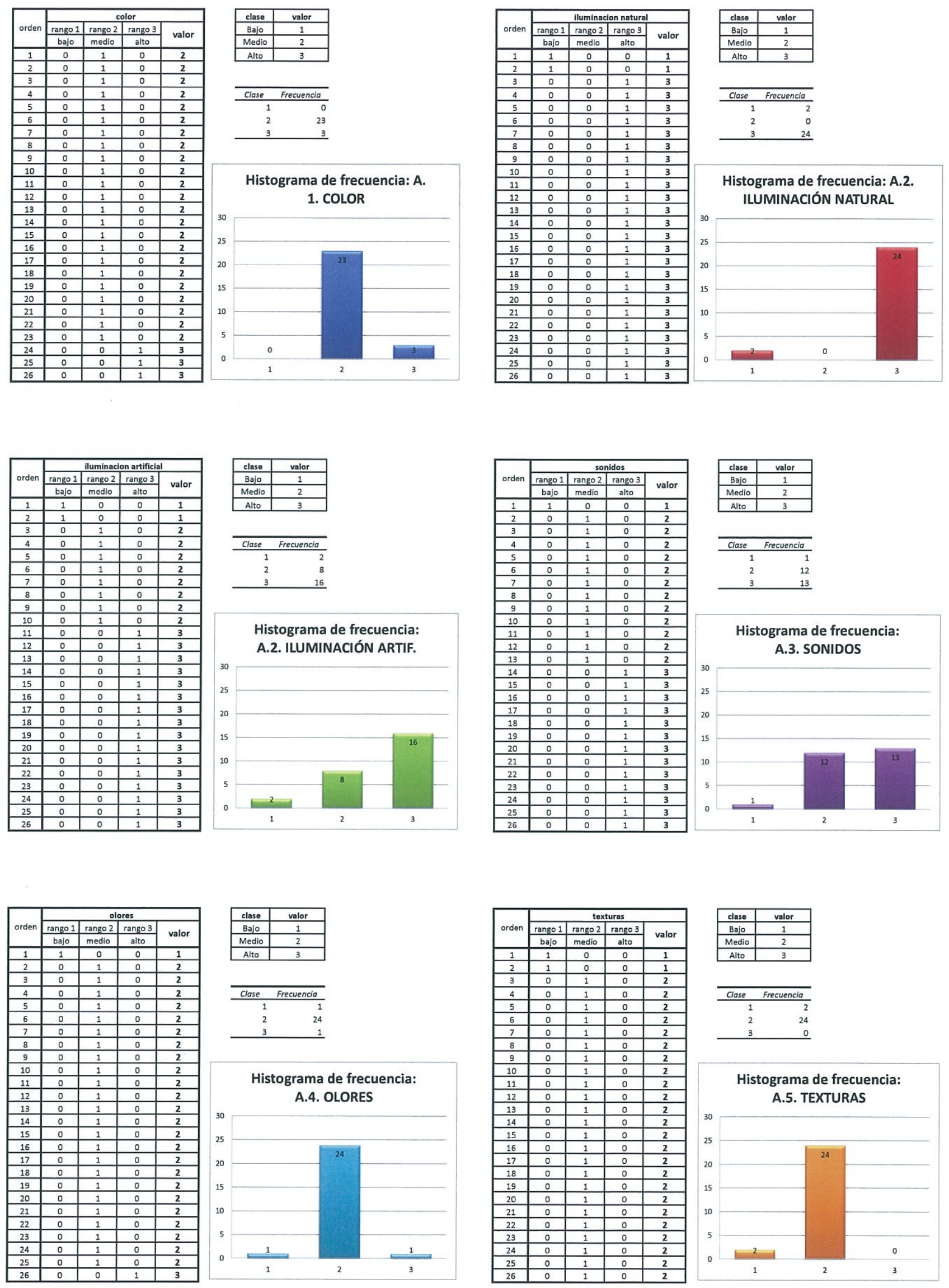

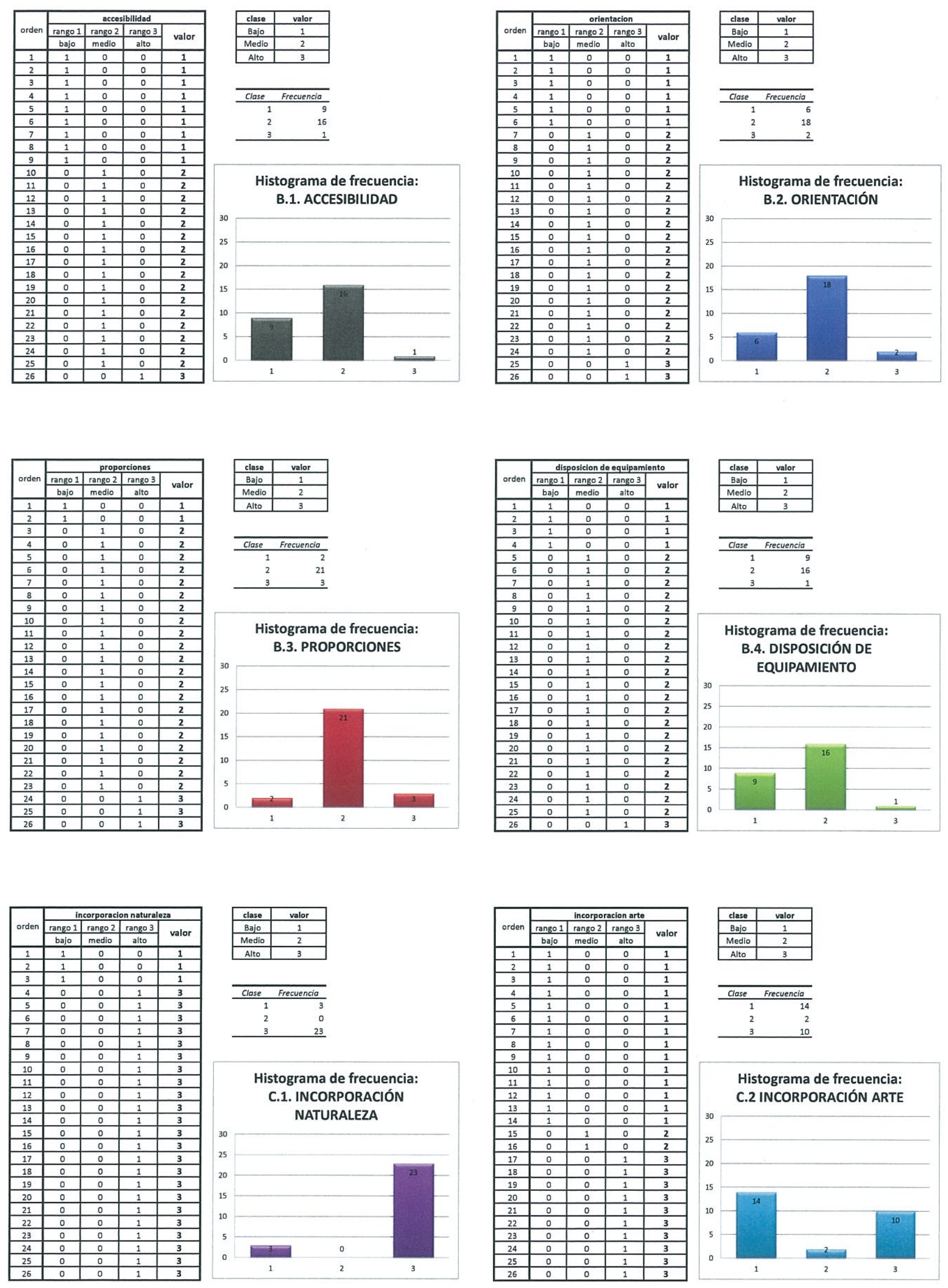

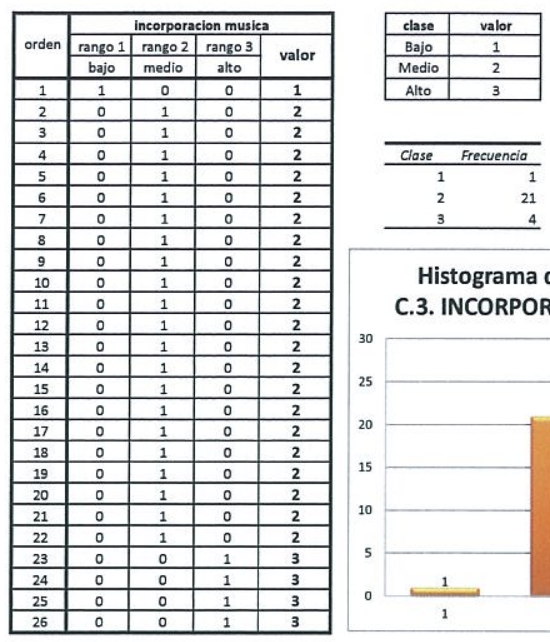

\section{Histograma de frecuencia:} C.3. INCORPORACIÓN MÚSICA
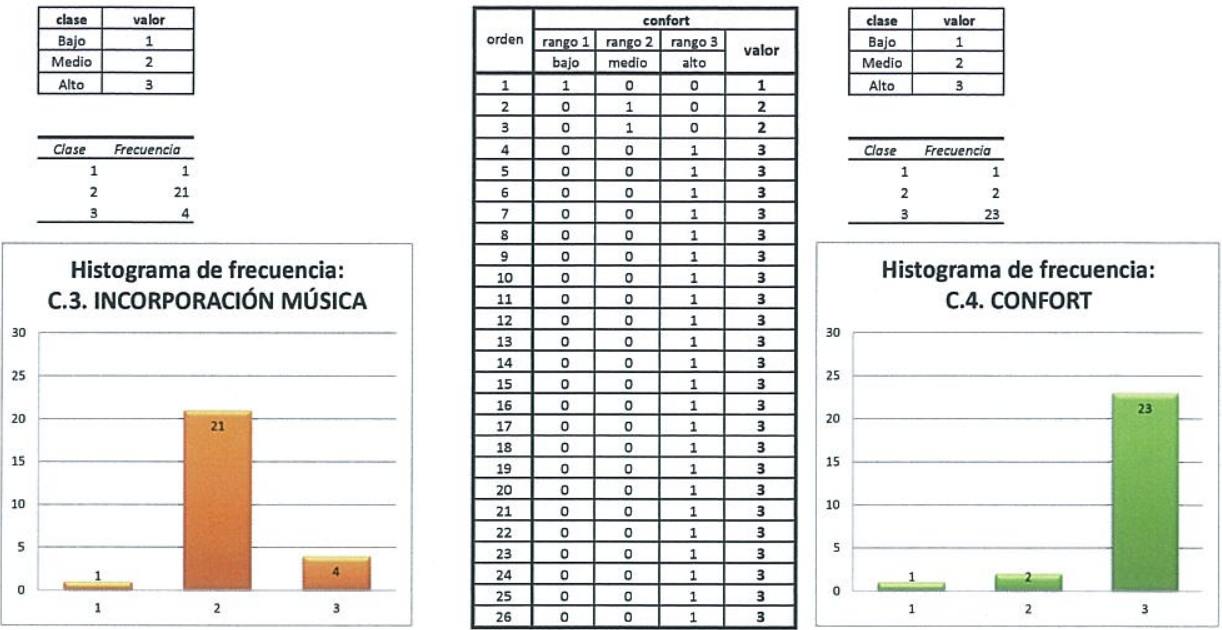


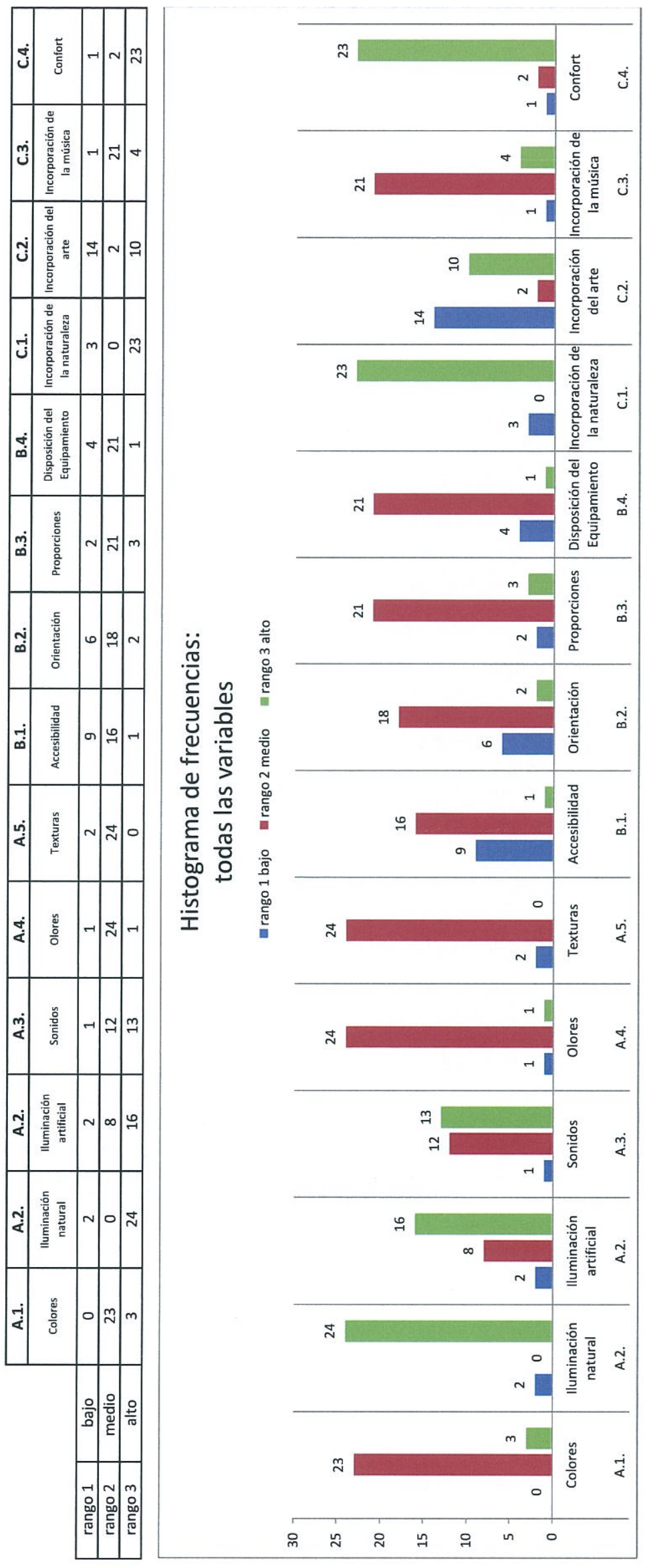




\subsubsection{Tercera Etapa Modelo Normalizado MN}

"Comunicar es poner en común - es tender puentes por lo menos entre dos sujetos, asi emerjan de un mismo individuo"

Katia Mandoki, Estética y Comunicación de acción, pasión y seducción (2006)

En la tercera Etapa de Modelo Normalizado MN se parte de las variables recreadas en el Modelo Referencial MR con los aportes de los datos obtenidos en los Modelos Observados.

Es necesario aclarar que en este trabajo de Investigación, nos referiremos a Modelo Normalizado como Modelo Normalizado MN Inicial. Se tratará la incorporación de la Norma, en todos los casos si esta existe, no existiendo Normas Especificas sobre algunas de las variables el aporte de los pacientes junto con el aporte de los Médicos Especializados en Cuidados Intensivos, se transforma en el único referente para la construcción del Modelo Normalizado MNI, sucesivas aplicaciones de las variables en diversos escenarios sentarán las bases del Modelo Normalizado Final.

\subsubsection{Variables de ambiente que estimule los sentidos}

\section{A.1. Colores}

Las Normas de Organización y Funcionamiento de Cuidados Intensivos Cardiológicos del Programa Nacional de Garantía de la Calidad Medica de la Nación PNGC Ministerio de Salud de la Nación MSN, RM 375/2002, señala en cuanto a la selección del color la utilización de colores "pastel" para la habitación.

Las Normas de Organización y Funcionamiento de Cuidados Intensivos, PNGC MSN, RM 318/2001, señalan también, "paredes pintadas con colores que no creen sensación depresiva ni sean excitantes por su brillo".

El Arq. José Luis Caivano, Director del Programa de Investigación "Color, luz y Semiótica Visual", de la Secretaría de Investigaciones, Facultad de Arquitectura, Diseño y Urbanismo, Universidad de Buenos Aire, sugiere para las habitaciones de Cuidados Intensivos usar colores fríos para las paredes y prestar mucha atención al cielorraso (que es lo que más ven los pacientes cuando están conscientes).

Agrega a estos conceptos, la sugerencia de usar en el cielorraso colores más bien cálidos pero no simplemente con un tono uniforme, liso, si no incorporando motivos o elementos que produzcan interés y ayuden a fijar la vista. Todos los colores en saturaciones bajas y luminosidades altas. 


\section{Comentarios de los pacientes, extraído del Modelo Observado $M O^{35}$}

Los pacientes en general al elegir optan por los tonos iluminados y los colores pastel. Sin embargo, llama la atención que muchos de los pacientes no han percibido el color de la habitación hasta que el Encuestador hace referencia a este, esto se puede atribuir a lo uniforme de los colores de las habitaciones.

Un paciente nos comenta "Tengo un recuerdo de celestes y techos blancos", debemos recordar que por el estado de los pacientes son muy pocas las alternativas hacia dónde dirigir la vista.

Ante la pregunta de si algún color les había llamado la atención los pacientes respondieron casi masivamente:

"No, era todo igual habia muy pocos elementos de color"

"En realidad todo es muy brillante y hay mucha luz artificial, creo que hay alguna pared color amarillo patito, pero me parece que no está dentro de la habitación aunque si dentro de la terapia y los marcos de las puertas color gris, imaginese todo muy "artificial" como una nave espacial".

"La verdad que no, pero tenga en cuenta que uno anda muy distraído ahi adentro. Uno se concentra en hacer todo bien para salir rápido, el resto no importa porque, el lugar es muy encerrado, muy solitario".

"La verdad que no aqui no resalta nada todo es uniforme".

La falta de luz natural de algunas de las habitaciones y la sobre difusión de luz artificial hace que los colores se vean brillantes y se marquen más los contrastes de luz y sombra.

Ante la pregunta especifica sobre los colores de la habitación, paredes, acolchados y cortinas, si estos eran "agradables / desagradables", "alegres / tristes", "brillantes / opacos" y "frías / cálidas". Los pacientes optaron por considerar los colores de la habitación en general como "agradables", la subvariable "alegres / tristes", no fue contestada o fue reemplazada en algunos casos por algunos pacientes por la palabra "adecuada", la sub-variable "opaco y brillante" fue seleccionada en partes similares dependiendo de la Institución en la que estaba haciéndose la consulta y la sub-variable "frías / cálidas", fríos fue la selección de la mayoria.

Es interesante observar algunas contradicciones en que incurren los entrevistados, ejemplo de esto es la sub-variable "agradables", elegida por algunos de los pacientes que se contradice con la posterior descripción que hacen los pacientes del lugar.

\section{A.2. Iluminación}

Las Normas de Organización y Funcionamiento de Cuidados Intensivos Cardiológicos, PNGC MSN RM 375/2002, aconsejan la incorporación de la iluminación natural en las habitaciones, con ventanas que permitan su apertura solo en casos excepcionales. Las Normas también nos informan en cuanto a la

${ }^{35}$ Los Comentarios de los pacientes, extraído del Modelo Observado MO, fueron extraídos en todos los casos del los conjuntos de Consolidados de las Unidades de Cuidados Intensivos y Cuidados Intensivos Cardiológicos. (Apéndice 2.) 
iluminación artificial, que las habitaciones deben tener luz central no menor a 100 lux, luz de lectura para paciente y luz articularle para procedimientos invasivos.

Las Normas de Organización y Funcionamiento de Cuidados Intensivos, PNGC MSN RM 318/2001, agregan que la iluminación adecuada consiste en:

a) Iluminación general en el techo aproximadamente $100 \mathrm{~W}$

b) Luz nocturna que permita el descanso del paciente

c) Luz de emergencia suspendida del cielorraso que ilumine la totalidad de paciente con una intensidad de aproximadamente $200-300 \mathrm{~W}$

d) Luz de gran intensidad, $150200 \mathrm{~W}$, focalizada y con algún sistema de aproximación para la realización de procedimientos específicos.

La iluminación natural estimula los sentidos y la falta de esta produce en muchos casos depresión. Dos estudios han demostrado que la exposición a luz brillante natural es igualmente eficaz en la reducción de la depresión.

El primer estudio demostró que los pacientes internados en Hospitales canadienses por depresión tenían un periodo de internación más corto si eran asignados a habitaciones soleadas respecto a aquellos que eran asignados a habitaciones sin luz natural (Beauchemin, K. M., \& Hays, P., 1996).

El segundo estudio se realizó en pacientes con problemas cardíacos, donde se observó la disminución en la mortalidad cuando estos fueron asignados en lugares iluminados frente a los internados en los lugares con orientación al norte. (se aclara que el estudio realizado en el hemisferio norte) (Beauchemin, K. M., \& Hays, P., 1998).

La premisa de la importancia de la luz natural en las habitaciones también fue corroborada en la Entrevista con el Dr. Carlos Rubianes ${ }^{36}$ Consultor de Cuidados Intensivos y Cuidados Intensivos Cardiológicos del Instituto Argentino de Diagnóstico y Tratamiento IADT.

\section{Comentarios de los pacientes, extraído del Modelo Observado MO}

\section{Luz natural}

Los pacientes se manifestaron muy positivamente cuando el Encuestador hace referencia a la luz natural, observaron la sensación de alegría que ésta les produce, se escucharon comentarios como los siguientes: "Agradable, relación con el dia, relación con el exterior". "Disminuye la sensación hospitalaria". "Es suficiente, estoy en armonia, estoy contento porque abro los ojos." "Me encanta que entre el sol. (el paciente se encontraba sentado en la cama, el sol entraba por la ventana, cuando el entrevistador entró en la habitación él estaba jugando moviendo sus pies hacia el sol)". "Me da sensación de bienestary de poder disfrutar".

${ }^{36}$ Entrevista al Dr. Carlos Rubianes en el Capitulo 4.2.2.4. Especialistas Médicos de Cuidados Intensivos. 
Los pacientes que no contaban con iluminación natural estaban muy disconformes, comentaron entre otras cosas sobre la desorientación que esto les genera, describieron esta situación con palabras como "angustia", "soledad", "encierro", "artificial". Los pacientes lucidos en estas circunstancias se quejaron de la desorientación que esto les causaba.

\section{Luz artificial}

Con respecto a la luz artificial, uno de los pacientes, que se quejó de excesiva luz artificial en la habitación hizo el siguiente comentario:

"Para la luz artificial tiene que haber dos instancias una para el médico y otra para el paciente"... "cuando viene el equipo de limpieza tiene que haber buena luz por si se ha caído una venda para poder limpiar y desinfectar todo."

Otro paciente comenta sobre la luz para el paciente: "La luz artificial estaba mal dirigida, la luz venia de atrás de la cama, no era suficiente era demasiado tenue, tenía que forzarme para poder leer, no la podia graduar, si la podia prender y apagar".

Se puede concluir que en general, la iluminación artificial específica para el paciente se encuentra en la mayoría de los casos no bien resuelta.

\section{A.3. Sonidos}

Las Normas de Organización y Funcionamiento de Cuidados Intensivos Cardiológicos, PNGC MSN RM 375/2002, consideran que es importante la ubicación del Servicio Internación dentro de la trama urbana ya que es esencial evitar que el lugar donde se encuentran internados los pacientes den a espacios de gran tránsito vehicular por la contaminación sonora que dichos espacios producen. Llama la atención que en las Normas no se hace referencia a los ruidos internos del Servicio.

Las Normas de Organización y Funcionamiento de Cuidados Intensivos, PNGC MSN RM 318/2001, mencionan en cuanto al tema de los ruidos, que las señales que provenga del llamado de pacientes y de las alarmas de los equipos deben estar reguladas a su mínima intensidad audible. El objetivo es disminuir la intensidad del ruido usualmente existente en el área de internación.

El ruido produce insomnio y fragmentación del sueño (Roger Ulrich y Quan 2004). Uno de los grandes problemas de las Unidades de Cuidados Intensivos, debido a lo lisas de las superficies y a lo poco porosos de los materiales, siempre en busca de la asepsia, es la reflexión de los sonidos.

Los umbrales de la sensación del sonido son los siguientes, sub-umbral $5 \mathrm{~dB}$, umbral $25 \mathrm{~dB}$ supra-umbral $60 \mathrm{~dB}$ y umbral máximo $120 \mathrm{~dB}$, los umbrales permiten conocer los límites de la sensibilidad del organismo. (Miguelina Guirao 1980)

Cuando el umbral es superior a los $60 \mathrm{~dB}$, se producen efectos negativos en nuestro organismo, entre estos efectos nocivos consideraremos los efectos psicopatológicos: como elevación del ritmo cardíaco, dilatación de pupilas, parpadeo acelerado, 
presión arterial y dolor de cabeza y los efectos psicológicos: insomnio, fragmentación de sueño, fatiga, estrés, irritabilidad y agresividad.

\section{Comentarios de los pacientes, extraído del Modelo Observado Mo}

En la Encuesta se consultaron a los pacientes por dos conjuntos de ruidos: los ruidos externos y por los ruidos internos (es decir aquellos producidos en la Unidad).

Algunas de las habitaciones fueron descriptas como poco ruidosas y otras como muy ruidosas, dependiendo del Establecimiento y la ubicación de la habitación, sin embargo la mayoría de los ruidos, descriptos por los pacientes como muy molestos, provenían de la misma Unidad.

"Todo el sistema de la UCO es ruidoso, es un sistema único, quiero decir que todos los ambientes están unidos aunque las visuales están separadas, pero en realidad esta todo abierto, se filtran las voces, se suman".

"Yo estaba solo pero hay dos tipos de ruido, están lo de fondo los que realmente molestan. Es decir uno se va acostumbrando a ellos y uno los siente cuando se paran; las torres de enfriamiento (un sonido lejano), de pronto no sentia el ventilador del Aire Acondicionado, sumados al propio ruido de las rejillas de ventilación que soplan y mandan aire".

"Muy ruidosa, sobre todo durante la noche, se habla como si no hubiera nadie, se escucha sobre todo sonidos desagradables de dolor, aunque quiero aclara que mi caso era especial ya que estaba en una habitación privada no compartida, sin embargo sentía los ruidos a mi alrededor".

Cuando se les pidió que especificaran estos ruidos un paciente nos comentó:

"Los ruidos eran del interior. Las enfermeras dejaban la puerta abierta y escuchaba los respiradores de los pacientes, estaba al lado del centro de enfermería con los pacientes más críticos, el ruido de las corridas junto con los respiradores era tremendo".

"Primero, la higiene trae que las superficies son lisas, son reflejantes, entonces hay reverberaciones que multiplican los sonidos presentes. Un gran contaminador de sonidos es el aire acondicionado. En general una persona que está alli, es incapaz de sentir el fragor de la situación que lo rodea, pero es un lugar de muchos sobresaltos, de mucha crisis, entonces eso, aunque el personal trate de que no se altere la calma del resto de los pacientes, igual percibis todo eso".

Con respecto a la pregunta sobre si demasiado silencio podría dar sensación de aislación una paciente fue más allá de la pregunta y nos respondió "No, el aislamiento me lo daba si llamaba a la enfermera y no atendia, yo dependía completamente de un tercero".

\section{A.4. Olores}

\section{Comentarios de los pacientes, extraído del Modelo Observado MO}

Gran parte de la población no percibió ningún aroma. Cuando se les planteó la posibilidad de elegir, optaron por las fragancias de la naturaleza que los conectaban con lugares con recuerdos felices, algunos de la infancia, aroma a pino, vainilla, limón o aroma a galletita.

"No he percibido ningún olor feo, me afectan mucho los olores en este caso no he percibido ningún olor". 
Si pudiera elegir: "se me ocurre ahora algo como avainillado algo dulce, sin ser empalagoso un olor de la infancia".

"Hoy estuve hablando con la mujer que limpia acá el piso, porque es riquísimo lo que ponen, y es un aroma a pino de una conocida marca, que es desinfectante. Habria que buscarlo".

"Algo verde, gramilla, olor de cuando se corta el pasto".

\section{A.5. Texturas}

Las Normas de Organización y Funcionamiento de Cuidados Intensivos Cardiológicos, PNGC MSN RM 375/2002, nos informa que la habitación deberá contar con paredes lavables de material ignifugo con pisos de superficie perfectamente lavable, antideslizante y con zócalo sanitario.

Las Normas de Organización y Funcionamiento de Cuidados Intensivos, PNGC MSN RM 318/2001, observan que paredes y cobertores de piso de la habitación deben contar con la capacidad de absorber ruidos.

En cuanto a las sabanas deberán ser de tipo Standard de entre 120 y 180 hilos, $100 \%$ Algodón, color Blancas y Planas (sin elástico, porque el cloro utilizado al lavarlas los deteriora), este algodón seleccionado tiene una resistencia especial a los productos antisépticos con que son tratadas las sabanas y a las altas temperaturas que deben resistir en el proceso de lavado y planchado.

\section{Comentarios de los pacientes, extraído del Modelo Observado MO}

No hubo comentarios especiales a esta variable referida a la elección de materiales y texturas de la habitación. Sin embargo cuando se le dio para elegir un material que les fuera de su agrado, nuevamente la elección recayó en materiales naturales como la madera.

Los pacientes coincidieron en general, respecto a esta variable, consideraron los materiales existentes como adecuados para uso, sin más connotaciones.

"Si, pero es que tenian que entrar equipos, me sacaban radiografias, me sacaban encefalogramas, todos esos aparatos entraban en el cuarto, de manera tal de que los pisos son semiduros para que las ruedas no hagan ruido".

Respecto a los pisos de la habitación muchos de los pacientes no se habían podido mover de la cama, por lo tanto desconocian el contacto con el material. Con respecto a las sabanas, fueron consideradas por la mayoría como agradables al tacto. 


\subsubsection{Variables de optimización de los aspectos funcionales}

\section{B.1. Accesibilidad}

Las Normas de Organización y Funcionamiento de Cuidados Intensivos Cardiológicos, PNGC MSN RM 375/2002, mencionan la conveniencia de la presencia de baños en la habitación, el cual deberá contar con llamador para enfermería y posibilidad de monitoreo del paciente.

Debido a la movilidad reducida de los pacientes, sin embargo, el baño dentro de la habitación es considerado un elemento necesario. Los baños generales públicos se consideran incómodos y poco accesibles.

\section{Comentarios de los pacientes, extraido del Modelo Observado MO}

En general los pacientes no se podían mover libremente en la habitación, pero esto pasaba, como mucho de ellos aclararon, debido a su estado de salud más que a un impedimento de tipo arquitectónico.

Estas observaciones a las características de los baños estaban dirigidas a la temperatura del ambiente y a la distribución del equipamiento y accesorios. Un paciente que tuvo una larga estadia y que tuvo muchas dificultades de movilidad nos comentó: "Dificil, dificil todo, es muy incómodo ir con el suero al baño, por un tema de altura era incomodo hasta para sentarme. No tenía una manija para uno sostenerse fácil, habia como un montón de detalles pero estaban mal ubicados. Por ejemplo ducharse habia que ducharse sentado en el inodoro, no habia ninguna silla especifica para esta función, tampoco hubiera cabido de todos modos. El papel higiénico siempre terminaba mojado, las toallas estaban mal ubicadas, en fin una cantidad de pequeñas cosas, siempre que me movía tocaba con los codos algún lado".

\section{B.2. Orientación}

Las Normas de Organización y Funcionamiento de Cuidados Intensivos Cardiológicos, PNGC MSN RM 375/2002, hace referencia a la incorporación de luz natural.

Las Normas de Organización y Funcionamiento de Cuidados Intensivos, del Programa Nacional de Garantía de la Calidad Medica de la Nación RM 318/2001, hacen referencia, a la incorporación de ventanas con la posibilidad de contar con luz natural para favorecer la orientación témporo espacial al paciente, agregan a su vez, en este sentido también es recomendable el uso de un reloj con almanaque.

La premisa de la importancia de la luz natural en las habitaciones para la orientación del paciente también fue corroborada en la Entrevista con el Dr. Carlos Rubianes.

\section{Comentarios de los pacientes, extraído del Modelo Observado MO}

Esta variable fue un tanto confusa para los entrevistados, algunos no tenían mucha conciencia de donde exactamente se hallaban. Hay que recordar que debido a su estado, tal vez por efecto de 
Facultad de Arquitectura y Urbanismo, Universidad Nacional de la Plata

medicamentos o por efectos posteriores de la anestesia, algunos pacientes tenían una idea confusa de donde se encuentran.

La mayoria de los paciente asume que fue fácil el acceso de sus familiares sin tener una clara idea de cómo fue que ellos llegaron hasta la Unidad. Otros pacientes más conscientes comparan el lugar con un gran laberinto, donde la gente que encuentra en el recorrido los ayuda a llegar a destino: "Es dificil llegar aquí, ahora mi esposa sabe cómo llegar pero es como un laberinto". "Una vez que se toma el hábito se sabe cómo llegar". "La gente es muy amable y a uno lo van guiando porque los carteles no los vi". "Hay que ir preguntando por todos lados, eso dicen mis familiares, muchos recovecos". Se asume muchas veces que el personal debe informar y dar instrucciones para acceder a los Servicios.

El problema de orientación de los familiares lo ejemplifica un paciente que nos comenta: "Para mi esposa fue muy fácil venir detrás del camillero que me trajo de la guardia pero pobrecita cuando se fue, no tenía la menor idea de dónde estaba. Después con el transcurso de los días se puso práctica y hasta ahora se ofrece a ir a buscar resultados al laboratorio o a acompañar a algún otro familiar pero la verdad es que la señalética es escasa".

\section{B.3. Proporciones}

Las Normas de Organización y Funcionamiento de Cuidados Intensivos Cardiológicos, PNGC MSN RM 375/2002, nos informan que cada habitación o box debe tener una superficie mínima de $9 \mathrm{~m} 2$, la puerta de acceso deberá ser lo suficiente ancha para que entre la con facilidad la cama del paciente y los equipos necesarios.

La Unidad de Cuidados Intensivos Cardiológicos deberá contar con una superficie total dada para la formula $N^{0}$ de camas $\times 9 \times 2$. Siendo el $50 \%$ de la superficie resultante destinado a las áreas de apoyo y otro $50 \%$ para las áreas de atención.

\section{Comentarios de los pacientes, extraido del Modelo Observado MO}

En general los pacientes estaban conformes con las dimensiones de la habitación. Respecto al tema de compartir o no la habitación, lo mismo que había ocurrido con los pacientes internados en Internación General en esta variable las apreciaciones son distintas respecto a los pacientes Encuestados del Subsector Público y del Privado. En el Subsector Publico esta idea fue más allá de la idea de consentimiento expresada por los pacientes de Atención de Internación General, estos pacientes observaron que sería muy agradable contar con un compañero para compartir la habitación. En el Subsector Privado la misma idea tuvo el efecto absolutamente contrario y los pacientes se manifestaron en contra de compartir la habitación con un extraño.

"Es el adecuado". "Es muy cómoda". "Me senti a gusto". "Si para mi es excesivo pero hay que entender que aqui hay muchos profesionales y tienen que moverse". "Si me siento cómodo faltan muebles estaria más lindo con un sillón alli". (el paciente señala el sector cerca de la ventana que da al patio exterior).

\section{B.4. Disposición del equipamiento}

Las Normas de Organización y Funcionamiento de Cuidados Intensivos Cardiológicos, PNGC MSN RM 375/2002, nos informan en cuanto al equipamiento necesario pero no hacen mención de una configuración especial para el mismo. 
Facultad de Arquitectura y Urbanismo, Universidad Nacional de la Plata

También comenta que en el mercado existe una amplia oferta sobre distintos grados de equipamiento, complejidad tecnológica, aplicabilidad informática, etc., que implican, naturalmente, distintos presupuestos económicos.

\section{Listado de Equipamiento Normas PNGC MSN RM 375/2002:}

El material que a continuación se detalla se debe considerar como mínimo e indispensable para el funcionamiento de una UCIC.

- Camas móviles, articuladas, con cabecera fácilmente rebatible, barandas articulables y desmontables, con lecho rigido que permita las maniobras de reanimación, se sugiere que el $20 \%$ de las camas de la Unidad tengan lecho radiosensible para los pacientes de mayor complejidad.

- Monitor de ECG en la cabecera del paciente (1 por cama).

- Estación central con control visual y registrador en papel del ECG de cada paciente. Debe disponer de sistemas de activación y detección de alarmas prefijadas en el monitor de cabecera. Se sugiere la conveniencia de sistemas de almacenado en memoria magnética del registro del ECG de al menos 48 hs de duración, $y$ de ser posible que se puedan imprimir.

- Desfibriladores sincronizables. Uno cada 4 camas y no menos de 2 en la Unidad. Se sugiere que al menos uno de ellos disponga de sistema de marcapasos externo mediante estimulación transtorácica.(opcional).

- Generadores de marcapasos temporales para atender las necesidades de electroestimulación mono y bicameral. Uno por cada 4 camas o fracción y no menos de 2 en la Unidad. Para cada equipo deben tenerse como mínimo dos catéteres electrodo.

- Carro de emergencia: con equipo para intubación endotraqueal completo, laringoscopio con 3 ramas, bolsa resucitadora tipo Ambú- (bolsa-válvula-máscara) con reservorio y tubuladuras adecuadas y sus adaptadores. Catéteres para drenaje torácico. Equipos completos para punción raquídea, torácica y abdominal para lavado peritoneal diagnóstico. Sondas nasogástricas y vesicales en cantidad suficiente. Tubos endotraqueales de distintos tamaños, Tubos de Mayo y pinzas de Magill. Tubuladuras para infusión de soluciones diversas y para aspiración de secreciones, Catéteres electrodo para marcapaso transitorio. Drogas según normas de la American Heart Association para tratamiento de la detención circulatoria.

- Bombas de infusión (dos por cada cama como minimo).

- Aparato de ECG en la Unidad (2 aparatos como mínimo).

- Respirador mecánico a presión positiva volumétrico (uno por cada 3 camas):

Debe permitir llevar a cabo las técnicas de ventilación convencional: Ventilación controlada por volumen (VCV), Ventilación asistida (VA), Ventilación mandatoria intermitente (IMV), Presión espiratoria de fin de espiración (PEEP). El $50 \%$ de los respiradores deben ser microprocesados con capacidad para llevar a cabo ventilación mecánica no convencional: ventilación controlada por presión, presión de soporte, inversión de la relación l:E

- Módulos de monitorización hemodinámica para, al menos dos camas, pueden ser incorporados al monitor o independientes de los mismos.

- Oximetro de pulso (uno cada 2 camas).

- Capnógrafo (uno por cada respirador microprocesado)

- Equipo de pericardiocentesis.

- Equipo portátil de rayos exclusivo para la Unidad.

- Ecocardiógrafo portátil preferentemente con Doppler, fácilmente transladable a la Unidad, puede ser compartido con el Servicio de cardiologia.

- Otro tipo de equipos, como el balón de contrapulsación o el soporte mecánico ventricular, podrán ser compartidos con el laboratorio de hemodinámica o el servicio de cirugía cardiaca.

- Es fundamental disponer de un adecuado servicio de mantenimiento que garantice el normal funcionamiento de los equipos con registros de los controles realizados. 
Facultad de Arquitectura y Urbanismo, Universidad Nacional de la Plata

\section{Comentarios de los pacientes, extraído del Modelo Observado MO}

Todos los pacientes consideraron que el equipo médico se movía cómodamente en la habitación, que el espacio era el suficiente, esto habla de que las dimensiones eran adecuadas para las tareas que se realizaban.

La disposición del equipamiento fue descrita como correcta por la generalidad de los pacientes, salvo pocas excepciones todos lo consideraron que el equipamiento era el apropiado.

Es en este tipo de variable es donde se observan las mayores diferencias entre los pacientes que están en una corta estadía de aquellos que deben guardar largos periodos de internación, como lo observó el paciente entrevistado, cuando menores son las restricciones de movimientos y mayor la discapacidad, es donde más se observa la falta o carencia de un buen diseño.

Un paciente relata lo siguiente "el único mueble era la cama un par de sillas, la mesa que se acercaba a la cama, si yo veía la entrada, (la cama) está bien ubicada. Era para mí importante ver la entrada, quienes venian a verme".

Otro paciente observó lo siguiente: "En el momento me estoy acordando de dos lugares diferentes, yo estuve internado en Swiss Medical (10 dias) y Los Arcos (3 dias), (...) sin embargo en Los Arcos (el equipamiento) tenía mucho mejor diseño".

"Los muebles son de tipo hospitalario y me parece bien que asi sea, por materiales y por diseño, pero fue alli donde me di cuenta que habia distintos diseños hospitalarios, muy muy diferentes, habia por ejemplo camas muy cómodas por un lado, y otras muy lindas de diseño pero muy incomodas, sobre todo para estar tantos dias".

"Lo mismo que la mesa auxiliar al costado de la cama, esa era de muy mal diseño, cuando uno menos se puede mover es cuando más percibe que es lo que no está bien diseñado. Las ruedas por ejemplo no las podia mover, se enganchaban hacia un lado si y hacia otro no, detalles como por ejemplo contar con un espejo de tocador que se movía solo en un ángulo de 90 grados!, era imposible en ese ángulo poder mirarse sentado en una cama., debia incorporarme haciendo un gran esfuerzo, yo me afeitaba en seco todos los días y era casi imposible afeitarme sin verme en un espejo. Era muy frustrante pensar que con solo unos centímetros más me podrian haber cambiado completamente el nivel de confort."

En cuanto a la ubicación de la cama en la habitación, la mayoria considero que el lugar era el adecuado, uno de los pacientes comenta respecto a sus preferencias respecto la ubicación de la cama: "Si, siempre que haya luz natural, si no tuviera la luz me gustaria que mirara afuera para matizar un poco. La cama esta perfecta en su lugar porque tiene que mirar hacia la cámara (la paciente señala la cámara que esta fija observándola enfrente de su cama)". Casi todos desean la cama en el centro de la habitación pero uno de los pacientes agrega: "En el centro de la habitación, mirando la puerta de entrada y pudiendo ver hacia afuera por una ventana".

Cabe destacar que los pacientes que no contaban con luz natural cuando se les dio la opción de elegir la gran mayoría opto por un lugar cerca de una ventana, como muy bien lo reflejan los siguientes comentarios de los pacientes: "Ya le dije Dra. Planifique con ventanas, ventanas, ventanas mire aquí en Clínica qué placer ver esos árboles, la lluvia, el sol, uno decididamente sigue estando enfermo pero vivol". "Al lado de la ventana, pero una que dé al exterior". "Me encantaría tener una ventana por donde entre luz natural, hasta los que están en coma podrían percibir la luz y un poco de aire pero no se si está permitido". "Me encantaria tener una ventana por donde entre luz natural y ver el sol". "Sería genial tener una ventana por donde entre luz natural, además seria más cálido". 
Respecto a tener un lugar específico para los familiares en la habitación, los pacientes tuvieron opiniones encontradas, mientras algunos consideraron que una silla o dos era suficientes, otros que no contaban ni siquiera con ese mobiliario declararon a favor de un lugar aunque pequeño para recibir a sus familiares.

Entre los que se encontraba a favor de un lugar, aunque pequeño para recibir a sus familiares: "Parece oportuno, (el lugar con que se cuenta) cumple con la necesidad". "El espacio que hay es cómodo y suficiente, más seria como desperdiciar lugar". "Lo que se pretende es que haya pocas personas poco tiempo". "Me parece fantástico, uno está solo y está deseando que le cuenten sobre el exterior". "Me parece muy clave, porque uno está en Terapia Intensiva y la parte de la visita a uno le resulta muy importante. Si habia dos personas tenian que estar parados, era una situación muy incómoda no era una situación de confort".

\subsubsection{Variables de Bienestar}

En la Entrevista el Dr. Carlos Rubianes resaltó sobre la importancia del conjunto de variables Bienestar, el contacto con la naturaleza, el contar con elementos de confort y distracción para el paciente.

\section{C.1. Incorporación de la Naturaleza}

Se reconoce para esta variable el aporte del trabajo de investigación llevado a cabo por el Dr. Roger Ulrich View through a window may influence recovery from surgery..(Ulrich Roger 1984) en este trabajo observa la relación entre la recuperación del paciente de cirugía y el acceso a vistas a través de una ventana.

Por otro lado, se considera el trabajo de Clare Cooper Marcus en su libro Healing Gardens: the Therapeutic Benefits and Design Recomendetions, (1999) y el articulo en común con el Dr. Roger Ulrich sobre el efecto de los jardines en los resultados médicos, Effects of gardens on health outcomes: Theory and research. (C. Cooper Marcus \& M.2002).

\section{Comentarios de los pacientes, extraído del Modelo Observado MO}

En esta variable se observa la contundente diferencia en las preguntas de aquellos pacientes que cuentan solo con luz artificial de aquellos que cuenta con acceso a iluminación natural y vistas al exterior.

Con respecto a la pregunta sobre la consecuencia y la sensación que esta falta de contacto con el exterior les provocaba, los pacientes se refirieron a esta carencia con expresiones como "tristeza", "aburrimiento", "frio", "ahogo", "falta de vida".

Se observó que esta variable, era mucho más abarcativa de lo que se pensaba inicialmente, ya que la incorporación de la naturaleza no terminaba en la habitación sino que incorporaba otros espacios como patios, balcones, terrazas, jardines y plazas, consideradas como exterior de la habitación, y accesibles como vistas para el paciente a través de las ventanas.

Los pacientes fueron unánimes cuando se les planteó la pregunta sobre la sensación que produce el contacto con la naturaleza, las respuestas fueron afirmativas hacia lo colaborativo y placentero que es 
Facultad de Arquitectura y Urbanismo, Universidad Nacional de la Plata

este contacto, expresándose de la siguiente manera: "Muy estimulante, muy agradable. Yo creo que para el paciente es muy estimulante". "Es lindo, deberiamos todos tener más contacto con la naturaleza los llevaría a estar más relajados y en calma". "Me agrada el contacto con la naturaleza, me gusta especialmente el mar por la mañana". "Y... lo curan a uno más rápido". "Es muy necesario, tanto como el afecto de la familia". "Es reparador".

Con respecto a la pregunta de otras áreas exteriores al Establecimiento para acceso de familiares y visitantes, un paciente comenta sobre su Hospital, "Yo conozco el Hospital (Durand) y cada vez van usando más jardín para seguir construyendo. (...) Yo naci en este Hospital mi querida Dra. Y creo que aquí moriré, yo lo adoro por pertenencia pero la verdad es que lo fueron convirtiendo en un mix de estilos según la politica del momento. Este Hospital tenia el parque más bello del barrio, fijese aún quedan tres palmeras pero nunca nadie hizo un Servicio de Internación con vistas al jardín siempre al estacionamiento, no lo entiendo. Cuando era viejo era todo luz y aire natural".

Es importante destacar la sensación de pertenencia que tienen muchos de los pacientes con su Hospital, esto va más allá de la idea que en un pasado se edificaban los edificios de otra forma, siguiendo otros principios.

\section{C.2. Incorporación del Arte}

Entre los trabajos del Dr. Roger Ulrich y la relación de la salud - arte, se destaca uno que relaciona las imágenes de cuadros con imagines de naturaleza o abstractos y sus efectos en los pacientes que se recuperan de intervenciones cardiacas, Effects of exposure to nature and abstract pictures on patients recovering from heart surgery. (Ulrich Roger 1991), en otro de sus trabajos estudia el impacto del arte en la salud, el arte saludable Healing arts: Nutrition for the soul (Ulrich Roger 2003).

Concurrente con la temática de la estimulación sensorial, la Dra. Arq. Ruzica Bozovic - Stamenovic, Profesora del Department of Architecture, la Universidad Nacional de Singapur, se encuentra trabajando las, "Guidelines for sensory stimulation design in healthcare". (Bozovic-Stamenovic, R, 2004).

\section{Comentarios de los pacientes, extraído del Modelo Observado MO}

Esta pregunta sorprendió, la idea de tener cuadros o algún objeto de arte desconcertó a los pacientes.

Por tratarse de Cuidados Intensivos las habitaciones de Cuidados Intensivos no cuentan con cuadros, salvo excepciones.

"Si. Seria muy agradable contar con esas imágenes en la habitación. Este lo tengo a la vista, ahora estoy en la internación intermedia (el paciente señala el cuadro frente a él), en la Unidad Coronaria no había cuadros, parece lógico que no haya cuadros, porque siempre estamos hablando de que en estas Unidades tiene que haber por sobre todo higiene".

La incorporación de imágenes religiosas también es importante para algunos pacientes que se sienten reconfortados en su contemplación, una paciente comenta: "Hay un Cristo, me impone un efecto de protección, puedo rezar, me da calma", otra paciente enfatiza, "(En la habitación) no habia cuadros, ni una Cruz!". 
Me interesaría comentar el caso de uno de los pacientes en particular, en su habitación había un cuadro, pero este estaba colocado como un objeto de simple decoración, sin considerar su observación por parte del paciente,: (El cuadro) "No estaba en el lugar en donde yo pudiera contemplarlo, es decir no estaba en frente mío, el cuadro estaba a un costado, es decir que yo tenía que darme vuelta muy forzadamente para mirarlo, cosa que a mi me gusta, mirar los cuadros".

Consultados por el tipo de imágenes los pacientes se volcaron masivamente a la selección de imágenes que respondieran a paisajes y plantas.

\section{C.3. Incorporación de la Música}

Se destacan los trabajos de Prof. Paul Robertson sus trabajos lo han vinculado con la Neurociencia y la Neuropsiquiatría, junto con el Dr. Peter Fenwick ha desarrollado un nuevo concepto de como la música y el cerebro en su funcionamiento se correlacionan y sintetizan.

\section{Comentarios de los pacientes, extraido del Modelo Observado Mo}

Los pacientes se mostraron atraídos con la idea de contar con música en la habitación, aunque del mismo modo que los pacientes internados en Internación General, hicieron la aclaración de que de existir este tipo de música, desearian controlarla con autonomía.

Acerca de la relación entre la música y los estados de ánimo, los pacientes comentaron que la música sería una compañia, que les ayudaria a pasar el tiempo y les brindaría distracción.

En cuanto a la selección del tipo de música que desearian escuchar, la mayoria prefirió música clásica o melódica suave no cantada, otro grupo prefirió la radio con información y noticias, como una forma de estar más en contacto con el exterior.

\section{C.4. Confort}

Las Normas de Organización y Funcionamiento de Cuidados Intensivos, PNGC MSN RM 318/2001 con respecto al Aire Acondicionado, menciona que la Unidad debe mantener la temperatura de $25^{\circ}-26^{\circ}$ centígrados y los niveles de humedad entre 30 $60 \%$ para prevenir accidentes eléctricos derivados de un ambiente extremadamente seco. Agrega también, que es deseable el recambio de aire 4 veces por hora en las habitaciones y 2 recambios en el resto de la Unidad.

Se destaca el trabajo de Investigación del Dr. Roger Ulrich en cuanto a la relación ente la televisión, la presión cardiaca y el estrés "Effects of environmental simulations and television on blood donor stress." (Ulich Roger 2003).

\section{Comentarios de los pacientes, extraído del Modelo Observado MO}

Los pacientes en general consideraron que la habitación en su conjunto era confortable.

"Como estuve en dos establecimientos diferentes pudo decir que hay camas que son más cómodas que otras Pueden ser modernas pero están las que uno se resbala hacia la piesera de la cama, es como que uno se desliza y queda siempre mal ubicado. Hay otras camas donde uno se siente bien agarrado como sostenido, sin deslizarse y terminar con las piernas encogidas, (esto es importante) sobre todo cuando uno está intubado y no puede sostenerse. 
Facultad de Arquitectura y Urbanismo, Universidad Nacional de la Plata

La cama también fue considerada como confortable, salvo los que no podían controlar sus posiciones.

Las quejas recayeron en particular sobre el hecho de no poder controlar las posiciones: "Si controlaba las posiciones de la cama, era fantástico, eso de estar pidiendo que lo suban y lo bajen no es de mi agrado".

Algunos establecimientos privados contaban con TV o circuito cerrado de TV. Ejemplos de esto los encontramos en El Instituto Argentino de Diagnóstico y Tratamiento IADT, la Suizo Argentina, Swiss Medical y Los Arcos.

Pero de la misma manera que la ubicación de los cuadros la ubicación de un televisor y la selección de los canales es un tema para tener en cuenta: "En otra institución tenia plasma pero no veia bien, hasta que finalmente descubrimos que el plasma si no está bien orientado, uno no ve, o ve mal, y no habia forma de moverlo". Otra paciente comenta: "Si (habia televisión), pero malísima, solo podía ver dos canales".

Con respeto al teléfono la mayoría de los pacientes estaba "conectado" con el exterior a través del teléfono celular. De todos modos la mayoría de los pacientes declaro sentirse "aislado", y en algunos casos "sin voz y sin voto".

La familia debe ser considerada como fuente de apoyo y conexión con el exterior, de allí la importancia de las visitas de los familiares.

La ubicación de lugares como Cafeterías, expendedor de bebidas o comestibles, están resuelto de diferente manera en los diferentes Establecimientos, algunos cuentan en sus instalaciones con Cafeterías, Bares o Restaurantes otros con Comedores de Cooperadora.

Una de las últimas preguntas a los pacientes se refería a si deseaban agregar algo que no se hubiera comentado. Los pacientes fueron siempre muy receptivos al cuestionario a lo largo de las entrevistas, lograr esta empatia Encuestador - Encuestado, fue una de las mayores fortalezas de este trabajo de Investigación. 

Capítulo 5.

Elaboración de la Propuesta y Contrastación de la Tesis 



\section{Capítulo 5}

\section{Elaboración de la Propuesta y Contrastación de la Tesis}

\subsection{Cuarta Etapa Modelo Propuesto MP}

\section{En una cuarta Etapa se realizara la Calificación de Variables Ambientales, y su comportamiento como Condicionantes del diseño Arquitectónico}

A continuación y con el mismo ordenamiento del Modelo Normalizado MN, se presenta una propuesta para cada una de las variables ambientales junto con una estructura de calificación, donde se considera un valor alto-fundamental, medio-de interés y bajo-de menor interés, acorde su efecto como condicionante del diseño Arquitectónico, dicho resultado surge de la valorización las Normas del PNGC MNS RM 318/2001 y RM 375/200, el estudio de los resultados de la Entrevistas a Pacientes, basada en los tres tipos de Rangos ${ }^{1}$ y el aporte de Médicos Especializados en Cuidados Intensivos.

Junto con el texto en cada variable se incorporan algunas imágenes ${ }^{2}$ de diferentes Establecimientos visitados por mí en estos últimos catorce años, corresponden a visitas de estudio realizadas con motivo de participar o presentar una ponencia en el Grupo de Salud Pública de la Unión Internacional de Arquitectos UIA PHG o en la Academia Internacional de Diseño \& Salud.

\subsubsection{Variables de ambiente que estimule los sentidos}

\section{A.1. Colores}

Las Normas de Organización y Funcionamiento de Cuidados Intensivos PNGC MSN RM 318/2001 e Intensivos Cardiológicos, PNGC MSN RM 375/2002 hacen referencia a ciertos colores. (Anexo 1).

Rangos de las respuestas de los Pacientes extraídos del Modelo Observado MO (Página 64).

\begin{tabular}{|c|c|c|c|c|c|}
\hline & & & Rango & Rango & Rango \\
ESTIMULO DE LOS SENTIDOS & & & 1 & 2 & 3 \\
\hline & A.1. & Colores & 0 & 23 & 3 \\
\hline
\end{tabular}

\footnotetext{
${ }^{1}$ Rango 1, en este grupo el Paciente se mostró indiferente o respondió no haber puesto atención a estos aspectos a los que hace alusión el Entrevistador, dentro de este rango de respuesta se incluyen Pacientes que dicen no recordar o no contestar.

Rango 2, en este grupo el Paciente, mostró cierto interés con la variable y comunicó una preferencia especifica.

Rango 3 en este grupo el Paciente mostro mayor interés y se expresó más allá de lo solicitado por el Encuestador, en este rango se consideran también las respuestas que aluden a emociones, sensaciones, y estados de ánimo que pudieron afectar de un modo o de otro al paciente.

${ }^{2}$ La mayoria de las fotos fueron tomas por mí salvo algunas excepciones, de todos modos cada una de ellas cuenta con su nombre, autoria y fecha en que fue tomada.
} 
Pareciera que en algunos pacientes internados en Cuidados Intensivos el color de la habitación es la continuación del estado anímico de los pacientes. El color es un elemento comunicacional, tradicionalmente al color rojo se lo relaciona con lo estimulante, el amarillo y anaranjado son considerados colores vitales, alegres e igualmente estimulantes, el verde calmante, el azul y violeta, sedante, atemperante.

En este marco, la propuesta es de un color celeste (color frio de saturación baja y luminosidad alta) con la incorporación de algún color o textura de contraste para evitar la uniformidad. Es también importante estudiar la composición del cielorraso, en esta propuesta se seleccionará una paleta de colores cálidos para el cielorraso suspendido.

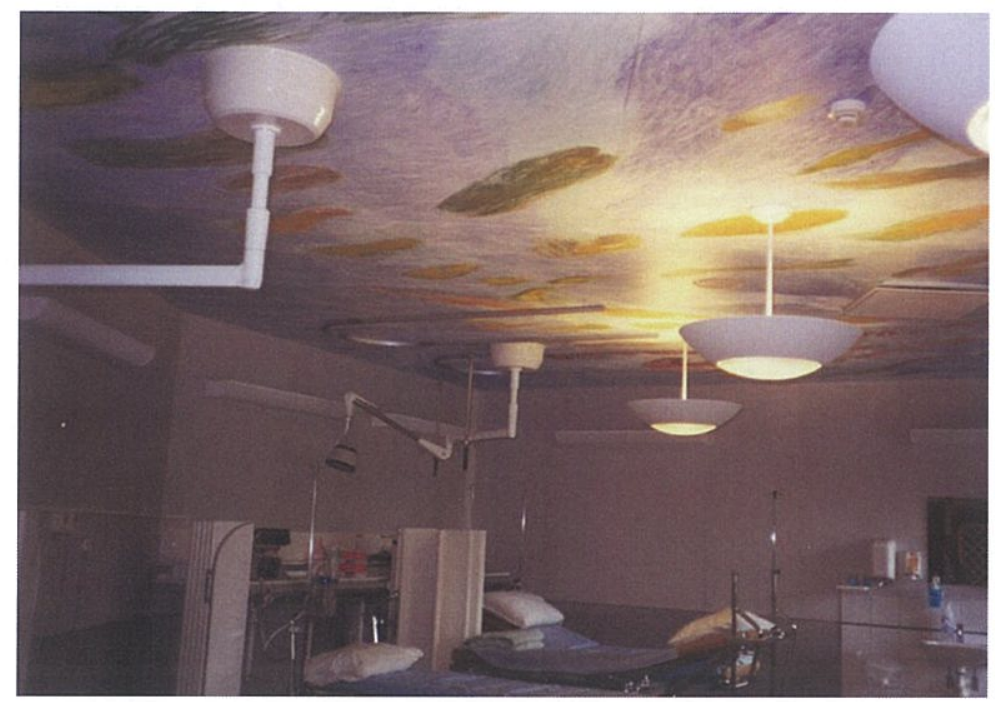

Detalle de cielorraso con diversos colores en recuperación de Cirugía Hospital Nortelje Estocolmo, Suecia (2002 Foto $\mathrm{AMD}^{3}$ )

El juego de colores en las paredes se resaltará con la utilización de una textura o trama de fácil limpieza, siempre recordando el principio de asepsia que es fundamental para los Cuidados Intensivos Cardiológicos.

\section{Conclusión:}

Se considera que si bien esta propuesta surge de la interacción del Modelo Normalizado MN con el modelo Observado MO debería haber un trabajo específico sobre el tema de color vinculado a los espacios de internación de Cuidados Intensivos para validar o refutar esta propuesta.

- La variable color se considera de interés como condicionante del diseño Arquitectónico.

\footnotetext{
${ }^{3} \mathrm{AMD}$ son las iniciales de mi nombre.
} 


\section{A.2. Iluminación}

\section{Luz natural}

Las Normas de Organización y Funcionamiento de Cuidados Intensivos Cardiológicos, PNGC MSN, RM 375/2002, aconseja la iluminación natural. (Anexo 1).

Rangos de las respuestas de los Pacientes extraídos del Modelo Observado MO.

\begin{tabular}{|c|c|c|c|c|c|}
\hline DE LOS SENTIDOS & & (1) & $\begin{array}{c}\text { Rango } \\
1\end{array}$ & $\begin{array}{c}\text { Rango } \\
2\end{array}$ & $\begin{array}{c}\text { Rango } \\
3\end{array}$ \\
\hline & A.2. & Iluminación natural & 2 & 0 & 24 \\
\hline
\end{tabular}

Los resultados del Modelo Observado $\mathrm{MO}$ junto con los estudios realizado por investigaciones, como se ha mencionado en el Modelo Normalizado MN, define como prioritaria la necesidad de ventanas en las Unidades Cuidados Intensivos Cardiológicos.

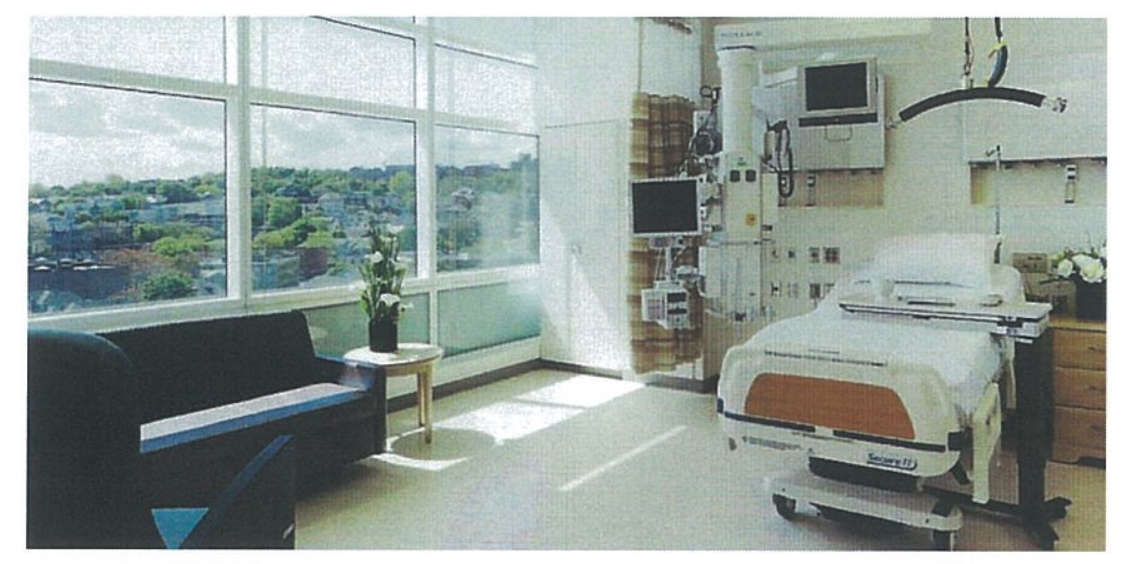

Detalle de la ventana hacia el exterior en la Habitación Shapiro Cardiovascular Center Boston, EE UU (2011Gentileza SCCenter)

La propuesta de este trabajo de Investigación es de ventanas que no solo dejen entrar la luz sino que también sirvan de elemento de orientación y distracción del paciente, con dimensiones suficientes para que el paciente tenga vistas al exterior desde su cama. Las ventanas deberán contar con tamices de control de luz para evitar juegos de sombras producidos por la luz directa.

\section{Luz artificial}

Las Normas de Organización y Funcionamiento de Cuidados Intensivos PNGC MSN RM 318/2001 e Intensivos Cardiológicos, PNGC MSN RM 375/2002, hacen referencia a la luz artificial. (Anexo 1).

Rangos de las respuestas de los Pacientes extraídos del Modelo Observado MO.

\begin{tabular}{|c|c|c|c|c|c|}
\hline & & & $\begin{array}{c}\text { Rango } \\
1\end{array}$ & $\begin{array}{c}\text { Rango } \\
2\end{array}$ & $\begin{array}{c}\text { Rango } \\
3\end{array}$ \\
\hline ESTIMULO DE LOS SENTIDOS & & & 2 & 8 & 16 \\
\hline
\end{tabular}


A través de las entrevistas con los pacientes, se explicitaron las actividades que desarrollan los mismos durante la internación.

Debido a las grandes restricciones de movimiento de algunos pacientes se hace fundamental el estudio de una iluminación que satisfaga y predisponga al paciente para realizar diferentes actividades, entre ellas la lectura, teniendo siempre como premisa el control por parte del paciente del encendido y apagado.

\section{Conclusión:}

Por todo lo antes expuesto se considera:

- La variable iluminación se considera fundamental como condicionante del diseño Arquitectónico.

\section{A.3. Sonidos}

Las Normas de Organización y Funcionamiento de Cuidados Intensivos PNGC MSN RM 318/2001 e Intensivos Cardiológicos, PNGC MSN RM 375/2002, hacen referencia a los ruidos. (Anexo 1).

Rangos de las respuestas de los Pacientes extraídos del Modelo Observado MO.

\begin{tabular}{|c|c|c|c|c|c|}
\hline & & & Rango & Rango & Rango \\
ESTIMULO DE LOS SENTIDOS & & & $\mathbf{1}$ & $\mathbf{2}$ & 3 \\
\hline & A.3. & Sonidos & 1 & 12 & 13 \\
\hline
\end{tabular}

Como se ha señalado el ruido es uno de los grandes problemas de las Unidades de Cuidados Intensivos; debido a lo lisas de las superficies, pisos, paredes y cielorraso que las delimitan y a lo poco porosos de los materiales, siempre en busca de la asepsia. A este problema se suma la reflexión de los sonidos. Un buen ejemplo de ámbito emisor de ruidos, confirmado en las Encuestas, es la Central de Enfermería, es inevitable que por tratarse de la Unidad de Cuidados Intensivos exista el ruido producido por las alarmas.

La propuesta de este trabajo de Investigación para la habitación, es primeramente el estudiar los centros emisores de ruido del Servicio, las alarmas de Central de Enfermería, el ruido producido por las conversaciones de equipo médico, las visitas de familiares, el movimiento de personal trasportando equipos de un sector a otro o encendido y apagado de equipos, para controlar el ruido antes de este llegue a la habitación.

Lo señalado implica estudiar la caja de la habitación por fuera, de forma tal de intentar aislarla de los ruidos que se producen alrededor, esto involucra el estudio de cielorrasos, paredes y pisos, no solo el revestimiento sino los materiales con que estos están construidos. 
Este proyecto de Investigación propone el estudio de las diferentes texturas de la habitación, estudio de aislamiento y absorbentes acústico de sonidos tanto en el piso como en cielorraso.

También es importante la incorporación de materiales de terminación con la incorporación de determinados tratamientos acústicos, capaces de absorber la mayor parte de la energía que reciben y por lo tanto evitar las reflexiones indeseadas. Se agrega a este estudio la propuesta de colocación de paneles en las paredes, ubicados en la cabecera y frente al paciente, cubiertos con un material que sea proclive a la absorción de sonidos y a su vez con una textura tal que sea de fácil limpieza.

\section{Conclusión:}

Por todo lo antes expuesto se considera:

- La variable sonidos se considera fundamental como condicionante del diseño Arquitectónico.

\section{A.4. Olores}

Rangos de las respuestas de los Pacientes extraídos del Modelo Observado MO.

\begin{tabular}{|c|c|c|c|c|c|}
\hline & & & Rango & Rango & Rango \\
ESTIMULO DE LOS SENTIDOS & & & $\mathbf{1}$ & $\mathbf{2}$ & $\mathbf{3}$ \\
\hline & A.4. & Olores & 1 & $\mathbf{2 4}$ & 1 \\
\hline
\end{tabular}

Como se ha mencionado con anterioridad los pacientes no han percibido olores estando internados en Cuidados Intensivo. Es notable sin embargo que cuando se les ha dado la posibilidad de elegir estos hayan optado por aromas que les recuerdan momentos agradables de su pasado o de su infancia.

Nuevamente los datos surgen de las preferencias de los pacientes, pero también podría ser interesante considerar el acceso a algunos aromas específicos, buscando ciertos resultados específicos como por ejemplo, predisponer el apetito de algún paciente.

\section{Conclusión:}

De la misma manera que la variable color, debería haber un trabajo específico sobre el tema de los aromas vinculado a los espacios de internación de Cuidados Intensivos Cardiológicos para realizar una propuesta.

Por todo lo antes expuesto se considera:

- La variable olores se considera de menor interés como condicionante del diseño Arquitectónico. 


\section{A.5. Texturas}

Las Normas de Organización y Funcionamiento de Cuidados Intensivos PNGC MSN RM 318/2001 e Intensivos Cardiológicos, PNGC MSN RM 375/2002, nos informa sobre determinas terminaciones para la habitación. (Anexo 1).

Rangos de las respuestas de los Pacientes extraídos del Modelo Observado MO.

\begin{tabular}{|c|c|c|c|c|c|}
\hline & & & Rango & Rango & Rango \\
ESTIMULO DE LOS SENTIDOS & & & $\mathbf{2}$ & $\mathbf{2}$ \\
\hline & A.5. & Texturas & 2 & 24 & 0 \\
\hline
\end{tabular}

Como hemos observado en la Encuesta, varios los pacientes observaron sobre su interés en la incorporación de la madera como material de revestimiento, si bien lo descantaron por considerarla inapropiada para una Internación.

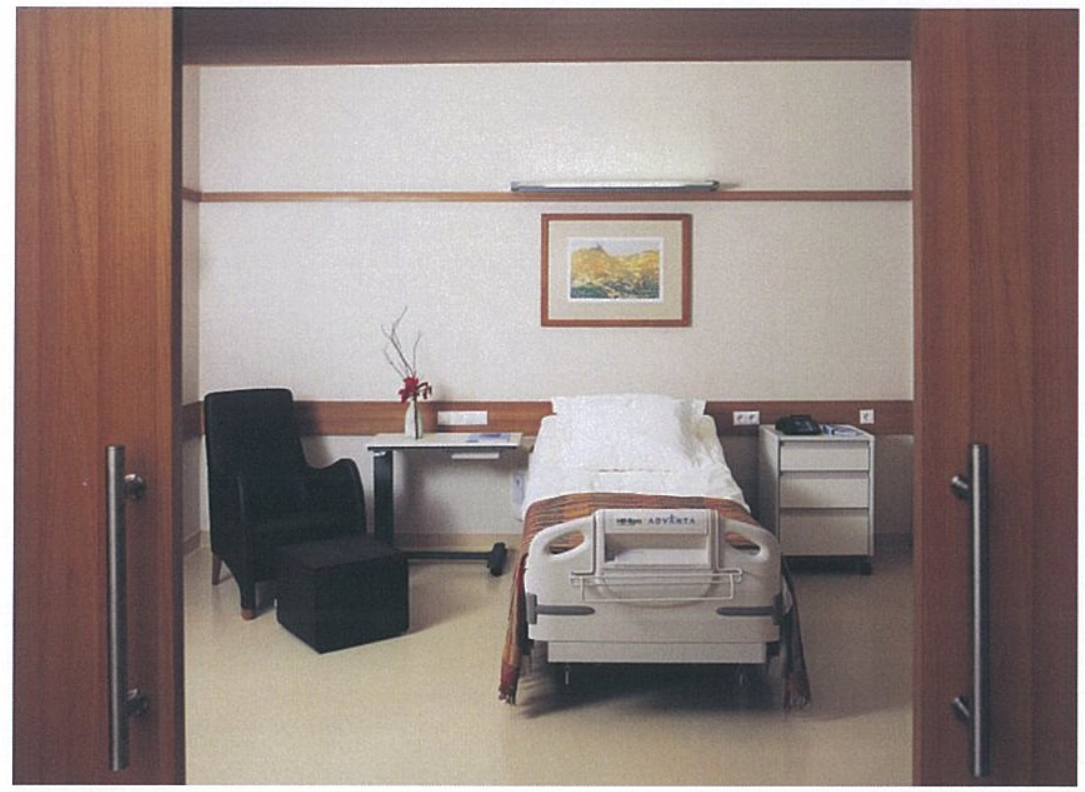

Detalle de texturas en el equipamiento y puertas con terminación símil madera.

El cuadro en la cabecera oculta el poliducto de gases médicos

Hospital Anadulu, Estambul, Turquía (2005 Gentileza Hospital Anadulu)

Es interesante observar en las últimas tendencias en diseño de interiores para Establecimientos de Salud la utilización de este material, por supuesto tratado de forma tal que cumpla con los requerimientos. Se buscará de incorporar en la habitación revestimientos en las paredes y cielorraso, que además de cumplir con la Norma, cumplan la doble función, decorativa y absorbentes acústico.

\section{Conclusión:}

Por todo lo antes expuesto se considera:

- La variable texturas se considera de interés como condicionante del diseño Arquitectónico. 


\subsubsection{Variables de optimización de los aspectos funcionales}

\section{B.1. Accesibilidad}

Las Normas de Organización y Funcionamiento de Cuidados Intensivos PNGC MSN RM 318/2001 e Intensivos Cardiológicos, PNGC MSN RM 375/2002, mencionan la conveniencia de la presencia de baños en las habitaciones. (Anexo 1).

Rangos de las respuestas de los Pacientes extraídos del Modelo Observado MO.

\begin{tabular}{|c|c|c|c|c|c|}
\hline $\begin{array}{c}\text { OPTIMIZACION DE ASPECTOS } \\
\text { FUNCIONALES }\end{array}$ & & & $\begin{array}{c}\text { Rango } \\
\mathbf{1}\end{array}$ & $\begin{array}{c}\text { Rango } \\
\mathbf{2}\end{array}$ & $\begin{array}{c}\text { Rango } \\
\mathbf{3}\end{array}$ \\
\hline & B.1. & Accesibilidad & 9 & $\mathbf{1 6}$ & 1 \\
\hline
\end{tabular}

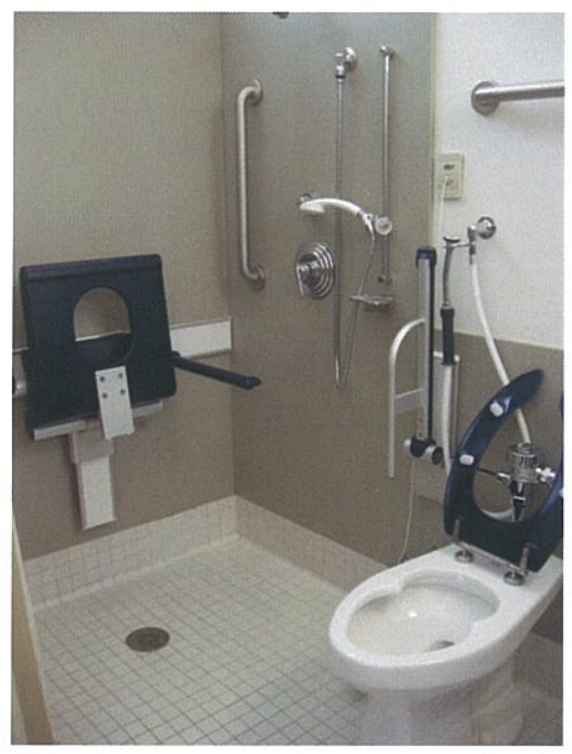

Detalle de baño de la Habitación con barrales y asiento para la ducha Shapiro Cardiovascular Center Boston, EE UU (2011 Foto AMD)

Los movimientos de los pacientes internados en Cuidados Intensivos es muy reducida, por lo tanto todo aquel elemento tanto arquitectónico como de equipamiento que promueva al paciente a desplazarse con seguridad o realizar alguna actividad debe ser especialmente promovido.

Se reconoce que los baños generales públicos por sector para las habitaciones son incómodos y poco accesibles. Como consecuencia de lo antes comentado, la incorporación de baños en las habitaciones de internación surge como una respuesta lógica a esta necesidad, estos baños deben estar ubicados lo más cerca posible del paciente. 
La disposición del baño próxima al paciente no es casual, son muchos los accidentes que pueden producirse por el desplazamiento del paciente, la respuesta desde la arquitectura es lograr que el paciente tenga la mayor y más franca accesibilidad.

Los baños de la habitación deberán contar con luz natural, barrales de apoyo, fijos y movibles, distancias específicas para el buen y cómodo desplazamiento, así como también contar con un asiento rebatible móvil en la ducha para la higiene del paciente. Se desea con todos estos elementos del equipamiento, promover la sensación de control por parte del paciente del medio que lo rodea.

Por otro lado para casos especiales, se deberá prever en la Unidad de baños que cumplan con todas las especificaciones de la Ley 962 "Accesibilidad para Todos".

\section{Conclusión:}

En los resultados de la Encuesta los Pacientes demostraron solo cierto interés por esta variable, el aporte de los Médicos Especializados en Cuidados Intensivos, las especificaciones de la Ley 962 "Accesibilidad para Todos", junto con el aporte de la Norma PNGC MSN RM 318/2001 y PNGC MSN RM 375/2002 que promueven la necesidad de baños próximos a la habitación con los correspondientes barrales de protección, llamador para enfermería y posibilidad de monitoreo del Paciente para la seguridad del Paciente, denotan la importancia de esta variable.

Por todo lo antes expuesto se considera:

- La variable accesibilidad se considera fundamental como condicionante del diseño Arquitectónico.

\section{B.2. Orientación}

Las Normas de Organización y Funcionamiento de Cuidados Intensivos PNGC MSN RM 318/2001 e Intensivos Cardiológicos, PNGC MSN RM 375/2002, hacen referencian a la incorporación de luz natural para la orientación del paciente. (Anexo 1).

Rangos de las respuestas de los Pacientes extraídos del Modelo Observado MO.

\begin{tabular}{|c|c|c|c|c|c|}
\hline $\begin{array}{c}\text { OPTIMIZACION DE ASPECTOS } \\
\text { FUNCIONALES }\end{array}$ & & & Rango & $\begin{array}{c}\text { Rango } \\
\mathbf{2}\end{array}$ & $\begin{array}{c}\text { Rango } \\
\mathbf{3}\end{array}$ \\
\hline & B.2. & Orientación & 6 & 18 & 2 \\
\hline
\end{tabular}

Esta variable tiene dos instancias, uno de ellas la orientación general o la ubicación de la Unidad de Cuidados Intensivos Cardiológicos dentro del Hospital y la otra se refiere a la conciencia de orientación es decir la orientación temporo-espacial del paciente cuando se encuentra internado. 
En cuanto a la orientación general, como se ha mencionado, las opiniones están divididas, de todos modos se recomienda el estudio de profesionales especializados en Diseño Gráfico para desarrollar junto con el proyecto de arquitectura, el proyecto de señalización del Establecimiento.

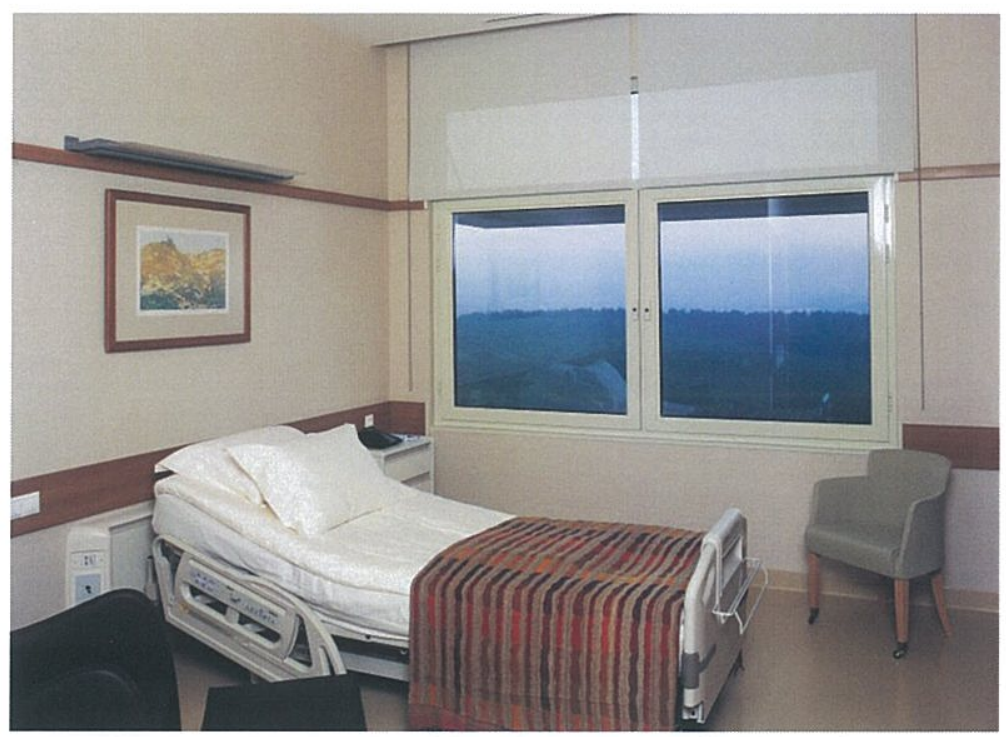

Detalle de ventana para orientación temporo-espacial Hospital Anadulu, Estambul Turquía (2005 Gentileza Hospital Anadulu)

En cuanto la conciencia de orientación de los pacientes, es fundamental la incorporación de luz natural para la orientación témporo espacial del paciente.

Se propone una ventana al exterior, para que el paciente tenga conocimiento del devenir del día y la colocación de un reloj con almanaque a la vista del paciente para que el paciente este consciente del día y la hora.

\section{Conclusión:}

Del mismo modo que con la variable Accesibilidad, en los resultados de la Encuesta los Pacientes demostraron solo cierto interés por esta variable, el aporte de los Médicos Especializados en Cuidados Intensivos, junto con el aporte de la Norma PNGC MSN RM 318/2001 y PNGC MSN RM 375/2002, refuerzan la importancia de esta Variable.

Por todo lo antes expuesto se considera:

- La variable orientación se considera fundamental como condicionante del diseño Arquitectónico. 


\section{B.3. Proporciones}

Las Normas de Organización y Funcionamiento de Cuidados Intensivos Cardiológicos, PNGC MSN, RM 375/2002, hacen referencia a las medidas mínimas de habitaciones o box para los pacientes. (Anexo 1). Junto con "Las Matrices de Atención de Internación Cuidados Intensivos Cardiológicos" del Proyecto "Nuevas Conceptualizaciones y Enfoques en Programación: Programación Funcional y Fisca del Recurso Físico en Salud" UBACyT A056 trabajo realizado por el CIRFS FADU UBA 2004 2007. (Anexo 2).

Rangos de las respuestas de los Pacientes extraídos del Modelo Observado MO.

\begin{tabular}{|c|c|c|c|c|c|}
\hline $\begin{array}{c}\text { OPTIMIZACION DE ASPECTOS } \\
\text { FUNCIONALES }\end{array}$ & & & $\begin{array}{c}\text { Rango } \\
\mathbf{1}\end{array}$ & $\begin{array}{c}\text { Rango } \\
\mathbf{2}\end{array}$ & $\begin{array}{c}\text { Rango } \\
\mathbf{3}\end{array}$ \\
\hline & B.3. & Proporciones & $\mathbf{2}$ & $\mathbf{2 1}$ & 3 \\
\hline
\end{tabular}

Si bien los pacientes parecen conformes con el tamaño de la habitación, la propuesta de dimensiones de las habitaciones de Cuidados Intensivos Cardiológicos debe surgir como respuesta a las actividades, tareas y recurso humano necesario para llevar a cabo su práctica.

\section{Conclusión:}

El estudio de las Tipologías "Espacio Tarea", proporcionará como resultado las características dimensionales de la habitación de Cuidados Intensivos Cardiológicos, para el buen desempeño del recurso humano que presta la atención.

Por todo lo antes expuesto se considera:

- La variable proporciones se considera fundamental como condicionante del diseño Arquitectónico.

\section{B.4. Disposición del equipamiento}

Las Normas de Organización y Funcionamiento de Cuidados Intensivos Cardiológicos, PNGC MSN, RM 375/2002, hacen mención a un listado de equipamiento pero no a su distribución (Anexo1).

Rangos de las respuestas de los Pacientes extraídos del Modelo Observado MO.

\begin{tabular}{|c|c|c|c|c|c|}
\hline $\begin{array}{c}\text { OPTIMIZACION DE ASPECTOS } \\
\text { FUNCIONALES }\end{array}$ & & $\begin{array}{c}\text { Rango } \\
\mathbf{1}\end{array}$ & $\begin{array}{c}\text { Rango } \\
\mathbf{2}\end{array}$ & $\begin{array}{c}\text { Rango } \\
\mathbf{3}\end{array}$ \\
\hline & B.4. & $\begin{array}{c}\text { Disposición del } \\
\text { Equipamiento }\end{array}$ & 4 & $\mathbf{2 1}$ & 1 \\
\hline
\end{tabular}

Debido a las restricciones físicas de los pacientes, el equipamiento específico para su uso debe estar fundamentalmente orientado su confort y a su fácil maniobrabilidad. 
Se propone como parte del equipamiento para confort del paciente, la ubicación de un ropero para el guardado de sus pertenencias ubicado en un sector de la habitación que funcione a su vez como vestidor (que promueva la privacidad del paciente), este espacio puede tener la doble función de lugar de espera de los familiares si este debe ser tratado mientras estos se encuentra visitándolo.

Por otro lado, la disposición del equipamiento para la atención médica, debe estar en función de las actividades y tareas que se practican y a su vez considerados los desplazamientos del recurso humano necesarios para llevarlas a cabo.

\section{Conclusión:}

El estudio de las Tipologias, a través del estudio de las actividades, donde se contemplara las tareas y el recurso humano participantes, nos proporcionará la disposición del equipamiento para la habitación de Cuidados Intensivos Cardiológicos.

Por todo lo antes expuesto se considera:

- La variable distribución del equipamiento se considera fundamental como condicionante del diseño Arquitectónico.

\subsubsection{Variables de Bienestar}

\section{C.1. Incorporación de la Naturaleza}

Rangos de las respuestas de los Pacientes extraídos del Modelo Observado MO.

\begin{tabular}{|c|c|c|c|c|c|}
\hline & & & $\begin{array}{c}\text { Rango } \\
\text { BIENESTAR }\end{array}$ & $\begin{array}{c}\text { Rango } \\
\mathbf{2}\end{array}$ & $\begin{array}{c}\text { Rango } \\
3\end{array}$ \\
\hline & C.1. & $\begin{array}{c}\text { Incorporación de la } \\
\text { naturaleza }\end{array}$ & 3 & 0 & 23 \\
\hline
\end{tabular}

Los resultados del estudio del Modelo Observado MO nos informan sobre el gran interés que los Pacientes dan a esta variable, debo aclarar sin embargo que en mucho de los casos esta preferencia venia unida a la idea de contar con una ventana al exterior con iluminación natural, esto se ve claramente reflejado en el $100 \%$ de las respuestas de los Pacientes del Hospital de Agudos Carlos G. Durand, cabe recordar que dicha Unidad es interior, por lo tanto no cuenta con iluminación natural.

La Unidad de Cuidados Intensivos es un lugar donde el contacto con la naturaleza solo se podrá realizar, a través de la visualización de una ventana que dé al exterior de la Unidad.

La propuesta orienta a la colocación de elementos exteriores para ser visto desde el interior de la habitación, doy como ejemplo la Unidad Polivalente de Cuidados Intensivos y Cardiológicos del Instituto Argentino de Diagnóstico y Tratamiento IADT. 
En esta Unidad se transformó un patio externo con visuales desde la internación para el confort del paciente y del recurso humano. (Entrevista Dr. Carlos Rubianes Pagina 58).

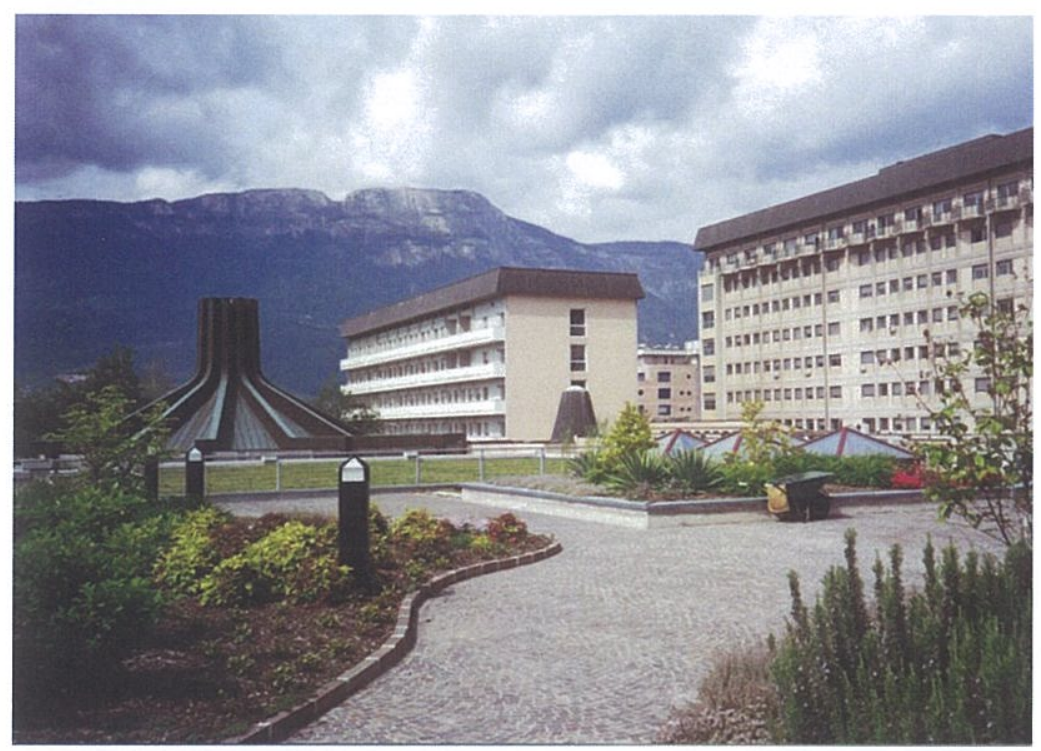

Hospital Central de Bolzano, Italia (2006 Foto AMD)

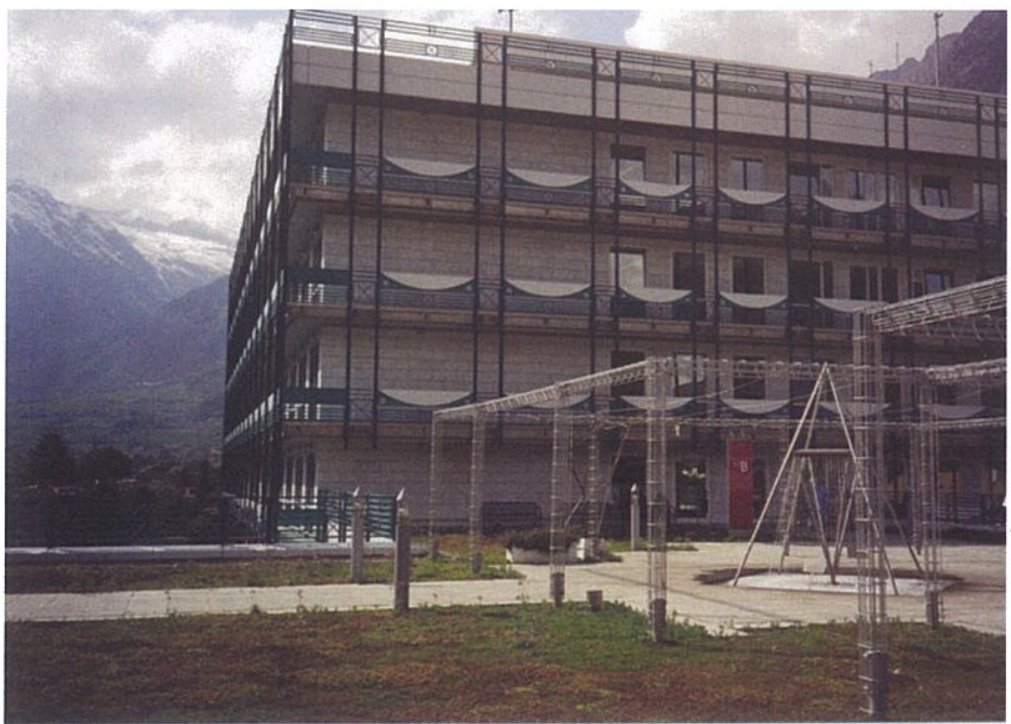

Un buen ejemplo de la incorporación de la naturaleza, Hospital rodeado por el magnífico paisaje de las montañas Dolomitas.

Hospital Franz Tappeiner, Merano, Italia (2006 Foto AMD)

\section{Conclusión:}

- La variable incorporación de la naturaleza se considera de interés como condicionante del diseño Arquitectónico. 


\section{C.2. Incorporación del Arte}

Rangos de las respuestas de los Pacientes extraídos del Modelo Observado MO.

\begin{tabular}{|c|c|c|c|c|c|}
\hline & & & $\begin{array}{c}\text { Rango } \\
1\end{array}$ & $\begin{array}{c}\text { Rango } \\
2\end{array}$ & $\begin{array}{c}\text { Rango } \\
3\end{array}$ \\
\hline BIENESTAR & C.2. & $\begin{array}{c}\text { Incorporación del } \\
\text { arte }\end{array}$ & 14 & 2 & 10 \\
\hline
\end{tabular}

El principio de limpieza que prima en la Unidad de Cuidados Intensivos hace que sea muy delicada la idea de colocar elementos decorativos (Ej.: cuadros) en la habitación. De allí la importancia de tomar todas las precauciones para que esta incorporación se de en términos de obtener el mejor resultado, tanto en la selección del material para exponer, como en la ubicación en la habitación para que este pueda ser contemplado por el paciente.

\section{Conclusión:}

En la Encuesta se ha restringido su estudio a la habitación, cuando tal vez esta variable sería más relevante en su incorporación como condicionante arquitectónica en otros espacios más públicos dentro del Establecimiento de Salud, como por ejemplo las Salas de Espera y las circulaciones, donde puede funcionar como hito de referencia para familiares y recurso humano.

- La variable incorporación del arte se considera de menor interés como condicionante del diseño Arquitectónico.

\section{C.3. Incorporación de la Música}

Rangos de las respuestas de los Pacientes extraídos del Modelo Observado MO.

\begin{tabular}{|c|c|c|c|c|c|}
\hline & & & $\begin{array}{c}\text { Rango } \\
\mathbf{1}\end{array}$ & $\begin{array}{c}\text { Rango } \\
\mathbf{2}\end{array}$ & $\begin{array}{c}\text { Rango } \\
\mathbf{3}\end{array}$ \\
\hline & C.3. & $\begin{array}{c}\text { Incorporación de la } \\
\text { música }\end{array}$ & 1 & $\mathbf{2 1}$ & 4 \\
\hline
\end{tabular}

Es interesante la incorporación de esta variable como elemento terapéutico y de distracción para el paciente.

Recordemos que los pacientes se refirieron en forma positiva a la incorporación de la música, considerándola un elemento de compañía. La propuesta es de música clásica o melódica, calmante y placentera, será fundamental que el paciente pueda controlar el volumen el encendido y el apagado. 


\section{Conclusión:}

De la misma manera que en la variables color, debería haber un trabajo específico sobre el tema de la música vinculado a los espacios de internación de Cuidados Intensivos para validar o refutar esta propuesta.

- La variable incorporación de la música se considera de interés como condicionante del diseño Arquitectónico.

\section{C.4. Confort}

Rangos de las respuestas de los Pacientes extraídos del Modelo Observado MO.

\begin{tabular}{|c|c|c|c|c|c|}
\hline & & & Rango & Rango & Rango \\
BIENESTAR & & & 1 & 2 & 3 \\
\hline & C.4. & Confort & 1 & 2 & 23 \\
\hline
\end{tabular}

A través de esta variable se detecta la importancia de la necesidad de control, en su acepción de Diccionario de la Real Academia Española, es decir; dominio, mando, preponderancia, en las acciones del paciente sobre lo que lo rodea.

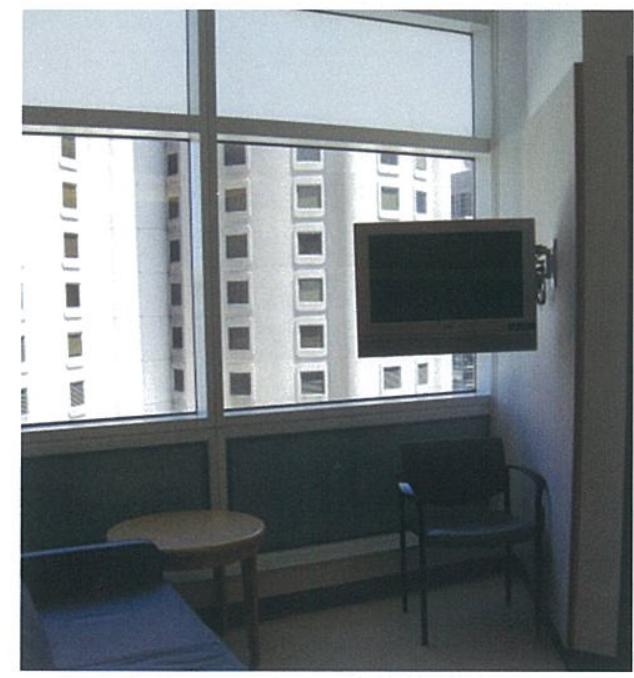

Detalle del sector para familiares en la Habitación Shapiro Cardiovascular Center Boston EE UU (2011 Foto AMD)

Este control en muchos casos es muy reducido, debido a la situación de algunos pacientes, el desafío desde lo arquitectónico es un diseño que promueva el control y la seguridad del paciente.

Entre los elementos para distracción del paciente, se plantea como propuesta la incorporación de un televisor en la habitación, este con ciertas características como acceso a determinada programación. La incorporación del televisor trae incorporado el a acceso música, otro elemento para distracción y compañía para el paciente. 
La internación en una Unidad de Cuidados Intensivos es un hecho traumático, la propuesta desde lo arquitectónico es lograr un ambiente que sea soporte de su recuperación, es decir, que el paciente cuente con las herramientas de diseño que lo ayuden en este proceso.

Controlar las posiciones de una cama, prender o apagar la luz, seleccionar un canal de televisión, caminar hacia el baño parecen cosas pequeñas pero implican un gran desafío para quien no cuenta con los recursos para auto valerse y realizarlas.

\section{Conclusión:}

- La variable confort se considera fundamental como condicionante del diseño Arquitectónico.

\subsubsection{Estudio Comparativos de Condicionantes Arquitectónicos}

En el marco de la valorización de las variables ambientales como condicionante del diseño Arquitectónico del Modelo Propuesto MP se realizará un estudio comparativo con los resultados basados en las Encuestas realizadas en los dos diferentes escenarios.

Para esta comparación, se toma como ejemplo los resultados de los estudios realizados en el Servicio de Atención de Internación Cuidados Generales (20062009) $)^{4}$ en las Unidades de Cuidados Intensivos y Cuidados Intensivos Cardiológicos (2009-2011).

Se asignan los siguiente Valores:

FUNDAMENTAL
DE INTERES
DE MENOR INTERES

${ }^{4}$ El Cuadro de "Variables con su Valor como Condicionantes Arquitectónico" para "Servicio de Atención de Internación 2006-2009", es una nueva creación, surge como elaboración del resultado de la Investigación "Las Condicionantes ambientales y de Humanización de los Espacios en el desarrollo de los Recursos Físicos en Salud" UBACyT A810 (2006-2009) (Anexo 3). 
Servicio de Atención de Internación (2006-2009)

Variables con su Valor como Condicionantes Arquitectónicos

\begin{tabular}{|c|c|c|c|c|c|}
\hline \multirow{2}{*}{$\begin{array}{l}\text { CONJUNTOS DE } \\
\text { VARIABLES }\end{array}$} & & \multirow{2}{*}{ VARIABLES } & \multicolumn{3}{|c|}{ VALOR } \\
\hline & & & BAJO & MEDIO & ALTO \\
\hline \multicolumn{6}{|l|}{$\begin{array}{l}\text { ESTIMULO DE LOS } \\
\text { SENTIDOS }\end{array}$} \\
\hline & A.1. & COLORES & & MEDIO & \\
\hline & A. 2 . & ILUMINACION & & & ALTO \\
\hline & A.3. & SONIDOS & & & ALTO \\
\hline & A.4. & OLORES & BAJO & & \\
\hline & A. 5 . & TEXTURAS & BAJO & & \\
\hline \multicolumn{6}{|l|}{$\begin{array}{c}\text { OPTIMIZACION DE } \\
\text { ASPECTOS } \\
\text { FUNCIONALES }\end{array}$} \\
\hline & B.1. & ACCESIBILIDAD & & & ALTO \\
\hline & B.2. & ORIENTACION & & MEDIO & \\
\hline & 8.3. & PROPORCIONES & & & ALTO \\
\hline & B.4. & $\begin{array}{l}\text { DISTRIBUCION } \\
\text { EQUIPAMIENTO }\end{array}$ & & MEDIO & \\
\hline \multicolumn{6}{|l|}{ BIENESTAR } \\
\hline & c.1. & NATURALEZA & & & ALTO \\
\hline & C.2. & ARTE & & MEDIO & \\
\hline & C.3. & MUSICA & & MEDIO & \\
\hline & C.4. & CONFORT & & & ALTO \\
\hline
\end{tabular}

Los datos surgen del estudio de Cuidados Intermedios, basado en el Proyecto UBACyT A810 (Anexo 3).

Base de Datos Pacientes Entrevistados sesenta (60) pacientes.

Establecimientos donde se realizaron las entrevistas:

- Hospital General de Agudos Juan A. Fernández de la Ciudad Autónoma de Buenos Aires del Subsector Público. Veinte (20) pacientes

- Centro de Estudios Médicos e Investigaciones Clínicas "Norberto Quirno", CEMIC Las Heras y CEMIC Saavedra del Subsector Privado. Veinte (20) pacientes.

- Hospital General de Agudos Carlos G. Durand del Subsector Público. Veinte (20) pacientes 
Unidades de Cuidados Intensivos y Cuidados Intensivos Cardiológicos (2009-2011)

Variables con su Valor como Condicionantes Arquitectónicos

\begin{tabular}{|c|c|c|c|c|c|}
\hline \multirow{2}{*}{$\begin{array}{l}\text { CONJUNTOS DE } \\
\text { VARIABLES }\end{array}$} & & \multirow{2}{*}{ VARIABLES } & \multicolumn{3}{|c|}{ VALOR } \\
\hline & & & BAJO & MEDIO & ALTO \\
\hline \multicolumn{6}{|l|}{$\begin{array}{l}\text { ESTIMULO DE LOS } \\
\text { SENTIDOS }\end{array}$} \\
\hline & A.1. & COLORES & & MEDIO & \\
\hline & A.2. & ILUMINACION & & & ALTO \\
\hline & A.3. & SONIDOS & & & ALTO \\
\hline & A.4. & OLORES & BAJO & & \\
\hline & A.5. & TEXTURAS & & MEDIO & \\
\hline \multicolumn{6}{|l|}{$\begin{array}{c}\text { OPTIMIZACION DE } \\
\text { ASPECTOS } \\
\text { FUNCIONALES }\end{array}$} \\
\hline & B.1. & ACCESIBILIDAD & & & ALTO \\
\hline & B.2. & ORIENTACION & & & ALTO \\
\hline & B.3. & PROPORCIONES & & & ALTO \\
\hline & 8.4. & $\begin{array}{l}\text { DISTRIBUCION } \\
\text { EQUIPAMIENTO }\end{array}$ & & & ALTO \\
\hline \multicolumn{6}{|l|}{ BIENESTAR } \\
\hline & c.1. & NATURALEZA & & MEDIO & \\
\hline & C.2. & ARTE & BAJO & & \\
\hline & c.3. & MUSICA & & MEDIO & \\
\hline & C.4. & CONFORT & & & ALTO \\
\hline
\end{tabular}

\section{Los datos surgen del estudio del Capitulo 5.1. Cuarta Etapa Modelo Propuesto MP para Cuidados Intensivos Cardiológicos.}

Base de datos Pacientes Entrevistados veintiséis (26) pacientes

Establecimientos donde se realizaron las entrevistas:

- Centro de Estudios Médicos e Investigaciones Clínicas "Norberto Quirno", CEMIC CEMIC Saavedra del Subsector Privado. Veinte (10) pacientes.

- Hospital General de Agudos Carlos G. Durand del Subsector Público. Veinte (10) pacientes

- Diferentes Instituciones Públicas y Privadas (6) 
La primera observación que surge del análisis de los Datos de las Tablas de Variables como Condicionantes Arquitectónicos de Cuidados Generales (2006-2009) y Cuidados Intensivos (2009-2011) es que a pesar de pertenecer a diferentes Servicios los resultados fueron muy similares, solo cabe destacar que debido a lo critica de la situación de algunos pacientes de Cuidados Intensivos se evidenciaron aún más algunos de los problemas, como los referentes a la falta de la iluminación natural, orientación y control sobre lo que lo rodea.

La comparación de ambas Tablas nos permite observar:

En el primer Conjunto de Variables "Estimulo de los Sentidos", los resultados son similares en ambos Servicios, las variables, iluminación y sonido se consideraran en ambos casos como variables de valor alto como condicionantes de diseño.

La variable color conserva su valor medio y como se ha comentado serán necesarias futuras investigaciones que permitan asociar los colores con su respuesta como condicionante Arquitectónico (no solo en el ámbito de la habitación de Cuidados Intensivos). En cuanto a la variable texturas, pasa del valor bajo al medio, cuando se trata de la Habitación de Cuidados Intensivos ya que se considera la utilización de las texturas en su doble rol de elemento de distracción para el paciente y absorbente acústico.

En el Conjunto de Variables "Optimización de Aspectos Funcionales", se observa un desplazamiento de los valores medio a alto en dos de sus variables.

Las variables accesibilidad y proporciones mantienen en ambos casos su valor alto como condicionante de diseño. En cuanto a las variables orientación y distribución del equipamiento pasan de valor medio a valor alto en Cuidados Intensivos, este desfasaje hacia una mayor valorización se debe en el caso de orientación a su fuerte relación con la variable iluminación y acceso a la luz natural. Para el caso de la variable distribución del equipamiento, debido a lo acotado y riguroso de los procedimientos, la disposición del equipamiento en su respuesta al confort y apoyo para el paciente, se trasforma en una pieza clave para el buen desempeño del equipo médico y de enfermería.

En el Conjunto de Variables "Bienestar" es donde se observan las mayores diferencias.

La variable naturaleza pasa de un valor alto a medio en Cuidados Intensivos, debido a la cuestión de asepsia, el paciente no puede salir de la Unidad de Cuidados Intensivos, la incorporación de la naturaleza solo se puede dar a través de una ventana sin embargo este dato no es menor.

La variable arte, pasa de un valor medio a bajo en Cuidados Intensivos, esto se debe nuevamente a las razones de asepsia antes mencionadas. En cuanto a la variable música, guarda el mismo valor medio en ambos Servicios, se considera 
apropiada la realización de más estudios sobre la música como elemento terapéutico. La variable confort conserva el mismo valor alto en ambos Servicios y esto evidencia la importancia del confort relacionada al proceso de recuperación de la salud y a la satisfacción del paciente y del recurso humano.

A través de este estudio comparativo en los dos escenarios se fundamenta la valorización realizada en el Modelo Propuesto MP, iniciando un proceso de contrastación de la propuesta.

\subsection{Propuesta de Tipologías "Espacio - Tarea" para la Habitación de Cuidados Intensivos Cardiológicos}

Con la documentación y datos obtenidos del Capítulo 4.1.5. Caracterización de las Tecnologías de Operación, donde se desarrolló una matriz con Funciones, Actividades, Tareas y Recurso Humano, sumandos a los aportes del Capitulo 5.1. Cuarta Etapa Modelo Propuesto MP de las Condiciones Ambientales, nos permitirá desarrollar una propuesta de seis Tipologías "Espacio - Tarea" para la habitación de Cuidados Intensivos Cardiológicos.

El cuadro que se presenta a continuación de "Espacio Tarea - Las Tipologías Seleccionadas", define en la primera columna las "Actividades", Cuidados Médicos, Cuidados de Enfermería, Exámenes y Diagnostico y Apoyo Familiar, en la siguiente columna "Tareas" se encuentran las Tipologías seleccionadas; Tipología T1 Examen Médico Inicial, Tipología T2 Control de Signos Vitales y/u Observación, Tipología T3 Higiene y/o Confort del Paciente (incluye cambios de ropa y cama), Tipología T4 Movilización o Traslado a otro Servicio, Tipología T5 Toma de Muestras para Laboratorio y Tipología T6 Visitas Familiares y Amigos, en la tercera columna el recurso humano necesario para el desarrollo de las Tareas. 


\begin{tabular}{|c|c|c|}
\hline ACTIVIDAD & TAREAS & RECURSO HUMANO \\
\hline $\begin{array}{l}\text { CUIDADOS } \\
\text { MÉDICOS }\end{array}$ & $\begin{array}{l}\text { Tipología T1 } \\
\text { EXAMEN MEDICO INICIAL }\end{array}$ & $\begin{array}{l}\text { MEDICO CARDIÓLOGO Y } \\
\text { MEDICO CARDIÓLOGO RESIDENTE } \\
\text { (MEDICO DE CABECERA, POCO } \\
\text { FRECUENTE) } \\
\text { ENFERMERA } \\
\text { PACIENTE }\end{array}$ \\
\hline \multirow{3}{*}{$\begin{array}{l}\text { CUIDADOS DE } \\
\text { ENFERMERIAA }\end{array}$} & $\begin{array}{l}\text { Tipología T2 } \\
\text { CONTROL DE SIGNOS VITALES Y } / U \\
\text { OBSERVACIÓN }\end{array}$ & $\begin{array}{l}\text { ENFERMERA O AUXILIAR DE } \\
\text { ENFERMERIA } \\
\text { PACIENTE }\end{array}$ \\
\hline & $\begin{array}{l}\text { Tipología T3 } \\
\text { HIGIENE Y I O CONFORT DEL PACIENTE } \\
\text { (INCLUYE CAMBIOS DE ROPA Y CAMA). }\end{array}$ & $\begin{array}{l}\text { ENFERMERA O AUXILIAR DE } \\
\text { ENFERMERÍA } \\
\text { PACIENTE }\end{array}$ \\
\hline & $\begin{array}{l}\text { Tipología T4 } \\
\text { MOVILIZACIÓN O TRASLADO A OTRO } \\
\text { SERVICIO }\end{array}$ & $\begin{array}{l}\text { ENFERMERA O AUXILIAR DE } \\
\text { ENFERMERIA } \\
\text { PACIENTE }\end{array}$ \\
\hline $\begin{array}{l}\text { EXÁMENES DE } \\
\text { DIAGNOSTICO }\end{array}$ & $\begin{array}{l}\text { Tipología T5 } \\
\text { TOMA DE MUESTRAS PARA LABORATORIO }\end{array}$ & $\begin{array}{l}\text { ENFERMERA O TÉCNICO } \\
\text { LABORATORIO } \\
\text { PACIENTE }\end{array}$ \\
\hline APOYO FAMILIAR & $\begin{array}{l}\text { Tipología T6 } \\
\text { VISITAS FAMILIARES Y AMIGOS }\end{array}$ & $\begin{array}{l}\text { PACIENTE } \\
\text { FAMILIARES O AMIGOS }\end{array}$ \\
\hline
\end{tabular}

En el Recurso Humano se reconoce a:

\begin{tabular}{|ll|}
\hline A & PACIENTE \\
B & FAMILIAR \\
C & MEDICO CARDIOLOGO \\
C1 & MEDICO CARDIOLOGO RESIDENTE \\
D & MEDICO DE CABECERA \\
E & ENFERMERA O AUXILIAR DE ENFERMERIA \\
F & TECNICO DE LABORATORIO \\
\hline
\end{tabular}

El estudio de las Tipologías también permitirá estudiar y reconocer claramente los espacios asignados a cada uno de ellos. 
Los Condicionantes de Diseño Arquitectónico serán primeramente incorporados en el diseño de las Tipologías seleccionadas y luego en la Propuesta Proyectual de la Habitación para Cuidados Intensivos Cardiológicos.

El Recurso Humano estará representado por circunferencias que contendrán sus movimientos; $90 \mathrm{~cm}$ de diámetro cuando se trate de movimientos gran maniobrabilidad o de traslado y $60 \mathrm{~cm}$ de diámetro cuando se trate de movimientos reducidos.

Las áreas grises o "espacio sombra", es el espacio previsto para la ubicación de equipamiento, se ha considerado el desarrollo de dos grandes espacios sombra, uno en la cabecera de la cama (fuera de las visuales del paciente) y otro frente al paciente para equipamiento poco frecuente.

Una línea de borde gruesa, continua para el caso que se trate de la localización de una pared / cerramiento, o discontinua para el caso de que se trate de borde blando de la Tarea completarán la suma total de la superficie de las Tipologías.

A cada una de las Tipologías le corresponde un Cuadro donde se observa, cual es el Recurso Humano que desarrolla la Tarea específica, las Determinantes Ambientales requeridas en cuanto a; la lluminación, el Aire Acondicionado y el Recambio de Aire.

El desarrollo de las Tipologias se completará con el estudio del Equipamiento, su configuración y su desagregado en 1) muebles, 2) artefactos y accesorios, 3) aparatos, equipos e instrumentos 4) utensilios y artículos varios y 5) elementos de trasporte, también se observarán los Detalles del Equipamientos, el Código y cumplimiento con la Normas del Programa Nacional de Garantía de la Calidad Medica del Ministerio de la Nación RM 318/2001 y 375/2002.

Es importante destacar que en el Código de Detalle de Equipamiento, se ha incorporado con una " $s$ " de satisfacción, a todo aquel equipamiento incorporado debido a las Condicionantes Ambientales estudiadas.

A continuación las Tipologías "Espacio - Tarea" para la Habitación de Cuidados Intensivos Cardiológicos. 


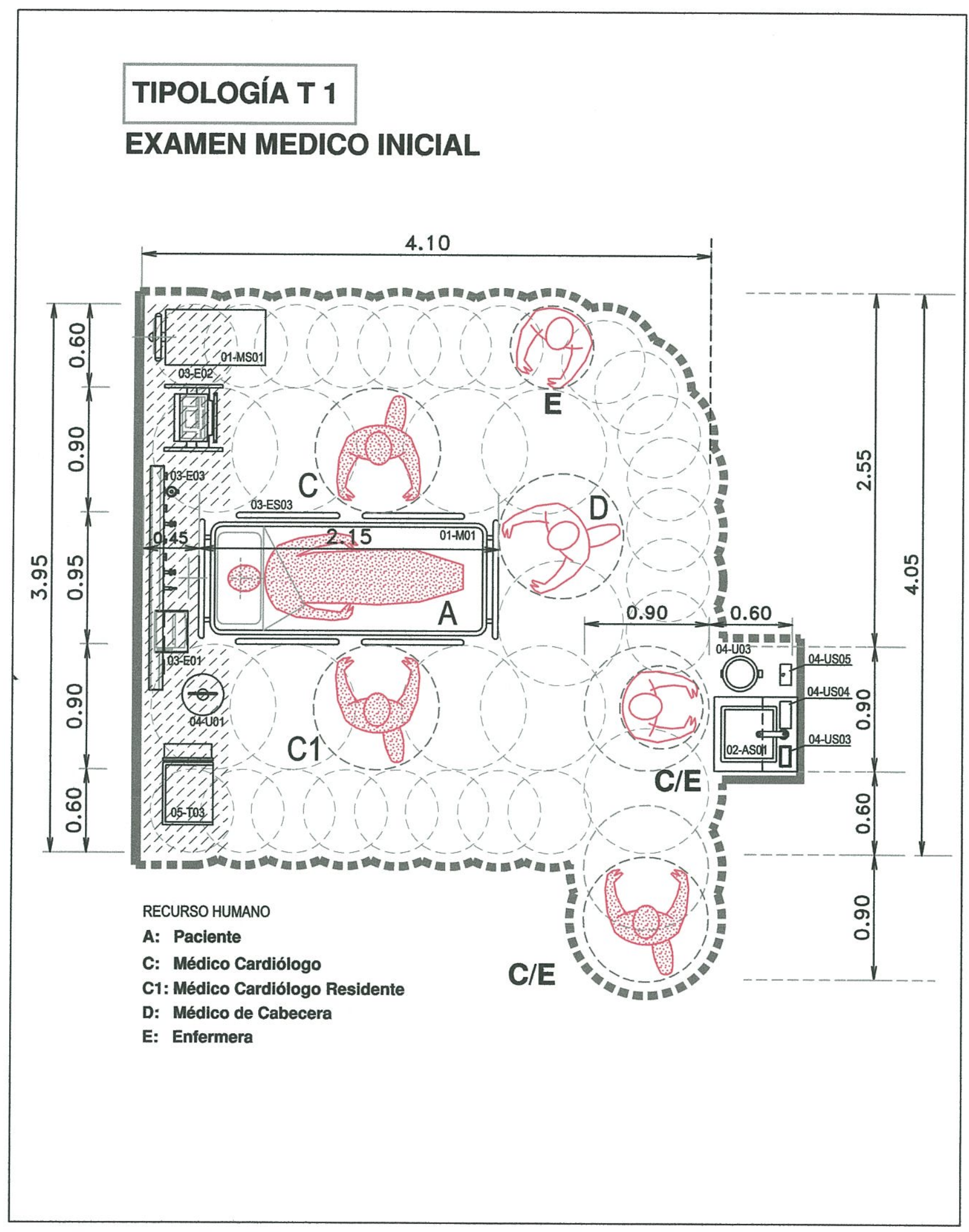




\begin{tabular}{|c|c|c|c|}
\hline \multicolumn{3}{|c|}{ RECURSO HUMANO } & \multirow[t]{2}{*}{ DETERMINACIONES AMBIENTALES } \\
\hline Cód. & Denominación & Cant & \\
\hline $\begin{array}{l}A \\
C \\
C 1 \\
D \\
E\end{array}$ & $\begin{array}{l}\text { Paciente } \\
\text { Médico Cardiólogo } \\
\text { Médico Cardiólogo Residente } \\
\text { Médico de Cabecera (poco } \\
\text { frecuente). } \\
\text { Enfermera }\end{array}$ & $\begin{array}{l}1 \\
1 \\
1 \\
1\end{array}$ & $\begin{array}{l}\text { Las habitaciones deberán contar con lluminación natural, aire } \\
\text { climatizado y estar insonorizadas del ambiente externo (RM } \\
375 / 2002 \text { ) } \\
\text { Aire Acondicionado, la Unidad debe mantener la temperatura de } 25^{\circ} \text { - } \\
26^{\circ} \text { centigrados y los niveles de humedad entre } 30-60 \% \text { para prevenir } \\
\text { accidentes eléctricos derivados de un ambiente extremadamente } \\
\text { seco. (RM } 318 / 2001 \text { ) } \\
\text { Es deseable el recambio de aire } 4 \text { veces por hora en las habitaciones } \\
\text { y } 2 \text { recambios en el resto de la Unidad. (RM } 318 / 2001 \text { ) }\end{array}$ \\
\hline
\end{tabular}

\begin{tabular}{|c|c|c|c|}
\hline CONJUNTOS DE EQUIPAMIENTO & DETALLE DE EQUIPAMIENTO & CÓDIGO & $\begin{array}{l}\text { PROGRAMA } \\
\text { NACIONAL DE } \\
\text { GARANTIA DE } \\
\text { CALIDAD }\end{array}$ \\
\hline \multirow[t]{2}{*}{01 - MUEBLES } & $\begin{array}{l}\text { CAMA MOVIL, ARTICULADA, CON CABECERA FACILMENTE REBATIBLE, } \\
\text { BARANDAS ARTICULABLES Y DESMONTABLES, CON LECHO RIGIDO QUE } \\
\text { PERMITA LAS MANIOBRAS DE REANIMACION } \\
\text { CON CONTROL DE MOVIMIENTOS POR PARTE DEL. PACIENTE }\end{array}$ & 01-M01 & RM 375/2002 \\
\hline & MESADA APOYO DE PACIENTE & 01-MSO1 & \\
\hline 02 -ARTEFACTOS Y ACCESORIOS & $\begin{array}{l}\text { LAVATORIO MONOCOMANDO (PROXIMO AL ACCESO PARA PROPICIAR EL } \\
\text { LAVADO DE MANOS). }\end{array}$ & 02-AS01 & \\
\hline \multirow[t]{4}{*}{$\begin{array}{l}\text { O3-APARATOS, EQUIPOS E } \\
\text { INSTRUMENTOS }\end{array}$} & $\begin{array}{l}\text { MONITOR MULTIPARAMETRICO (ECG, PO2, Pl, PNI, TEMP. CENTRAL, } \\
\text { TEMP. EXTERNA). EN LA CAEECERA DEL, PACIENTE }\end{array}$ & O3-E01 & RM $375 / 2002$ \\
\hline & RESPIRADOR & 03-EO2 & RM 375/2002 \\
\hline & $\begin{array}{l}\text { POLIDUCTO A PARED CON TOMAS ELECTRICOS, GASES MEDICINALESY } \\
\text { SOPORTE PARA EQUIPAMIENTOS. }\end{array}$ & 03-E03 & RM 375/2002 \\
\hline & $\begin{array}{l}\text { CONTROI. REMOTO PROXIMO AL PACIENTE, DE FUNCIONES, LLAMADO A } \\
\text { ENFERMERA, ILUMINACION, ENCEDIDO DE TVY OTROS }\end{array}$ & O3-ES03 & \\
\hline \multirow[t]{5}{*}{ O4 - UTENSILIOS Y ARTÍCULOS VARIOS } & SOPORTE PARA SUERO & 04-U01 & \\
\hline & CESTO METALICO TAPA A PEDAL & $04-\mathrm{U} 03$ & \\
\hline & JABON ESPECIAL LAVADO DE MANOS & 04-US03 & \\
\hline & TOALLAS DE PAPEL PARA SECADO DE MANOS & O4-USO4 & \\
\hline & GUANTES DESCARTABLES & 04.USO5 & \\
\hline O5 - ELEMENTOS DE TRANSPORTE & CARRO O BANDEJA PORTA EQUIIPO & $05-703$ & \\
\hline & & & \\
\hline
\end{tabular}

Resolución Ministerial RM 318/2001. Unidades de Cuidados Intensivos. Programa Nacional de Garantia de la Calidad de la Atención Médica, Ministerio de Salud de la Nación Argentina.

Resolución Ministerial RM 375/2002. Unidades de Cuidados Intensivos Cardiológicos. Programa Nacional de Garantia de la Calidad de la Atención Médica, Ministerio de Salud de la Nación Argentina. 


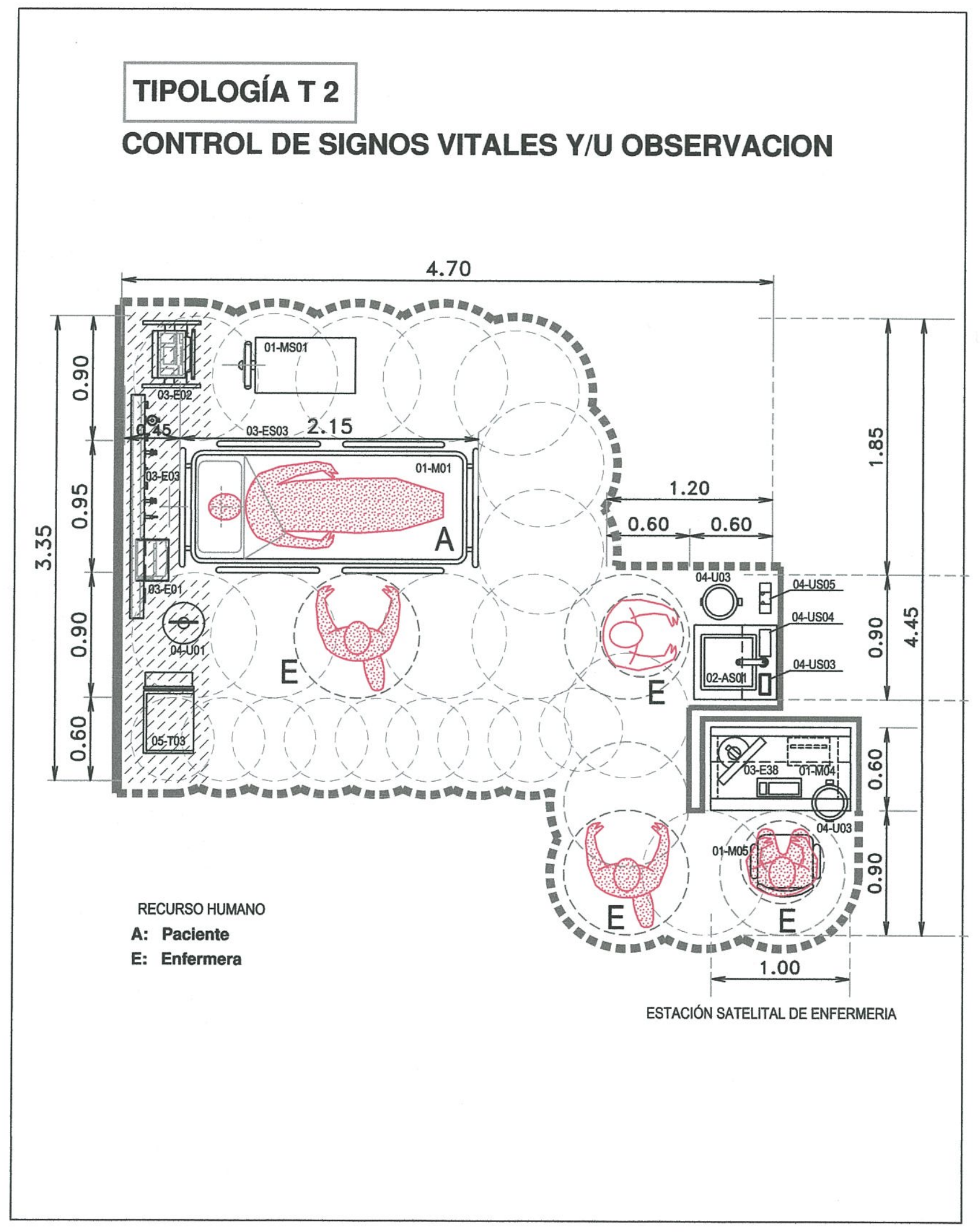




\section{\begin{tabular}{|l|l|l|l|} 
TIPOLOGÍA T 2 & CONTROL DE SIGNOS VITALES Y I U OBSERVACIÓN
\end{tabular}}

\begin{tabular}{|c|c|c|c|}
\hline \multicolumn{3}{|c|}{ RECURSO HUMANO } & \multirow{2}{*}{ DETERMINACIONES AMBIENTALES } \\
\hline Cód. & Denominación & Cant & \\
\hline $\begin{array}{l}A \\
E\end{array}$ & $\begin{array}{l}\text { Paciente } \\
\text { Enfermera o Auxiliar de Enfermeria }\end{array}$ & $\begin{array}{l}1 \\
1\end{array}$ & $\begin{array}{l}\text { Las habitaciones deberán contar con lluminación natural, aire } \\
\text { climatizado y estar insonorizadas del ambiente externo (RM } \\
375 / 2002 \text { ) } \\
\text { Aire Acondicionado, la Unidad debe mantener la temperatura de } 25^{\circ} \text { - } \\
26^{\circ} \text { centigrados y los niveles de humedad entre } 30-60 \% \text { para prevenir } \\
\text { accidentes eléctricos derivados de un ambiente extremadamente } \\
\text { seco. (RM } 318 / 2001 \text { ) } \\
\text { Es deseable el recambio de aire } 4 \text { veces por hora en las habitaciones } \\
\text { y } 2 \text { recambios en el resto de la Unidad. (RM } 318 / 2001 \text { ) }\end{array}$ \\
\hline
\end{tabular}

\begin{tabular}{|c|c|c|c|}
\hline CONJUNTOS DE EQUIPAMIENTO & DETALLE DE EQUIPAMIENTO & CÓDIGO & $\begin{array}{l}\text { PROGRAMA } \\
\text { NACIONAL DE } \\
\text { GARANTIADE } \\
\text { CALIDAD }\end{array}$ \\
\hline \multirow[t]{2}{*}{01 - MUEBLESS } & $\begin{array}{l}\text { CAMA MOVIL, ARTICULADA, CON CABECERA FACILMENTE REBATIBLE, } \\
\text { BARANDAS ARTICULABLES Y DESMONTABLES, CON LECHO RIGIDO QUE } \\
\text { PERMTA LAS MANOBRAS DE REANMACION } \\
\text { CON CONTROL DE MOVIMIENTOS POR PARTE DEL PACIENTE }\end{array}$ & 01-M01 & RM 375/2002 \\
\hline & MESADA APOYO DE PACIENTE & 01-MS01 & \\
\hline O2 - ARTEFACTOS Y ACCESORIOS & $\begin{array}{l}\text { LAVATORIO MONOCOMANDO (PROXIMO AL ACCESO PARA PROPICIAR } \\
\text { ELLAVADO DE MANOS). }\end{array}$ & 02-AS01 & \\
\hline \multirow[t]{4}{*}{03 - APARATOS, EQUIPOS E INSTRUMENTOS } & $\begin{array}{l}\text { MONITOR MULTIPARAMÉTRICO (ECG, PO2, PI, PNI, TEMP, CENTRAL, } \\
\text { TEMP. EXTERNA). EN LA CABECERA DEL PACIENTE }\end{array}$ & 03-E01 & RM 375/2002 \\
\hline & RESPIRADOR & $03-\mathrm{EO} 2$ & RM 375/2002 \\
\hline & $\begin{array}{l}\text { POLIDUCTO A PARED CON TOMAS ELECTRICOS, GASES MEDICINALES Y } \\
\text { SOPORTE PARA EQUIPAMIENTOS. }\end{array}$ & 03-E03 & RM 375/2002 \\
\hline & $\begin{array}{l}\text { CONTROL REMOTO PROXIMO AL PACIENTE, DE FUNCIONES, LLAMADO } \\
\text { A ENFERMERA, ILUMINACION, ENCEDIDO DE TVY OTROS }\end{array}$ & 03-ES03 & \\
\hline \multirow[t]{5}{*}{04 - UTENSILIOS Y ARTICULLOS VARIOS } & SOPORTE PARA SUERO & 04-L01 & \\
\hline & CESTO METALICO TAPA A PEDAL & 04-L03 & \\
\hline & JABON ESPECIAL LAVADODE MANOS & 04-LSO3 & \\
\hline & TOALLAS DE PAPEL PARA SECADO DE MANOS & 04-LSO4 & \\
\hline & GUANTES DESCARTABLES & 04-USO5 & \\
\hline 05 - ELEMENTOS DE TRANSPORTE & CARRO O BANDEJA PORTA EQUUIPO & $05-T 03$ & \\
\hline
\end{tabular}

\section{ESTACION SATELITAL DE ENFERMERIA}

\begin{tabular}{|c|c|c|c|}
\hline CONJUNTOS DE EQUIPAMIENTO & DETALLE DE EQUIPAMIENTO & Código & $\begin{array}{l}\text { PROG. NACIONAL } \\
\text { DE GARANTIA DE } \\
\text { CALIDAD }\end{array}$ \\
\hline 01 - MUEBLES & MESAMOSTRADOR & 01-M04 & \\
\hline & SILLA RODANTE GIRATORIA & $01-M 05$ & \\
\hline D3-APARATOS, EQUIPOS EINSTRUMENTOS & ESTACION SATELITAL DE MONITOREO (PC) & $03-E 38$ & \\
\hline O4 - UTENSILIOS Y ARTICULOS VARIOS & CESTO METÁLICO TAPA A PEDAL. & $04-\mathrm{U} 03$ & \\
\hline
\end{tabular}

Resolución Ministerial RM 318/2001. Unidades de Cuidados Intensivos. Programa Nacional de Garantia de la Calidad de la Atención Médica, Ministerio de Salud de la Nación Argentina.

Resolución Ministerial RM 375/2002. Unidades de Cuidados Intensivos Cardiológicos. Programa Nacional de Garantia de la Calidad de la Atención Médica, Ministerio de Salud de la Nación Argentina. 


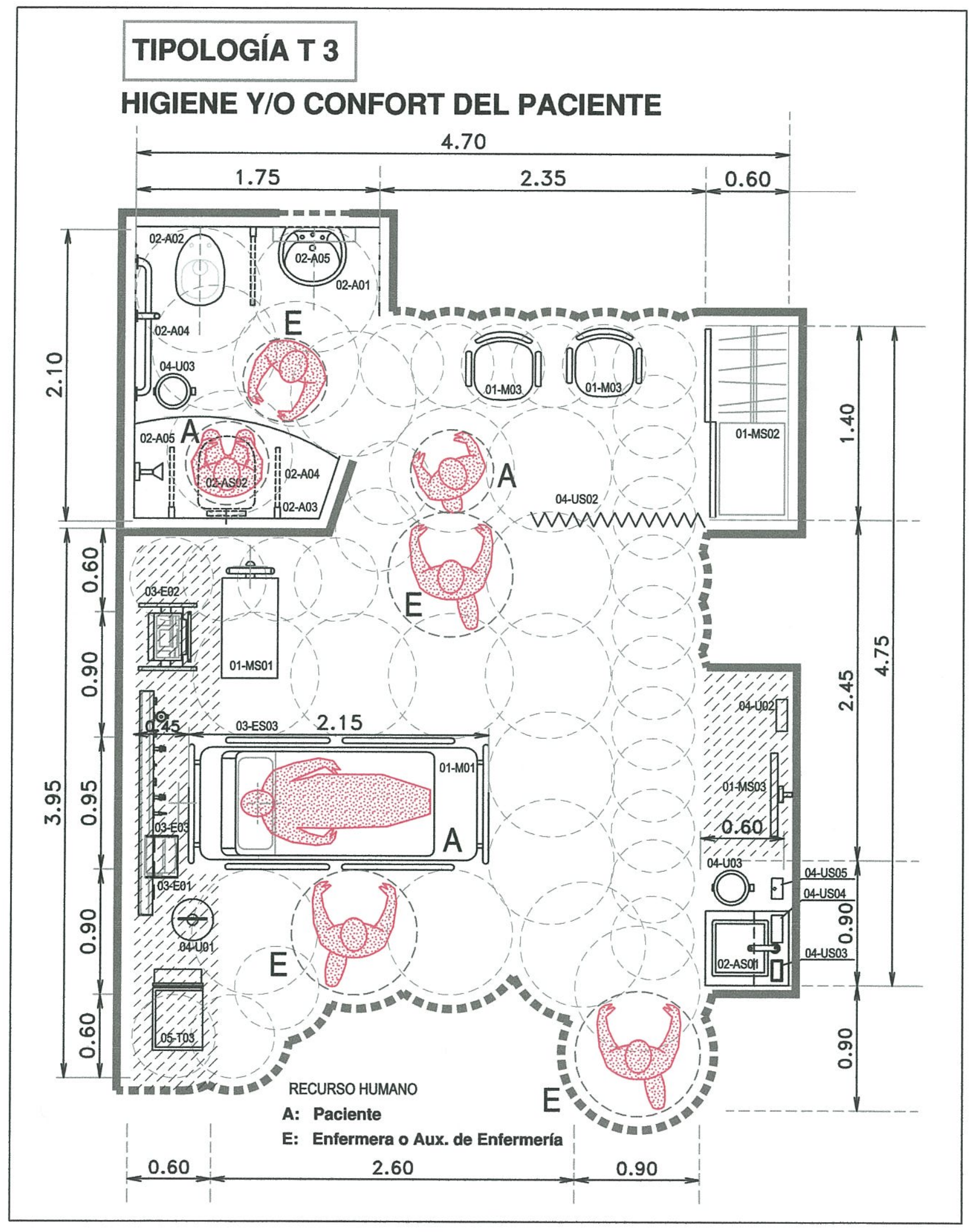


Facultad de Arquitectura y Urbanismo, Universidad Nacional de la Plata

TIPOLOGÍA T 3

HIGIENE Y I O CONFORT DEL PACIENTE (INCLUYE CAMBIOS DE ROPA Y CAMA)

\begin{tabular}{|c|c|c|c|}
\hline \multicolumn{3}{|c|}{ RECURSO HUMANO } & \multirow[t]{2}{*}{ DETERMINACIONES AMBIENTALES } \\
\hline Cód. & Denominación & Cant & \\
\hline $\begin{array}{l}\mathbf{A} \\
\mathbf{E}\end{array}$ & $\begin{array}{l}\text { Paciente } \\
\text { Enfermera o Auxiliar de Enfermeria }\end{array}$ & $\begin{array}{l}1 \\
1\end{array}$ & $\begin{array}{l}\text { Las habitaciones deberán contar con lluminación natural, aíre } \\
\text { climatizado y estar insonorizadas del ambiente externo (RM } \\
375 / 2002 \text { ) } \\
\text { Aire Acondicionado, la Unidad debe mantener la temperatura de } 25^{\circ} \text { - } \\
26^{\circ} \text { centígrados y los niveles de humedad entre } 30-60 \% \text { para prevenir } \\
\text { accidentes eléctricos derivados de un ambiente extremadamente } \\
\text { seco. (RM } 318 / 2001 \text { ) } \\
\text { Es deseable el recambio de aire } 4 \text { veces por hora en las habitaciones } \\
\text { y } 2 \text { recambios en el resto de la Unidad. (RM } 318 / 2001 \text { ) }\end{array}$ \\
\hline
\end{tabular}

\begin{tabular}{|c|c|c|c|}
\hline CONJUNTOS DE EQUIPAMIENTO & DETALLE DE EQUIPAMIENTO & Código & $\begin{array}{l}\text { PROGRAMA } \\
\text { NACIONAL DE } \\
\text { GARANTIA DE } \\
\text { CALIDAD }\end{array}$ \\
\hline \multirow[t]{5}{*}{01 - MUEBLES } & $\begin{array}{l}\text { CAMA MOVIL, ARTICULADA, CON CABECERA FACILMENTE REBATIBLE, } \\
\text { BARANDAS ARTICULABLES Y DESMONTABLES, CON LECHO RIGIDO QUE } \\
\text { PERMITA LAS MANOBRAS DE REANIMACION } \\
\text { CON CONTROL DE MOVIMIENTOS POR PARTE DEL PACIENTE }\end{array}$ & 01-Mo: & RM 375/2002 \\
\hline & MESADA APOYO DE PACIENTE & 01-MS01 & \\
\hline & ROPERO PARA OBJETOS DEL PACIENTE & $01-\mathrm{MSO} 2$ & \\
\hline & TELEVISOR CON CONTROL REMOTO & $01-\mathrm{MSO3}$ & \\
\hline & SILLON DE ACOMPANAANTE & 01-M03 & \\
\hline & & & \\
\hline \multirow[t]{7}{*}{ O2 - ARTEFACTOS Y ACCESORIOS } & $\begin{array}{l}\text { LAVATORIO MONOCOMANDO (PROXIMO AL ACCESO PARA PROPICIAR } \\
\text { EL LAVADO DE MANOS). }\end{array}$ & 02-AS01 & \\
\hline & LAVATORIO DE BANO MONOCOMANDO & O2-A01 & \\
\hline & INODORO & O2-A02 & \\
\hline & RECEPTACULO DUCHA & $02 \cdot A 03$ & \\
\hline & BARRALES FIJOS Y BARRALES REBATIBLES & $02 \cdot A 04$ & \\
\hline & GRIFERIA DE FACIL ACCIONAMIENTO & 02.405 & \\
\hline & ASIENTO DE DUCHA REBATIBLE & 02-AS02 & \\
\hline \multirow[t]{4}{*}{ O3-APARATOS, EQUIPOS E INSTRUMENTOS } & $\begin{array}{l}\text { MONITOR MULTIPARAMETRICO (ECG, PO2, PI, PNI, TEMP. CENTRAL, } \\
\text { TEMP. EXTERNA). EN LA CABECERA DEL PACIENTE }\end{array}$ & 03-E01 & RM 375/2002 \\
\hline & RESPIRADOR & 03.E02 & RM 375/2002 \\
\hline & $\begin{array}{l}\text { POLIDUCTO A PARED CON TOMAS ELECTRICOS, GASES MEDICINALESY } \\
\text { SOPORTE PARA EQUIPAMENTOS. }\end{array}$ & O3-E03 & RM 375/2002 \\
\hline & $\begin{array}{l}\text { CONTROL REMOTO PROXIMO AL PACIENTE, DE FUNCIONES, LLAMADO } \\
\text { A ENFERMERA, ILUMINACION, ENCEDIDO DE TVY OTROS }\end{array}$ & 03-ES03 & \\
\hline \multirow[t]{7}{*}{ O4 - UTENSILIOS Y ARTICULOS VARIOS } & SOPORTE PARA SUERO & 04-U01 & \\
\hline & RELOJ DE PARED CON ALMANAQUE & $04-402$ & \\
\hline & CESTO METÁLIICO TAPA A PEDAL & 04-U03 & \\
\hline & CORTINA PARA GUARDAR PRIVACIDAD DEL. PACIENTE & 04-USO2 & \\
\hline & JABON ESPECIAL LAVADO DE MANOS & 04.US03 & \\
\hline & TOALLAS DE PAPEL PARA SECADO DE MANOS & 04-US04 & \\
\hline & GUANTES DESCARTABLES & 04-US05 & \\
\hline 05 - ELEMENTOS DE TRANSPORTE & CARRO O BANDEJA PORTA EQUIPO & $05-T 03$ & \\
\hline
\end{tabular}

Resolución Ministerial RM 318/2001. Unidades de Cuidados Intensivos. Programa Nacional de Garantia de la Calidad de la Atención Médica, Ministerio de Salud de la Nación Argentina.

Resolución Ministerial RM 375/2002. Unidades de Cuidados Intensivos Cardiológicos. Programa Nacional de Garantía de la

Calidad de la Atención Médica, Ministerio de Salud de la Nación Argentina. 


\section{TIPOLOGÍA T 4}

\section{MOVILIZACIÓN O TRASLADO A OTRO SERVICIO}

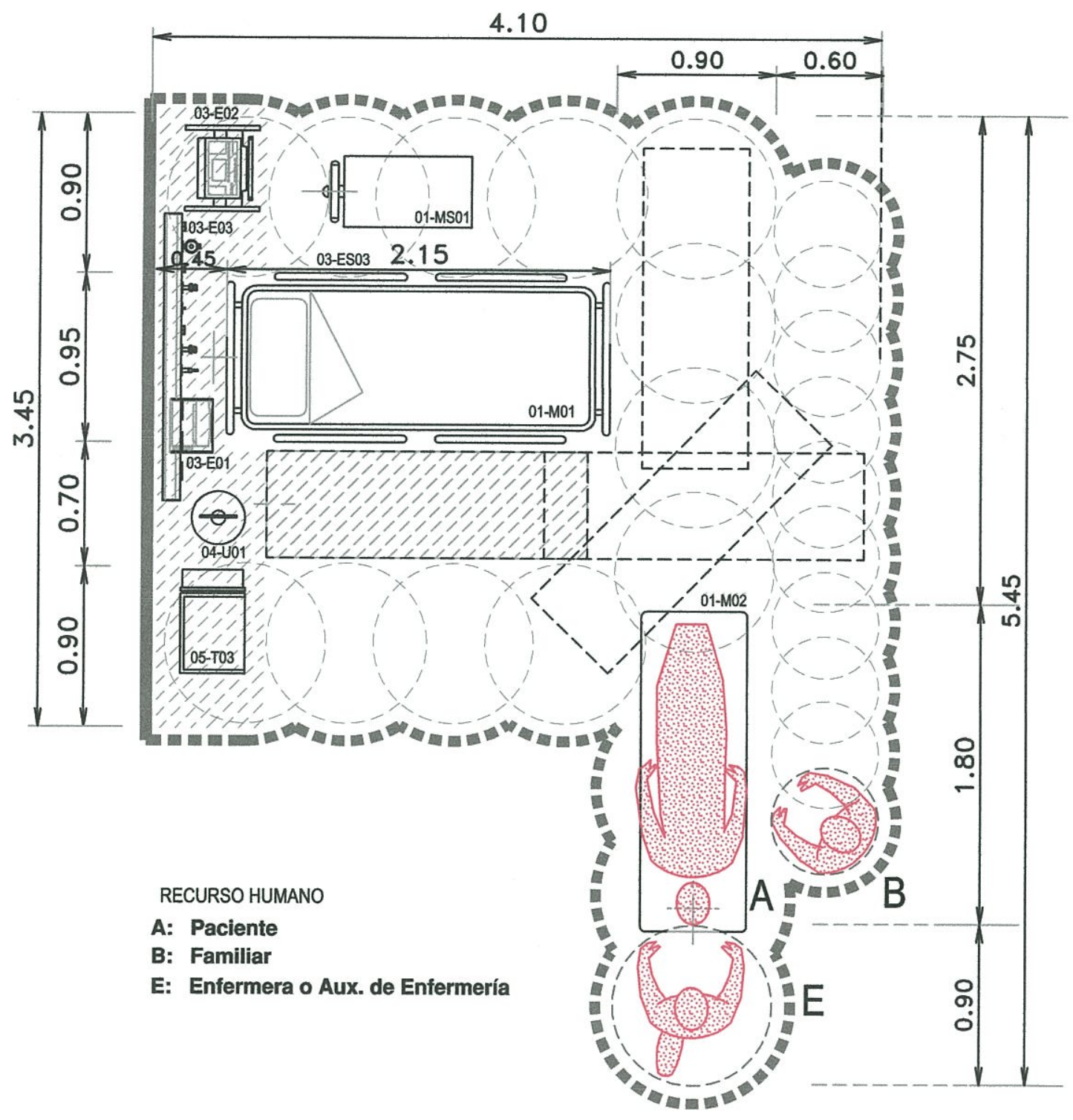




\begin{tabular}{|c|c|c|c|}
\hline \multicolumn{3}{|c|}{ RECURSO HUMANO } & \multirow{2}{*}{ DETERMINACIONES AMBIENTALES } \\
\hline Cód. & Denominación & Cant & \\
\hline $\begin{array}{l}A \\
B \\
E\end{array}$ & $\begin{array}{l}\text { Paciente } \\
\text { Familiar } \\
\text { Enfermera o Auxiliar de Enfermería }\end{array}$ & $\begin{array}{c}1 \\
102 \\
1\end{array}$ & $\begin{array}{l}\text { Las habitaciones deberán contar con lluminación natural, aire } \\
\text { climatizado y estar insonorizadas del ambiente externo (RM } \\
375 / 2002) \\
\text { Aire Acondicionado, la Unidad debe mantener la temperatura de } 25^{\circ} \text { - } \\
26^{\circ} \text { centígrados y los niveles de humedad entre } 30-60 \% \text { para prevenir } \\
\text { accidentes eléctricos derivados de un ambiente extremadamente } \\
\text { seco. (RM } 318 / 2001 \text { ) } \\
\text { Es deseable el recambio de aire } 4 \text { veces por hora en las habitaciones } \\
\text { y } 2 \text { recambios en el resto de la Unidad. (RM } 318 / 2001 \text { ) }\end{array}$ \\
\hline
\end{tabular}

\begin{tabular}{|c|c|c|c|}
\hline CONJUNTOS DE EQUIPAMIENTO & DETALLE DE EQUIPAMIENTO & CÓdiGo & $\begin{array}{l}\text { PROGRAMA } \\
\text { NACIONAL DE } \\
\text { GARANTIA DE } \\
\text { CALIDAD }\end{array}$ \\
\hline \multirow[t]{3}{*}{01 - MUEBLES } & $\begin{array}{l}\text { CAMA MOVIL, ARTICULADA, CON CABECERA FACILMENTE REBATIBLE, } \\
\text { BARANDAS ARTICULABLES Y DESMONTABLES, CON LECHO RIGIDO QUE } \\
\text { PERMITA LAS MANIOBRAS DE REANIMACION } \\
\text { CON CONTROL DE MOVIMIENTOS POR PARTE DEL, PACIENTE }\end{array}$ & 01-M01 & RM 375/2002 \\
\hline & CAMILLA DE TRANSPORTE & 01-M02 & \\
\hline & MESADA APOYO DE PACIENTE & 01-MS01 & \\
\hline 02-ARTEFACTOS Y ACCESORIOS & $\ldots$ & $\ldots$ & \\
\hline \multirow[t]{4}{*}{03 - APARATOS, EQUIPOS E INSTRUMENTOS } & $\begin{array}{l}\text { MONITOR MULTIPARAMETRICO (ECG, PO2, P1, PNI, TEMP. CENTRAL, } \\
\text { TEMP. EXTERRA). EN LACABECERA DEL PACIENTE }\end{array}$ & 03-E01 & RM 375/2002 \\
\hline & RESPIRADOR & $03-\mathrm{E} 02$ & RM 375/2002 \\
\hline & $\begin{array}{l}\text { POLIDUCTO A PARED CON TOMAS ELECTRICOS, GASES MEDICINALES Y } \\
\text { SOPORTE PARA EQUIPAMENTOS. }\end{array}$ & 03-E03 & RM 375/2002 \\
\hline & $\begin{array}{l}\text { CONTROL. REMOTO PROXIMO AL PACIENTE, DE FUNCIONES, LLAMADO A } \\
\text { ENFERMERA, ILUMINACION, ENCEDIDO DE TV Y OTROS }\end{array}$ & 03-ESO3 & \\
\hline \multirow[t]{2}{*}{ O4 - UTENSILIOS Y ARTICULOOS VARIOS } & SOPORTE PARA SUERO & 04.บ01 & \\
\hline & & & \\
\hline 05 - ELEMENTOS DE TRANSPORTE & CARRO OBANDEJA PORTA EQUIPO & $05-503$ & \\
\hline & & & \\
\hline
\end{tabular}

Resolución Ministerial RM 318/2001. Unidades de Cuidados Intensivos. Programa Nacional de Garantia de la Calidad de la Atención Médica, Ministerio de Salud de la Nación Argentina.

Resolución Ministerial RM 375/2002. Unidades de Cuidados Intensivos Cardiológicos. Programa Nacional de Garantia de la Calidad de la Atención Médica, Ministerio de Salud de la Nación Argentina. 


\section{TIPOLOGÍA T 5}

\section{TOMA DE MUESTRAS PARA LABORATORIO}

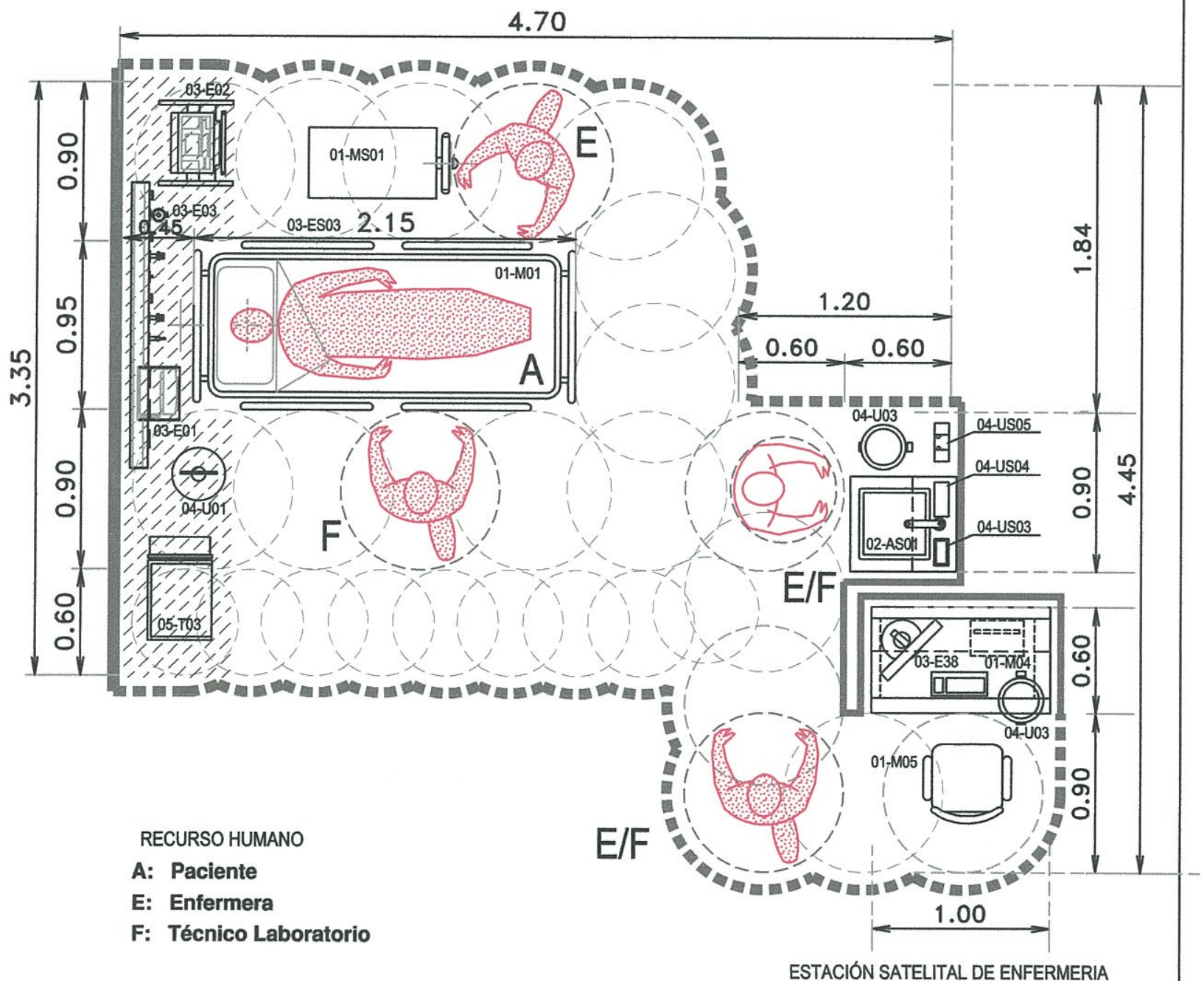

ESTACIÓN SATELITAL DE ENFERMERIA 


\begin{tabular}{|c|c|c|c|}
\hline \multicolumn{2}{|c|}{ TIPOLOGÍA T 5} & \multicolumn{2}{|c|}{ TOMA DE MUESTRAS PARA LABORATORIO } \\
\hline \multicolumn{3}{|c|}{ RECURSO HUMANO } & \multirow{2}{*}{ DETERMINACIONES AMBIENTALES } \\
\hline Cód. & Denominación & Cant & \\
\hline $\begin{array}{l}A \\
E \\
F\end{array}$ & $\begin{array}{l}\text { Paciente } \\
\text { Enfermera o Auxiliar de Enfermeria } \\
\text { Técnico de Laboratorio }\end{array}$ & $\begin{array}{l}1 \\
1 \\
1\end{array}$ & $\begin{array}{l}\text { Las habitaciones deberán contar con lluminación natural, aire } \\
\text { climatizado y estar insonorizadas del ambiente externo (RM } \\
375 / 2002 \text { ) } \\
\text { Aire Acondicionado, la Unidad debe mantener la temperatura de } 25^{\circ} \text { - } \\
26^{\circ} \text { centigrados y los niveles de humedad entre } 30-60 \% \text { para prevenir } \\
\text { accidentes eléctricos derivados de un ambiente extremadamente } \\
\text { seco. (RM } 318 / 2001 \text { ) } \\
\text { Es deseable el recambio de aire } 4 \text { veces por hora en las habitaciones } \\
\text { y } 2 \text { recambios en el resto de la Unidad. (RM } 318 / 2001 \text { ) }\end{array}$ \\
\hline
\end{tabular}

\begin{tabular}{|c|c|c|c|}
\hline CONJUNTOS DE EQUIPAMIENTO & DETALLE DE EQUIPAMIENTO & Código & $\begin{array}{l}\text { PROGRAMA } \\
\text { NACIONAL DE } \\
\text { GARANTIA DE } \\
\text { CALIDAD }\end{array}$ \\
\hline \multirow[t]{2}{*}{01 - MUEELES } & $\begin{array}{l}\text { CAMA MOVIL, ARTICULADA, CON CABECERA FACILMENTE REBATIBLE, } \\
\text { BARANDAS ARTICULAABLES Y OESMONTABLES, CON LECHO RIGIDO QUE } \\
\text { PERMITA LAS MANIOBRAS DE REANIMACION } \\
\text { CON CONTROL DE MOVIMIENTOS POR PARTE DEL PACIENTE }\end{array}$ & 01-M01 & RM 375/2002 \\
\hline & MESADA APOYO DE PACIENTE & 01-MSO1 & \\
\hline 02 - ARTEFACTOS Y ACCESORIOS & $\begin{array}{l}\text { LAVATORIO MONOCOMANDO (PROXIMO AL ACCESO PARA PROPICIAR } \\
\text { EL LAVADO DE MANOS). }\end{array}$ & 02-AS01 & \\
\hline \multirow[t]{4}{*}{ O3 - APARATOS, EQUIPOS E INSTRUMENTOS } & $\begin{array}{l}\text { MONITOR MULTIPARAMETRICO (ECG, PO2, PI, PNI, TEMP. CENTRAL, } \\
\text { TEMP. EXTERNA). EN LA CABECERA DEL PACIENTE. }\end{array}$ & 03-EO1 & RM 375/2002 \\
\hline & RESPIRADOR & $03-E 02$ & RM 375/2002 \\
\hline & $\begin{array}{l}\text { POLIDUCTO A PARED CON TOMAS ELECTRICOS, GASES MEDICINALES Y } \\
\text { SOPORTE PARA EQUIPAMIENTOS. }\end{array}$ & 03-E03 & RM 375/2002 \\
\hline & $\begin{array}{l}\text { CONTROL REMOTO PROXIMO AL PACIENTE, DE FUNCIONES, LLAMADO } \\
\text { A ENFERMERA, ILUMINACION, ENCEDIDO DE TVY OTROS }\end{array}$ & O3-ESO3 & \\
\hline \multirow[t]{5}{*}{ 04-UTENSILIOS Y ARTICULOS VARIOS } & SOPORTE PARA SUERO & 04.L101 & \\
\hline & CESTO METALICO TAPA A PEDAL. & $04-\mathrm{U} 03$ & \\
\hline & JABON ESPECIAL LAVADO DE MANOS & 04.US03 & \\
\hline & TOALLAS DE PAPEL PARA SECADO DE MANOS & 04-US04 & \\
\hline & GUANTES DESCARTAELES & O4-US05 & \\
\hline O5-ELEMENTOS DE TRANSPORTE & CARRO O BANDEJA PORTA EQUIPO & 05-T03 & \\
\hline
\end{tabular}

\section{ESTACION SATELITAL DE ENFERMERIA}

\begin{tabular}{|c|c|c|c|}
\hline CONJUNTOS DE EQUIPAMIENTO & DETALLE DE EQUIPAMIENTO & CóDIGO & $\begin{array}{c}\text { PROG. NACIONAL } \\
\text { DE GARANTIAA DE } \\
\text { CALIDAD }\end{array}$ \\
\hline 01 -MUEBLES & MESA MOSTRADOR & $01-M 04$ & \\
\hline & SILLA RODANTE GIRATORIA & $01-\mathrm{M} 05$ & \\
\hline O3 - APARATOS, EQUIPOS E INSTRUMENTOS & ESTACION SATELITAL DE MONITOREO (PC) & 03-E38 & \\
\hline O4 - UTENSILIOS Y ARTICULOS VARIOS & CESTO METÁLICO TAPA A PEDAL & $04-603$ & \\
\hline
\end{tabular}

Resolución Ministerial RM 318/2001. Unidades de Cuidados Intensivos. Programa Nacional de Garantía de la Calidad de la Atención Médica, Ministerio de Salud de la Nación Argentina.

Resolución Ministerial RM 375/2002. Unidades de Cuidados Intensivos Cardiológícos. Programa Nacional de Garantía de la Calidad de la Atención Médica, Ministerio de Salud de la Nación Argentina. 


\section{TIPOLOGÍA T 6 :}

VISITA DE FAMILIARES

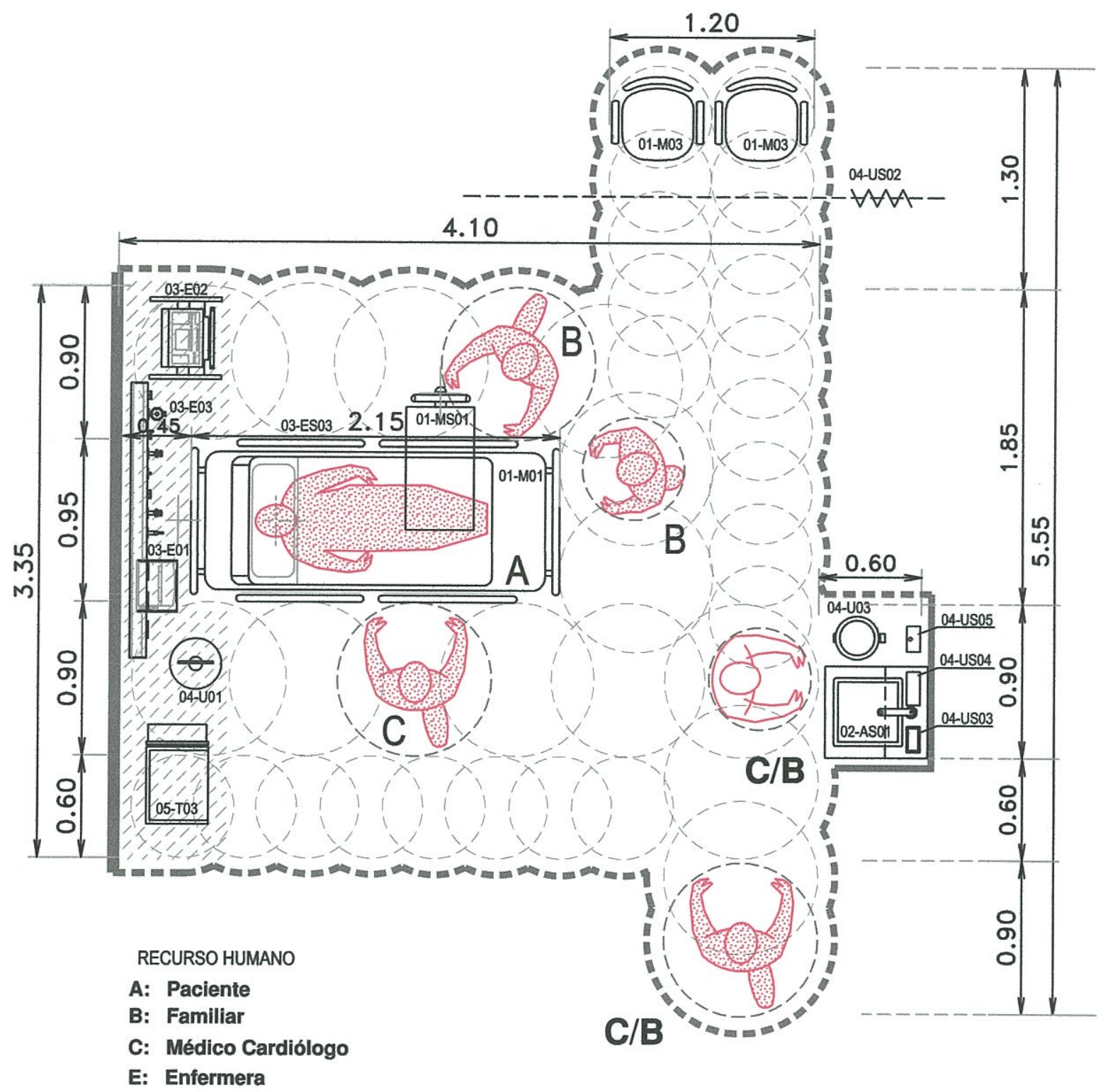


Facultad de Arquitectura y Urbanismo, Universidad Nacional de la Plata

\section{TIPOLOGÍA T 6}

\section{VISITA DE FAMILIARES}

\begin{tabular}{|c|c|c|c|}
\hline \multicolumn{3}{|c|}{ RECURSO HUMANO } & \multirow[t]{2}{*}{ DETERMINACIONES AMBIENTALES } \\
\hline Cód. & Denominación & Cant & \\
\hline $\begin{array}{l}\mathrm{A} \\
\mathrm{B} \\
\mathrm{C} \\
\mathrm{E}\end{array}$ & $\begin{array}{l}\text { Paciente } \\
\text { Familiar } \\
\text { Medico Cardiólogo } \\
\text { Enfermera }\end{array}$ & $\begin{array}{c}1 \\
102 \\
1 \\
1\end{array}$ & $\begin{array}{l}\text { Las habitaciones deberán contar con lluminación natural, aire } \\
\text { climatizado y estar insonorizadas del ambiente externo (RM } \\
375 / 2002 \text { ) } \\
\text { Aire Acondicionado, la Unidad debe mantener la temperatura de } 25^{\circ} \text { - } \\
26^{\circ} \text { centigrados y los niveles de humedad entre } 30-60 \% \text { para prevenir } \\
\text { accidentes eléctricos derivados de un ambiente extremadamente } \\
\text { seco. (RM } 318 / 2001 \text { ) } \\
\text { Es deseable el recambio de aire } 4 \text { veces por hora en las habitaciones } \\
\text { y } 2 \text { recambios en el resto de la Unidad. (RM } 318 / 2001 \text { ) }\end{array}$ \\
\hline
\end{tabular}

\begin{tabular}{|c|c|c|c|}
\hline CONJUNTOS DE EQUIPAMIENTO & DETALLE DE EQUIPAMIENTO & Código & $\begin{array}{l}\text { PROGRAMA } \\
\text { NACIONAL DE } \\
\text { GARANTIA DE } \\
\text { CALIDAD }\end{array}$ \\
\hline \multirow[t]{4}{*}{ Of - MUEEBLES } & $\begin{array}{l}\text { CAMA MOVIL, ARTICULADA, CON CABECERA FACILMENTE REBATIBLE, } \\
\text { BARANDAS ARTICULAELES Y DESMONTABLES, CON LECHO RIGIDO QUE } \\
\text { PERMITA LAS MANIOERAS DE REANIMACION } \\
\text { CON CONTROL OE MOVIMIENTOS POR PARTE DEL PACIENTE }\end{array}$ & 01-M01 & RM 375/2002 \\
\hline & SILLON DE ACOMPANANTE & 01-M03 & \\
\hline & MESADA APOYO DE PACIENTE & 01-MS01 & \\
\hline & TELEVISOR CON CONTROL REMOTO & $01-\mathrm{MSO3}$ & \\
\hline 02 - ARTEFACTOS Y ACCESORIOS & $\begin{array}{l}\text { LAVATORIO MONOCOMANDO (PROXIMO AL ACCESO PARA PROPICIAR } \\
\text { EL LAVADO DE MANOS). }\end{array}$ & 02-AS01 & \\
\hline \multirow[t]{4}{*}{ 03 - APARATOS, EQUIPOS E INSTRUMENTOS } & $\begin{array}{l}\text { MONITOR MULTIPARAMETRRICO (ECG, PO2, PI, PNI, TEMP. CENTRAL, } \\
\text { TEMP. EXTERNA). EN LA CABECERA DEL PACIENTEE }\end{array}$ & 03-E01 & RM 375/2002 \\
\hline & RESPIRADOR & $03-\mathrm{E} 02$ & RM 375/2002 \\
\hline & $\begin{array}{l}\text { POLIDUCTO A PARED CON TOMAS ELECTRICOS, GASES MEDICINALES Y } \\
\text { SOPORTE PARA EQUIPAMIENTOS. }\end{array}$ & 03-E03 & RM 375/2002 \\
\hline & $\begin{array}{l}\text { CONTROL REMOTO PROXIMO AL PACIENTE, DE FUNCIONES, LLAMADO A } \\
\text { ENFERMERA, LLUMINACION, ENCEDIDO DE TVY OTROS }\end{array}$ & 03-ES03 & \\
\hline \multirow[t]{6}{*}{ O4 - UTENSILIOS Y ARTICULOS VARIOS } & SOPORTE PARA SUERO & 04-U01 & \\
\hline & CESTO METÄLICO TAPA A PEDAL & 04-U03 & \\
\hline & CORTINA PARA GUARDAR PRIVACIDAD DE PACIENTE & 04-USO2 & \\
\hline & JABON ESPECIAL LAVADO DE MANOS & 04-USO3 & \\
\hline & TOALLAS DE PAPEL PARA SECADO DE MANOS & 04-LSO4 & \\
\hline & GUANTES DESCARTABLES & O4-USO5 & \\
\hline O5 - ELEMENTOS DE TRANSPORTE & CARRO O BANDEJA PORTA EQUIPO & 05-T03 & \\
\hline & & & \\
\hline
\end{tabular}

Resolución Ministerial RM 318/2001. Unidades de Cuidados Intensivos. Programa Nacional de Garantía de la Calidad de la Atención Médica, Ministerio de Salud de la Nación Argentina.

Resolución Ministerial RM 375/2002. Unidades de Cuidados Intensivos Cardiológicos. Programa Nacional de Garantía de la Calidad de la Atención Médica, Ministerio de Salud de la Nación Argentina. 


\subsection{Contrastación de la Hipótesis a través de la Argumentación Proyectual. Propuesta Arquitectónica para Habitación de Cuidados Cardiológicos}

La Propuesta Arquitectónica presentada para la Habitación del Cuidados Intensivos Cardiológicos contiene los nuevos Condicionantes Ambientales indispensables para caracterizar el nuevo ambiente saludable que se propone. La aplicación de la Propuesta en nuevos proyectos arquitectónicos, permitirá verificar el valor de las nuevas concepciones.

La Propuesta Proyectual surge y de la aplicación de Modelo Propuesto MP de Condicionantes Arquitectónicas y del estudio de las Tipologías Seleccionadas. Por lo tanto, todas las especificaciones presentadas están incluidas en la Propuesta Arquitectónica.

Desearia, sin embargo, hacer algunas observaciones y aclarar algunos conceptos en cuanto a la forma en que fueron aplicados los Condicionantes en la Solución Proyectual

Las Condicionantes de Valor Alto o Fundamental, Iluminación, Sonidos, Accesibilidad, Orientación, Proporciones, Distribución del Equipamiento y Confort, fueron las primeras en ser incorporadas, sin embargo surgieron algunas superposiciones e inclusiones en los espacios para la localización de las mismas.

La ubicación de una ventana por la cual el paciente pudiera observar el exterior premisa resaltada como fundamental para propiciar la orientación temporo - espacial del paciente y la ubicación del baño próximo a este para disminuir su desplazamiento, plantearon un problema de superposición de espacios, esto fue resuelto a través de la disposición de una pared en diagonal, concurrente con las visuales del paciente desde la cama, que posibilita a su vez la entrada de mayor cantidad de luz en la habitación. El baño de la propuesta cuenta con luz natural, junto con todos los elementos necesarios para el confort del paciente. Se ha incorporado en la ducha un asiento especial para que el paciente se pueda bañar sentado, se adicionaron barrales fijos y móviles a los lados de los artefactos de baño para la seguridad de sus movimientos.

La premisa de proporcionar un espacio para los familiares se reforzó con la idea de crear un área personal para el paciente, con la ubicación de un ropero y una cortina para resguardar su privacidad. Este mismo espacio se propone como de área de espera de familiares si es necesario realizar algún procedimiento al paciente estando estos presentes.

Si bien la habitación deberá contar con aislantes acústicos en sus pisos, paredes y cielorraso. Se propone la colocación de dos paneles; a la cabecera y al frente del paciente que funcionen como absorbentes acústicos y a su vez como elemento de diseño. 
Facultad de Arquitectura y Urbanismo, Universidad Nacional de la Plata

El espacio sombra a la cabecera de la cama, es justamente el espacio fuera de la vista del paciente, la cama se encuentra desplazada de la pared para fácil acceso y maniobra del equipo médico y de enfermería. El espacio sombra frente al paciente funciona como lugar para la ubicación de equipamiento no frecuente.

El lavatorio en la habitación propicia el lavado de manos, se supone que previa a la entrada de los familiares a la habitación estos ya se han lavado las manos en otro espacio de la Unidad previsto para este cuidado. La localización del lavatorio en el acceso a la habitación cumple con la función de brindar el confort a médicos, enfermeras y técnicos mediante el fácil acceso a este accesorio para antes y después de realizar los diferentes procedimientos en el paciente.

La iluminación artificial central esta especificada en las Normas del Programa Nacional de Garantía de la Calidad de la Atención Medica del Ministerio de la Nación RM 318/2001 y RM 375/2002 y la luz específica para el paciente esta estudiada de manera que el paciente pueda realizar algunas de las actividades como lo es la lectura. En cuanto a elementos para distracción como lo son la televisión, y el reloj con almanaque están ubicados al frente del paciente y serán de fácil visualización, los controles para su encendido así como los controles de la luz del paciente se encuentran adosados al costado de la cama.

En cuanto al equipamiento médico y no médico (correspondiente al pacientes y sus familiares), este no solo debe cumplir con especificaciones de la normativa sino que también deberá cumplir con proveer de un diseño que promueva su fácil accionamiento y el máximo confort por parte de sus usuarios, sean estos el paciente y sus familiares o el equipo médico. Se necesita del estudio de ideas innovadoras que cumplan con los estrictos estándares de seguridad, cuya premisa sea la simplicidad de la forma, con la aplicación de materiales durables y de excelente calidad. Se puede tomar como ejemplo de la actualidad el desarrollo alcanzado por la industria aeronáutica para el interior de cabinas de aviones donde lo reducido del espacio hace necesario un muy ajustado control de las formas.

En cuanto a las Condicionantes de Valor Medio o de Interés, Colores, Texturas, Naturaleza y Música, fueron incorporados asociados en muchos casos a las Condicionantes de Valor Alto, un ejemplo de esto se ve en la ubicación de plantas en el exterior de la habitación para ser observadas desde el interior para el caso de incorporación de la Naturaleza o la colocación del panel absorbente de sonidos con el diseño de Color y Textura, o la incorporación de la Música a través del Confort de la televisión.

La cercanía de la estación Satelital de Enfermería, en el acceso a la habitación brinda al paciente el confort psicológico de la presencia del equipo médico, las puertas corredizas con vidrio superior del acceso dan posibilidad al paciente de observar hacia el interior de la Unidad. La cortina ubicada paralela al cerramiento ofrece privacidad al paciente si este la necesita. 
En concordancia de la Propuesta Arquitectónica se desarrolla un Cuadro donde se reconoce el recurso humano y se observan los determinantes ambientales solicitadas en cuanto a; la lluminación, el Aire Acondicionado y Recambio de Aire, a su vez se indican los Conjuntos de Equipamiento, Detalles del Equipamientos, Código (donde nuevamente se ha incorporado con una "s" de satisfacción, a todo aquel equipamiento incorporado debido a las Condicionantes Ambientales estudiadas), junto con los requerimientos de las Instalaciones y cumplimiento con la Normas PNGC MSN RM 318/2001 y 375/2002.

La Documentación presentada de la habitación de Internación de Cuidados Intensivos Cardiológicos a través de un Plano realizado en Autocad, se completa con la presentación de tres Cortes Vista, Corte Vista 1-1, Corte Vista 2-2 y Corte Vista 3-3.

El estudio de esta nueva propuesta observada desde la perspectiva del paciente, permite observar al paciente ubicado en el centro de las actividades de la atención, controlando con su mirada el espacio que lo rodea a través de las imágenes de Visuales del Paciente Internado 1 y Visuales del Paciente Internado 2.

Dentro de las posibilidades de contrastación, que nos permiten las nuevas tecnologías informáticas, es interesante tener en cuenta que esta propuesta también puede ser contrastada a través de la Realidad Virtual (Virtual Reality). El desarrollo de los planos en Autocad, señala un antecedente previo para el diseño de la maqueta electrónica que posibilitará la estructuración de dicho modelaje

\section{A continuación La Propuesta Arquitectónica para la Habitación de Cuidados Intensivos Cardiológicos}

Planta de la Propuesta Arquitectónica para la Habitación de Cuidados Intensivos Cardiológicos. Esc. 1:40, con su respectivo cuadro de análisis.

Cortes Vista, Corte Vista 1-1, Corte Vista 2-2 y Corte Vista 3-3 Esc. 1:40

En base a la Propuesta Arquitectónica, Visuales del Paciente Internado 1 y 2 


\section{PROPUESTA ARQUITECTONICA PARA HABITACION DE CUIDADOS INTENSIVOS CARDIOLOGICOS}

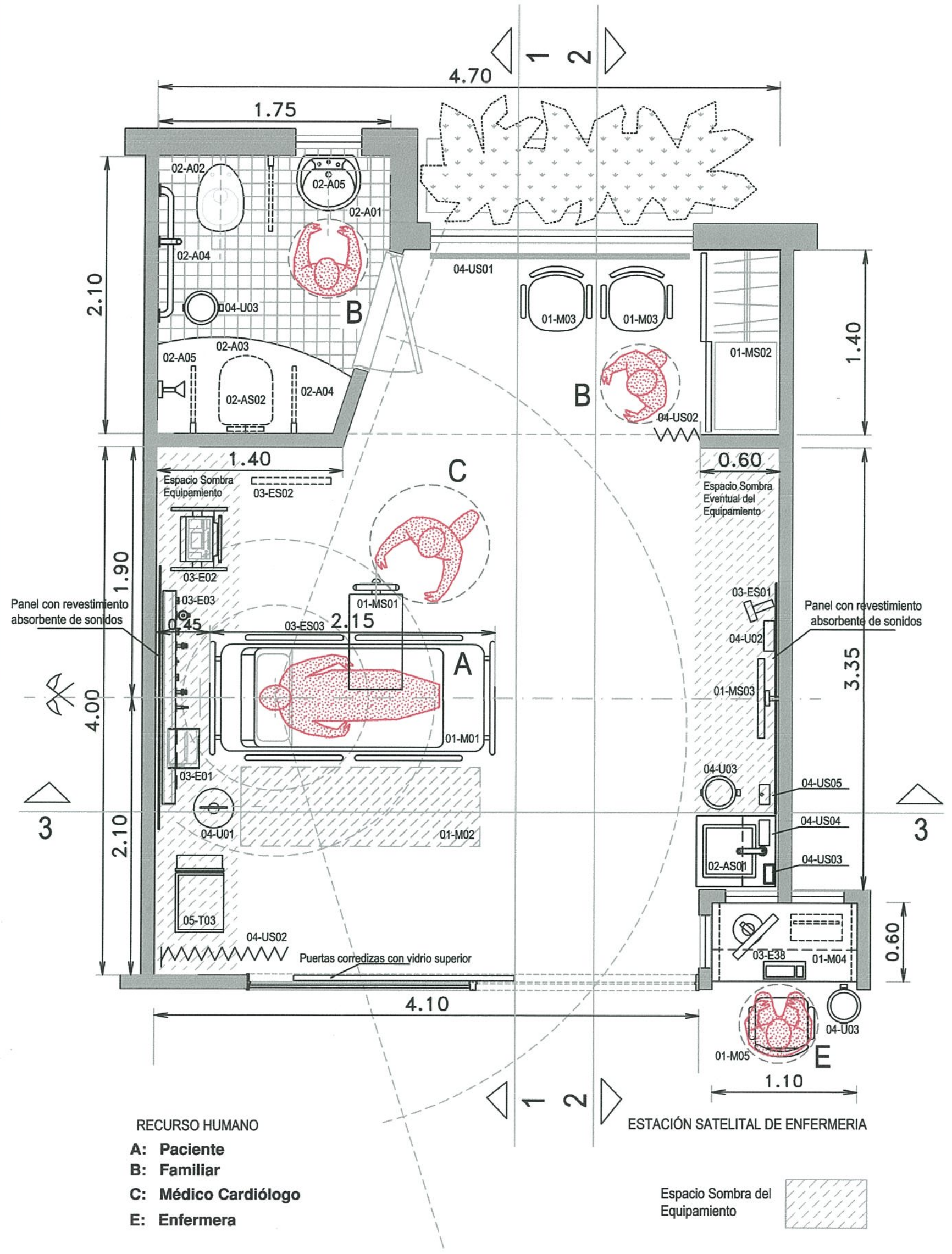




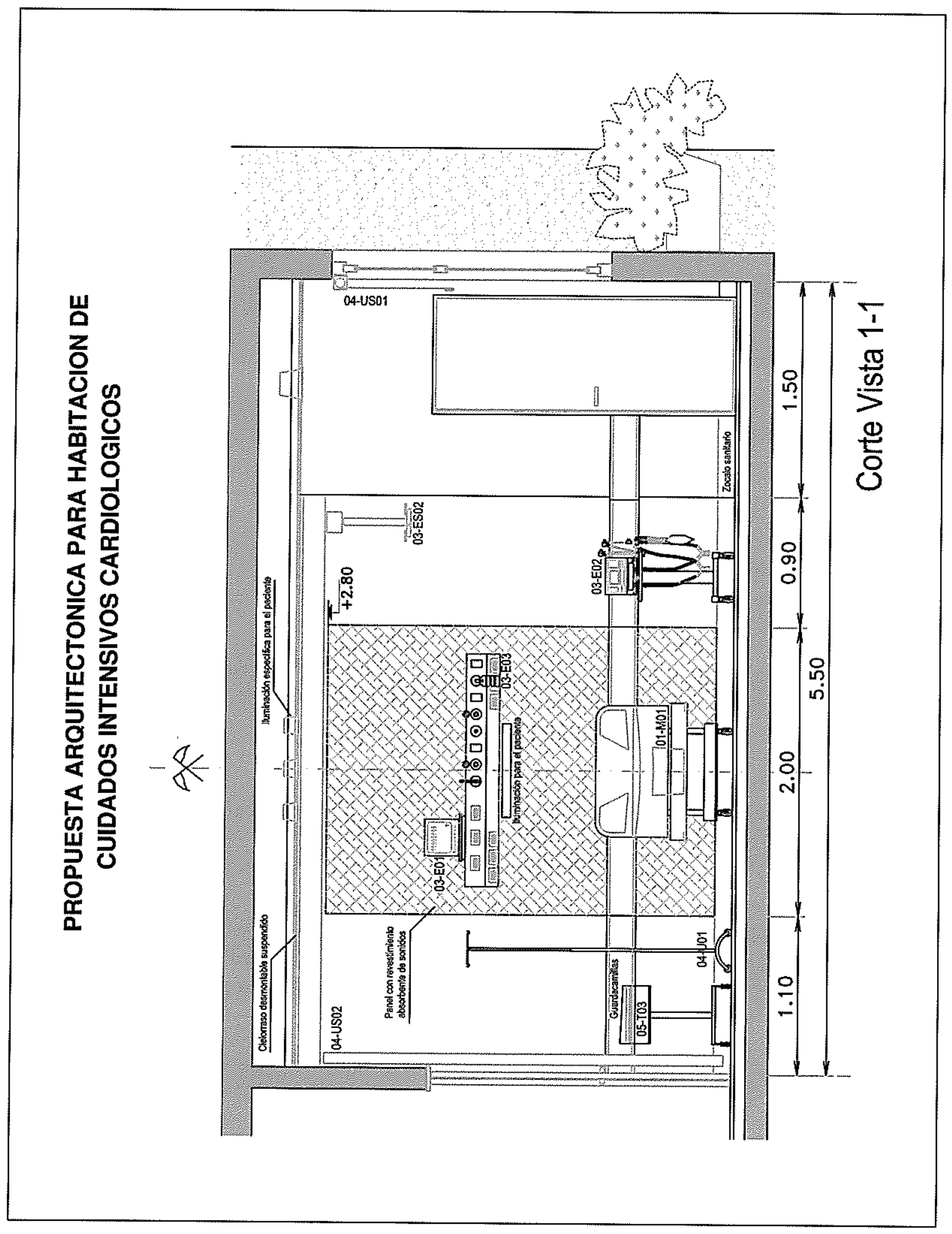




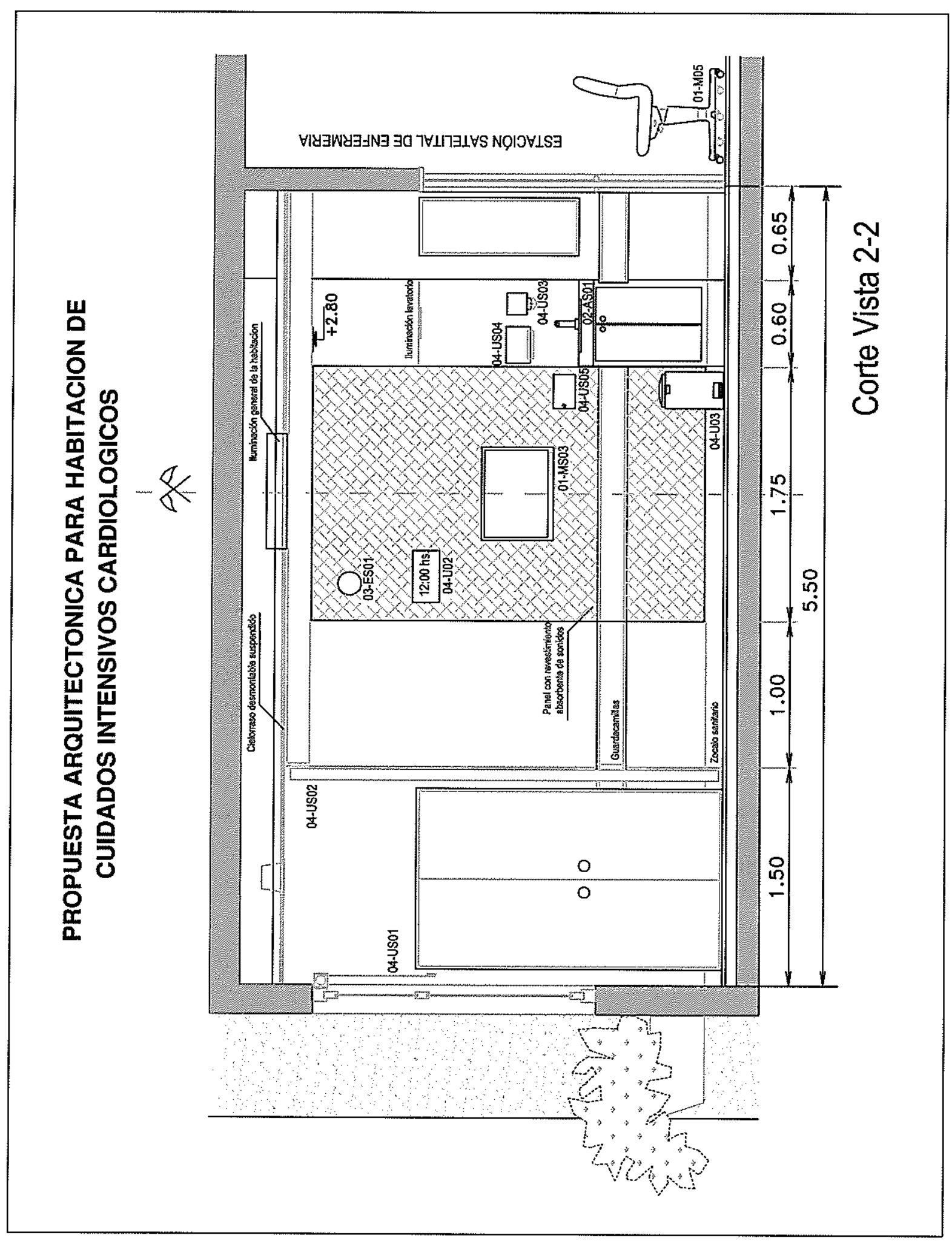




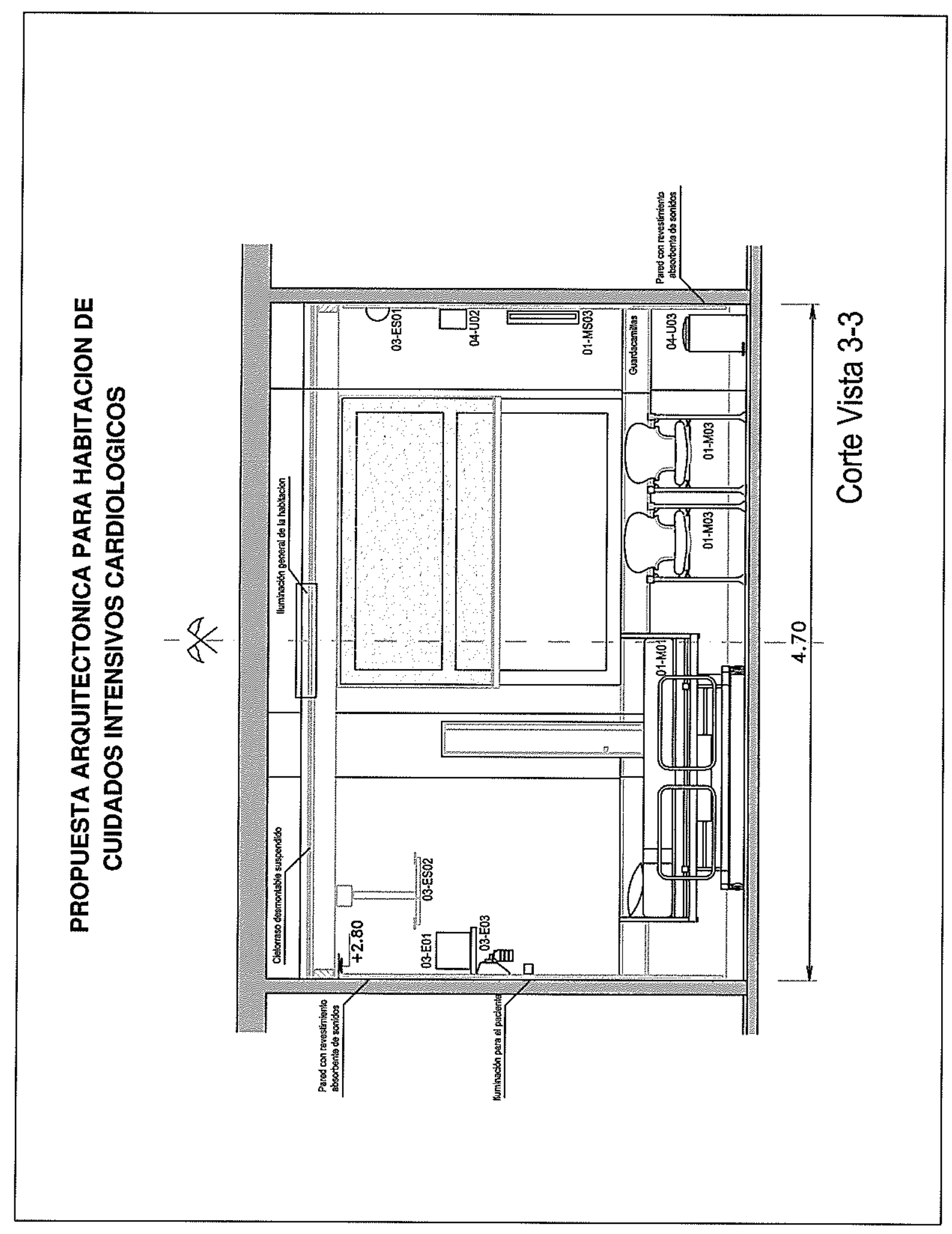




\section{HABITACIÓN DEL CUIDADOS INTENSIVOS CARDIOLÓGICOS}

\begin{tabular}{|c|c|c|c|}
\hline \multicolumn{3}{|c|}{ RECURSO HUMANO } & \multirow{2}{*}{ DETERMINACIONES AMBIENTALES } \\
\hline Cód. & Denominación & Cant & \\
\hline $\begin{array}{l}\mathrm{A} \\
\mathrm{B} \\
\mathrm{C} \\
\mathrm{E}\end{array}$ & $\begin{array}{l}\text { Paciente } \\
\text { Familiar } \\
\text { Medico Cardiólogo } \\
\text { Enfermera }\end{array}$ & $\begin{array}{c}1 \\
102 \\
1 \\
1\end{array}$ & $\begin{array}{l}\text { Las habitaciones deberán contar con lluminación natural, aire } \\
\text { climatizado y estar insonorizadas del ambiente externo (RM } \\
375 / 2002 \text { ) } \\
\text { Aire Acondicionado, la Unidad debe mantener la temperatura de } 25^{\circ} \text { - } \\
26^{\circ} \text { centígrados y los niveles de humedad entre } 30-60 \% \text { para prevenir } \\
\text { accidentes eléctricos derivados de un ambiente extremadamente } \\
\text { seco. (RM } 318 / 2001 \text { ) } \\
\text { Es deseable el recambio de aire } 4 \text { veces por hora en las habitaciones } \\
\text { y } 2 \text { recambios en el resto de la Unidad. (RM } 318 / 2001 \text { ) }\end{array}$ \\
\hline
\end{tabular}

\begin{tabular}{|c|c|c|c|}
\hline CONJUNTOS DE EQUIPAMIENTO & DETALLE DE EQUIPAMIENTO & CÓDIGO & $\begin{array}{l}\text { PROGRAMA } \\
\text { NACIONAL DE } \\
\text { GARANTIA DE } \\
\text { CALIDAD }\end{array}$ \\
\hline \multicolumn{4}{|l|}{ O1 - MUEBLES } \\
\hline & $\begin{array}{l}\text { CAMA MOVIL, ARTICULADA, CON CABECERA FACILMENTE REBATIBLE, } \\
\text { BARANDAS ARTICULABLES Y DESMONTABLES, CON LECHO RIGIDO QUE } \\
\text { PERMITA LAS MANIOBRAS DE REANIMACION, SE SUGIERE QUE EL } 20 \% \\
\text { DE LAS CAMAS DE LA UNIDAD TENGAN LECHO RADIOSENSIBLE PARA } \\
\text { LOS PACIENTES DE MAYOR COMPLEJIDAD. }\end{array}$ & 01-M01 & RM 375/2002 \\
\hline & CAMILLA DE TRANSPORTE & $01-M 02$ & \\
\hline & SILLON DE ACOMPAÑANTE & $01-M 03$ & \\
\hline & & & \\
\hline & MESADA APOYO DE PACIENTE & 01-MS01 & \\
\hline & ROPERO PARA OBJETOS DEL PACIENTE & $01-\mathrm{MSO} 2$ & \\
\hline & TELEVISOR CON CONTROL REMOTO & $01-\mathrm{MSO3}$ & \\
\hline \multicolumn{4}{|l|}{ 02 - ARTEFACTOS Y ACCESORIOS } \\
\hline & LAVATORIO MONOCOMANOO BAN̄O & $02-A 01$ & \\
\hline & INODORO & 02-A02 & \\
\hline & RECEPTACULO DUCHA & $02-A 03$ & \\
\hline & BARRALES FIJOS Y BARRALES REBATIBLES & $02-A 04$ & \\
\hline & GRIFERIA DE FACIL ACCIONAMIENTO & 02-A05 & \\
\hline & $\begin{array}{l}\text { LAVATORIO MONOCOMANDO PROXIMO AL ACCESO PARA PROPICIAR EL } \\
\text { LAVADO DE MANOS }\end{array}$ & 02-ASO1 & \\
\hline & ASIENTO DE DUCHA REBATIBLE & 02-ASO2 & \\
\hline \multicolumn{4}{|l|}{03 - APARATOS, EQUIPOS E INSTRLMENTOS } \\
\hline & $\begin{array}{l}\text { MONITOR MULTIPARAMÉTRICO (ECG, PO2, Pl, PNI, TEMP. CENTRAL, } \\
\text { TEMP. EXTERNA). EN LA CABECERA DEL PACIENTE }\end{array}$ & 03-E01 & RM 375/2002 \\
\hline & RESPIRADOR & 03-E02 & RM 375/2002 \\
\hline & $\begin{array}{l}\text { POLIDUCTO A PARED CON TOMAS ELÉCTRICOS, GASES MEDICINALES Y } \\
\text { SOPORTE PARA EQUIPAMIENTOS. DEBERA DISPONER DE DOS TOMAS DE } \\
\text { OXIGENO UNA DE AIRE COMPRIMIDO Y UNA DE VACIO. }\end{array}$ & 03-E03 & RM 375/2002 \\
\hline & CAMARA A CIRUCITO CERRADO TV CON MONITOREO LAS 24HS & D3-ES01 & \\
\hline & $\begin{array}{l}\text { SOPORTE PARA DESPAZAMIENTO DE PACIENTE MEDIANTE RIELES EN } \\
\text { CIERLORRASO }\end{array}$ & O3-ESO2 & \\
\hline & $\begin{array}{l}\text { CONTROL REMOTO PROXIMO AL PACIENTE, DE FUNCIONES, LLAMADO A } \\
\text { ENFERMERA, ILUUMINACION, ENCEDIDO DE TVY OTROS }\end{array}$ & O3-ES03 & \\
\hline
\end{tabular}




\begin{tabular}{|c|c|c|c|}
\hline CONJUNTOS DE EQUIPAMIENTO & DETALLE DE EQUIPAMIENTO & Código & $\begin{array}{l}\text { PROGRAMA } \\
\text { NACIONAL DE } \\
\text { GARANTIA DE } \\
\text { CALIDAD }\end{array}$ \\
\hline \multicolumn{4}{|l|}{04 - UTENSILIOS Y ARTICULOS VARIOS } \\
\hline & SOPORTE PARA SUERO & 04-U04 & \\
\hline & RELOJ DE PARED (QUE SEA VISUALIZADO POR EL PACIENTE). & 04-L02 & \\
\hline & CESTO METÁLICO TAPA A PEDAL & 04-U03 & \\
\hline & CORTINA TAMIZ CONTROL ACCESO DE LUZ & $04-$ US01 & \\
\hline & CORTINA PARA GUARDAR PRIVACIDAO DE PACIENTE & $04 \cdot \mathrm{USO2}$ & \\
\hline & JABON ESPECIAL LAVADO DE MANOS & 04-USO3 & \\
\hline & TOALLAS DE PAPEL PARA SECADO DE MANOS & $04-U S O 4$ & \\
\hline & GUANTES DESCARTABLES & 04-USO5 & \\
\hline \multicolumn{4}{|l|}{05 - ELEMENTOS DE TRANSPORTE } \\
\hline & CARRO O BANDEJA PORTA EQUIPO & $05-703$ & \\
\hline
\end{tabular}

\section{ESTACION SATELITAL DE ENFERMERIA}

\begin{tabular}{|c|c|c|c|}
\hline CONJUNTOS DE EQUIPAMIENTO & DETALLE DE EQUIPAMIENTO & CÓDIGO & $\begin{array}{l}\text { PROG. NACIONAL } \\
\text { DE GARANTÍA DE } \\
\text { CALIDAD }\end{array}$ \\
\hline O1-MUEBLES & MESA MOSTRADOR & $01-M 04$ & \\
\hline & SILLA RODANTE GIRATORIA & $01 . \mathrm{MO5}$ & \\
\hline 03 - APARATOS, EQUIPOS E INSTRUMENTOS & ESTACIONN SATELITAL DE MONITOREO (PC) & 03-E38 & \\
\hline 04 - UTENSILIOS Y ARTICULOS VARIOS & CESTO METÁLICO TAPA A PEDAL & 04.403 & \\
\hline
\end{tabular}

\begin{tabular}{|c|c|}
\hline INSTALACIONES & $\begin{array}{l}\text { PROGRAMA } \\
\text { NACIONAL. DE } \\
\text { GARANTIA DE } \\
\text { CALIDAD }\end{array}$ \\
\hline $\begin{array}{l}\text { ESTACION CENTRAL CON CONTROL VISUAL. Y REGISTRO EN PAPEL DEL ECG DE CADA PACIENTE. DEBE DISPONER DE SISTEMA DE } \\
\text { ACTIVACION Y DETECCION DE ALARMAS PREFIJADAS EN EL MONITOR DE CABECERA. SE SUGIERE LA CONVENIENCIA DE SITEMA DE } \\
\text { ALMACENADO EN MEORIA MAGNATICA DEL. REGISTRO DEL ECS DE AL MENOS } 48 H S \text {. DE DURACION Y DE SER POSIBLE QUE SE PUEDA } \\
\text { IMPRIMIR. }\end{array}$ & RM 375/2001 \\
\hline OXIGENO CENTRALIZADO & RM 375/2002 \\
\hline ASPIRACIÓN CENTRALIZADA & RM 375/2002 \\
\hline AIRE COMPRIMIDO CENTRALIZADO & RM $375 / 2002$ \\
\hline ILUMINACION CENTRAL. & RM 375/2002 \\
\hline $\begin{array}{l}\text { ILUMINACIÓN INDIVIDUAL PARA EL PACIENTE NO MENOR DE } 100 \text { LUX (CONTROLADA DE FORMA AUTONOMA POR EL PACIENTE DESDE } \\
\text { LA CAMA). }\end{array}$ & RM 375/2002 \\
\hline $\begin{array}{l}\text { TOMAS ELECTRICOS: } 10 \text { TOMAS CORRIENTE DE } 220 \text { VOLTS, ES ACONSEJABLE LA PRESENCIA EN CADA HABITACION DE TOMAS PARA } \\
\text { CORRIENTE } 110 \text { VOLTS Y UNA TOMA CON CARACTERITICAS DISTINTAS DE LAS DEMAS PARA EQUIPOS DE RAYOS PORTATIL CON LINEA } \\
\text { CORRIENTE INDEPENDIENTE DE LA DE LA HABITACION. }\end{array}$ & RM 375/2002 \\
\hline TODOS LOS SISTEMAS ELECTRONICOS DEBERAN ESTAR PROTEGIDOS CON SITEMAS TERMICOS CONTRA CHOQUES ELECTRICOS. & RM $375 / 2002$ \\
\hline $\begin{array}{l}\text { DESOE LA CABECERA DEL PACIENTE DEBE SER POSIBLE ACTIVAR CON FACILIDAD UN INTERRUPTOR QUE DE LA SEÑAL DE ALARMA EN } \\
\text { LA ESTACION CENTRAL DE ENFERMERIA, LA HABITACION DEL MEOICO DE GUARDIALA SALA DE TRABAJO MEDICO EN CASO DE } \\
\text { EMRGENCIA, PERFECTAMENTE INDIVIDUALIZADA Y DE COLOR DISTIGUIBLE DE LOS DEMAS. }\end{array}$ & RM 375/2002 \\
\hline
\end{tabular}

Resolución Ministerial RM 318/2001. Unidades de Cuidados Intensivos. Programa Nacional de Garantía de la Calidad de la Atención Médica, Ministerio de Salud de la Nación Argentina.

Resolución Ministerial RM 375/2002. Unidades de Cuídados Intensivos Cardiológicos. Programa Nacional de Garantia de la Calidad de la Atención Médica, Ministerio de Salud de la Nación Argentina. 


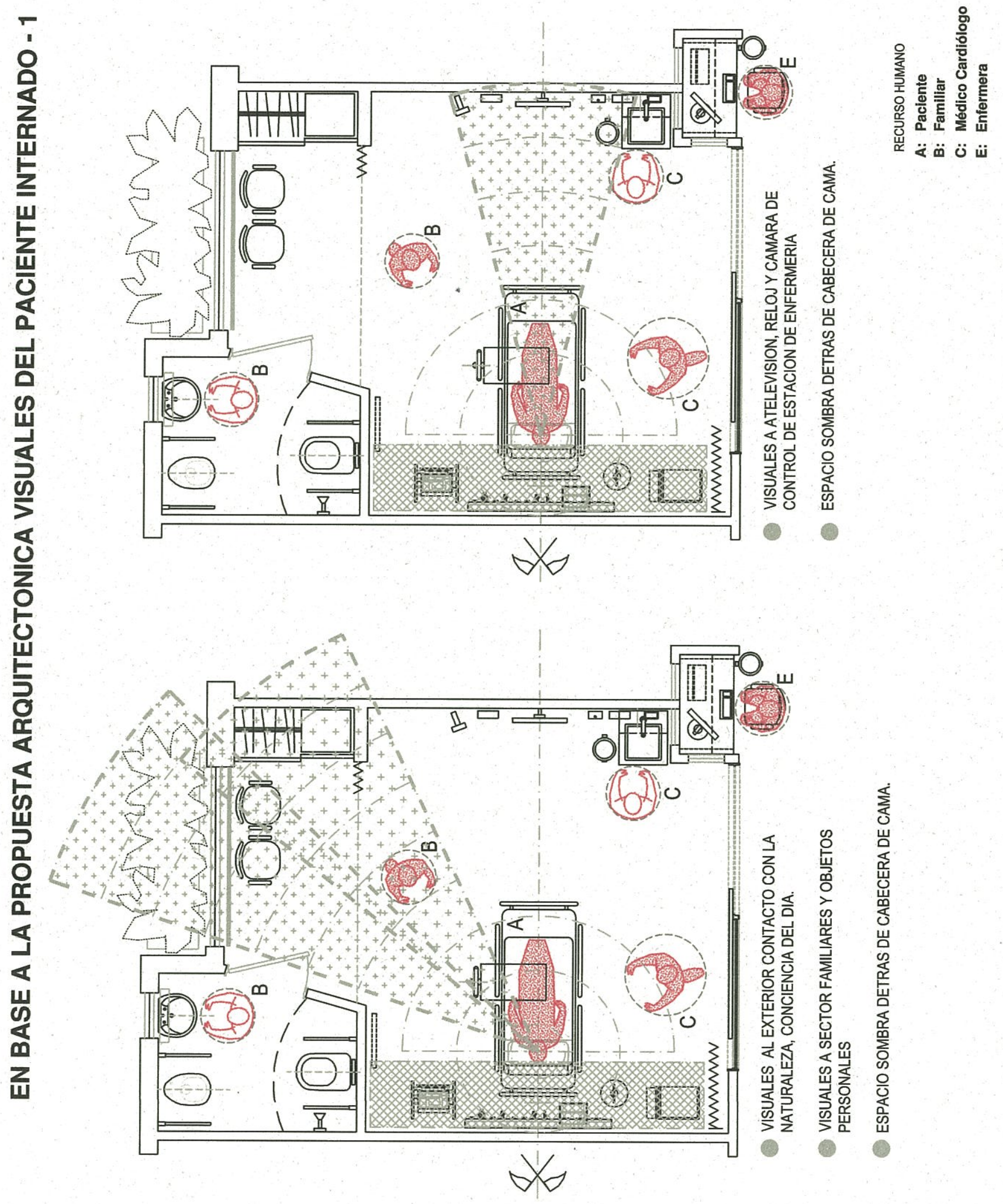




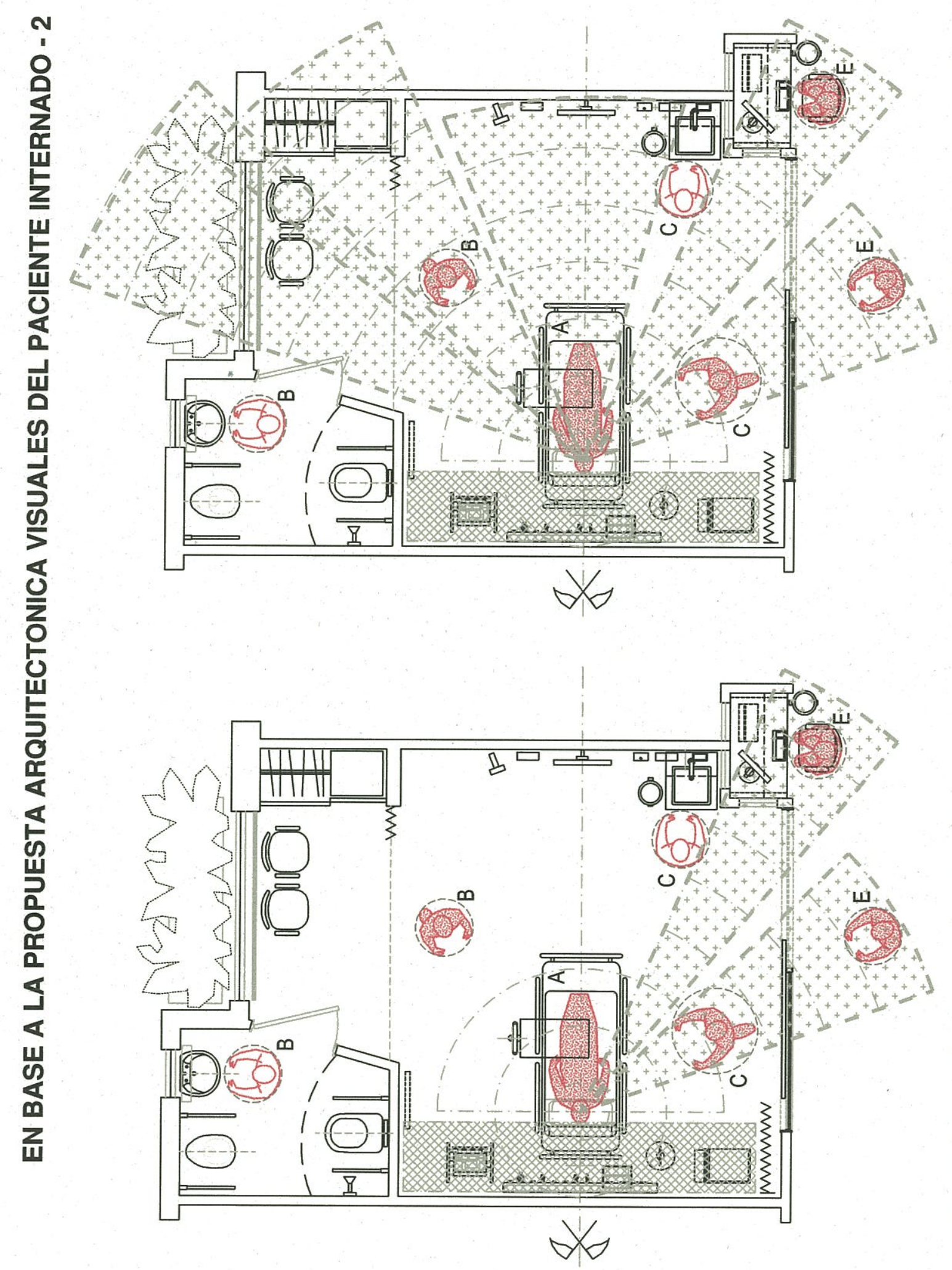

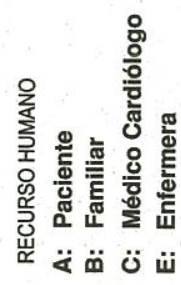

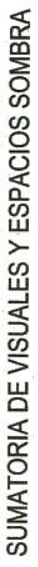

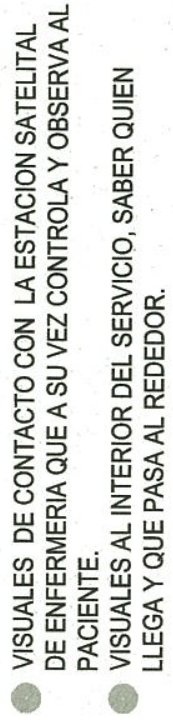




\section{Conclusiones}





\section{Conclusiones:}

El objetivo principal de este trabajo de investigación fue el estudio de las nuevas condicionantes de diseño, para el desarrollo de una calificación de Condicionantes Ambientales Arquitectónicos, que propusieran un nuevo ámbito para la habitación de Cuidados Intensivos Cardiológicos, en el marco del Planeamiento del Recurso Físico en Salud.

Se ha recorrido el proceso de Planeamiento del Recurso Físico en Salud, a través de la caracterización de la tecnología de operación de Cuidados Intensivos Cardiológicos, a partir del reconocimiento de la Política Operacional y el Desarrollo de Funciones, Actividades y Tareas; donde se tomó como ejemplo para dicha caracterización la Unidad de Cuidados Intensivos Cardiológicos del Centro de Estudios Médicos e Investigaciones Clínicas "Norberto Quirno" CEMIC Saavedra. Esta documentación se completó con la incorporación de planos de diferentes Instituciones que fueron abordadas durante el estudio.

En estudio de las variables, para la búsqueda de las condicionantes ambientales, concluyó con la identificación de cuatro conjuntos de variables; el "ambiente que estimule los sentidos", la "optimización de los aspectos funcionales", el "bienestar" y el "cumplimiento de normas y seguridad", con sus respectivas variables, como posibles condicionantes arquitectónicas.

El análisis de la Encuesta "Evaluación del Recurso Físico en Atención de Internación en busca de los Satisfactores del Recurso Fisco", permitió un mayor grado de acercamiento al ámbito de la habitación de Cuidados Intensivos, al presentar una descripción de la percepción de los pacientes internados, donde se confirmaron las presunciones sobre cómo afecta a estos el ambiente que los rodea. Se observó que los problemas primeramente señalados en los pacientes de Atención de Internación Cuidados Generales toman un cariz más severo en los pacientes de Cuidados Intensivos, tanto es así que algunos pacientes expresaron sentir que no habían sido tomados en cuenta a la hora del diseño de la habitación y que el equipamiento no estaba pensado primeramente para su confort sino para cumplir con otros requerimientos. Si bien esto en cierta medida es cierto, debido a lo compleja de la situación de algunos pacientes, con sus funciones asistidas en forma mecánica, se observó un gran porcentaje de pacientes lucidos durante las Encuestas y por lo tanto conscientes de lo que los rodea.

El estudio de Las Normas de Organización y Funcionamiento de Cuidados Intensivos Cardiológicos del Programa Nacional de Garantía de la Calidad Medica de la Nación PNGC Ministerio de Salud de la Nación MSN, RM 375/2002 y Las Normas de Organización y Funcionamiento de Cuidados Intensivos, PNGC MSN, RM 318/2001, nos permitió observar el impacto de estas en la definición de las variables, no existiendo Normas Específicas sobre algunas de las variables, el aporte de los pacientes sumados a al aporte de los datos obtenidos mediante 
Facultad de Arquitectura y Urbanismo, Universidad Nacional de la Plata

Entrevistas a Médicos Especialistas en Cuidados Intensivos y Cardiológicos resultaron un importante referente.

La propuesta de valorización para cada una de las variables como condicionantes, permito asignar un valor a cada una de las variables, donde se observó el peso de cada una de ellas como Condicionantes Arquitectónicos.

Las variables iluminación, sonido, accesibilidad, orientación, proporciones, distribución del equipamiento y confort se destacaron por su alto valor como condicionantes arquitectónicos. Entre los resultados de la aplicación de las Condicionantes del alto valor, destaco como una de las más significativas contribuciones de esta investigación, el reconocimiento de la importancia de construir Unidades de Cuidados Intensivos tenido en cuenta la incorporación la iluminación natural y acceso por parte del paciente de visuales al exterior, se observó claramente cómo afecta negativamente a los pacientes la falta de iluminación natural. Las Normas del Programa Nacional de Garantía de la Calidad de la Atención Medica del Ministerio Nacional de Salud, PNGC MSN RM 318/2001 y RM 375/2002, los datos aportado por los investigadores (Ulrich Roger 1984) ${ }^{5}$, (Beauchemin, K. M., \& Hays, P., 1996) ${ }^{6}$, los resultados de la Encuesta y las Entrevistas con Expertos en Cuidados Intensivos y Cardiológicos coinciden en esta propuesta.

Por otro lado las variables color, texturas, naturaleza y música se destacaron por su valor medio, siendo necesario para algunas de ellas futuros estudios para corroborar o proporcionar una nueva propuesta a la presentada por este trabajo de investigación. En cuanto a las variables olores y arte, se destacaron por su valor bajo, se considera que tal vez la habitación de Cuidados Intensivos no sea el ámbito más apropiado para el estudio de estas variables como Condicionantes Arquitectónicas.

La selección de dos diferentes escenarios para la comparación de los resultados de las Encuestas; la realizada a los pacientes internados en el Servicio de Atención de Internación Cuidados Generales (2006-2009) y a los pacientes internados en las Unidades de Cuidados Intensivos y Cuidados Intensivos Cardiológicos (2009-2011) permitió corroborar una vez más los datos obtenidos en la valorización realizada.

El sustento metodológico del Planeamiento del Recursos Físico en Salud, a partir de la caracterización de las Tipologías de "Espacio - Tarea", permitió la delimitación de los espacios de la habitación de Cuidados Intensivos Cardiológicos y a su vez observar la dinámica de las actividades que se realizan en la habitación, incorporado

\footnotetext{
${ }^{5}$ Ulrich, Roger S. View through a window may influence recovery from surgery. Science, 224(4647), 420-421. 1984.

${ }^{6}$ Beauchemin K.M., Hays P: Sunny hospital rooms expedite recovery from severe and refractory depressions. Journal of Affective Disorders 40:49-51, 1996.
} 
el equipamiento y el recurso humano con sus desplazamientos. La interacción de estas Tipologías permitió reconocer la conformación de una nueva solución Proyectual para la habitación de Cuidados Intensivos Cardiológicos.

La Propuesta Arquitectónica presentada para la Habitación del Cuidados Intensivos Cardiológicos contiene los nuevos Condicionantes Ambientales indispensables para caracterizar el nuevo ambiente saludable que se propone. La aplicación de la Propuesta en proyectos arquitectónicos así como su materialización en nuevos proyectos y obras de arquitectura, con una dinámica de continua evaluación de resultados y de estudio de impacto - beneficios permitirá verificar el valor de las nuevas concepciones.

Este trabajo de Investigación estuvo centrado en el paciente, es por esto que se propone como futuro trabajo de Investigación, la importancia de ampliar el universo y profundizar la investigación incorporando al estudio a los familiares y al recurso humano que brinda la atención.

Si bien entonces no se puede hablar de una universalización de estas variables, los resultados alcanzados por el estudio prueban la existencia de un conjunto de condicionantes que actúan desde lo proyectual y favorecen las obtención de espacios más saludables. Las condicionantes ambientales y la Propuesta Arquitectónica para la habitación de Cuidados Intensivos Cardiológicos se incorporaran como antecedente para estudios de los diferentes espacios del proceso del Planeamiento del Recurso Físico en Salud.

La visión de que nuestro entorno o los espacios que nos rodean generan en nosotros una suerte de efecto y que este va unido directa o indirectamente a un proceso de recuperación de la salud de un individuo, no es nuevo. Sin embargo, lo que ha variado es la forma de acercamiento a esta temática, donde el énfasis comienza a estar puesto en el reconocimiento de aquellos factores del medioambiente que actuando en forma positiva sobre el individuo colaboran en la obtención de "espacios saludables".

Buenos Aires 1 de abril de 2014 



\section{Glosario}

\section{Bibliografía}

\section{Presentaciones en Reuniones Científicas}



Facultad de Arquitectura y Urbanismo, Universidad Nacional de la Plata

\section{Glosario}

Calidad: diccionario de la Real Academia Española 1. f. Propiedad o conjunto de propiedades inherentes a algo, que permiten juzgar su valor. 2. f. Buena calidad, superioridad o excelencia. 3 . f. Carácter, genio, índole. 4. f. Condición o requisito que se pone en un contrato. 5. f. Estado de una persona, naturaleza, edad y demás circunstancias y condiciones que se requieren para un cargo o dignidad. 6. f. Nobleza del linaje.

"El concepto de Calidad ha evolucionado significativamente durante los últimos años. De ser universalmente concebido como un valor referido a características físicas de bienes materiales, fue ampliando su contenido incorporando componentes que tienen que ver con percepciones $y$ expectativas respecto de todo tipo de prestaciones."

"Hoy la Calidad dejó de ser definida por el "prestador" para pasar a ser definida por el "destinatario" de la prestación, el cual debe resultar plena y consistentemente satisfecho con la misma."

Fundación Premio Nacional de la Calidad creada el 15 de marzo de 1993, de acuerdo con lo dispuesto por la Ley 24127, sancionada en agosto de 1992.

Eficiencia: diccionario de la Real Academia Española 1. f. Capacidad de disponer de alguien o de algo para conseguir un efecto determinado.

Humanización. Diccionario de la Real Academia Española 1. f. Acción y efecto de humanizar o humanizarse.

Humanizar. Diccionario de la Real Academia Española 1. tr. Hacer humano, familiar y afable a alguien o algo. 2. prnl. Ablandarse, desenojarse, hacerse benigno.

EI CIRFS FADU UBA en el año 1990 en el Capítulo I de las Fichas Técnicas en lo correspondiente a la Tipologías de Recurso Físico", define a la "humanización" de la siguiente manera: "Con la concepción de espacios a partir del hombre sujeto, prestador - usuario, en el respeto e incorporación de su identidad, en la consideración de condiciones de privacidad, habitabilidad, confort, seguridad y barreras arquitectónicas.

Con la concepción del sistema equipamiento apoyada, fundamentalmente en la ergonomia del diseño (ciencia ergonométrica aplicada al diseño), es decir la adaptación optima de las operaciones físicas a las exigencias biológicas, físicas y psíquicas de los usuarios".

Líneas de proceso La Tecnología de Operación se explica a través de una línea de proceso donde se reconoce la secuencia de las tareas y sus interrelaciones, así como las vinculaciones entre la Tecnología Central y las Tecnologías de Apoyo.

De las Fichas Técnicas sobre el Recurso Físico en Salud. CIRFS 1990. En proceso de Actualización Proyectos SI FADU UBA 2010

Política Operacional: Se reconoce como el marco de definición de la Tecnología de Operación se delimita en la caracterización de la política operacional que estable los macro procesos organizacionales y recursos participantes, así como la relación ínter e intra tecnologías.

De las Fichas Técnicas sobre el Recurso Físico en Salud. CIRFS 1990. En proceso de Actualización Proyectos SI FADU UBA 2010.

Recursos Físicos en Salud Se reconoce como el medio, "espacio - instrumento", para acceder a la salud, condicionado por el entorno físico, socioeconómico y tecnológico, concebido en un proceso de

7 CENTRO DE INVESTIGACIÓN EN PLANEAMIENTO DEL RECURSO FÍSICO EN SALUD, Facultad de Arquitectura, Diseño y Urbanismo, Universidad de Buenos Aires CIRFS-FADU-UBA: Fichas Técnicas sobre el Recurso Físico en Salud. Espacio, Equipamiento e Instalaciones según Tecnología. Fundación W.K. Kellogg / OPS / FIRS. Buenos Aires, 1990. En proceso de actualización Proyectos de la Secretaria de Investigación SI FADU UBA 2011. 
desarrollo a partir de su formulación, hasta su operación. Su papel no se restringe a la envolvente "físico - espacial", de actividades de salud, sino que lo ampliamos en su reconocimiento como elemento de apoyo concurrente a la ejecución de la actividad y como integrante del equipamiento social, con la participación conjunta de los recursos sectoriales extras sectoriales, y a partir de la interacción de los recursos humanos, financieros y jurídicos.

De las Fichas Técnicas sobre el Recurso Físico en Salud. CIRFS 1990. En proceso de Actualización Proyectos SI FADU UBA 2010.

Satisfactores "Son los que definen la modalidad dominante que una cultura o una sociedad imprimen a las necesidades. Los satisfactores no son los bienes económicos disponibles sino que están referidos a todo aquello que, por representar formas de ser, tener, hacer y estar, constituye a la realización de necesidades humanas".

MAX-NEEF Manfred, ELIZALDE Antonio, HOPENHAYN Martín "Desarrollo a Escala Humana, una opción para el futuro" Editor Sven Hamrell y Olle Norberg pp. 35-49. Development Dialogue Número especial 1986.

\section{Sensación - Percepción}

"La diferente acepción que se ha dado a los términos "sensación" y "percepción" obedece principalmente al vocabulario propio de cada disciplina científica. Así, en el campo de la Fisiología el concepto de sensación se aplica de preferencia al estudio de la sensibilidad - umbrales máximos, mínimos y diferenciales -, a la formulación de leyes psicofísicas y a todos aquellos fenómenos psíquicos que, de acuerdo con este enfoque, tienen su raíz en la Anatomía y Fisiologia de los órganos receptores periféricos. En cambio, los problemas relativos a la percepción se sitúan en el dominio de la Psicología, juntamente con otros procesos que, se presupone, están determinados por procesos nerviosos centrales como el aprendizaje, la motivación y la memoria."

Miguelina Guirao, Los Sentidos base de la Percepción, Editorial Siluetas SA 1980.

Tecnología de Operación Se reconoce como tecnología de operación la organización del desarrollo de la aplicación de las técnicas. Hace referencia a la modalidad de ejecución de las acciones de salud, las reglas de juego de los distintos participantes, usuarios, prestadores y recursos físicos.

Conformada por la politica operacional, las funciones actividades y tares - recurso humano y las líneas de proceso.

De las Fichas Técnicas sobre el Recurso Físico en Salud. CIRFS 1990. En proceso de Actualización Proyectos SI FADU UBA 2010.

Tecnología Nuclear Son aquellas tecnologías que constituyen el núcleo central en toda organización de salud.

De las Fichas Técnicas sobre el Recurso Físico en Salud. CIRFS 1990. En proceso de Actualización Proyectos SI FADU UBA 2010.

Tecnologías de Apoyo Son aquellas tecnologías que necesariamente deben adaptarse y servir a las tecnologías nucleares para alcanzar los resultados deseados. Algunas se vinculan más directamente y otras se encuentran mas alejadas en las líneas de proceso.

De las Fichas Técnicas sobre el Recurso Físico en Salud. CIRFS 1990. En proceso de Actualización Proyectos SI FADU UBA 2010. 


\section{Bibliografía}

$2^{\text {nd }}$ International Conference on Health and Design, "Design and Health - The Therapeutic Benefits of Design", Editor Alan Dilani and AB Svensk Byggtjanst, 2001. ISBN 91-7332-963-0.

$4^{\text {nd }}$ International Conference on Health and Design, "Future Trends in Healthcare Design", Editor Dr. Arq. Alan Dilani. Estocolmo. Suecia. 2006. ISBN 91-7140-840-1

Beauchemin K.M., Hays P: Sunny hospital rooms expedite recovery from severe and refractory depressions. Journal of Affective Disorders 40:49-51, 1996.

Bozovic - Stamenovic, Ruzica "Guidelines for sensory stimulation design in healthcare". Publicadas en el libro: Programming, Guidelines and Masterplanning for Hospitals, ed. UIA International Union of Architects Workprogramme Public Health, 7-17. Dusseldorf: UIA Work Programme Public Health, 2004.

Caivano, José Luis, Guia para realizar, escribir y publicar trabajos de investigación (Buenos Aires: Arquim). 1995.

Caivano, José Luis, Sistemas de orden del color (Buenos Aires: Secretaría de Investigaciones FADUUBA, Serie Difusión N 12). 1995.

Caivano, José Luis "Towards an order system for visual texture", Languages of Design 2 (1), 59-84. (1994).

Centro de Investigación en Planeamiento del Recurso Físico en Salud, Facultad de Arquitectura, Diseño y Urbanismo, Universidad de Buenos Aires CIRFS-FADU-UBA: "Fichas Técnicas sobre el Recurso Físico en Salud. Espacio, Equipamiento e Instalaciones según Tecnologia". Edición y Publicación Fundación W.K. Kellogg, Organización Mundial de la Salud / Organización Panamericana de la Salud OPS/OMS. Buenos Aires, 1990.

Centro de Investigación en Planeamiento del Recurso Físico en Salud, Facultad de Arquitectura, Diseño y Urbanismo, Universidad de Buenos Aires CIRFS-FADU-UBA: Guías para el Desarrollo del Recurso Físico en Salud. Edición y Publicación Organización Mundial de la Salud / Organización Panamericana de la Salud OPS/OMS. Washington D.C., 1990

Cooper Marcus, Clare, Design \& Health, the Theapeutic Benefits of Design, "Garden and Health", Editor Alan Dilani and AB Svensk Byggtjanst, 2001. ISBN 91-7332-963-0.

Dilani, Alan, Design and Care in Hospital Planning. Karolinska Intitutet. Institute for Psychosocial Factors and Health Public Health and Treatment Research Design. . Estocolmo Suecia 1999. ISBN 91-7170371-3.

Eco Umberto. Como se hace una tesis, técnicas y procedimientos de estudio, investigación y escritura. Biblioteca de Educación, Herramientas Universitarias. Editorial Gedisa S.A. Impreso en Barcelona España, 2002.

Girao, Miguelina. Los Sentidos, bases de la Percepción. Editorial Alambra. ISBN 84-205-0732-6. Impreso en España 1980.

Grupo de Salud Pública de la Unión Internacional de Arquitectos UIA PHG. $19^{\circ}$ Seminario Internacional del UIA PHG "Hospital Design at the Beginning of the $21^{\text {st }}$ Century". Editor Arq. Fani Vavili. Publicado por el Colegio de Arquitectos de Grecia. Thessalonica, Grecia 1999. 
Grupo de Salud Pública de la Unión Internacional de Arquitectos UIA PHG. $29^{\circ}$ Seminario Internacional del UIA PHG "The Cultue for the Future Healthcare Architecture". Editor Prof. Romano del Nord. Publicado por TESIS. Editorial Alinea.. Florencia, Italia. Septiembre 2009. ISBN 978-88-6055-421-5

Guidelines for Design and Construction of Health Care Facilities

The Facility Guidelines Institute FGI. Included ANSI/ASHRAE/ASHE. Standard 170-2008, of Ventilation of Health Care Facilities, with the assistance of the U.S. Department of Health and Human Services. Publicado por ASHE. ISBN 978-0-87258-859-2. Estados Unidos de América. Edición 2010.

Hamilton Kick El Diseño Basado en Evidencia Four Levels of Evidence-Based Practice 2003 The American Institute of Architects | www.aia.org 2004

http:/www.arch.ttu.edu/courses/2007/fall/5395/392/students/garay/Research/Research.pdf

Max-Neef Manfred, Elizalde Antonio, Hopenhayn Martín, Desarrollo a Escala Humana, una opción para el futuro. Development Dialogue Numero especial 1986. Editor Sven Hamrell y Olle Norberg. 1986.

Mandoki, Katya. Estética y Comunicación: de Acción, Pasión y Seducción. Enciclopedia Latinoemaricana de Sociocultura y Comunicación, Grupo Editorial Norma S.A. Impreso en Colombia. Septiembre de 2006. ISBN 958-04-9637-4

Robertson Paul, Design \& Health, the Theapeutic Benefits of Design, "Music and Health", Editor Alan Dilani and AB Svensk Byggtjanst, 2001. ISBN 91-7332-963-0.

Samaja Juan, Libro de la Semiótica de la Ciencia, Primera Parte. Los Caminos del Conocimiento. Segunda Parte. El Papel de la hipótesis y de las formas de inferencia en el trabajo científico. Tercera Parte. Análisis del Proceso de Investigación (Textos en proceso de Elaboración) 2004.

Samaja Juan, Proceso, Diseño y Proyecto, JVE Ediciones, 2004.

Scher, Peter and Senior, Peter, The Exeter Evaluation, for the Royal Devon and Exeter Healthcare, N.H.S. Trust. Manchester: Arts for Health, Faculty of Art and Design, the Manchester Metropolitan University 1999. ISBN 1900756129.

Scher, Peter, Patient-Focused Architecture for Health

Care. (Manchester: Faculty of Art and Design, the Manchester Metropolitan University, 1996. ISBN 1 900756015

Senior Peter, Design \& Health, the Theapeutic Benefits of Design, "Art and Health", Editor Alan Dilani and AB Svensk Byggtjanst, 2001. ISBN 91-7332-963-0.

Ulrich, Roger S. View through a window may influence recovery from surgery. Science, 224(4647), 420421. 1984.

UIrich, Roger. S. Effects of interior design on wellness: Theory and recent scientific research. Journal of Health Care Interior Design, 3(1), 97-109. 1991.

Ulrich, Roger. S., Simons, R. F., Losito, B. D., Fiorito, E., Miles, M. A., \& Zelson, M. Stress recovery during exposure to natural and urban environments. Journal of Environmental Psychology, 11(2): 201230. 1991.

Ulrich, Roger. S., Lunden, O., \& Eltinge, J. L.. Effects of exposure to nature and abstract pictures on patients recovering from heart surgery. Paper presented at the thirty-third meeting of the Society for Psychophysiological Research, Rottach-Egern, Germany. Abstract in Psychophysiology, 30(Suppl. 1), 7. 1993. 
Ulrich Roger S. Effects of gardens on health outcomes: Theory and research. In C. Cooper Marcus \& M. Barnes (Eds.), Healing Gardens (pp. 27-86). New York: Wiley. 1999.

Ulrich, R. S., \& Gilpin, L.. Healing arts: Nutrition for the soul. In S. B. Frampton, L. Gilpin \& P. Charmel (Eds.), Putting patients first: Designing and practicing patientcentered care (pp. 117-146). San Francisco: Jossey-Bass. 2003.

Ulrich, Roger. S., Lawson, B., \& Martinez, M. Exploring the patient environment: An NHS estates workshop. London: The Stationery Office. 2003.

Ulrich, Roger. S., Simons, R. F., \& Miles, M. A. Effects of environmental simulations and television on blood donor stress. Journal of Architectural \& Planning Research, 20(1), 38-47. 2003

Ulich Roger S, Xiaobo Quan, The Role of the Physical Environment in the Hospital of the 21st Century: A Once-in-a-Lifetime Opportunity, Center for Health Systems and Design, College of Architecture, Texas A\&M, University Craig Zimring*, Anjali Joseph, Ruchi Choudhary, College of Architecture, Georgia Institute of Technology, 2004.

http://www.healthdesign.org/chd/research/role-physical-environment-hospital-21st-century

Ulrich, Roger.S., Zimring, C., Quan, X., \& Joseph, A. The environment's impact on Stress. In S. Marberry (Eds.), Improving healthcare with better building design (37-61). Chicago: Health Administration Press. 2006. 


\section{Presentaciones en Reuniones Científicas vinculadas al Trabajo de Investigación}

Ponencia: "The Environment and the Health Facility"

XXIV Seminario Internacional del Grupo de Salud de la Unión Internacional de Arquitectos, PHG/UIA, San Pablo, Brasil, 29 de mayo a 3 de junio de 2004.

En este proyecto, el CIRFS, propone el desarrollo de una metodología con el soporte instrumental adecuado para la evaluación del recurso físico en salud y del impacto ambiental a nivel de los nodos de las redes de salud, extendiendo el análisis a la evaluación de la humanización de los espacios espacios saludables.

Autor: Centro de Investigación en Planeamiento del Recurso Físico en Salud CIRFS-FADU-UBA.

Autor y Presentador: Arq. Astrid María Debuchy

Ponencia: "El Ambiente y los Recursos Fisicos en Salud"

I Encuentro Regional de Investigación Proyectual, XIX Jornadas de Investigación SI + PRO, FADU UBA, Buenos Aires, 4 de Nov. de 2004.

Autor: Centro de Investigación en Planeamiento del Recurso Físico en Salud CIRFS-FADU-UBA.

Autor y Presentador: Arq. Astrid María Debuchy.

Ponencia: "El Ambiente y los Recursos Físicos en Salud"

$15^{\circ}$ Congreso Latinoamericano de Arquitectura e Ingeniería Hospitalaria y $8 \mathrm{vo}$. Encuentro del MERCOSUR, EXPO AADAIH, Buenos Aires, 5 al 8 de octubre de 2004.

Autor: Centro de Investigación en Planeamiento del Recurso Físico en Salud CIRFS-FADU-UBA.

Autor y Presentador: Arq. Astrid María Debuchy.

Ponencia: "Process, Planning and Interdiscipline"

XXII World Congress of Architecture, XXV Seminario Internacional del Grupo de Salud de la Unión Internacional de Arquitectos, PHG/UIA, Estambul, Turquía, 2 de junio a 6 de julio de 2005.

Autor: Centro de Investigación en Planeamiento del Recurso Fisico en Salud CIRFS-FADU-UBA.

Presentador: Arq. Astrid Maria Debuchy.

Ponencia: "La Programación en el Planeamiento del Recurso Físico en Salud: GUíAS INSTRUMENTOS PARA SU DESARROLLOO"

11 Congreso Internacional SMAES "El Hospital Del Futuro", en la CD. de México, México, 17,18,Y 19 noviembre de 2005.

Autor: Centro de Investigación en Planeamiento del Recurso Físico en Salud CIRFS-FADU-UBA.

Presentador: Arq. Astrid Maria Debuchy.

Ponencia: "The Research - Transference, for the Development of the Health Facility"

XXVI, Seminario Internacional del Grupo de Salud de la Unión Internacional de Arquitectos, PHG/UIA, Pretoria, Sudáfrica, 14 al 19 de agosto de 2006

Autor: Centro de Investigación en Planeamiento del Recurso Físico en Salud CIRFS-FADU-UBA.

Presentador: Arq. Astrid María Debuchy.

Ponencia "La Investigación - Transferencia para el Desarrollo del Recurso Físico en Salud" III Encuentro Regional de Investigación Proyectual, XXI Jornadas de Investigación SI + HCT, FADU UBA, Buenos Aires, 14 al 15 de septiembre de 2006.

Autor: Centro de Investigación en Planeamiento del Recurso Físico en Salud CIRFS-FADU-UBA.

Presentador: Arq. Astrid Maria Debuchy.

Ponencia: "La Investigación - Transferencia para el Desarrollo del Recurso Físico en Salud" I Seminario de Ciencia y Tecnología para el Hábitat Popular, Construcción y Participación del Conocimiento, Universidad Católica de Córdoba, Córdoba, 28 y 29 de noviembre y 1 de diciembre de 2006. 
Facultad de Arquitectura y Urbanismo, Universidad Nacional de la Plata

Autor: Centro de Investigación en Planeamiento del Recurso Físico en Salud CIRFS-FADU-UBA. Presentador: Arq. Astrid María Debuchy.

Ponencia: "En la Búsqueda de los Satisfactores, en el Marco de la Humanización de los Espacios"

Seminario Internacional "Nuevas Tendencias de la Arquitectura Hospitalaria en la Región de las Américas: Relación con el Desarrollo de los Sistemas de Salud y las Tecnologías" IMFiS FAUD, Auspiciado por la Oficina Panamericana de la Salud, OPS, Córdoba, 23 al 26 de abril de 2007. Autor: Centro de Investigación en Planeamiento del Recurso Físico en Salud CIRFS-FADU-UBA.

Autor y Presentador: Arq. Astrid Maria Debuchy.

Ponencia: "Instrumentos de transferencia tecnológica y de gestión, para el desarrollo del Recurso Fisco en Salud"

Seminario Internacional "Gestión estratégica de los recursos físicos y tecnológicos en la Región de las Américas: "Arquitectura, Ingenieria e Ingeniería Clínica para la Salud", Realizado por AADAIH en la Sociedad Central de Arquitectos SCA, Auspiciado por la Oficina Panamericana de la Salud, OPS, Buenos Aires, 27 de abril de 2007.Autor: Centro de Investigación en Planeamiento del Recurso Físico en Salud CIRFS-FADU-UBA.

Presentador: Arq. Astrid María Debuchy.

Ponencia: "Instrumentos de transferencia tecnológica y de gestión, para el desarrollo del Recurso Fisco en Salud"

Seminario Internacional "La Transición Epidemiológica y su Impacto en la Calidad de Atención"

VI Jornada Nacional De La Sociedad Argentina, para la Calidad en Atención de la Salud, Centro Argentino de Ingenieros, Salón Constantini. Buenos Aires, 10 al 12 de septiembre de 2007.

Autor: Centro de Investigación en Planeamiento del Recurso Físico en Salud CIRFS-FADU-UBA

Presentador: Arq. Astrid Maria Debuchy

Ponencia "Los Recursos Fiscos en Salud, Visión del Grupo de Salud Pública de la Unión Internacional de Arquitectos, UIA PHG."

XVIII CONGRESO LATINOAMERICANO DE ARQUITECTURA E INGENIERIA HOSPITALARIA "Diseño y Tecnologia ante Nuevos Requerimientos" Centro Cultural Borges, Buenos Aires Argentina 2 al 5 de Octubre de 2007.

Autor y Presentador: Arq. Astrid María Debuchy UIA PHG EM Región III Américas.

Ponencia: "Environment And Humanization, Condition of The Spaces, Looking for the Satisfactors of the Health Facility".

XXVII, Seminario Internacional del Grupo de Salud de la Unión Internacional de Arquitectos, UIA PHG, Florencia, Italia, 22 al 28 de junio de 2008.

Autor y Presentador: Arq. Astrid María Debuchy CIRFS FADU UBA - UIA PHG

Ponencia: "Los Condicionantes del Espacio en la búsqueda de los Satisfactores del Recurso Físico en Salud"XXIII Jornadas de Investigación Facultad de Arquitectura, Diseño y Urbanismo FADU UBA, V Encuentro Regional de InvestigaciónSI + MORF FADU UBA

Facultad de Arquitectura, Diseño y Urbanismo, Universidad de Buenos Aires, Argentina 3 al 5 de Septiembre 2008.

Autor y Presentador: Arq. Astrid María Debuchy CIRFS FADU UBA.

Ponencia: "La Ínterdisciplina en el Planeamiento del Recurso Físico en Salud". "XIX CONGRESO LATINOAMERICANO DE ARQUITECTURA E INGENIERIA HOSPITALARIA "EI Hospital, Integrador de Nuevas Disciplinas" Centro Cultural Borges, Buenos Aires Argentina 9 al 12 de Septiembre de 2008.

Autor y Presentador: Arq. Astrid Maria Debuchy CIRFS FADU UBA - UIA PHG. 
Ponencia: "Trends in Health Facility; Vision of the Public Health Group, International Union of Architects UIA PHG"

22 de octubre de 2008 (mañana)

$1^{\text {st }}$ Eastern Caribbean Conference for Health Services Managers and Clinical Engineers, "Trends in Management of Healthcare Delivery Services and Clinical Engineering".

Organizada por Eastern Caribbean Countries (PWR-ECC) en colaboracion con the Health Systems and Services (HSS), the Technology, Health Care and Research Areas (THR) y la Organización Mundial de la Salud - Oficina Panamericana de Salud OMS OPS.

Bridgetown BARBADOS, del 20 al 24 de October de 2008

Autor y Presentador: Arq. Astrid María Debuchy CIRFS FADU UBA - UIA PHG.

Ponencia: "The Future Hospital"

Cierre de Conferencia 22 de octubre de 2008 (tarde)

$1^{\text {st }}$ Eastern Caribbean Conference for Health Services Managers and Clinical Engineers, "Trends in Management of Healthcare Delivery Services and Clinical Engineering".

Organizada por Eastern Caribbean Countries (PWR-ECC) en colaboracion con the Health Systems and Services (HSS), the Technology, Health Care and Research Areas (THR) y la Organización Mundial de la Salud - Oficina Panamericana de Salud OMS OPS.

Bridgetown BARBADOS, del 20 al 24 de October de 2008

Autor y Presentador: Arq. Astrid María Debuchy CIRFS FADU UBA - UIA PHG.

Poster: "The Humanization of Architecture in Intensive Care and Coronary Care Units" Area Interdisciplinary Topics, de la Expo Research and Scholarship de Northeastern University 6 de Abril de 2011.

Autor y Presentador: Arq. Astrid María Debuchy

Ponencia "Nuevas Tendencias en Recursos Físicos en Salud, observadas desde la Investigación, la Docencia y la Cooperación Técnica"

Presentación realizada en el marco del Taller de Expertos del Área de Sistemas de Salud basados en la Atención Primaria de la Salud, de la Organización Panamericana de la Salud, La Habana Cuba, 22 al 24 de Mayo 2011.

Autor y Presentador: Arq. Astrid María Debuchy

Poster "The Humanization of Architecture in Intensive Care and Coronary Care Units"

$7^{\circ}$ World Congress Exhibition of International Academy of Design and Health, Ciudad de Boston del 6 al 10 de junio Boston 2011.

Autor y Presentador: Arq. Astrid Maria Debuchy

Capítulos de Libros Publicados por Editorial con Arbitraje o Comité Editorial relacionadas con el Trabajo de Investigación:

Título del Libro: "Recomendaciones para Desarrollar Políticas Públicas, Hacia una Accesibilidad Universal" Uso y accesibilidad arquitectónica y urbana para personas con discapacidad. Autores: Federación de Colegios de Arquitectura de la República Mexicana, Unión Internacional de Arquitectos. Arq. Luis Enrique López Cardiel. Federación de Colegios de Arquitectura de la República Mexicana, Unión Internacional de Arquitectos. Versión en Inglés y Español. 06/2005

Título del Libro CD Rom; Basado en el "XXVI Seminario del Grupo de Salud de la Unión Internacional de Arquitectos" Pretoria, Sudáfrica.

Capitulo: "The Research - Technological Transference for the Development of the Health Facility". Publicado en Versión CD por el CSR Pretoria 2006. Con referato 
Título del Libro CD- Rom: III Encuentro Regional de Investigación Proyectual, XXI Jornadas de Investigación, del clip al territorio SI + HCT FADU UBA, Buenos Aires, 14 al 15 de septiembre de 2006.

Capitulo: "La Investigación - Transferencia para el Desarrollo del Recurso Físico en Salud"

Autor: Centro de Investigación en Planeamiento del Recurso Físico en Salud CIRFS-FADU-UBA.

ISBN-10: 950-29-0944-5

ISBN-13: 978-950-29-0944-8

Edición Universidad de Buenos Aires UBA, 2006. Con referato.

Titulo del Libro: "The Culture for the Future of Healthcare Architecture"

Basado en el XXVIII Seminario Internacional del Grupo de Salud, de la Union Internacional de Arquitectos, PHG/UIA, Florencia, Italia año 2008.

Capitulo: "Enviroment and Humnization, Condition of Spaces, Loocking for the Satisfactors of the Health Facilities"

Autores: Astrid Maria Debuchy, Centro de Investigación en Planeamiento del Recurso Físico en Salud, CIRFS-FADU-UBA.

Editor: ALINEA EDITRICE, Florencia Italia. Año 2009

Páginas: 257 a 261

ISBN: $978-88-6055-421-5$

\section{Artículos de Revistas con Arbitraje o Comité Editorial:}

Revista del Instituto Técnico para la Acreditación de los Establecimientos de Salud ITAES

Título del Articulo: "El Ambiente y los Recursos Físicos en Salud" Publicación del Instituto Técnico para la Acreditación de Establecimientos de Salud.

Autor Astrid María Debuchy CIRFS/FADU/UBA.

Volumen $7 \mathrm{~N}^{\circ} 2$ abril, mayo, junio. 2005. Con referato.

Revista del Instituto Brasileiro de Desenvolvimento e de Pesquisas Hopitalares IPH Título del Articulo: Presentación del UIA PHG, en el marco del "XXVI Seminario del Grupo de Salud de la Unión Internacional de Arquitectos" Pag 59 a 63. Pretoria, Sudáfrica.

Autor Astrid Maria Debuchy CIRFS/FADU/UBA UIA PHG

ISSN 1519-1451 Año 5 Numero 8 Diciembre 2006.

Revista Oficial del Colegio de Arquitectos de la Provincia de Córdoba. Revista - Arquitextos 103.

Título del Articulo: Crear Espacios Saludables. Pag. 6465

Autor Astrid María Debuchy CIRFS/FADU/UBA UIA PHG

Editor: Colegio de Arquitectos de la Provincia de Córdoba.

Registro de marca: N 1.724.680. Año 21 Revista N 103 Mayo / Junio 2007.

Revista Anuario Oficial de la Asociación Argentina de Arquitectura e Ingeniería Hospitalaria 2009.

Basado en el $19^{\circ}$ Congreso Latinoamericano de Arquitectura e Ingeniería Hospitalaria. "El Hospital, Integrador de Nuevas Disciplinas" Centro Cultural Borges, 9 al 12 de Septiembre de 2008.

Título del Articulo: "La Interdisciplina en el Planeamiento del Recurso Físico en Salud", El Grupo de Salud Pública de la Unión Internacional de Arquitectos UIA PHG" Pag. 82 y 83.

Autor: Astrid María Debuchy CIRFS/FADU/UBA UIA PHG

Editor: Asociación Argentina de Arquitectura e Ingenieria Hospitalaria. 